UNIVERSIDADE DE SÃO PAULO

FACULDADE DE ECONOMIA, ADMINISTRAÇÃO E CONTABILIDADE

DEPARTAMENTO DE CONTABILIDADE E ATUÁRIA

PROGRAMA DE PÓS-GRADUAÇÃO EM CIÊNCIAS CONTÁBEIS

UTILIZAÇÃO DA INFORMAÇÃO CONTÁBIL

NA ADESÃO AOS INCENTIVOS FISCAIS DE INOVAÇÃO TECNOLÓGICA

ESTABELECIDOS PELA LEI № 11.196/2005

Alberto Luiz Zucchi

Orientador: Prof. Dr. Carlos Alberto Pereira 
Prof. Dr. João Grandino Rodas

Reitor da Universidade de São Paulo

Prof. Dr. Reinado Guerreiro

Diretor da Faculdade de Economia, Administração e Contabilidade

Prof. Dr. Edgard Bruno Cornacchione Júnior

Chefe do Departamento de Contabilidade e Atuária

Profa. Dra. Silvia Pereira de Castro Casa Nova

Coordenadora do Programa de Pós-Graduação em Controladoria e Contabilidade 


\title{
UTILIZAÇÃO DA INFORMAÇÃO CONTÁBIL NA ADESÃO AOS INCENTIVOS FISCAIS DE INOVAÇÃO TECNOLÓGICA ESTABELECIDOS PELA LEI № 11.196/2005
}

\author{
Tese apresentada ao Departamento de \\ Contabilidade e Atuária da Faculdade de \\ Economia, Administração e Contabilidade da \\ Universidade de São Paulo para a obtenção do \\ título de Doutor em Ciências.
}

Orientador: Prof. Dr. Carlos Alberto Pereira

\section{Versão corrigida}

A versão original encontra-se disponível da biblioteca da FEA-USP

\section{SÃO PAULO}




\section{FICHA CATALOGRÁFICA}

Elaborada pela Seção de Processamento Técnico do SBD/FEA/USP

\section{Zucchi, Alberto Luiz}

Utilização da informação contábil na adesão aos incentivos fiscais de inovação tecnológica estabelecidos pela Lei 11.196/05 / Alberto Luiz

Zucchi. -- São Paulo, 2013

$$
255 \mathrm{p} \text {. }
$$

TESE (Doutorado) - Universidade de São Paulo, 2013.

Orientador: Carlos Alberto Pereira.

1. Contabilidade decisorial 2. Informações contábeis 3.Contabilidade tributária 4. Isenção de impostos I. Universidade de São Paulo. Faculdade de Economia, Administração e Contabilidade. II. Título.

$$
\text { CDD - 655.151 }
$$


À memória de meu estimado Professor que me ensinou a estudar e rezar, e à de meu pai, Sidney Luiz Alberto

Zucchi, primeiro contador que conheci, do qual recordo, ainda dos meus tempos de menino, seus "fechamentos de balanço" que entravam pela noite.

Aos meus seis filhos: Maria Regina, que teve papel fundamental na elaboração desta tese e Pedro Paulo que optaram por seguir a profissão de seu pai; José Luiz e Maria Teresa, que escolheram outro caminho; Francisco e Antonio que ainda devem decidir sobre seu futuro.

E, sobretudo, à minha esposa Lúcia, mãe exemplar, que tão bem cuida da nação Zucchi. 

Agradecer é sempre uma tarefa agradável, uma vez que, agradecer consiste em reconhecer o bem que alguém nos fez. Portanto, agradecemos quando já estamos na posse de um algum bem. Ao mesmo tempo, agradecer é sempre uma tarefa difícil, porque é necessário colocar uma hierarquia nos agradecimentos que devem ser feitos e não é raro esquecer alguém a quem devemos o favor de nos ter ajudado.

Por tudo isso, começo por agradecer, de forma geral, a todos aqueles que colaboraram para a conclusão deste trabalho, e se me esqueço injustamente de citar alguém nominalmente nas linhas a seguir, é por falta de memória e não por falta de gratidão. “Os elefantes não esquecem".

Primeiramente, agradeço ao meu orientador, Professor Doutor Carlos Alberto Pereira. Suas contribuições para esta pesquisa foram muito valiosas e, tenho certeza de que sem seu apoio, este trabalho não teria chegado ao fim, mas sobretudo agradeço a ele por ter acreditado na realização deste estudo. Minha primeira aula de Doutorado no Departamento de Contabilidade da FEA-USP ocorreu no início de 1995. Foram, portanto, dezoito anos de muitos contratempos, incluindo um grave acidente e a admissão no curso por duas vezes, até o momento do depósito da tese. Valeu a pena? "Tudo vale a pena quando a alma não é pequena". Agradeço também ao Professor Doutor Luiz Paulo Fávero que apresentou excelentes sugestões na qualificação e contribuiu de forma decisiva para a análise estatística dos dados da pesquisa, e à Professora Doutora Mônica Calijuri que igualmente apresentou oportunas análises e sugestões no exame de qualificação.

Tenho ainda muito a agradecer aos profissionais da empresa GAC Brasil, consultoria especializada na aplicação dos incentivos fiscais de inovação tecnológica, que em muito colaboraram na realização deste estudo. Em especial agradeço a seu diretor-presidente no Brasil, André Palma; os consultores, Bruno de Oliveira e André Siano e à secretaria Vanessa Rosin, que deram apoio decisivo para a realização da pesquisa desta tese.

Resta, ainda, agradecer o grande apoio que recebi de meus colegas da Secretaria da Fazenda do Estado de São Paulo, dentre os quais destaco: o atual coordenador da CAT, José Clovis Cabrera, o antigo coordenador, Otávio Fineis, Newton Oller de Mello coordenador da CPM na época de meu ingresso no doutorado, e, nas pessoas dos delegados, Luciano Francisco Reis e Newton Cley Jehle de Araújo, agradeço a todos os meus colegas que bem souberam entender minhas ausências. 

"Mas tudo dispusestes com medida, número e peso"

(Livro da Sabedoria 11,20)

"A moderna organização racional das empresas capitalistas não teria sido possível sem dois outros fatores importantes em seu desenvolvimento: a separação dos negócios da moradia da família, fato que domina completamente a vida econômica e, estritamente ligada a isso, uma contabilidade racional". Max Weber 



\section{RESUMO}

Os incentivos fiscais têm sido utilizados pelos mais diversos países, das mais variadas tendências políticas e econômicas, como instrumento para promover o desenvolvimento e a inovação tecnológica das organizações empresariais. No caso brasileiro, alguns estudos têm demonstrado que os efeitos dos benefícios fiscais, muitas vezes, estão aquém do esperado pelas entidades governamentais, com baixo nível de adesão por parte das empresas. As causas desse fenômeno geralmente são atribuídas a fatores econômicos, embora se reconheça que possam existir outras razões, dentre as quais a influência de fatores ambientais e estruturais no processo decisório das organizações. Para o estudo mais aprofundado dessas influências no ambiente empresarial, o framework proposto pela teoria da contingência tem sido utilizado em pesquisas científicas, especialmente no campo da contabilidade, na análise de fenômenos relacionados ao uso da informação contábil no processo de tomada de decisões. Sob essa perspectiva teórica, este trabalho tem como objetivo identificar, analisar e discutir os fatores que influenciam a utilização da informação contábil no processo decisório das empresas especificamente relacionado à adesão aos incentivos fiscais estabelecidos no capítulo III da Lei 11.196/05, conhecida no ambiente tributário brasileiro como "Lei do Bem". Após algumas breves considerações sobre as políticas de incentivos adotadas no âmbito dos países membros da OCDE, são apresentadas uma retrospectiva histórica e uma análise detalhada, com base na legislação, dos incentivos fiscais de inovação tecnológica em vigor no Brasil. A finalidade dessa parte do estudo é demonstrar que há uma clara necessidade de um processo de decisão estruturado, por parte dos gestores das empresas, para a opção sobre a adesão ao incentivo fiscal, que envolve informações contábeis. Em vista dessas considerações a questão de pesquisa é definida como: "quais os fatores indutores e inibidores da utilização de informações contábeis para tomada de decisão sobre adesão aos incentivos fiscais de inovação tecnológica?". Na revisão bibliográfica, são analisadas aplicações da teoria da contingência no que se refere ao processo de tomada de decisão e à importância do sistema de informações contábeis, definindo-se 17 fatores e 55 variáveis que podem influenciar na utilização da informação contábil, os quais foram divididos em cinco grandes grupos, cada um com variáveis próprias. Com base nesse referencial, foi elaborado um questionário estruturado, o qual foi enviado às 542 empresas que se utilizaram dos incentivos fiscais de inovação tecnológica no ano base de 2.009 no Brasil, tendo sido obtidas 77 respostas válidas. O tratamento estatístico dos dados coletados foi realizado por meio da técnica denominada análise de homogeneidade (HOMALS). A pesquisa encontra que a informação contábil é comumente usada no processo de adesão aos benefícios fiscais. No entanto, o modelo de decisão utilizado pela maioria dos gestores é o assim chamado "classical", que parece ser inapropriado para esse tipo de decisão, segundo a teoria da contingência, o que pode demonstrar ou a necessidade de revisão da teoria nesse ponto, ou que um modelo inapropriado está sendo utilizado. Como resultado da base de dados obtida da pesquisa confirma-se que há fatores indutores e inibidores no uso da informação contábil. Os fatores indutores identificados são: dinamismo, heterogeneidade, hostilidade, rentabilidade, lucratividade, instrumentos gerenciais, escopo, agregação, relevância, comparabilidade e confiabilidade. Os fatores inibidores são: heterogeneidade, agregação e confiabilidade. $\mathrm{O}$ fato de que alguns fatores sejam indutores e inibidores mostra que a influência desses fatores varia de acordo com as características de cada companhia ou do meio, confirmando, neste sentido, um dos princípios básicos da teoria da contingência. Do ponto de vista teórico, esses achados contribuem para um melhor entendimento da realidade acerca do tema, permitindo que, na prática, gestores empresariais e governamentais atuem sobre fatores importantes que influenciam a efetividade de suas ações, mas que, nem sempre, são claramente percebidos no cotidiano da dinâmica empresarial. 



\begin{abstract}
Tax benefits have been used in a variety of countries, which adopt different political and economic trends, as a way of promoting the development and the technological innovation in companies. In Brazil some researches have shown that the effects of tax benefits have frequently had less impact than it would be expected by the government because of the low adoption rates of these benefits by companies. The causes of these low adoption rates are generally attributed to economic factors, although other reasons are recognized, such as the influence of environmental and structural factors in the decision-making process in companies. In order to further study these influences in the corporate environment, scientific researches - mainly in the accounting field -have used the framework proposed by the contingency theory for the analysis of accounting information in the decision-making process. This thesis aims to identify, analyze and discuss, according to that theory, the factors which influence the use of accounting information in the corporate decision-making process. The study considers specifically this process related to the adoption of tax benefits as established by Chapter III of Act 11.196/05, known in the Brazilian tributary environment as "Lei do Bem" (in a loose translation, "Law of the Goodness"). After brief considerations on incentive policies adopted by countries which are members of the OECD (Organization for Economic Co-operation and Development), there is a historical retrospective and a detailed analysis of tax benefits for technological innovation in Brazil, based on the current Brazilian legislation. The objective of this part of the study is to demonstrate that the leaders of the companies must have a structured decision-making process in order to opt for adopting tax benefits, and this involves accounting information. Based on these considerations, the research question is proposed: "what are the promoting and the hindering factors concerning the use of accounting information which influence the decision about the adoption of tax benefits for technological innovation?" In the literature review the study analyzes the applications of the contingency theory, taking into account the decision-making process and the importance of the system of accounting information. Seventeen factors and fifty-five variations which may influence the use of accounting information are defined, and they were divided into five large groups, each one with its own variables. Based on this referential a structured questionnaire was elaborated, which was sent to the 543 companies which used tax benefits for technological innovation in the base year of 2009 in Brazil, and 77 valid answers were received. The statistical treatment of the data assembled was done through a technique named homogeneity analysis (HOMALS). The research finds out that accounting information is commonly used in the process of adopting tax benefits. However, the decision-making model used by the majority of the leaders is the so- called classical, which seems to be inappropriate for this kind of decision, according to the contingency theory. This consideration can demonstrate that either the theory must be reviewed at this point or the inappropriate model is being used. As a result of the database obtained by the research, it was confirmed that there are promoting and hindering factors concerning the use of accounting information. The promoting factors identified are the dynamism, heterogeneity, hostility, profitability, managerial instruments, scope, aggregation, relevance, comparability and reliability. The hindering factors are heterogeneity, aggregation and reliability. The fact that some of these factors are both promoters and hinders shows that the influence of these factors varies according to the characteristics of each company or according to the environment, confirming one of the basic principles of the contingency theory. From the theoretical point of view, these conclusions contribute to the better understanding of the reality about the theme, allowing that, in practice, business and government leaders work on important factors which influence the effectiveness of their actions, factors which are not always clearly distinguished in the day-to-day corporate dynamics.
\end{abstract}


RESUMO.....

\section{SUMÁRIO}

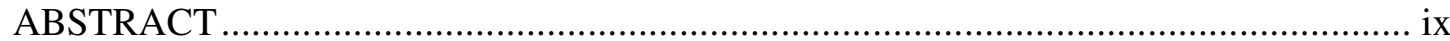

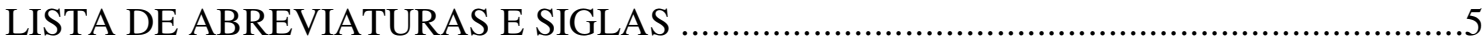

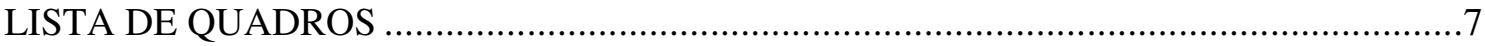

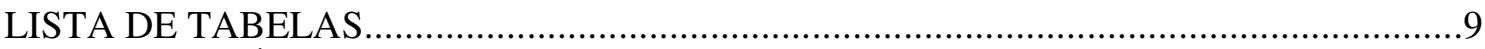

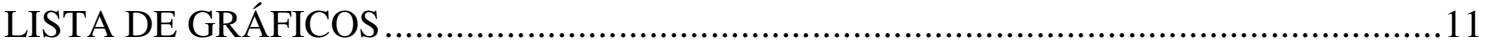

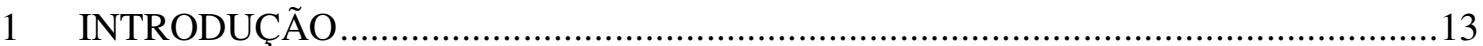

1.1 Importância do tema.......................................................................................13

1.1.1 Contabilidade para a tomada de decisões ..................................................13

1.1.2 Carga tributária no Brasil .........................................................................15

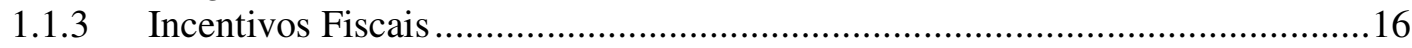

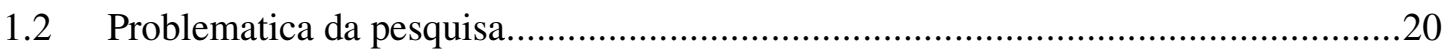

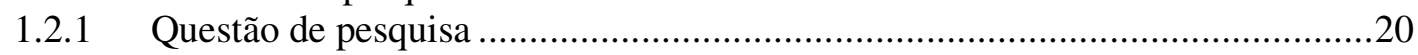

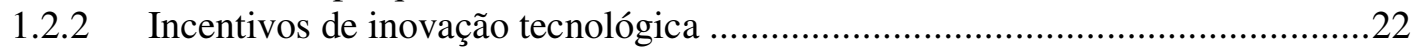

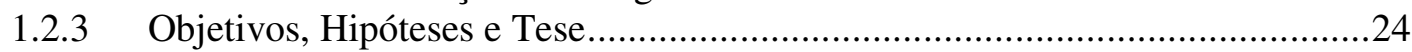

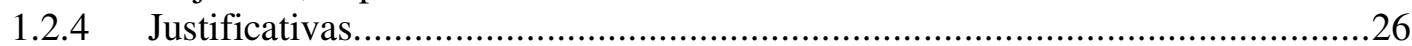

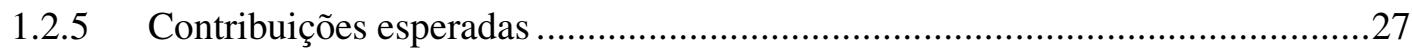

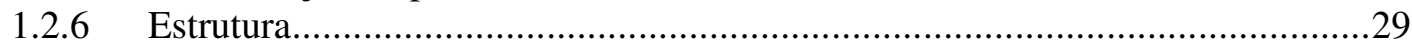

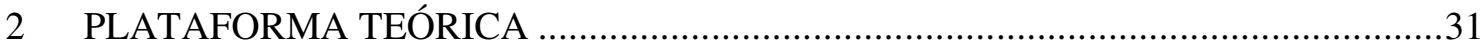

2.1 Incentivos fiscais de inovação tecnológica...............................................................31

2.1.1 Visão geral de benefícios fiscais concedidos pelos países da OCDE ..................31

2.1.2 Política de incentivos fiscais para a inovação tecnológica no Brasil ...................33

2.1.3 Incentivos fiscais para a inovação tecnológica no Brasil ....................................35

2.1.4 Registro, controle e mensuração contábil dos incentivos fiscais de inovação

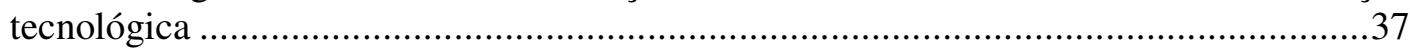

2.1.5 Utilização da informação contábil na adesão dos incentivos fiscais de inovação

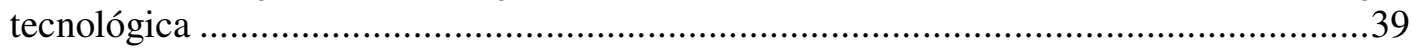

2.2 Teoria da contingência .................................................................................4

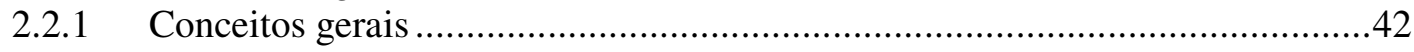

2.2.2 Teoria da contingência aplicada à contabilidade gerencial ................................45

2.2.3 Teoria da contingência e tomada de decisão ....................................................47

2.2.4 Aplicação dos modelos de decisão à adesão aos incentivos fiscais de inovação

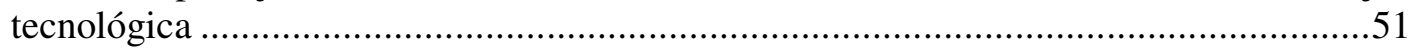

2.3 Fatores que podem influenciar o uso da informação contábil ......................................54

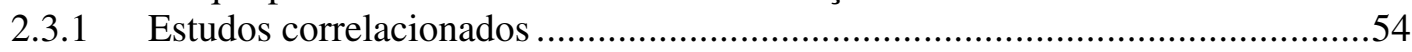

2.3.1.1 Fatores condicionantes da gestão de custos interorganizacionais na cadeia de valor de hospitais privados no Brasil: uma abordagem à luz da Teoria da Contingência - Tese de Doutorado, Reinaldo Rodrigues Camacho, 2010 ....................54

2.3.1.2 Arranjos entre fatores situacionais e sistema de contabilidade gerencial (SCG) sob a ótica da teoria da contingência - Dissertação de Mestrado, Almir Rogério Guerra, 2007

2.3.1.3 Fatores determinantes do nível de disclosure voluntário de companhias abertas no Brasil - Tese de Doutorado, Fernando Dal-Ri Murcia, 2009......................56

2.3.2 Qualidades da informação contábil.............................................................57

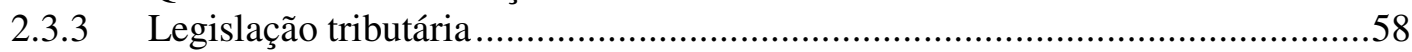

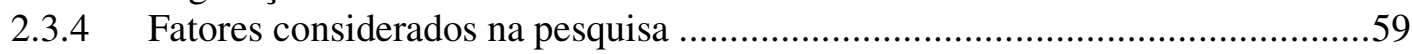

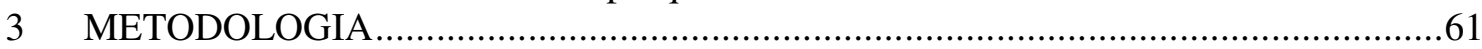

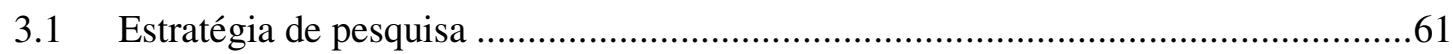

3.2 População abrangida pela pesquisa .........................................................................61 


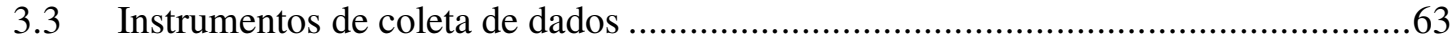

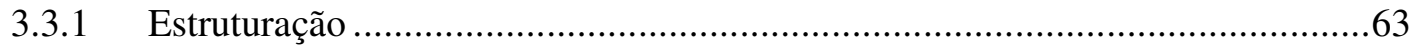

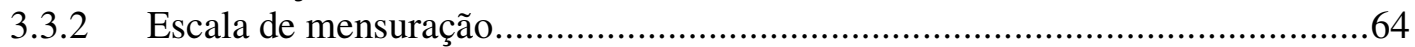

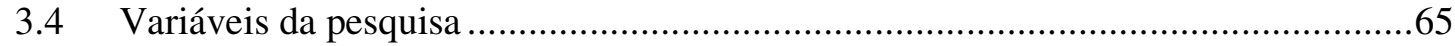

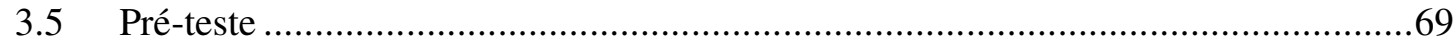

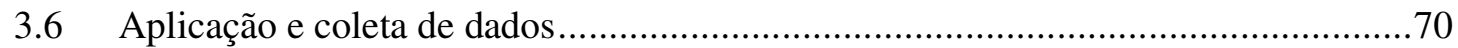

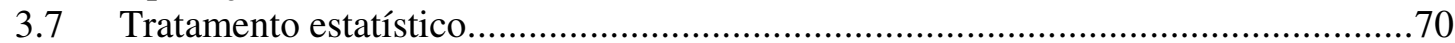

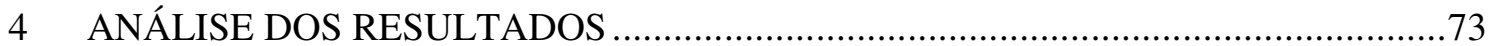

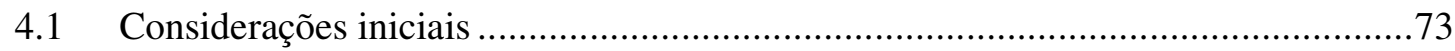

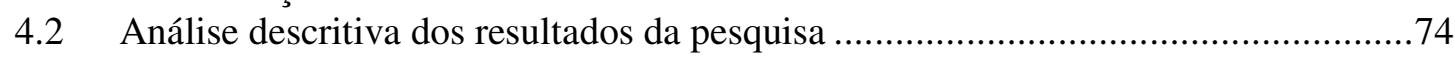

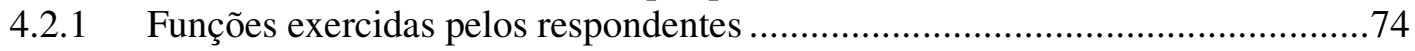

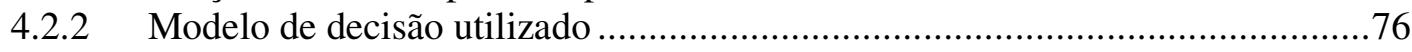

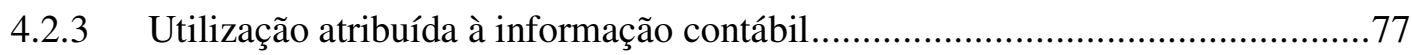

4.3 Análise dos fatores da utilização da informação contábil - observações gerais .......79

4.4 Análise detalhada dos diversos fatores da utilização da informação contábil ...........82

4.4.1 Características ambientais - fator "dinamismo" .............................................82

4.4.2 Características ambientais - fator "heterogeneidade" .....................................91

4.4.3 Características ambientais - fator "hostilidade" ...........................................96

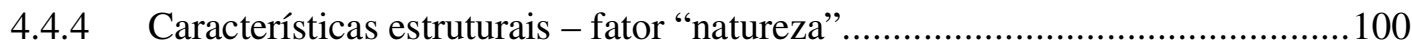

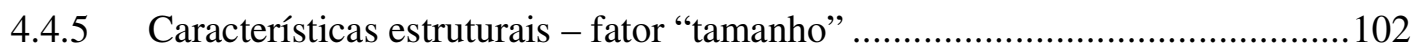

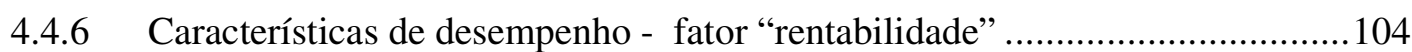

4.4.7 Características de desempenho - fator "lucratividade" .................................106

4.4.8 Atributos da informação - fator "instrumentos gerenciais contemporâneos"..108

4.4.9 Atributos da informação - fator "instrumentos gerenciais tradicionais"...........116

4.4.10 Atributos da informação contábil - fator "escopo" .....................................122

4.4.11 Atributos da informação contábil - fator "agregação" .................................129

4.4.12 Qualidade da informação contábil - fator "relevância"...................................134

4.4.13 Qualidade da informação contábil - fator "confiabilidade"............................138

4.4.14 Qualidade da informação contábil - fator "comparabilidade" .........................144

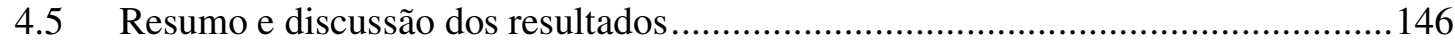

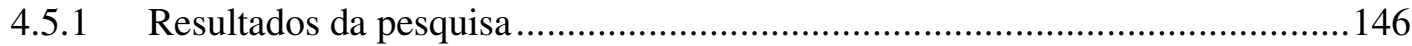

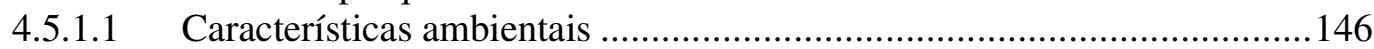

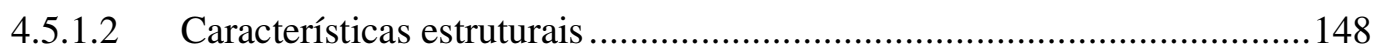

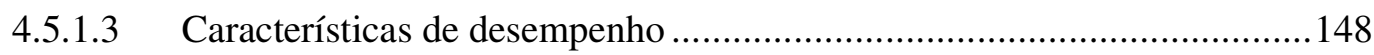

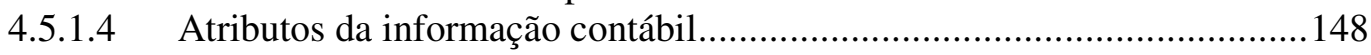

4.5.1.5 Qualidades da informação contábil .................................................151

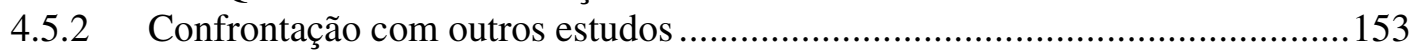

4.5.2.1 Arranjos entre fatores situacionais e sistema de contabilidade gerencial sob a ótica da teoria da contingência..................................................................... 153

4.5.2.2 Fatores condicionantes de gestão de custos interorganizacionais na cadeia de valor de hospitais privados no Brasil .............................................................155 4.5.2.3 Fatores determinantes no nível de disclosure voluntário de companhias

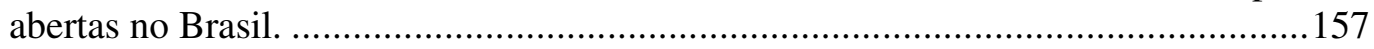

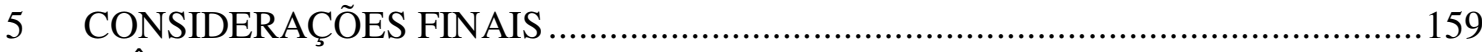

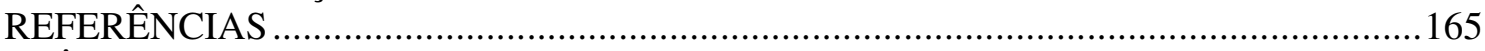

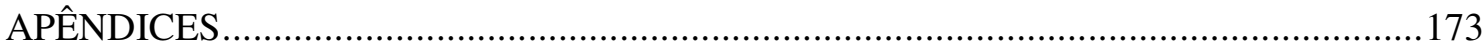





\title{
LISTA DE ABREVIATURAS E SIGLAS
}

\author{
$\mathrm{ABC}-\quad$ Activity Based Costing \\ ABM - Activity Based Management \\ CNPJ - Cadastro Nacional da Pessoa Jurídica \\ CSLL - Contribuição Social sobre o Lucro Líquido \\ EVA - Economic Value Added \\ IBGE - Instituto Brasileiro de Geografia e Estatística \\ IN - Instrução Normativa \\ IPI - Imposto sobre Produtos Industrializados \\ IRPJ - Imposto de Renda Pessoa Jurídica \\ GCI - Gestão de Custos Interorganizacionais \\ LALUR - Livro de Apuração do Lucro Real \\ MDIC - Ministério do Desenvolvimento, Indústria e Comércio \\ MCT - Ministério da Ciência e Tecnologia \\ MCTI - Ministério da Ciência Tecnologia e Inovação \\ MP - Medida Provisória \\ OCDE - Organização de Cooperação e Desenvolvimento Econômico \\ P \& D - Pesquisa e Desenvolvimento \\ PIB - $\quad$ Produto Interno Bruto \\ PDTA - Programa de Desenvolvimento Tecnológico Avançado \\ PDTI - Programa de Desenvolvimento Tecnológico Industrial \\ RFB - $\quad$ Receita Federal do Brasil \\ RTT - Regime Tributário de Transição \\ SCG - Sistema Contábil de Gestão
}





\section{LISTA DE QUADROS}

Quadro 1 - Comparação entre os modelos de decisão de Trater e Hoy .................................50

Quadro 2 - Situações empresariais e respectivo modelo de decisão ......................................51

Quadro 3 - Relação entre as etapas de decisão do modelo mixed scanning e o processo de adesão aos incentivos fiscais de inovação tecnológica.......................................................52

Quadro 4 - Relação entre as etapas de decisão do modelo optimizing e o processo de decisão de adesão aos incentivos fiscais de inovação tecnológica

Quadro 5 - Fatores que influenciam no nível de disclosure voluntário de companhias abertas

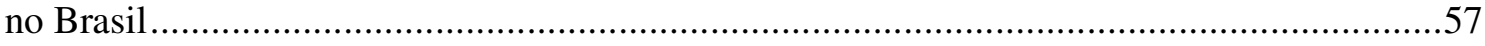

Quadro 6 - Características ambientais, fatores e respectivas variáveis ..............................66

Quadro 7 - Características estruturais, fatores e respectivas variáveis................................67

Quadro 8 - Características de desempenho, fatores e respectivas variáveis...........................67

Quadro 9 - Atributos da informação contábil, fatores e respectivas variáveis ........................68

Quadro 10 - Qualidades da informação contábil, fatores e respectivas variáveis...................69

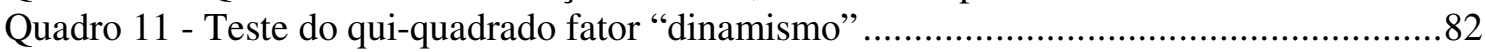

Quadro 12 - Teste do qui-quadrado fator "heterogeneidade" ...............................................91

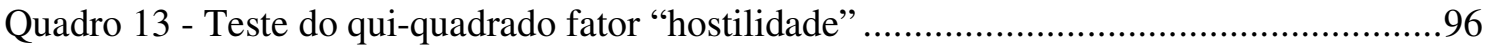

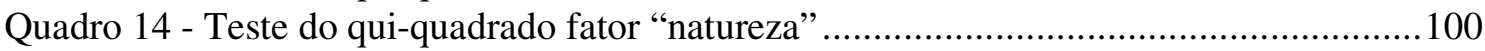

Quadro 15 - Teste do qui-quadrado fator "tamanho" "..................................................... 102

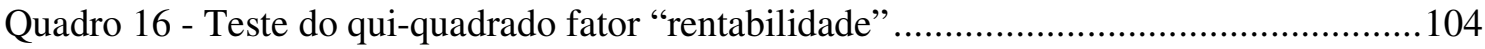

Quadro 17 - Teste do qui-quadrado fator "lucratividade" ................................................106

Quadro 18 - Teste do qui-quadrado fator "instrumentos gerenciais contemporâneos" .........108

Quadro 19 - Teste do qui-quadrado fator "instrumentos gerenciais tradicionais".................117

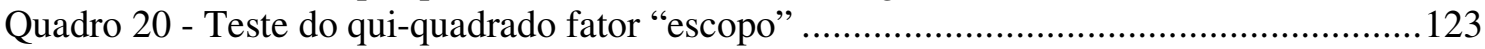

Quadro 21 - Teste do qui-quadrado fator "agregação" .................................................129

Quadro 22 - Teste do qui-quadrado fator "relevância" .....................................................134

Quadro 23 - Teste do qui-quadrado fator "confiabilidade" ............................................138

Quadro 24 - Teste do qui-quadrado fator "comparabilidade" .........................................144 



\section{LISTA DE TABELAS}

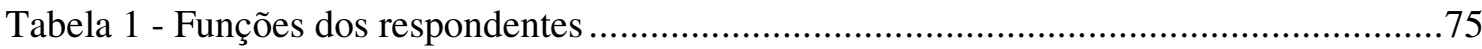

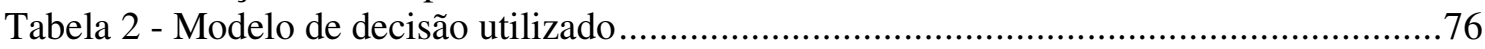

Tabela 3 - Grau de utilização da informação contábil - Geral ............................................78

Tabela 4 - Grau de utilização da informação contábil por aspecto ....................................79

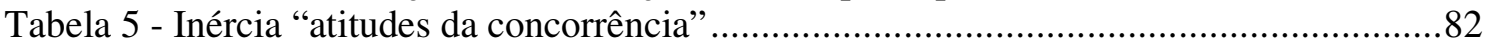

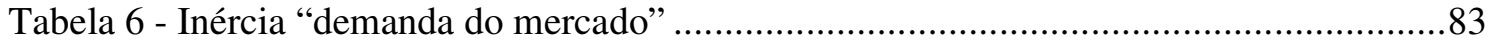

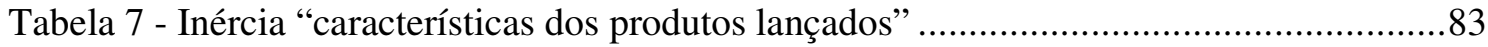

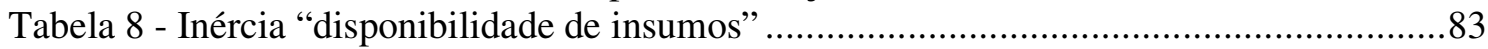

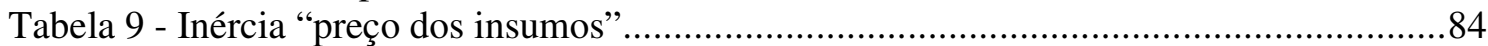

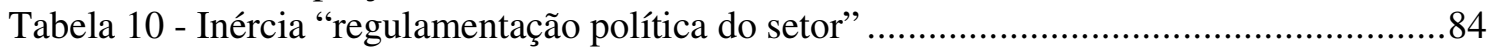

Tabela 11 - Inércia "características dos produtos encontrados no mercado" .........................92

Tabela 12 - Inércia "características dos concorrentes" .................................................92

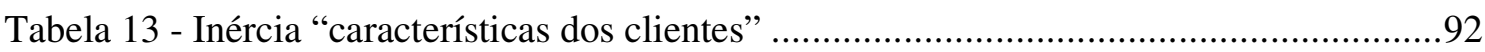

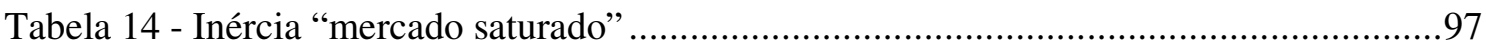

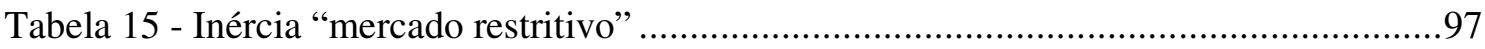

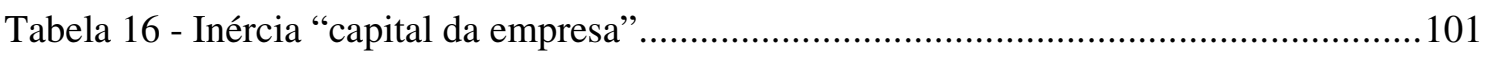

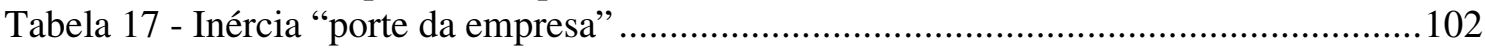

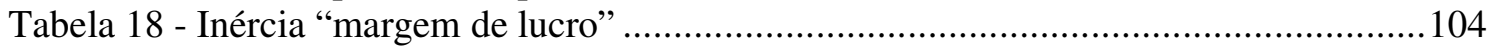

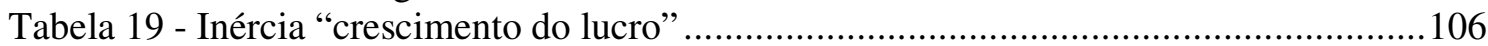

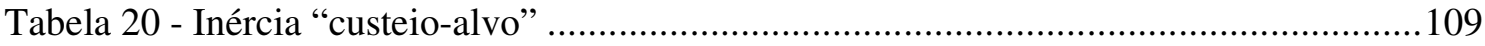

Tabela 21 - Inércia "relatório de controle de qualidade"..................................................109

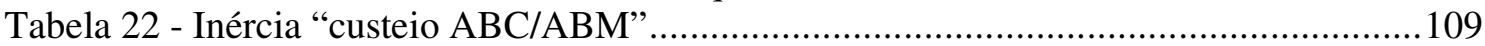

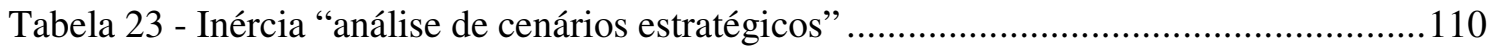

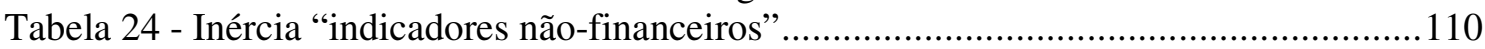

Tabela 25 - Inércia “demonstração de resultados mensais" .............................................117

Tabela 26 - Inércia “custeio variável ou por absorção"...................................................117

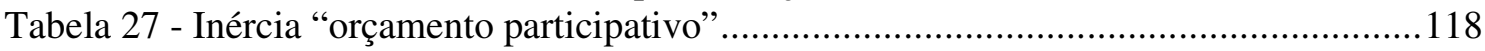

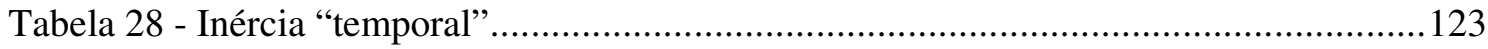

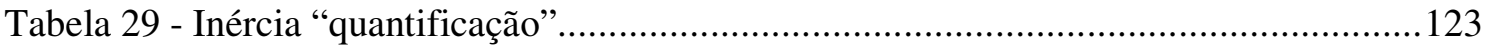

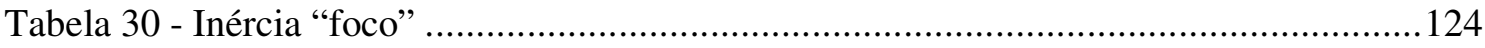

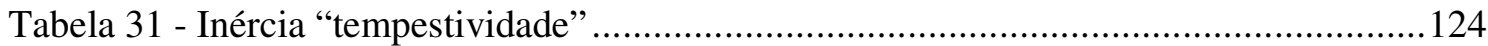

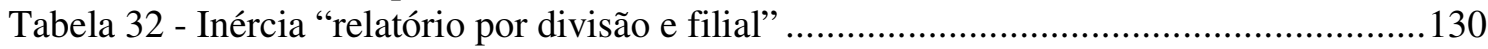

Tabela 33 - Inércia "relatório preço de transferência interno" ...........................................130

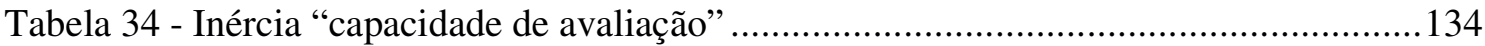

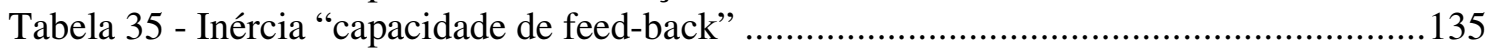

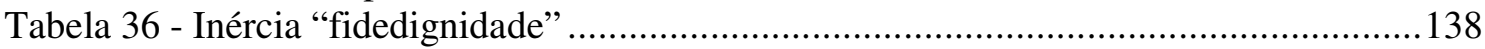

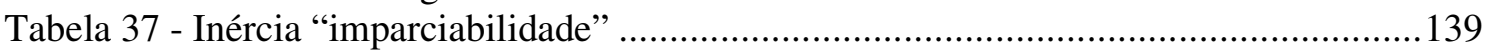

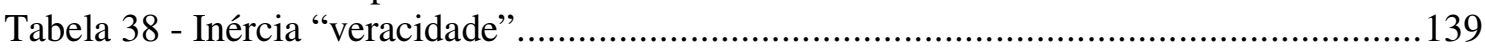

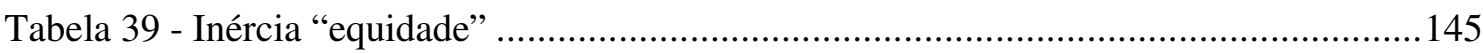





\section{LISTA DE GRÁFICOS}

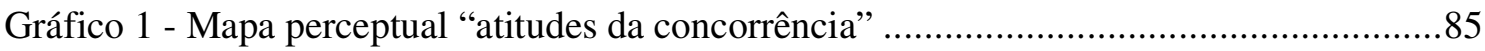

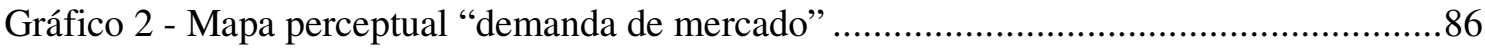

Gráfico 3 - Mapa perceptual "características dos produtos lançados no mercado" ..................87

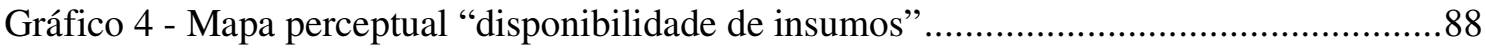

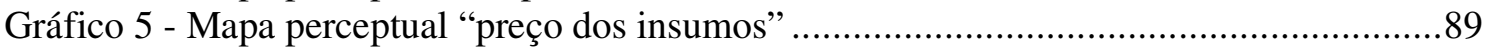

Gráfico 6 - Mapa perceptual "regulamentação política do setor" ........................................90

Gráfico 7 - Mapa perceptual "características dos produtos encontrados no mercado"............93

Gráfico 8 - Mapa perceptual "características dos concorrentes" .........................................94

Gráfico 9 - Mapa perceptual "características dos clientes" ..............................................95

Gráfico 10 - Mapa perceptual "mercado saturado"..........................................................98

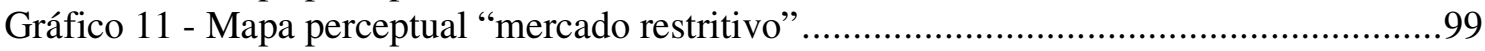

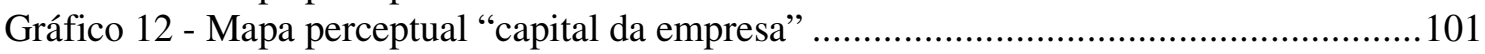

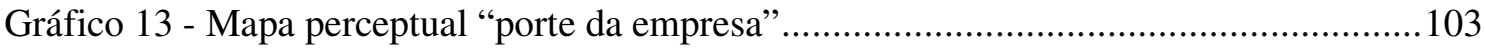

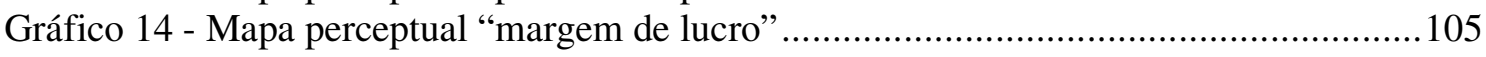

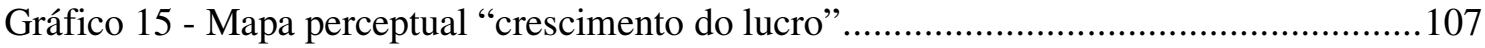

Gráfico 16 - Mapa perceptual "custeio-alvo" ...................................................................111

Gráfico 17 - Mapa perceptual "relatório de controle de qualidade" ....................................112

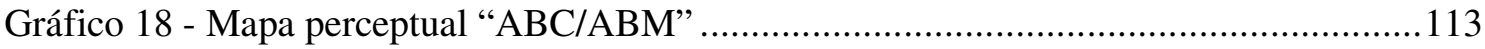

Gráfico 19 - Mapa perceptual “cenários estratégicos”....................................................114

Gráfico 20 - Mapa perceptual "indicadores não-financeiros" .......................................115

Gráfico 21 - Mapa perceptual "demonstração de resultados mensais" ...............................118

Gráfico 22 - Mapa perceptual "custeio variável ou por absorção" ....................................120

Gráfico 23 - Mapa perceptual "orçamento participativo" .................................................121

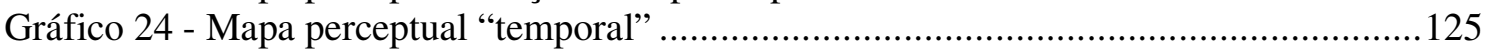

Gráfico 25 - Mapa perceptual “quantificaçãa”" .............................................................126

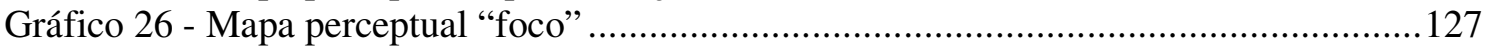

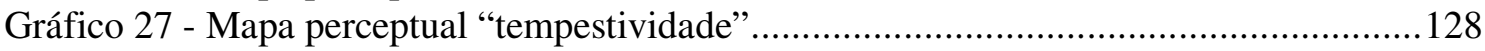

Gráfico 28 - Mapa perceptual "relatório por divisão e filial”.............................................131

Gráfico 29 - Mapa perceptual "relatório preço de transferência interno" .............................133

Gráfico 30 - Mapa perceptual "capacidade de avaliação"..............................................135

Gráfico 31 - Mapa perceptual "capacidade de feedback" ................................................137

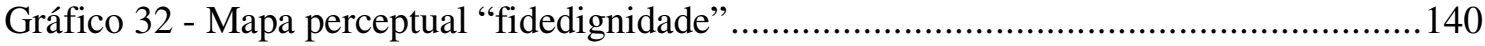

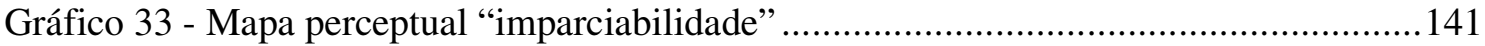

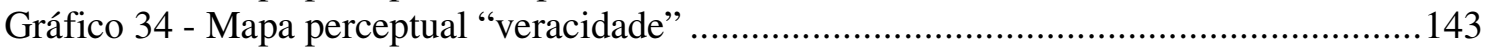

Gráfico 35 - Mapa perceptual "equidade" .................................................................... 145 



\section{INTRODUÇÃO}

\subsection{Importância do tema}

Os diversos autores especialistas na área da metodologia da investigação cientifica realçam alguns requisitos para que um tema seja adequado à elaboração de uma tese, dentre os quais a importância dele.

Pode-se afirmar que um tema é importante quando

[...] está de alguma forma ligado a uma questão crucial que polariza ou afeta um segmento substancial da sociedade. Um tema também pode ser importante se está ligado a uma questão teórica que merece atenção continuada na literatura especializada (CASTRO, 1978, p. 56).

O tema e o assunto, que serão analisados na pesquisa, são, pois, as matérias-primas utilizadas na elaboração do produto final do trabalho científico. Caso elas não sejam boas e adequadas, as exigências do produto final não serão atendidas e nenhum processo produtivo será capaz de suprir essa deficiência.

Neste trabalho, as 'matérias-primas' selecionadas foram:

- $\quad$ Assunto: contabilidade para fins de tomada de decisão (contabilidade gerencial) ;

- Tema: utilização da informação contábil para adesão a incentivos fiscais.

Este trabalho está focado em uma questão teórica que tem merecido muita atenção na literatura contábil, a utilização de técnicas e conceitos da contabilidade e sua aplicação na tomada de decisão, além de tratar, ainda, de uma questão que afeta uma parcela significativa de nossa sociedade: os tributos incidentes sobre as atividades empresariais.

\subsubsection{Contabilidade para a tomada de decisões}

Há muito tempo os principais autores que tratam da teoria da contabilidade destacam a importância que ela deve ter para suportar decisões.

A tomada de decisões desempenha papel crucial na teoria da contabilidade. Sua importância tem sido ressaltada frequentemente nas definições de contabilidade [...]. É evidente, portanto, que precisamos estudar como os usuários de informações contábeis tomam decisões. Se pudéssemos determinar como isso ocorre, poderíamos ser capazes de deduzir que informação teria mais valor para eles (HENDRIKSEN et al., 1999 p. 135). 
Um dos principais campos da contabilidade gerencial é entender como se processam as decisões gerenciais, com a finalidade de criar um sistema de informações que possa dar suporte aos gestores para essa tomada de decisão. Muitos trabalhos acadêmicos têm se voltado para esse assunto. Para que a contabilidade gerencial pudesse atingir seus objetivos foram desenvolvidos instrumentos contábeis que procuram auxiliar os gestores na tomada de decisão, dentre os quais podem-se destacar: o ABC (Activity Based Costing), o Custeio Meta (Target Costing), o EVA (Economic Value Added), o BSC (Balanced Scorecard) e o GECON (Modelo de Gestão Econômica).

Os estudos para apoio à tomada de decisão têm tomado muito destaque em todos os campos de estudos teóricos ou aplicados da contabilidade. Entretanto, a aceitação por parte dos gestores das empresas das teorias desenvolvidas nesses estudos não tem ocorrido:

Pesquisas empíricas constatam que existe atualmente um aparente paradoxo no que diz respeito à prática da contabilidade gerencial. Apesar de fatores indutores e facilitadores do ambiente externo, apesar do rol de novas técnicas e instrumentos à disposição dos gestores empresariais, o que se observa efetivamente, na prática, é o baixo grau de implementação de novas técnicas e conceitos de contabilidade gerencial nas empresas (GUERREIRO et al., 2004, p. 1)

O mesmo autor prossegue os comentários citando diversas trabalhos que seguem sua linha de observação:

\footnotetext{
A despeito da existência de fortes fatores motivadores, facilitadores e catalisadores para a modernização da contabilidade gerencial, ela pouco tem se modificado. Diversos autores e pesquisadores têm alertado para o problema do que se pode denominar 'estabilidade da contabilidade gerencial', chamando a atenção para o fato de que a pesquisa contábil tem tido pouco impacto na prática empresarial e para as diferenças existentes entre o que diz a teoria e o que é feito na prática. Diversos trabalhos desde o início da década de 90 , de forma direta ou indireta, abordam esse tema, destacando-se os de Otley (1985), Choudhury (1986), Johnson e Kaplan (1987), Edwards e Emmanuel (1990), Cohen e Paquette (1991), Brigth et al. (1992), Emore e Ness (1991), Green e Amenkhienan (1992), Ask e Ax (1992), Drury et al. (1993), Scapens e Roberts (1994), Scapens (1994), Covaleski et al. (1996), Evans e Ashworth (1996), Libby e Waterhouse (1996), Granlund e Lukka (1998), Burns (2000), Burns e Scapens (2000) e Granlund (2001). (GUERREIRO et al., 2004, p. 3)
}

Ainda que já existam muitos estudos sobre a utilização da contabilidade para a tomada de decisões, esse campo do conhecimento contábil está sempre em modificação, passando por constantes revisões de conceitos. Nesse sentido, relatando os embates entre Ittner e Larcker contra Zimmerman, quando os dois primeiros apresentaram criticas aos estudos relativos à contabilidade gerencial, afirmando que ela não produzia, mediante trabalhos empíricos, novos conhecimentos, para a área contábil, Frezatti comenta que: 
Não se trata de uma discussão entre anglo-saxões, sobre algo que os latinos nada teriam a contribuir. Pelo contrário, os trabalhos devem provocar uma profunda reflexão sobre o que ocorre em termos de desenvolvimento na contabilidade gerencial no Brasil. Essa reflexão permitiria o entendimento de alguns problemas existentes e limitações percebidas (FREZATTI et al., 2008 p. 2).

\subsubsection{Carga tributária no Brasil}

Em relação aos tributos é conhecido que eles afetam uma boa parte de nossa sociedade, pois há muito tempo tornou-se um fato marcante na economia nacional a significativa carga tributária existente no Brasil. Assim, segundo dados do IBGE - Instituto Brasileiro de Geografia e Estatística (IBGE, 2011), a carga tributária, no ano de 2009, atingiu 33,7\% do PIB. Ainda de acordo com a série histórica divulgada pelo IBGE, no ano de 1947, a carga tributária representava $13,8 \%$ do PIB, o que significava um acréscimo de $244 \%$ nesse período.

Conforme Pereira et al (2004, p. 3),

[...] uma pesquisa realizada pela revista Exame, publicada em sua edição de 5 de setembro de 2001, aponta que a carga tributária média encontrada nos diversos setores de atividade foi de $42,9 \%$. Revela-se ainda que, na distribuição das riquezas geradas pelas empresas, a maior parcela fica com o governo através dos tributos arrecadados (43\%), enquanto a remuneração de capital absorve $34 \%$ e os gastos com pessoal e encargos atingem $23 \%$.

Os significativos valores referentes à arrecadação de tributos têm levado contadores, auditores e outros profissionais das mais diferentes áreas como Direito, Economia, Administração e mesmo de áreas técnicas, como, por exemplo, Engenharia, a uma especial atenção sobre os impactos que os tributos produzem em geral na sociedade e, de forma particular, nas organizações.

Como um dos exemplos de que a atenção aos tributos atinge também a área acadêmica, podem-se citar os estudos voltados à análise da redução da carga tributária para as empresas e, dentre eles, a comparação entre a opção de adoção dos sistemas denominados Lucro Real e Lucro Presumido. Nesse sentido a dissertação de mestrado de Rullo (2008), desenvolveu um modelo matemático para auxilio na tomada de decisão para se optar ou não pelo lucro presumido, enquanto que o trabalho realizado por Oliveira (2009) procurou obter evidências de que, quando a contabilidade é elaborada, a opção entre os regimes tributários (lucro presumido ou lucro real) é feita de maneira correta e resulta em economia tributária. A pesquisa apresentada por Bispo, Calijuri e Lima (2009) discutiu a relação entre a carga tributária, os setores econômicos e os tamanhos das empresas brasileiras. Uma abordagem 
nova nos estudos tributários foi a desenvolvida por Calijuri e Lopes (2011), relacionando a gestão dos tributos à maximização do valor das empresas.

\subsubsection{Incentivos Fiscais}

É muito comum na literatura de divulgação e mesmo em artigos e trabalhos técnicos o uso da denominação "incentivo fiscal" como sinônimo de "benefício fiscal", entretanto, em uma análise mais apurada verifica-se que esses termos podem ser empregados com significados diferentes. Sem a intenção de definir em qual situação cada um desses termos deveria ser utilizado, mas apenas com a finalidade de precisar sua utilização neste trabalho, a seguir apresenta-se um quadro com uma adequada distinção de nomenclatura.

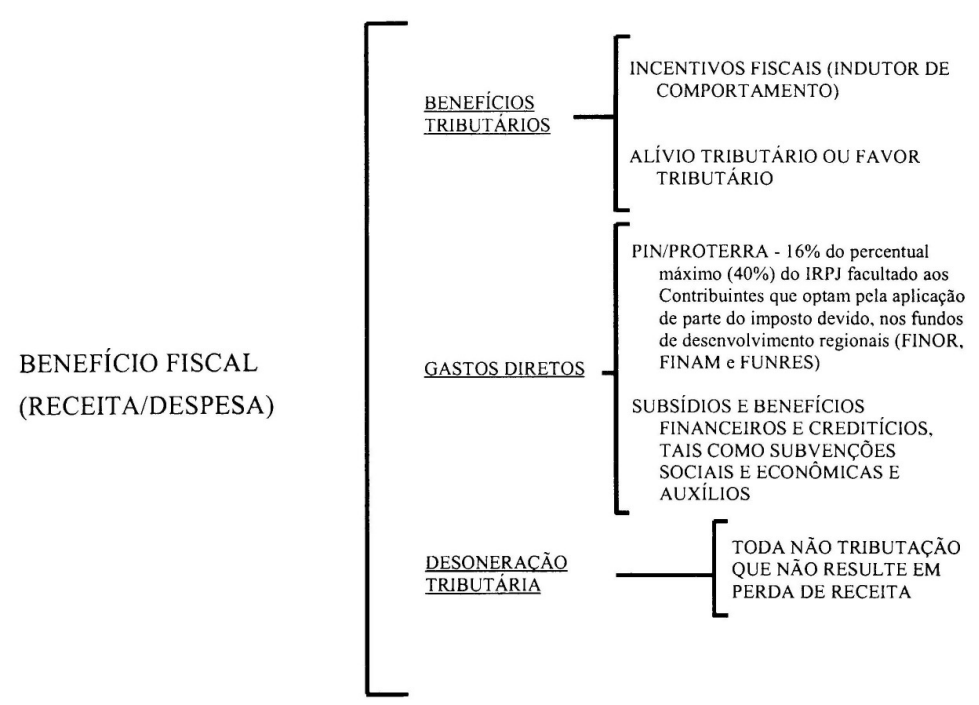

Nota: o benefício fiscal é gênero enquanto o benefício tributário é espécie.

Ilustração 1 - Distinção entre diferentes nomenclaturas

FONTE: ALMEIDA: 2000, p. 32

Almeida (2000, p. 28) apresenta a distinção entre benefício fiscal e incentivo fiscal da seguinte forma:

Cabe ressaltar que, tradicionalmente, no Brasil tem-se empregado o termo 'benefício fiscal' como sinônimo de 'benefício tributário', para designar disposições especiais à regra tributária geral. Contudo, a rigor, benefício fiscal é um termo mais abrangente, pois em economia a palavra fiscal envolve tanto questões ligadas à receita como à despesa, podendo, assim, designar não apenas os benefícios tributários como também os gastos diretos na forma de subsídios, subvenções, etc.

Já a expressão 'incentivo fiscal' é conhecida como um subconjunto dos benefícios tributários. Para um benefício tributário ser também enquadrado como incentivo fiscal é preciso que seja 'indutor de comportamento', vale dizer, estimule os agentes a agir de determinada forma, objetivando a atingir um alvo econômico ou social previamente definido. 
Constata-se, portanto, que a denominação mais adequada para este trabalho é incentivo fiscal, uma vez que por meio da redução dos impostos a pagar as empresas são estimuladas a agir de uma determinada forma, ou seja, inovar, objetivando a atingir um alvo econômico, a saber, tornarem-se mais competitivas.

A questão dos incentivos fiscais é amplamente debatida no campo do Direito Tributário. Normalmente, denomina-se 'função fiscal' a atividade do Estado voltada à obtenção das receitas tributárias. Nesse caso, o Estado aplica a cobrança de um tributo a toda a coletividade. Quando essa cobrança é reduzida para uma parte da coletividade, ou mesmo para um determinado setor de atividade ou geográfico, visando estimular uma atividade, denomina-se 'função extrafiscal' ou 'extrafiscalidade' (NOGUEIRA, 1986, p. 200).

Assim, os incentivos fiscais caracterizam-se por uma relação entre o poder público (fisco) e os agentes privados, por intermédio da qual é concedida a diminuição, que é a prática mais frequente, ou mesmo a eliminação de tributos, com vista a promover uma determinada ação.

Seixas Filho (1999, p. 114) atribui uma essência econômica para esse tipo de ação estatal ao afirmar que: "[...] os incentivos físcais são concedidos para exercerem uma função de desenvolver determinada atividade, considerada relevante para o legislador".

Pereira e Formigoni acrescem à visão econômica um enfoque social na concessão de incentivos fiscais:

\footnotetext{
Os incentivos fiscais estão diretamente relacionados aos tributos, que são arrecadados pelo Estado e servem de fonte de financiamento para as atividades constitucionais por ele desenvolvidas em benefício da população no âmbito da saúde, educação, segurança, habitação, transporte e outros. Muito embora a função primordial dos tributos seja a de prover recursos para o Estado, adicionalmente, os tributos servem a outros objetivos de natureza social, política e econômica, situação em que ele adquire uma configuração extrafiscal, também denominada de renúncia fiscal [...]" (PEREIRA; FORMIGONI., 2009, p.1).
}

Os incentivos fiscais impactam as organizações de forma direta, por intermédio da redução da carga tributária e ainda podem acarretar uma melhor rentabilidade, conforme foi constatado na pesquisa realizada por Formigoni: "Os principais achados deste estudo foram [...] identificou-se a correlação estatisticamente significativa entre incentivo fiscal e os indicadores de rentabilidade das empresas" (FORMIGONI, 2008, p. 165). 
Como exemplos de incentivos fiscais destinados ao incremento de atividades específicas por parte das organizações Higuchi et al. (2009), menciona os seguintes:

\footnotetext{
- Incentivo ao desporto - Lei 11.438/06 alterada pela Lei 11.472 de 2007;

- Incentivos para projetos audiovisuais - Lei 8.685/93, art. 44 MP 2.228/01;

- Incentivos a atividades culturais e artísticas - Lei 8.313/91;

- Programa de alimentação ao trabalhador (PAT) - Lei 6.321/76;

- Fundo de amparo à criança e ao adolescente - Lei 8.069/90, art. 260, Decreto 3.000/99, art. 591;

- Incentivos à inovação tecnológica, Lei 11.196/05, o qual é o objeto do presente trabalho.
}

Diversos estudos foram realizados no Brasil e no exterior cujo objetivo foi avaliar se as políticas tributárias, implementadas mediante de benefícios fiscais, produziram o efeito esperado, como os realizados por Rodrigues Júnior (2003), Bronzini e Balsio (2006), Calzolaio (2011). Outros procuraram analisar os efeitos econômicos dos incentivos fiscais sobre as empresas, tais como Formigoni (2008), Lyra (1995), Souza et al. (2007).

A pesquisa desenvolvida por Estache e Gaspar (1995) demonstrou que os efeitos dos benefícios fiscais, muitas vezes, estão aquém do esperado pelas entidades governamentais. Nesse caso, a análise das causas desse fenômeno é enfocada em questões econômicas, sendo reconhecido pelos autores que podem existir outras razões.

Entretanto, em todos esses trabalhos não se verifica uma análise sobre o processo de adesão das empresas aos incentivos fiscais, o que é fundamental para que se possa atuar sobre o processo a fim de aprimorá-lo e corrigir eventuais distorções.

A ausência de um estudo mais aprofundado sobre a relação entre os incentivos fiscais e a gestão tributária pode ter origem na idéia comum, mas incompleta, de que o único fator para se tomar uma decisão sobre o aproveitamento de um incentivo fiscal seja a redução do montante de tributos a pagar.

O que se constata, na realidade, é que nem sempre existe um significativo aproveitamento de incentivos fiscais concedidos pelo governo, como é o caso dos incentivos fiscais de inovação tecnológica. Por exemplo, conforme os relatórios publicados pelo Ministério da Ciência e Tecnologia e Inovação - MCTI no período de 2007 a 2010, a quantidade de empresas que se utilizaram dos incentivos fiscais de inovação tecnológica foram as seguintes:

Período base de 2007 - 130 empresas (MCTI 2008); 
Período base de 2008 - 460 empresas (MCTI 2010);

Período base de 2009 - 542 empresas (MCTI 2010);

Período base de 2010 - 632 empresas (MCTI 2011);

Entretanto, esses benefícios fiscais poderiam ter sido utilizados por qualquer empresa optante pelo sistema denominado "lucro real", que tenha apresentado lucro tributável.

Nesse mesmo sentido, não se pode deixar de considerar que a concessão dos incentivos físcais sempre é acompanhada de um conjunto de normas e da exigência da adoção de procedimentos contábeis que visam assegurar que não haverá a subtração indevida, por parte das organizações, do montante de tributos a recolher. Normalmente, tratam-se de normas detalhadas, complexas e, muitas vezes, subjetivas e que acarretam ou mesmo exigem a adoção de controles e trabalhos adicionais, contábeis e extra-contábeis e, mesmo, algumas vezes, a contratação de consultorias especializadas.

Verifica-se, portanto, que uma pesquisa que possa identificar se e como os dados contábeis são utilizados pelos gestores, nas decisões relativas à utilização de incentivos fiscais, certamente possibilitará um melhor entendimento sobre esse fenômeno que, como foi visto, envolve um processo de decisão.

No contexto atual da economia brasileira, existem perspectivas promissoras de que os incentivos fiscais para a inovação tecnológica, ora em vigor, sejam mantidos e possivelmente ampliados. Essa é a visão apresentada pelo então Ministro do MCTI, Aloizio Mercadante:

\begin{abstract}
O ministro da Ciência e Tecnologia, Aloizio Mercadante, ao participar da posse do novo presidente da Finep, Glauco Arbix, nesta sexta-feira, 28/01, no Rio de Janeiro, reiterou a necessidade de revisão da Lei da Inovação, regulamentada em 2005. Segundo ele, ao contemplar apenas as empresas de lucro real, a Legislação comete uma injustiça com a maior parte das companhias, produtivas, usuárias do regime de lucro presumido (BRAIM - BRASIL INOVAÇÃO, 2011).
\end{abstract}

Na mesma linha, pronunciou-se a Secretária do Desenvolvimento da Produção do MDIC (Ministério de Desenvolvimento Industria e Comércio), Heloisa Menezes:

Uma das principais demandas é ampliar o leque de empresas que podem se enquadrar na Lei do Bem, disse a secretária. O regime de tributação pelo lucro real representa cerca de $80 \%$ da arrecadação da Receita Federal, mas é utilizado somente por $10 \%$ das empresas brasileiras (PORTAL DO SINDCONT, 2011). 
O processo de decisão com vistas ao aproveitamento de inventivos fiscais para redução da carga tributária é, portanto, um tema que afeta uma parte substancial da contabilidade, polariza diversos setores que estudam o assunto e afeta uma parte significativa de nossa sociedade, devendo, portanto, ser considerado um tema importante.

Ademais, é razoável supor que os conhecimentos adquiridos quanto à utilização da informação contábil para a tomada de decisão em relação à adesão de incentivos fiscais de inovação tecnológica possam ser aplicados, ao menos como uma base de futuros estudos, em outras atividades empresariais para as quais seja necessário ou desejável, o emprego da informação contábil.

\title{
1.2 Problematica da pesquisa
}

\subsubsection{Questão de pesquisa}

Um adequado exame da realidade, que é o objetivo da investigação científica, depende de uma definição clara e objetiva da problemática que será analisada no trabalho de pesquisa. Segundo Martins (2007, p. 22):

\begin{abstract}
$\mathrm{Na}$ apresentação e discussão deste texto a problemática é um elemento do processo de pesquisa que assume fundamental importância. Segundo o entendimento aqui assumido, a pesquisa se inicia pelo problema e é a busca de solução para o problema que orienta a lógica de toda a investigação.
\end{abstract}

Assim, um trabalho científico exige a apresentação de um problema que deverá ter as seguintes características:

Primeiro, o problema deve expressar uma relação entre duas ou mais variáveis [...]. Segundo, o problema deve ser apresentado em forma interrogativa [...]. O terceiro é mais complexo. Exige que o problema seja tal que implique possibilidades de testagem empírica" (KERLINGER, 1980, p. 36).

Verifica-se, portanto, que um problema de pesquisa científica deve ser feito de forma interrogativa e relaciona duas ou mais variáveis.

Tendo em vista o tratado no tópico anterior, em que ficou demonstrada a existência de uma lacuna nos estudos relativos ao processo de adesão aos incentivos fiscais, bem como a importância da carga tributária e dos incentivos fiscais em geral e especificamente dos incentivos fiscais de inovação tecnológica na realidade brasileira, faz-se útil e necessário 
identificar a existência de fatores indutores e inibidores para a utilização da informação contábil. Assim, neste trabalho o problema de pesquisa é apresentado da seguinte forma:

Quais os fatores indutores e inibidores na utilização das informações contábeis para a adesão aos incentivos fiscais de inovação tecnológica?

A questão de pesquisa supõe, portanto, um processo decisório para avaliar a adesão, de forma parcial ou total, ou, ainda, a não adesão ao incentivo fiscal oferecido pelo governo. O input deste processo é dado pelo conhecimento das informações relativas ao incentivo fiscal e por uma análise jurídica que verifique, previamente, se a empresa atende às exigências da lei estabelecidas para o aproveitamento do incentivo.

A partir do input, inicia-se o processo decisório para avaliar a adesão ao incentivo fiscal. Nessa etapa, as informações contábeis devem suportar essa decisão, mas existem fatores que são indutores ou inibidores para essa utilização, o que pode afetar significativamente o processo decisório.

O output desse processo é a informação sobre a decisão escolhida que pode ser a adesão total, a adesão parcial ou a não adesão aos incentivos. Essa decisão poderá, posteriormente, alimentar o sistema de informações contábeis e influenciar as decisões a serem tomadas.

A Ilustração 2, a seguir, apresenta, esquematicamente, o processo de decisão de aproveitamento do incentivo fiscal, os encadeamentos desse processo e as variáveis que serão analisadas. 


\section{PROCESSO DE DECISÃO DE APROVEITAMENTO DE INCENTIVO FISCAL}

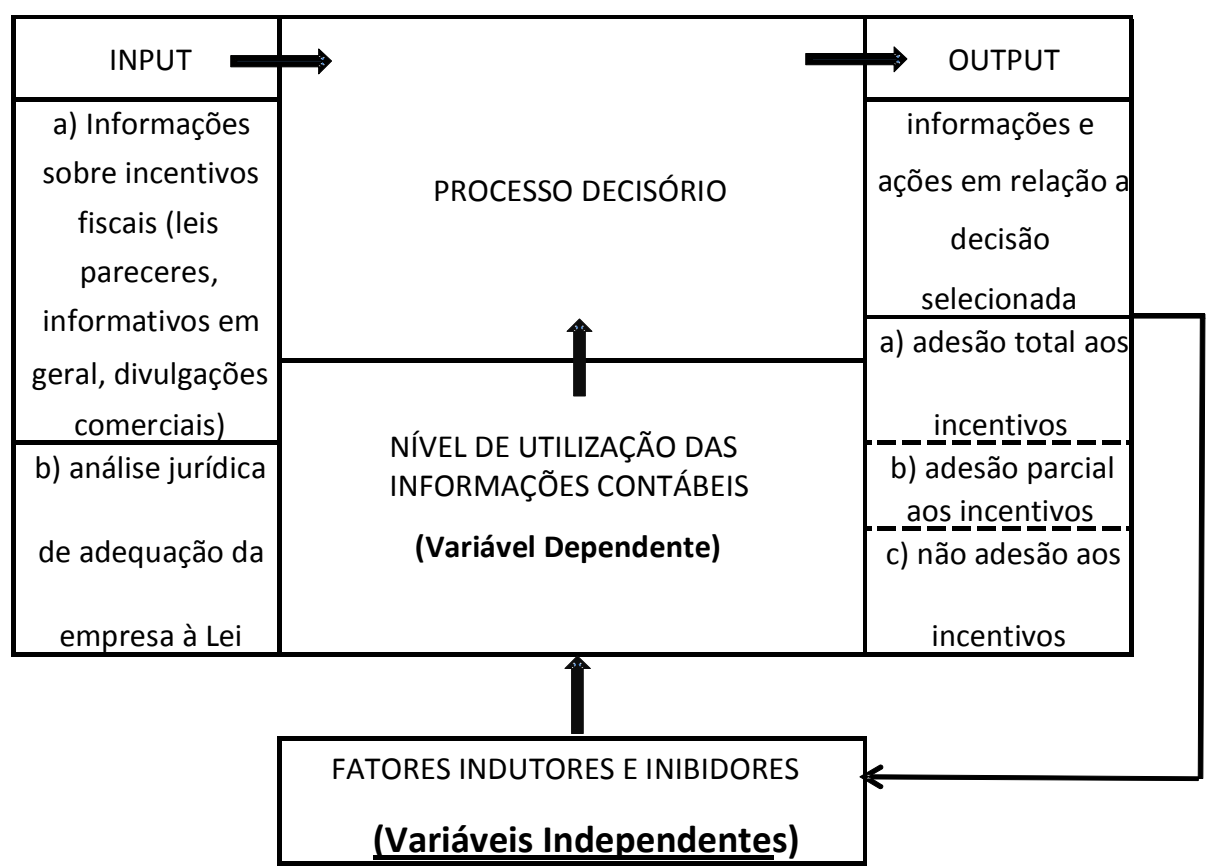

Ilustração 2 - Processo de decisão de aproveitamento do incentivo fiscal

As variáveis que se pretende relacionar, no presente estudo, são o nível de utilização da informação contábil (variável dependente) e os diversos fatores que podem incentivar o uso da informação contábil (variável independente). Em se tratando de variáveis qualitativas o que se pretende obter é um mapa que estabeleça uma noção de proximidade por associação ou frequência das categorias variáveis não-métricas.

\subsubsection{Incentivos de inovação tecnológica}

Como forma de garantir a viabilidade no desenvolvimento do trabalho, o estudo delimita-se à análise dos incentivos fiscais conhecidos como 'incentivos fiscais à inovação tecnológica', atualmente em vigor. Tratam-se dos incentivos fiscais decorrentes da chamada 'lei de inovação' e que foram estabelecidos na Lei 10.973/04 e disciplinados por meio do capítulo III da Lei 11.196/05 (lei do bem), em conjunto com Decreto 5.798/06, tendo sido alterada pela Lei $11.774 / 08$ em seu artigo $4^{\circ}$. 
A empresa que se utiliza desses incentivos pode reduzir a carga tributária de alguns impostos federais, a saber: IRPJ (Imposto de Renda Pessoa Jurídica), CSLL (Contribuição Social sobre o Lucro Líquido) e IPI (Imposto sobre Produtos Industrializados).

A utilização do incentivo fiscal envolve um processo decisório no qual devem ser analisadas diversas informações e situações que incluem:

- $\quad$ informações contábeis sobre os dispêndios realizados nos projetos;

- $\quad$ análise técnica dos projetos considerados, que normalmente são alterados anualmente;

- $\quad$ avaliação do risco fiscal, uma vez que não há uma prévia aprovação por parte do governo para a utilização do incentivo;

- avaliação do custo da implantação dos procedimentos necessários para a obtenção do incentivo em comparação com a diminuição da carga tributária a ser obtida;

- $\quad$ projeção de resultados.

A necessidade de análise de todas essas variáveis traz como consequência que a decisão sobre a utilização ou não do incentivo não deve ser tomada de forma imediata e automática e sem uma considerável reflexão por parte dos gestores da empresa.

A implantação de todas as medidas necessárias para o aproveitamento do incentivo fiscal, muitas vezes, requer o apoio de uma consultoria especializada, o que provavelmente acarreta uma melhor estruturação do processo de decisão.

O MCTI tem um equipe dedicada ao acompanhamento da utilização desses incentivos e anualmente publica um relatório contendo informações diversas. Ao final, são relacionadas, no Apêndice 2, as empresas que se utilizaram do incentivo fiscal no ano base de 2009.

Dessa forma, é possível coletar evidências empíricas para a realização dos testes necessários para verificar as hipóteses levantadas com base no referencial teórico. 


\subsubsection{Objetivos, Hipóteses e Tese}

O objetivo geral do trabalho será identificar, analisar e discutir, sob a perspectiva da teoria da contingência, os fatores indutores e inibidores na utilização da informação contábil para a tomada de decisão no aproveitamento de incentivos fiscais relativos à inovação tecnológica.

O trabalho possui, ainda, os seguintes objetivos específicos:

- $\quad$ caracterizar a política fiscal e a legislação relativa aos incentivos fiscais, especialmente aqueles voltados para a inovação tecnológica nas organizações;

- $\quad$ apresentar o papel que devem assumir as informações contábeis no processo de registro, mensuração e avaliação dos incentivos de inovação tecnológica;

- procurar aprimorar o entendimento de como se realiza o processo de tomada de decisão nas organizações em relação aos incentivos fiscais de inovação tecnológica;

- avaliar a importância atribuída às informações contábeis pelas empresas em relação ao aproveitamento e utilização dos incentivos fiscais de inovação tecnológica nas diversas fases do processo decisório.

Existe um consenso entre os diversos autores na área de metodologia de que a importância e o valor que devem ser dados ao trabalho científico não se limitam à definição do problema e à explicitação dos objetivos da pesquisa, mas, também, incluem a definição de hipóteses e respectivas teses que deverão ser testadas no decorrer do trabalho científico. Nesse sentido afirma Martins (2007, p. 31):

A abordagem metodológica hipotética-dedutiva - comum nos estudos da área de humanidades pede o enunciado de hipóteses que no desenvolvimento do trabalho serão testadas e comprovadas através do suporte do referencial teórico e análises dos resultados de avaliações quantitativas e qualitativas das informações, dados e evidências conseguidas. As questões/problemas de pesquisa, os objetivos da investigação e as hipóteses contextualizam a essência de um estudo científico.

Kerlinger (1980, p. 39) apresenta hipótese como:

Um enunciado conjetural das relações entre duas ou mais variáveis. Hipóteses são sentenças declarativas e relacionam de algum forma variáveis a variáveis. São enunciados de relações e, como os problemas, devem implicar a testagem das relações enunciadas. Problemas e hipóteses são semelhantes. Ambos enunciam relações, só que os problemas são sentenças interrogativas e as hipóteses sentenças afirmativas. 
Conforme já mencionado anteriormente, este trabalho procura estudar a relação entre as informações contábeis e o processo decisório para utilização dos incentivos fiscais de inovação tecnológica.

A informação contábil foi definida por Yamamoto e Salotti (2006, p.5) "como aquela que altera o estado da arte do conhecimento de seu usuário em relação à empresa e, a partir de interpretações, a utiliza na solução de problemas [...]".

Para Carvalho e Nakagawa (2004), a contabilidade é capaz de fornecer um significativo volume de informações que foram classificadas, ordenadas de forma sintética ou análitica e dentro de um mesmo padrão monetário ou, algumas vezes quantitativo. Assim, a contabilidade destaca-se por dar origem às informações que podem ser utilizadas para a tomada de decisão.

Nesse sentido Beuren (1998, p.43) afirma que "a informação é fundamental no apoio às estratégias e aos processos de tomada de decisão, bem como no controle das operações empresariais."

Levando-se, ainda, em conta o cenário atual do mundo dos negócios com aumento da concorrência, diminuição dos recursos disponíveis e necessidade de constantes alterações no processo de gestão, o papel das informações ganha importância extraordinária. Ainda, segundo Beuren (1998, p.12), a informação é fundamental nos processos de decisão e deve auxiliar os gestores a atingir os objetivos propostos.

Fica claro que as informações contábeis são importantes para que os gestores possam decidir sobre a adesão ou não aos incentivos fiscais. Seria de se esperar, portanto, que a decisão sobre o aproveitamento dos incentivos tivesse uma base racional suportada pelas informações contábeis. Entretanto, muitas vezes as informações contábeis não são utilizadas de maneira adequada. Assim, autores como Guerreiro et al., (2000) chegam a afirmar que existe um verdadeiro paradoxo no emprego das informações contábeis que leva os usuários a não se utilizarem dos melhores métodos e práticas contábeis, devido a influências psicológicas.

Outros estudos como Soares (1998) e Zanotelli (2001), também, constataram que existe uma lacuna entre as informações contábeis e a sua efetiva utilização por parte dos gestores 
responsáveis pela tomada de decisão. As causas normalmente atribuidas a esse fato são o atraso da disponibilização da informação e o fato de os relatórios contábeis, muitas vezes, serem de dificil compreensão.

Em vista do exposto, este trabalho apresenta as seguintes hipóteses:

a) Hipotese 1 - Existem fatores indutores e inibidores na utilização da informação contábil, para a adesão dos incentivos fiscais de inovação tecnológica ;

b) Hipotese 2 - A influência desses fatores varia de acordo com as caracteristicas ambientais, empresariais e da própria informação contábil e

c) Hipotese 3 - As decisões sobre o aproveitamento dos incentivos fiscais podem ocorrer ignorando-se uma parcela significativa das informações contábeis.

Tendo em vista que na criação e na adesão aos incentivos fiscais para a Inovação Tecnológica, as informações contábeis são um instrumento útil e necessário para a tomada de decisão, a tese proposta é que: é possível identificar a existência de fatores indutores e inibidores, com características diversas, da utilização das informações contábeis na adesão aos incentivos fiscais de inovação tecnológica e, portanto, a utilização da informação contábil não depende apenas de uma avaliação técnica por parte dos gestores envolvidos na decisão, sendo necessário considerar esses fatores indutores e inibidores para um adequado processo de decisão sobre a adesão aos incentivos fiscais de inovação tecnológica.

\subsubsection{Justificativas}

Na literatura contábil tributária, há uma grande escassez de trabalhos acadêmicos que tenham como objetivo entender o processo de adesão aos incentivos fiscais de uma forma geral. As pesquisas, normalmente, enfocam questões relativas ao chamado planejamento tributário, ou seja, procedimentos contábeis que permitam a redução dos impostos a pagar ou procuram identificar os efeitos das políticas tributárias mediante os resultados obtidos nas empresas.

Exemplo recente desse tipo de estudo foi o desenvolvido por Calzolaio (2011), no qual se procura identificar se as empresas que se utilizaram dos incentivos fiscais de inovação tecnológica de fato tiveram um desempenho inovativo. 
Não colocando em dúvida a importância de avaliar os resultados dessas políticas, parece, também, fundamental entender como o processo de adesão aos incentivos fiscais se realiza, uma vez que, como exposto neste trabalho, os governos de praticamente todos os países desenvolvidos têm políticas para incentivos à P \& D (Pesquisa e Desenvolvimento). No Brasil, políticas semelhantes foram implantadas recentemente e, de acordo com o discurso apresentado pelas autoridades governamentais, devem permanecer e, possivelmente, os incentivos serão ampliados.

Analisar resultados numéricos é uma tarefa que parece mais objetiva do que entender processos. Quando resultados numéricos são analisados estão envolvidas variáveis quantitativas, entretanto, quando se trata de processos empresariais, deve-se levar em consideração que o comportamento humano ocorre dentro de um determinado contexto organizacional, formado por pressões ambientais, políticas, sociais, estruturais etc., cujas variáveis normalmente são mais subjetivas e de natureza qualitativa.

Assim, na análise da pesquisa, foi necessário aplicar um método, também inovador, que possibilitasse identificar a proximidade de diversas variáveis qualitativas com o grau de utilização da informação contábil em diversos aspectos.

\footnotetext{
A análise das Correspondências Múltiplas revelou-se uma ferramenta utilíssima para ultrapassar (com um considerável poder 'explicativo') o procedimento clássico de 'apuramento', baseado em percentagens e cruzamento de variáveis duas a duas. Em especial tornou possível o estabelecimento das relações entre as perguntas específicas que são objeto do inquérito e as variáveis de caracterização da população dos respondentes [...]. (CARVALHO 2008, p. 11)
}

Trata-se, ainda, de uma oportunidade única para esse tipo de análise, se se considerar a importância dos valores de renúncia fiscal envolvidos pois, segundo o relatório anual do MCTI, no ano base de 2011, foram aplicados em dispêndios passíveis da utilização dos incentivos fiscais aproximadamente 8,6 bilhões de reais. Ademais, em se tratando de incentivos recentes, o momento atual é bastante oportuno para se investigarem os processos de decisão utilizados pelos gestores com relação ao tema.

\subsubsection{Contribuições esperadas}

Por intermédio do desenvolvimento deste trabalho espera-se contribuir no campo da teoria com um arcabouço teórico sobre a utilização das informações contábeis para aproveitamento dos incentivos fiscais de inovação tecnológica. 
De fato, como já comentado anteriormente, os estudos da utilização da informação contábil são aplicados a diversas áreas como, por exemplo, as decisões sobre investimentos, a avaliação do valor da empresa, e mesmo sobre o resultado de políticas fiscais. Entretanto, pouco se analisou sobre a utilização da informação contábil para suportar decisões sobre o aproveitamento de incentivos fiscais.

O conhecimento dos fatores indutores e inibidores na utilização da informação contábil poderá permitir aos gestores nas empresas compreender melhor o processo de tomada de decisão na adesão ao incentivo fiscal. Isso permitirá que as decisões sejam tomadas mediante critérios mais objetivos, levando-se em consideração variáveis que influenciam no processo decisório, mas que nem sempre são claramente percebidas no cotidiano das organizações.

Um entendimento adequado sobre como as informações contábeis são utilizadas no processo de decisão do aproveitamento de um incentivo fiscal poderá, também, contribuir para uma melhor gestão por parte do governo, no que se refere à implementação e ao controle de políticas de concessão desses incentivos, com vistas a uma maior efetividade no alcance dos resultados desejados.

Ademais, para os agentes públicos que criaram, por meio da legislação, para fins de controle e avaliação, regras na utilização dos incentivos fiscais que incluem o controle dos dispêndios relativos à inovação tecnológica mediante os dados registrados na contabilidade e a obrigatoriedade de uma prestação de contas ao MCTI baseada em dados contábeis, é importante entender que existem fatores que induzem ou inibem a utilização da informação contábil. Por último, espera-se que os resultados deste trabalho contribuam para promover uma discussão mais aprofundada e um aprimoramento na legislação relacionada ao tema. 


\subsubsection{Estrutura}

Este trabalho está estruturado em cinco capítulos e se inicia pela apresentação da importância do tema, por meio de uma rápida análise da carga tributária e dos incentivos fiscais no Brasil, relacionando-os com a utilização das informações contábeis para a tomada de decisão.

O desenvolvimento do trabalho é feito a partir da análise de três assuntos:

O primeiro é relativo aos incentivos fiscais de inovação tecnológica e engloba o exame da legislação pertinente e a demonstração detalhada da possível redução de tributos a pagar em decorrência da aplicação dos incentivos fiscais, para, então, demonstrar de forma inequívoca a necessidade da utilização das informações contábeis para a tomada de decisão na adesão aos referidos incentivos fiscais.

Uma vez identificada a existência de um processo de tomada de decisão, o segundo assunto investigado tem a finalidade de caracterizar como se realiza o processo de decisão sobre a adesão aos incentivos fiscais. Para tanto, é utilizada como referencial teórico a teoria da contingência, sendo identificada por meio desse referencial a existência de um modelo próprio para as decisões relativas à adesão aos incentivos fiscais denominado "mixed scanning”, e um segundo modelo, menos adequado, mas que por se tratar de um modelo mais conhecido no meio empresarial também pode ser utilizado nas decisões aos incentivos fiscais denominado "classical".

Complementando a parte teórica do trabalho, e ainda tendo como base o referencial teórico da teoria da contingência, e estudos correlatos ao presente, são analisados e definidos os fatores que podem se constituir em indutores e inibidores da informação contábil.

Na sequência é apresentada a metodologia aplicada na pesquisa de campo, a qual foi realizada por intermédio de um questionário estruturado, enviado às empresas que aderiram aos benefícios fiscais de inovação tecnológica no ano calendário de 2009. O tratamento estatístico dos dados coletados foi realizado mediante técnica denominada análise de homogeneidade (HOMALS).

Com base na aplicação da técnica estatística, são apresentados os fatores indutores e inibidores da utilização da informação contábil na adesão dos benefícios fiscais de inovação 
tecnológica, sendo o resultado comparado com o esperado no referencial teórico e com os estudos utilizados como base para a definição desses mesmos fatores.

Ao final, analisa-se se os objetivos do trabalho são alcançados e se as teses propostas foram confirmadas. 


\section{PLATAFORMA TEÓRICA}

Nesse capítulo, são analisadas, sob uma perspectiva histórica e da legislação atualmente em vigor, as políticas de incentivos fiscais adotadas no Brasil. Nessas políticas, destaca-se o papel relevante atribuído pela legislação ao uso da informação contábil para fins de avaliação e controle, por parte do governo, dos incentivos fiscais à inovação tecnológica.

Em seguida, é analisada a aplicação da teoria da contingência como base para o estudo do uso da informação contábil no processo decisório relacionado à adesão aos incentivos físcais de inovação tecnológica. A aplicação dessa teoria servirá para identificar os fatores e as variáveis que, possivelmente, influenciam o uso da informação contábil nesse processo, essa análise constitui a base para a elaboração do questionário para a coleta de dados nas empresas.

\subsection{Incentivos fiscais de inovação tecnológica}

Os incentivos fiscais como instrumento para o desenvolvimento da inovação tecnológica têm sido utilizados pelos mais diversos países das mais variadas tendências políticas e econômicas. A origem para a concessão desses incentivos muito provalmente está relacionada ao fato de que existe um consenso de que para o desenvolvimento econômico é necessário um progresso contínuo de inovação tecnológica (POSSAS, 2003).

\subsubsection{Visão geral de benefícios fiscais concedidos pelos países da OCDE}

Os instrumentos de apoio para desenvolvimento de inovação tecnológica são concedidos por diversos países. No âmbito da OCDE (Organização de Cooperação e Desenvolvimento Econômico) o setor produtivo é quem emprega maior volume de recursos no gasto total com P\&D e, conforme Negri et al (2008, p. 149), a parcela do valor agregado destinada a atividades de $\mathrm{P} \& \mathrm{D}$ vem se expandido em diversos países.

Os gastos do setor privado têm sido acompanhados de iniciativas de apoio generalizadas, por parte dos governos dos países da OCDE, porém, como ressaltam Negri et al (2008, p. 151): “[...] sem que entanto se caracterize, como será indicado adiante, uma relação necessária entre intensidade do apoio governamental e maior comprometimento das empresas com tais atividades". 
Esse apoio governamental demonstra a importância dada pelos agentes governamentais desses países e tem como finalidade reduzir o custo e o risco, que normalmente são significativos, relacionados às atividades e projetos de inovação. $\mathrm{O}$ apoio governamental é dado pela concessão de financiamentos subsidiados ou mediante incentivos fiscais que reduzam a carga tributária que recai sobre as empresas.

Os países da OCDE têm recorrido a ambos os mecanismos, ou seja, tanto ao financiamento público quanto à concessão de incentivos fiscais às atividades de $\mathrm{P} \& \mathrm{D}$ conduzidas por empresas privadas. Todos os países concedem algum apoio financeiro a essas atividades. Por outro lado, dos 24 países analisados apenas 7 não oferecem nenhum benefício fiscal aos gastos com $P \& D$ além de eventual depreciação acelerada" (NEGRI et al, 2008, p. 153).

A Ilustração 3 procura demonstrar a intensidade do apoio dado às empresas de alguns países da OCDE tanto no que se refere ao financiamento público como à concessão de benefícios fiscais.

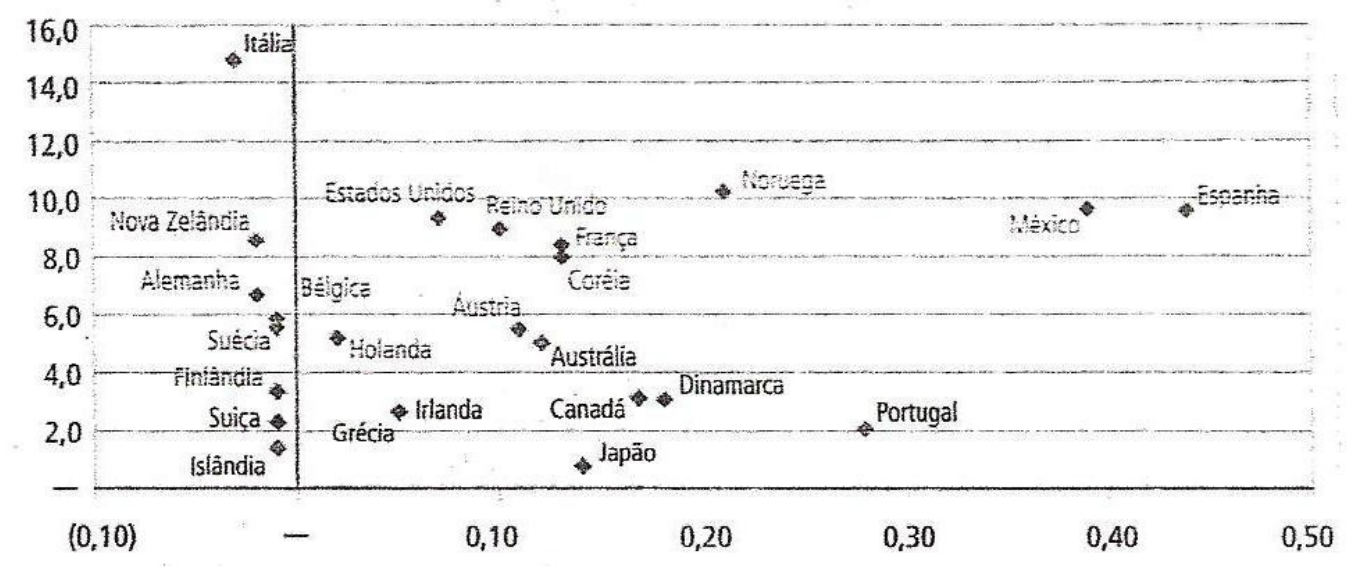

Generosidade relativa do tratamento fiscal $[1$ - indice-B] - 2004

Ilustração 3 - Participação de recursos públicos no financiamento dos gastos das empresas com $P \& D$

Fonte: Negri et al, 2008 p. 154

A importância do financiamento público é indicada pelo eixo vertical: quanto maior o índice, mais esse tipo de apoio é concedido. A intensidade do incentivo fiscal concedido é medida pelo eixo horizontal. Assim, na análise do gráfico, verifica-se que a Itália é um pais que concede muitos incentivos fiscais de financiamento público e nenhum benefício de ordem fiscal, pois se situa no campo negativo do eixo horizontal, enquanto Portugal tem uma posição diferente pois concede incentivos de ordem fiscal e pouco financiamento. 
É interessante notar que países como os Estados Unidos e a França, que tradicionalmente são conhecidos por não concederem incentivos às empresas privadas, aparecem no gráfico utilizando os incentivos para a implementação de atividades de P\&D. Os Estados Unidos oferecem principalmente financiamento público e a França numa zona intermediária oferece financiamento e incentivos fiscais.

A principal vantagem para a utilização de incentivos fiscais ao invés de financiamento público está no fato de permitir às empresas direcionarem quais os gastos e investimentos que devem ser realizados em P\&D. Entretanto, mesmo na concessão de incentivos físcais é possível ao governo introduzir algum tipo de orientação, concedendo incentivos especiais a algum segmento empresarial (por exemplo, atividade de telefonia) ou a alguma atividade das empresas (por exemplo, parcerias com universidades). Além disso, outra vantagem desse tipo de incentivo é que ele tem um custo menor de administração, quando comparado ao financiamento público, que exige editais, concorrências e análise detalhada de projetos.

Contudo, apesar do menor custo administrativo, o mecanismo de incentivo fiscal pode, eventualmente, ser extremamente oneroso para o erário, pela magnitude da renúncia fiscal envolvida. O mecanismo tem sido também criticado por não permitir a orientação do investimento em P\&D para áreas e setores de maior rentabilidade social favorecendo projetos com retorno no curto prazo, em detrimento daqueles de retorno mais lento, remunerando projetos que não demandariam incentivo para serem realizados" (NEGRI et al 2008, p. 156).

\subsubsection{Política de incentivos fiscais para a inovação tecnológica no Brasil}

Como parte de um plano audacioso e heterodoxo de desenvolvimento econômico e de combate à inflação, a chamada 'Era Collor' promoveu a extinção de toda a estrutura de incentivos fiscais, nela incluídos os incentivos para a inovação tecnológica.

Atualmente, constata-se um grande esforço do governo brasileiro em estimular a inovação no cenário econômico nacional.

A Política Industrial, Tecnológica e de Comércio Exterior (PITCE), lançada em novembro de 2003, e o Plano de Desenvolvimento da Produção, em maio de 2008, colocam a inovação como fator fundamental para que a indústria brasileira dê um salto de qualidade rumo à diferenciação de produtos, transformando, assim, sua própria estrutura industrial (NEGRI et al, 2008, p. 13).

Esse esforço teve início com a Lei no 8.661 que, em 1993, promoveu o retorno dos incentivos à inovação tecnológica por meio do Programa de Desenvolvimento Tecnológico Industrial (PDTI) e o Programa de Desenvolvimento Tecnológico Agropecuário (PDTA). 
Em 1997, já no Governo Fernando Henrique, foi editada a Lei no 9.352, que reformulava de forma ampla a legislação da tributação federal. As alterações promovidas no PDTI e PDTA não foram significativas, limitando-se a uma redução nos percentuais dos incentivos fiscais. Os incentivos consistiam, sobretudo, no financiamento de projetos de inovação, mas em ambos os programas era exigido que os projetos fossem previamente aprovados pelo MCT (Ministério da Ciência e Tecnologia) ou por entidades federais e estaduais de fomento à pesquisa tecnológica, autorizadas pelo MCT para realizar essa tarefa.

O Governo Lula promoveu uma alteração na legislação que mudou a orientação no financiamento público com pesquisa e desenvolvimento, através da Lei $n^{\circ} 10.973$, de 2 de dezembro de 2004, conhecida como 'lei de inovação tecnológica' que previa, em seu artigo 28, que deveriam ser criados incentivos fiscais no prazo de 120 dias para apoio às atividades de $\mathrm{P} \& \mathrm{D}$.

Apesar do prazo de 120 dias não ter sido cumprido, em 16 de junho de 2005 foi editada a MP (Medida Provisória) no 252, que perdeu sua eficácia devido à não votação pelo Congresso Nacional, mas cujo texto foi novamente editado por meio da MP no 255 , que foi convertida na Lei no 11.196/05, a qual também contemplou uma série de alterações na legislação fiscal federal, sendo conhecida como 'lei do bem'.

A lei pretendeu fomentar as atividades de inovação tecnológica através de três ações: a constituição de ambiente propício às parcerias estratégicas entre as universidades, institutos tecnológicos e empresas; o estímulo à participação de institutos de ciência e tecnologia no processo de inovação e o estímulo à inovação nas empresas” (FERNANDES, 2006, p. 28).

A Lei no 11.196/05 foi regulamentada pelo decreto no 5.798/06, que permitiu que os incentivos fiscais da referida lei fossem usufruídos a partir de 1ำ de janeiro de 2006. Posteriormente houve uma pequena ampliação dos incentivos fiscais pela Lei no $11.774 / 08$ artigo 4. O Decreto no 5.798/06 foi alterado pelo Decreto n- 6.909/09.

A Receita Federal do Brasil (RFB) disciplinou a utilização dos incentivos fiscais relativos às atividades de pesquisa tecnológica e desenvolvimento de inovação tecnológica mediante a IN (Instrução Normativa) no 1.187 , de 29 de agosto de 2011. 


\title{
2.1.3 Incentivos fiscais para a inovação tecnológica no Brasil
}

Por meio do Decreto no 5.798/06 inciso I do artigo 2 foi definida a inovação tecnológica como:

A concepção de novo produto ou processo de fabricação, bem como a agregação de novas funcionalidades ou características ao produto ou processo que implique melhorias incrementais e efetivo ganho de qualidade ou produtividade, resultando maior competitividade no mercado.

No mesmo artigo no inciso II são relacionadas as atividades relativas à pesquisa e desenvolvimento tecnológico como:

\begin{abstract}
a) pesquisa básica dirigida: os trabalhos executados com o objetivo de adquirir conhecimentos quanto à compreensão de novos fenômenos, com vistas ao desenvolvimento de produtos, processos ou sistemas inovadores;

b) pesquisa aplicada: os trabalhos executados com o objetivo de adquirir novos conhecimentos, com vistas ao desenvolvimento ou aprimoramento de produtos, processos e sistemas;

c) desenvolvimento experimental: os trabalhos sistemáticos delineados a partir de conhecimentos pré-existentes, visando à comprovação ou demonstração da viabilidade técnica ou funcional de novos produtos, processos, sistemas e serviços ou, ainda, um evidente aperfeiçoamento dos já produzidos ou estabelecidos;

d) tecnologia industrial básica: aquelas tais como a aferição e calibração de máquinas e equipamentos, o projeto e a confecção de instrumentos de medida específicos, a certificação de conformidade, inclusive os ensaios correspondentes, a normalização ou a documentação técnica gerada e o patenteamento do produto ou processo desenvolvido; e

e) serviços de apoio técnico: aqueles que sejam indispensáveis à implantação e à manutenção das instalações ou dos equipamentos destinados, exclusivamente, à execução de projetos de pesquisa, desenvolvimento ou inovação tecnológica, bem como à capacitação dos recursos humanos a eles dedicados.
\end{abstract}

A seguir, são apresentados os incentivos fiscais que constam da Lei no 11.196/05 e que foram disciplinados e normatizados em diversos diplomas legais já citados. Para cada um dos incentivos é mencionada a sua base legal, o incentivo fiscal previsto, ou seja, em que ele consiste e qual o imposto ou contribuição que pode ser reduzido mediante a utilização dos incentivos fiscais e eventuais explicações necessárias para uma melhor compreensão:

a) Dedução com os dispêndios com inovação tecnológica (inciso I, artigo 17). Dedução para fins de determinação da base de cálculo do IRPJ e da CSLL de todos os dispêndios relacionados com inovação tecnológica inclusive aqueles relacionados com universidades, instituição de pesquisa ou inventor independente, desde que a empresa fique com o risco empresarial, a gestão e o controle da utilização dos resultados. De forma geral, essa permissão já constava do Regulamento do Imposto de Renda em seus artigos 325 e 349 .

b) Redução do IPI (inciso II, artigo 17). Redução de 50\% do IPI nas aquisições sobre equipamentos, máquinas, aparelhos e instrumentos, bem como acessórios sobressalentes 
e ferramentas que acompanhem esses bens destinados à pesquisa e ao desenvolvimento tecnológico.

c) Depreciação Acelerada (inciso III, artigo 17, alterado pela Lei no 11.774 de 17 de setembro de 2008). Depreciação integral, no próprio ano da aquisição, de máquinas, equipamentos, aparelhos e instrumentos, novos, destinados à utilização nas atividades de pesquisa tecnológica e desenvolvimento de inovação tecnológica, para efeito de apuração do IRPJ e da CSLL.

d) Amortização Acelerada (inciso IV, artigo 17). Amortização acelerada, mediante dedução como custo ou despesa operacional, no período de apuração em que forem efetuados, dos dispêndios relativos à aquisição de bens intangíveis, vinculados exclusivamente às atividades de pesquisa tecnológica e desenvolvimento de inovação tecnológica, classificáveis no ativo diferido, para efeito de apuração do IRPJ.

e) Crédito do imposto sobre a renda retido na fonte (inciso V, artigo 17). Manutenção como crédito, com direito a compensação em outros impostos, do imposto de renda retido na fonte incidente sobre os valores pagos, remetidos ou creditados a beneficiários residentes ou domiciliados no exterior, a título de royalties, de assistência técnica ou científica e de serviços especializados, previstos em contratos de transferência de tecnologia averbados ou registrados nos termos da Lei n- 9.279, de 14 de maio de 1996. Esse incentivo dependia de regulamentação que nunca foi realizada e acabou por ser revogado pela Lei n- $12.350 / 10$, não tendo, portanto, nunca produzido qualquer efeito prático.

f) Exclusão adicional dos dispêndios com inovação tecnológica (artigo 19). Exclusão adicional do lucro líquido na determinação da base do Lucro Real para fins de cálculo do IRPJ e da CSLL realizados no período de apuração com pesquisa tecnológica e desenvolvimento de inovação tecnológica, classificáveis como despesa pela legislação do IRPJ. Essa exclusão pode chegar a $80 \%$ dos dispêndios caso exista um incremento de pesquisadores. Através do Decreto no 5.798/06 foi estabelecido que no caso de incremento de pesquisadores em relação ao ano anterior de até $5 \%$, a exclusão adicional será de $70 \%$. Caso esse incremento supere $5 \%$, a exclusão passará a ser de $80 \%$. Ainda desse artigo consta um incentivo adicional de $20 \%$ na determinação da base do lucro real no caso de dispêndios realizados com inovação tecnológica em que tenham sido concedidas patentes ou cultivar registrado. Neste caso a dedução adicional seria de $100 \%$ do valor do dispêndio. Note-se que todas essas deduções estão limitadas ao valor do lucro real e da base de cálculo da CSLL, não sendo permitido o aproveitamento em períodos posteriores. Esse tipo de mecanismo é denominado 'tax allowance' e segundo Negri et al, "consiste na dedução - para efeito de determinação da base de cálculo do $I R$ incidente sobre o lucro das empresas - de um valor superior ao efetivamente despendido pela empresa em suas atividades de P\&D” (2008, p. 156).

g) Depreciação e amortização aceleradas quando da conclusão de pesquisas (artigo 19). Os dispêndios incorridos em instalações fixas e na aquisição de aparelhos, máquinas e equipamentos, destinados à utilização em projetos de pesquisa e desenvolvimento tecnológico, metrologia, normalização técnica e avaliação da conformidade, aplicáveis a produtos, processos, sistemas e pessoal, procedimentos de autorização de registros, licenças, homologações e suas formas correlatas, bem como relativos a procedimentos de proteção de propriedade intelectual, poderão ser depreciados ou amortizados na 
forma da legislação vigente, podendo o saldo não-depreciado ou não-amortizado ser excluído na determinação do lucro real no período de apuração em que for concluída sua utilização.

h) Subvenção (artigo 21). A União por meio de agências de fomento poderá subvencionar o valor pago a mestres e doutores que se dediquem às atividades de inovação tecnológica em empresas que estejam em território brasileiro. Conforme o texto legal da MP 252, essa subvenção pode chegar a 50\%.

i) Dedução adicional para atividades de informática (artigo 21). A pessoa jurídica que se aproveitar dos incentivos da lei de informática ou da Zona Franca de Manaus, relativamente às atividades de informática e automação, poderá deduzir, para efeito de apuração do lucro real e da base de cálculo da CSLL, o valor correspondente a até $160 \%$ (cento e sessenta por cento) dos dispêndios realizados no período de apuração com pesquisa tecnológica e desenvolvimento de inovação tecnológica. Esse incentivo foi incluído pela Lei - 11.774/08. Essa dedução poderá chegar a até $180 \%$ (cento e oitenta por cento) dos dispêndios em função do número de empregados pesquisadores contratados pela pessoa jurídica.

As principais alterações introduzidas pelos novos diplomas legais iniciados com a Lei no 11.196/05 foram assim definidas por Negri et al (2008, p. 183):

A estrutura de incentivos definida pela Lei no $11.96 / 05$ distingue-se, antes de mais nada, daquela delineada pela Lei no 8.661/1993, no início da década de 1990, por ampliar o foco dos benefícios concedidos [...]. A nova estrutura contempla qualquer empresa engajada na realização de atividades de $\mathrm{P} \& \mathrm{D}$.

Do ponto de vista dos instrumentos adotados, a principal modificação introduzida pela Lei n11.196/2005, em comparação à legislação precedente, é a substituição do crédito tributários previsto pela Lei no 8.661/1993 (dedução do IR devido, até o limite de 4\% do referido imposto, de valor equivalente à aplicação de alíquota cabível do IR à soma dos dispêndios, em atividade de pesquisa e de desenvolvimento tecnológico) por um tax allowance (exclusão do lucro líquido na determinação do lucro real e da base de cálculo da CSLL), de valor corresponde a até $160 \%$ da soma dos dispêndios realizados no período de apuração".

\subsubsection{Registro, controle e mensuração contábil dos incentivos fiscais de inovação tecnológica}

Nesse tópico serão mencionadas as implicações contábeis de registro, controle e mensuração para as empresas que usufruem dos incentivos fiscais de inovação tecnológica pois, além dos procedimentos contábeis que visam a garantir uma adequada representação da situação patrimonial, são diversas as regras estabelecidas na legislação fiscal que as empresas devem seguir, e que deixam clara a importância da contabilidade no registro, controle e mensuração contábil desses incentivos. 
A finalidade dessa abordagem é demonstrar que para a decisão quanto à adesão aos incentivos fiscais objetos desta tese é necessária a utilização, de forma inequívoca, de informações contábeis, tendo em vista o estabelecido pela própria legislação.

Conforme determinado na IN RFB no $1.187 / 11$ em seu artigo 3o, para a utilização dos incentivos as empresas devem elaborar projeto de pesquisa tecnológica e desenvolvimento de inovação tecnológica, com controle analítico dos custos e despesas integrantes para cada projeto incentivado. Ademais, na mesma instrução, em seu artigo 18, fica determinado que os dispêndios e pagamentos devam ser controlados contabilmente em contas específicas.

Esses dois controles estabelecidos pela IN, ou seja, controle analítico de custos e despesas por projeto e segregação em contas contábeis são especialmente importantes para o registro e controle da dedução do IRPJ e CSLL e a respectiva exclusão adicional dos dispêndios com inovação tecnológica, tratados nos itens 1 e e 6o do tópico anterior.

A mensuração de todos esses registros também é feita por meio da contabilidade, uma vez que os valores com os dispêndios com inovação tecnológica se encontram nos registros contábeis.

O capítulo III da referida IN trata de depreciação e amortização aceleradas. Nesse caso há um registro no LALUR (Livro de Apuração do Lucro Real) do valor total do bem ou direito a ser depreciado, reduzindo a base de cálculo do IRPJ e da CS. Na contabilidade registra-se a depreciação normal do bem com o decorrer do tempo, sendo que o valor que superar o custo de aquisição deve ser adicionado ao lucro líquido no LALUR, no período em que esse fato ocorrer.

$\mathrm{Na}$ depreciação e amortização aceleradas existe ainda a necessidade da contabilização do IRPJ e da CSLL diferidos por se tratar de uma dedução de natureza temporária. (IUDICIBUS et al, 2010, p. 324).

$\mathrm{Na}$ subvenção governamental os valores recebidos devem ser considerados como receita ao longo do período no qual esta será confrontada com a despesa que se pretende compensar (CPC, 07 2012).

Verifica-se, portanto, que a adesão aos incentivos fiscais de inovação tecnológica têm uma significativa repercussão nos registros e controles contábeis, entretanto isso não implica 
afirmar que o resultado contábil ficará distorcido ou que a contabilidade não poderá seguir os padrões técnicos desejados, isso porque, a partir da adoção do Regime Tributário de Transição (RTT):

[...] o Governo Federal genuinamente deu o maior dos saltos, porque passou a separar a Contabilidade para fins informacionais, societários, de divulgação do que ocorre com a empresas para o mundo exterior (credores, investidores, sindicatos e tantos outros interessados), da contabilidade para fins tributários. (IUDICIBUS, 2010, p. 318).

\subsubsection{Utilização da informação contábil na adesão dos incentivos fiscais de inovação tecnológica}

A importância do papel da informação como uma vantagem competitiva tem sido cada vez mais ressaltada no contexto de um universo empresarial em que estão inseridas as empresas atualmente e no qual a concorrência entre organizações é cada vez mais acirrada. A informação tornou-se um recurso imprescindível para as empresas (GOLDRATT, 1991).

Evidentemente nas organizações as informações têm origem em uma multiplicidade de fontes e são diversas as formas como essas informações são empregadas. Dentre essas várias fontes, a contabilidade tem um papel de destaque como produtora de informações.

A literatura, a respeito dos sistemas de informações relacionados à contabilidade apresenta termos como 'sistema de informação contábil', 'sistema de informação gerencial' e 'contabilidade gerencial', os quais são usados de forma indistinta, sem que exista um consenso sobre a definição conceitual de cada um e, portanto, sem limites claros da área abrangida por cada termo.

De outro lado, existe unanimidade em afirmar que o sistema de informação contábil ou qualquer outro termo semelhante que lhe seja atribuído tem como finalidade o fornecimento de informações para a tomada de decisão. Veja-se, por exemplo o conceito apresentado por Horngren et al (2004, p. 4):

\footnotetext{
A contabilidade gerencial refere-se à informação contábil desenvolvida para gestores dentro de uma organização, ou seja, é o processo de identificar, mensurar, acumular, analisar, preparar, interpretar e comunicar informações que auxiliem os gestores a atingir seus objetivos organizacionais .
} 
O principal objetivo do sistema contábil é elaborar um conjunto de informações adequadas e relevantes que possam auxiliar e suportar a tomada de decisão (BEUREN, 1998). Dentre aqueles que devem se utilizar desse tipo de informação estão os gestores da empresa pois, segundo Guerreiro (1992), eles representam um tipo diferenciado de usuário da informação contábil, já que necessitam dela para uma adequada tomada de decisão. Verifica-se, portanto, que as informações contábeis podem se transformar em um instrumento importante de apoio às decisões empresarias.

No que se refere à adesão aos incentivos fiscais de inovação tecnológica, as informações contábeis podem ser utilizadas das seguintes formas:

a) Na fase de planejamento da utilização do incentivo

- Informações fiscais: informações gerais sobre a possibilidade de utilização do incentivo ;

- $\quad$ Regularidade fiscal: verificação se a empresa se encontra em situação regular perante o fisco, uma vez que, a ausência de regularidade fiscal é condição impeditiva de utilização dos incentivos (IN no $11.187 / 11$, artigo 19) ;

- Projeção de resultados: como as maiores reduções da carga tributária são obtidas em relação ao IRPJ e a CS e esse incentivo somente pode ser utilizado se a empresa tiver lucro no período-base de apuração, é necessário que a empresa faça uma projeção de seus resultados a fim de determinar se deve iniciar os trabalhos para a obtenção do incentivo. No caso de empresas com opção pelo lucro trimestral, ou seja, que têm um período de apuração dos impostos sobre o lucro trimestralmente, essa projeção deve ser realizada anteriormente ao início de cada trimestre. Para as empresas que apuram seu lucro anualmente a projeção deve ser feita no início do período-base, mas o aproveitamento pode ser feito no decorrer do ano, considerando-se que muitas vezes essas empresas elaboraram balanços para suspensão ou redução dos pagamentos.

b) Na aplicação do incentivo fiscal

Identificação dos dispêndios: informações relativas aos dispêndios considerados como despesa pela legislação do Imposto de Renda, de forma que seja possível verificar se eles são relacionados às atividades empresariais enquadradas como inovativas nos 
termos da lei;

- Segregação em contas-contábeis: informações sobre os dispêndios efetivamente utilizados nos incentivos fiscais para a segregação em contas-contábeis individualizadas;

- Avaliação dos riscos fiscais: informações que possibilitem avaliar a existência de riscos fiscais na adesão aos incentivos, inclusive em relação a interpretações conflitantes existentes na legislação. Isso decorre do fato que, como para a maioria dos incentivos fiscais não há uma aprovação prévia por parte do governo que autorize a adesão, esses estão sempre sujeitos a uma verificação posterior que pode implicar em penalidades por parte da fiscalização;

- Informações para registro das operações: registros dos dispêndios, da depreciação acelerada e de outras informações no LALUR, registro nos livros contábeis dos impostos apurados, incluindo a dedução obtida com o incentivo e registro de outros ganhos como, por exemplo, com o IPI.

c) Na avaliação do resultado do incentivo

- Comparação entre o custo de implantação dos projetos e o resultado esperado: a apuração dos projetos e respectivos dispêndios realizados pela empresa que pode gozar dos incentivos exige muitas vezes um trabalho significativo por parte do pessoal das áreas de Engenharia, Pesquisa e Desenvolvimento e Tecnologia, assim, após concluídos os trabalhos para obtenção dos incentivos e determinados os valores de redução dos impostos, é necessário que seja verificado se o esforço realizado pela empresa foi compensado pela diminuição da carga tributária, se as metas propostas foram atingidas e se foi feita a identificação de eventuais riscos fiscais.

\subsection{Teoria da contingência}

Um trabalho científico deve procurar analisar e explicar a realidade. Essa explicação, segundo Martins (2007), deve estar suportada por uma teoria que se constitui no pólo teórico. A pesquisa do presente trabalho é suportada pelas proposições da teoria da contingência, a qual, conforme pode ser observado, tem sido utilizada em diversos estudos com o objetivo de 
proporcionar um melhor entendimento sobre os fatores que influenciam os sistemas de contabilidade gerencial nas organizações.

\subsubsection{Conceitos gerais}

Segundo Martins (2007, p. 27), o termo 'teoria' tem sido empregado de muitas maneiras e de modos distintos, de tal forma que muitas vezes se apresentam sentidos ambíguos e até mesmo contraditórios. Citando Kerlinger, o mesmo autor (2007, p. 28) apresenta a seguinte definição de teoria:

Uma teoria é um conjunto de constructos (conceitos), definições e proposições relacionadas entre si, que apresentam uma visão sistemática de fenômenos especificando relações entre variáveis, com a finalidade de explicar e prever fenômenos da realidade.

Guerra (2007, p. 13 a 23) analisa o surgimento da teoria da contingência, contrapondo-a a teorias anteriores como a teoria da administração científica de Frederick Taylor, à teoria clássica de Henri Fayol e à teoria da burocracia de Max Weber. Os novos conceitos que suportam a teoria da contingência estão relacionados à importância dada ao ambiente externo e à negação de que exista uma forma ideal de organização aplicável a qualquer empresa, sendo esse conceito conhecido como One Best Way.

Essas duas críticas levaram ao surgimento da abordagem sistêmica que deu origem à teoria da contingência. A Ilustração 4, representa os conceitos que suportam a teoria da contingência. 


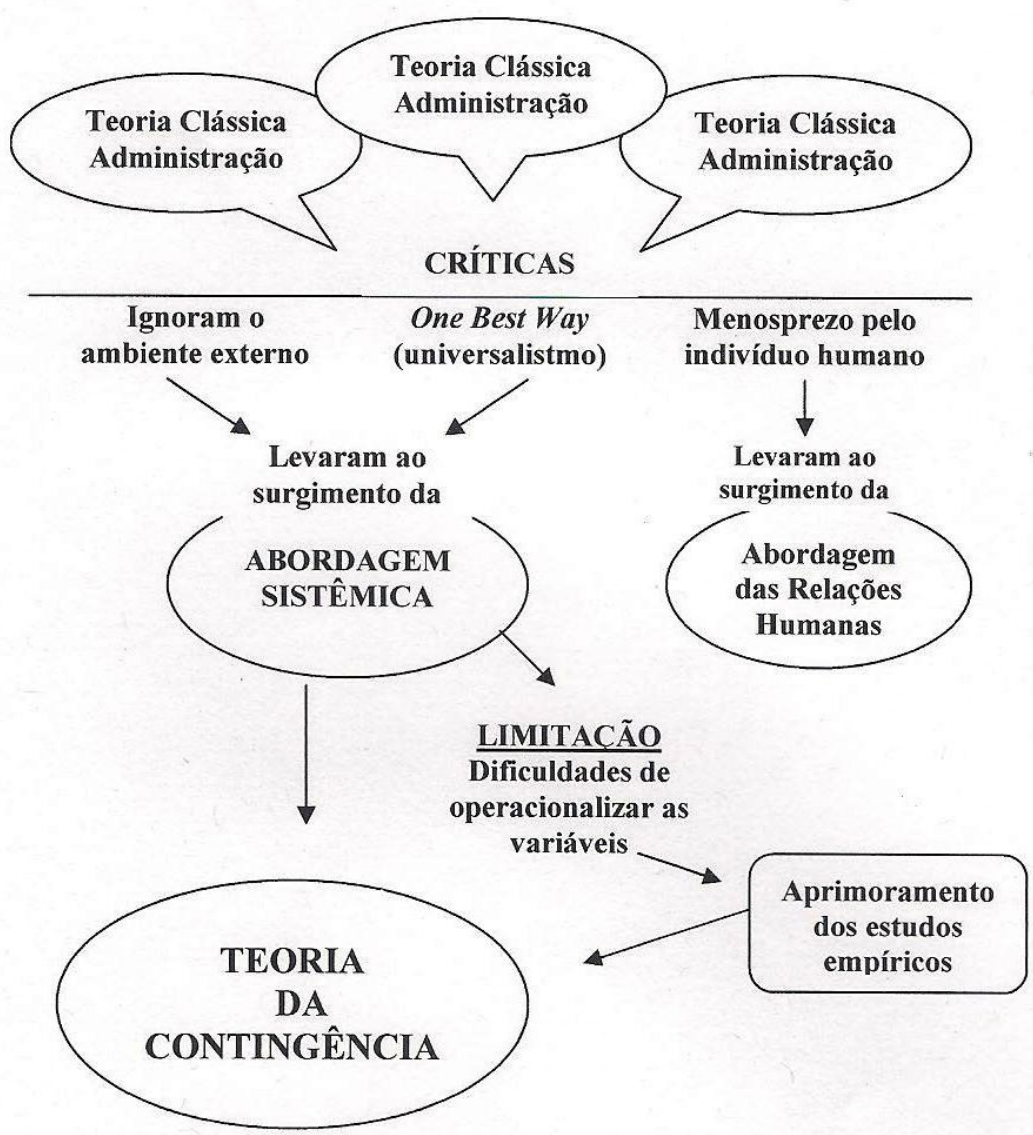

Ilustração 4 - Surgimento da teoria da contingência FONTE: Guerra. 2007, p. 21

Morgan (1996, p. 53), citado por Guerra (2007, p. 21) resume os conceitos básicos da teoria da contingência da seguinte forma:

- Organizações são sistemas abertos que necessitam de cuidados da administração para satisfazer e equilibrar necessidades internas, assim como adaptar-se a circunstâncias ambientais.

- Não existe a melhor forma de organizar. A forma adequada depende do tipo de tarefa ou do ambiente dentro do qual se está lidando.

- A administração deve estar preocupada acima de tudo em atingir 'boas' medidas. Diferentes enfoques em administração devem ser necessários para desempenhar diferentes atividades dentro da mesma organização e tipos bem diferentes ou 'espécies' de organizações são necessários em diferentes tipos de ambientes.

Ainda, segundo Guerra (2007, p. 22), na teoria da contingência as variáveis consideradas são:

Variáveis independentes, que são os fatores situacionais que incluem o ambiente externo e a tecnologia, sendo assim consideradas porque a organização não exerce qualquer forma de influência sobre elas, reagindo apenas às suas alterações. 
Variáveis dependentes ou intervenientes: que incluem fatores internos ou organizacionais, como a estratégia, a estrutura organizacional, tamanho, cultura e sistema de contabilidade gerencial sobre os quais a organização tem um controle significativo.

Cabe notar, entretanto, que as organizações não obrigatoriamente reagem às mudanças do ambiente e da tecnologia e que os fatores internos ou organizacionais se influenciam mutuamente e, dessa forma, não podem ser considerados apenas como variáveis dependentes.

Em vista da necessidade da adaptação da organização ao ambiente, um conceito importante na teoria da contingência é o de adequação (também denominado de ajuste, encaixe ou associação). É esse conceito que procura demonstrar a relação entre a organização e o ambiente externo, de tal forma que o sucesso da organização depende dessa adequação.

Assim, segundo Kast e Rosenzweig (1976, apud CHIAVENATO, 2003, p. 501), a teoria da contingência tem o seu foco principal na análise dos sistemas organizacionais e gerenciais.

Fagundes (2009, p. 3) apresenta diversos trabalhos que contribuíram para a construção da teoria da contingência, como:

[...] Woodward $(1958,1965)$ que tratou da tecnologia como fator de contingência; Burns e Stalker (1960) que estudaram o ambiente externo - mecânico e orgânico; Chandler (1962) que relacionou a estratégia e a estrutura; Lawrence e Lorsch (1967) que pesquisaram sobre ambiente e estrutura; Perrow (1976) que tratou da tecnologia e a estrutura, e, mais recentemente, Chenhall (2003) que fez uma revisão sobre estudos utilizando esta teoria desde 1980, ressaltando a urgência de futuros trabalhos a serem desenvolvidos com abordagem qualitativa; Tilema (2005), Aguiar e Frezatti (2007) e Cadez (2007) estudaram fatores de contingência relacionando sistemas contábeis e Chen (2008) tratou efeitos dos fatores de contingência nas questões orçamentárias.

Molinari e Guerreiro (2004, p. 3 a 5) relacionam diversos estudos que se basearam na teoria da contingência aplicada à contabilidade, como ética, controles internos, análise ambiental, processo de tomada de decisões, tecnologia da informação, administração pública, contabilidade internacional, avaliação de performance, concluindo que a teoria da contingência:

[...] pode ser utilizada em diversas áreas de estudo da gestão empresarial, pois uma contingência representa uma circunstância do ambiente externo à qual a organização precisa se adaptar para garantir sua continuidade e atingir seus objetivos. 


\title{
2.2.2 Teoria da contingência aplicada à contabilidade gerencial
}

Guerra (2007, p. 34 a 36) descreve as aplicações dos conceitos da teoria da contingência à contabilidade gerencial. De acordo com esse pesquisador, a evolução desses estudos ocorreu de forma semelhante às análises organizacionais citadas no item anterior.

Frezatti, (2007, p. 2), apresenta semelhante evolução:

\begin{abstract}
Em especial, a adoção da abordagem contingencial para o estudo da Contabilidade Gerencial, em meados da década de 70 , representou um avanço em relação à perspectiva neoclássica vigente até então. Sua premissa básica é a de que não há um sistema contábil universalmente apropriado que possa ser igualmente aplicado a todas as organizações em todas as circunstâncias, assim, a abordagem contingencial deveria identificar aspectos específicos do sistema contábil associado com certas circunstâncias identificadas e demonstrar um matching apropriado.
\end{abstract}

Dessa forma, as teorias contábeis que inicialmente eram baseadas exclusivamente na teoria econômica passaram a incluir aspectos sociais e psicológicos. De igual modo, houve uma evolução na pesquisa contábil que migrou de uma metodologia normativa para a positiva. Essa por meio do seu empirismo acabou por levar à compreensão de que um sistema gerencial contábil, ainda que estivesse bem estruturado e organizado não teria a mesma eficiência em todos os casos devido às situações contextuais e ambientais não serem as mesmas para todas as organizações. 
Molinari e Guerreiro (2004, p. 2) também discorrem sobre a evolução da pesquisa contábil:

Até a década de 1960, a teoria contábil é, predominantemente, desenvolvida de acordo com o paradigma normativo, ou seja, determina como a realidade deveria ser, ao invés de buscar explicações para determinados fenômenos da contabilidade, como sugere o paradigma positivo. $\mathrm{O}$ caráter normativo da contabilidade pode ser comprovado pela existência de organismos como: International Accounting Standards Board (IASB), Financial Accounting Standards Board (FASB) e Conselho Federal de Contabilidade (CFC). O paradigma positivo surge, na pesquisa contábil, com o desenvolvimento de modelos econométricos e estatísticos na pesquisa da contabilidade financeira e de mercados de capitais.

Guerra (2007 p. 35) relata como as pesquisas contábeis foram aplicadas a partir dos conceitos da teoria da contingência:

[...] percebe-se, dessa forma, a mudança do objetivo principal das pesquisas contábeis em relação aos estudos originais. Enquanto os primeiros trabalhos buscavam entender com a estrutura organizacional deveria ser arquitetada diante dos fatores contingenciais (ambiente, tecnologia, estratégia etc.), as pesquisas contábeis começaram a estudar como o sistema de informações gerenciais deveria ser moldado diante dos diferentes fatores contingenciais (ambiente, tecnologia, estratégia e estrutura organizacional). De certa forma, a variável dependente estrutura organizacional passou a ser vista como uma variável interveniente que, em conjunto com as demais (ambiente, tecnologia e estratégia), passou a impactar a nova variável dependente: sistema de contabilidade gerencial.

Evidentemente, os conceitos da teoria da contingência não são isentos de críticas e algumas são relacionadas à aplicação nos estudos da contabilidade gerencial, sendo duas as principais.

A primeira delas refere-se ao fato de que as pesquisas contingenciais não realizam uma análise temporal, limitando os estudos a um curto período de tempo denominado crosssectional. Frezatti (2007, p. 2) descreve essa deficiência da seguinte forma:

[...] geralmente, os estudos cross-sectional tendem a associar fatores contingentes a características do sistema de contabilidade gerencial em um determinado momento do tempo, para um grande número de empresas, o que possibilita o uso de métodos estatísticos e, consequentemente, a tentativa de generalização dos achados.

Outra crítica também relatada por Frezatti refere-se a que a maior parte dos estudos contingenciais tem um conjunto restrito de variáveis, sem relação com o desempenho organizacional.

Apesar das referidas críticas poderem se constituir em restrições a este trabalho de pesquisa, o fato de os incentivos fiscais de inovação tecnológica serem recentes, como já comentado anteriormente, faz com que, ao menos nesse momento, a existência de uma cross-sectional temporal não traga prejuízos para a análise. Fica, ainda, claro ser uma tarefa importante 
determinar quais os fatores e as respectivas variáveis que determinam a utilização do sistema de informações contábeis, o que será detalhado adiante.

\subsubsection{Teoria da contingência e tomada de decisão}

Como visto anteriormente, os conceitos decorrentes da teoria da contingência têm sido aplicados em diversos estudos e pesquisas, tanto no que se refere ao campo da administração como da contabilidade.

Um desses estudos desenvolvidos por Trater e Hoy (1998) relaciona a teoria da contingência à tomada de decisão. Segundo os autores, diversos fatores sistêmicos empresariais influenciam na forma como as decisões são tomadas pelos gestores.

Os autores relacionam seis modelos de decisão, de acordo com as circunstâncias nas quais as decisões devem ser tomadas (TRATER; HOY, 1998, p. 225). A fim de não prejudicar o entendimento sobre o conceito de cada modelo, optamos por não traduzir o nome atribuído pelos autores. Uma sumária descrição de cada um desses modelos é apresentada a seguir:

a) Classical: trata-se do modelo clássico de decisão. É aplicado quando os problemas são específicos e as informações são completas. Esse modelo tem como base a teoria econômica clássica aplicável aos casos em que existem objetivos organizacionais claros, informação completa e capacidade cognitiva para analisar o problema. Conforme os autores há uma série sequencial de seis passos no processo de tomada de decisão:

(1) Identificar o problema: determinar discrepâncias entre realidade e os resultados desejados;

(2) Diagnosticar o problema: coletar e analisar informações que explicam a natureza do problema;

(3) Definir as alternativas: desenvolver todas as opções que são potenciais soluções;

(4) Examinar as consequências: antecipar os prováveis efeitos de cada alternativa;

(5) Tomar a decisão: avaliar e escolher a melhor alternativa, o que maximiza as metas e objetivos;

(6) Executar a decisão: implementar a decisão (TRATER; HOY, 1998, p. 212).

Os autores apresentam significativas restrições a esse modelo, resumindo-o conceitualmente da seguinte forma:

O objetivo principal do modelo clássico é o de encontrar a melhor solução, o que é mais fácil de dizer do que fazer. Os tomadores de decisão quase nunca têm acesso a toda a informação relevante nem podem conhecer todas as possíveis alternativas e antecipar todas as consequências. O modelo clássico é um ideal, em vez de uma descrição de como se processam as tomadas de decisão. (TRATER; HOY, 1998, p. 213)

b) Administrative: procura apresentar um lado mais realista para o modelo clássico. Ele considera que a racionalidade na decisão é necessariamente limitada pelo conhecimento humano que nunca é completo, pela existência de um número grande de opções de 
consequências imprevisíveis e de incertezas, as quais são agravadas por preconceitos e diferentes concepções dos objetivos dos administradores. Esse modelo introduzido por Herbert Simon é amplamente comentado na literatura que trata de modelos de decisão.

Herbert Simon na década de 50 fez uma leitura destas divergências e dificuldades da abordagem racional e elaborou o estudo clássico que concluiu por uma racionalidade limitada dos indivíduos. Para ele os indivíduos possuem sim uma certa racionalidade, porém esta é limitada e as decisões relacionadas estão condicionadas a possibilidades e não a situações ótimas. Além disso, como o próprio nome diz, existe uma limitação clara da racionalidade humana. Isto se caracteriza por uma total impossibilidade de análise de todas as informações, alternativas e dimensões envolvidas no processo decisório, o que acarreta em uma inconsistência com a decisão ótima apregoada pela decisão ideal normativa. Sendo assim, a racionalidade se reduz a uma aceitação do razoável, onde as alternativas são selecionadas pelo critério de encaixe em algum sistema de valores. (BARREIROS 2008, p. 3)

Uma diferença significativa entre esse modelo e o de otimização refere-se ao critério de decisão:

O critério para uma boa decisão é o satisfatório e não necessariamente o melhor. Mas o que é uma decisão satisfatória? O tomador de decisão deve decidir anteriormente à decisão quais resultados são aceitáveis. Assim, após o diagnóstico das dificuldades, critérios para resultados satisfatórios devem ser definidos. (TRATER; HOY, 1998, p. 214)

Assim, a diferença entre o modelo administrativo e o clássico refere-se mais a como os objetivos são definidos do que ao processo de como a decisão é tomada. No modelo clássico, os resultados esperados são definidos como um ideal a ser alcançado e no modelo administrativo, os resultados são relacionados a níveis de satisfação.

c) Incremental: esse modelo é utilizado quando existe grande dificuldade em discernir as alternativas a serem utilizadas para que os objetivos possam ser atingidos. Isso ocorre nos casos em que é inviável a realização de previsões seguras. Nesse caso os gestores realizam pequenas mudanças avaliando em seguida seus resultados.

Charles Lindblom descreveu pela primeira vez este modelo incremental de tomada de decisão como a ciência de procrastinação [...]. A estratégia incremental realiza comparações sucessivas das consequências de cada mudança incremental até que os tomadores de decisão estão confortáveis com uma escolha. (TRATER; HOY, 1998 p. 215)

Assim, nessa situação, os objetivos e alternativas aparecem simultaneamente e uma pequena gama de opções semelhantes à situação existente é considerada. As informações são incompletas, os resultados incertos e não há princípios orientadores. As estratégias são de curto prazo.

O modelo incremental tem características muito diferentes dos modelos anteriores: 
O quadro incremental possui uma série de características que o distinguem dos modelos satisficing e optimizing. Definição de objetivos e geração de alternativas não são separados. A priori os objetivos não orientam a análise. A direção não é fixada pelo processo e a complexidade dos problemas e os objetivos mudam de acordo com as decisões. (TRATER; HOY, 1998, p. 216)

Dessa forma, no modelo de decisão incremental nem os objetivos nem as políticas são determinantes da ação.

A validade de uma política é demonstrada, paralela e comparativamente, através de sua descrição e de políticas alternativas. A reflexão tem como centro de análise não a argumentação de quais objetivos estão sendo atingidos, mas a de que uma política é preferível a outra. A esfera de validação reside na concordância no plano propriamente político, não no plano dos valores e objetivos (GONTIJO. 2004, p. 20).

d) Mixed scanning (estratégia adaptativa): nesse modelo a decisão é dirigida por uma política empresarial, uma mudança incremental e um número limitado de informações.

Thomas (1984) apresenta esse modelo como sendo um intermediário entre os que realizam as avaliações nos planos políticos e aqueles voltados exclusivamente para modelos racionais. $\mathrm{O}$ mesmo autor (THOMAS, 1984, p. 14) coloca como objetivo de seu estudo "fazer um apelo para a adoção do 'mixed scanning' para futuras pesquisas no campo".

A política e a missão da empresa são, portanto, orientadores nas decisões. É uma estratégia que combina as regras do modelo racionalista com a flexibilidade do modelo incremental.

De acordo com Trater e Hoy (1998, p. 217), esse modelo tem cinco características distintivas:

(1) política organizacional direciona tentativas de decisões incrementais;

(2) boas decisões são coerentes com a política;

(3) as ações são experimentais, reversíveis, limitadas e, normalmente, estão próximas aos problemas;

(4) incerteza e pouca informação são a regra e não a exceção, e

(5) uma estratégia de adoção determina um curso de ação pela teoria de mixed e através de comparações e de experiências sucessivas.

Nesse modelo, a política básica deve guiar até mesmo a menor das decisões em uma estratégia de adaptação. A maioria dos administradores são instados pela necessidade a tomar decisões com informação apenas parcial, pois eles não têm toda a informação de que precisam, e, ainda assim, eles devem agir. Isso não significa que eles procedem cegamente com os poucos ou inexistentes dados. Pelo contrário, eles agem deliberadamente não permanecendo imobilizados devido a informações parciais.

Segundo os mesmos autores as etapas na decisão desse modelo são: 
- $\quad$ levantamento dos problemas;

- $\quad$ análise da dificuldade;

- $\quad$ adoção de um curso provisório como tentativa de solução;

- $\quad$ avaliação do resultado e, se algo falhar, alteração no curso tomado.

e) Garbage can: aplicam-se para as decisões de caráter fortuito. Segundo TRATER e HOY (1998, p. 218):

Este modelo é útil para compreender o que de outra forma pareceria ser completamente um comportamento irracional. No 'garbage can', as decisões não começam com um problema e terminam com uma solução, mas as decisões são um produto de uma trilha independente de eventos organizacionais que fortuitamente fluem juntos

f) Political: aplicam-se para as decisões irracionais originarias de conflitos entre os objetivos da empresa e objetivos individuas, ou seja, das pessoas que compõem a empresa (TRATER; HOY 1998, p. 219).

Trater e Hoy (1998) apresentam dois quadros que sumarizam de forma muita adequada, a parte teórica de seu estudo.

O primeiro deles apresenta um resumo das principais características de cada um dos modelos de decisão:

Quadro 1 - Comparação entre os modelos de decisão de Trater e Hoy

\begin{tabular}{|c|c|c|c|c|c|}
\hline $\begin{array}{l}\text { Modelo } \\
\text { decisão }\end{array}$ & $\begin{array}{l}\text { Conjunto de } \\
\text { objetivos }\end{array}$ & $\begin{array}{l}\text { Análise dos meios e dos } \\
\text { fins }\end{array}$ & $\begin{array}{l}\text { Teste de uma boa } \\
\text { decisão }\end{array}$ & $\begin{array}{l}\text { Princípios } \\
\text { orientadores }\end{array}$ & \\
\hline Classical & $\begin{array}{l}\text { Objetivos } \\
\text { organizacionais }\end{array}$ & Sempre existe & $\begin{array}{l}\text { Os melhores meios } \\
\text { para obter o fim }\end{array}$ & Teoria & \\
\hline Admistrative & $\begin{array}{l}\text { Objetivos } \\
\text { organizacionais }\end{array}$ & $\begin{array}{ll}\text { Frequentemente } & \text { existe } \\
\text { mas pode } & \text { haver } \\
\text { mudanças } & \end{array}$ & $\begin{array}{l}\text { Satisfação } \\
\text { organizacional }\end{array}$ & $\begin{array}{l}\text { Teoria } \\
\text { experiência }\end{array}$ & $\mathrm{e}$ \\
\hline Incremental & $\begin{array}{lr}\text { Objetivos } & \mathrm{e} \\
\text { alternativas } & \mathrm{se} \\
\text { confundem } & \end{array}$ & $\begin{array}{l}\text { Não há analise dos } \\
\text { meios e dos fins }\end{array}$ & $\begin{array}{l}\text { Consenso dos } \\
\text { gestores }\end{array}$ & $\begin{array}{l}\text { Experiência } \\
\text { comparação }\end{array}$ & $\mathrm{e}$ \\
\hline Mixed scanning & $\begin{array}{l}\text { Princípios } \\
\text { baseados } \quad \text { em } \\
\text { políticas }\end{array}$ & $\begin{array}{l}\text { Fins amplos e meios } \\
\text { experimentais }\end{array}$ & $\begin{array}{l}\text { Satisfação } \\
\text { organizacional }\end{array}$ & $\begin{array}{l}\text { Teoria, } \\
\text { experiência } \\
\text { comparação }\end{array}$ & $\mathrm{e}$ \\
\hline Garbage can & $\begin{array}{l}\text { Objetivos } \\
\text { emergem } \\
\text { espontaneamente }\end{array}$ & $\begin{array}{l}\text { Meios e fins são } \\
\text { independentes }\end{array}$ & $\begin{array}{l}\text { Consenso entre os } \\
\text { participantes }\end{array}$ & Mudança & \\
\hline Political & $\begin{array}{l}\text { Objetivos } \\
\text { emergem } \\
\text { espontaneamente, } \\
\text { mas são pessoais }\end{array}$ & $\begin{array}{l}\text { Pessoas determinam os } \\
\text { meios }\end{array}$ & $\begin{array}{l}\text { Atingir objetivos } \\
\text { pessoais }\end{array}$ & Poder & \\
\hline
\end{tabular}

Fonte: adaptado de Trater e Hoy (1998, p. 221) 
Outro quadro apresentado pelos mesmos autores, coerente com os princípios estabelecidos pela teoria da contingência, se refere às situações em que cada modelo de decisão deve ser aplicado.

Quadro 2 - Situações empresariais e respectivo modelo de decisão

\begin{tabular}{|c|c|}
\hline Modelo & Situações em que a decisão é tomada \\
\hline Classical & Problemas específicos, informação completa \\
\hline Admistrative & $\begin{array}{l}\text { Informação incompleta, resultados definidos por } \\
\text { satisfação }\end{array}$ \\
\hline Incremental & $\begin{array}{l}\text { Informações incompletas, decisões complexas, } \\
\text { resultados incertos, falta de princípios orientadores, } \\
\text { estratégias de curto prazo }\end{array}$ \\
\hline Mixed scanning & $\begin{array}{l}\text { Informação incompleta, decisões } \begin{array}{l}\text { complexas, } \\
\text { resultados incertos, existência de políticas } \\
\text { orientadoras }\end{array}\end{array}$ \\
\hline Garbage can & Para entendimento de decisões fortuitas \\
\hline Political & Para entendimento de decisões irracionais \\
\hline
\end{tabular}

Fonte: Trater e Hoy (1998, p. 225)

\subsubsection{Aplicação dos modelos de decisão à adesão aos incentivos fiscais de inovação tecnológica}

A análise dos modelos apresentados aplicados à tomada de decisão no que se refere à adesão aos incentivos fiscais de inovação tecnológica deverá ser entendida mediante a utilização do modelo denominado mixed scanning, pois:

- $\quad$ As decisões são complexas, uma vez que envolvem um grande número de variáveis;

- $\quad$ As informações são incompletas, pois há dificuldade em definir de forma clara quais atividades e respectivos dispêndios podem ser incluídos para aproveitamento dos incentivos fiscais;

- $\quad$ Os resultados são considerados incertos, pois não existe uma prévia aprovação por parte do governo para aproveitamento. As empresas devem avaliar ainda o risco de uma eventual autuação por parte dos órgãos fiscalizadores, o que pode levar não só a empresa a deixar de aproveitar o incentivo fiscal como incorrer em significativo prejuízo;

- A incerteza em relação à atitude da fiscalização faz com que a decisão envolva a definição de uma política empresarial sobre os riscos a que a empresa está disposta a correr em relação à economia de tributos.

O Quadro 3, apresenta as relações entre as etapas do modelo de decisão mixed scanning e a etapa correspondente na adesão aos incentivos fiscais de inovação tecnológica, assim como as informações contábeis, que são úteis para cada etapa da decisão, na adesão aos incentivos fiscais de inovação tecnológica, e que estão relacionadas no item 2.1.5 deste trabalho. 
Quadro 3 - Relação entre as etapas de decisão do modelo mixed scanning e o processo de adesão aos incentivos fiscais de inovação tecnológica

\begin{tabular}{|c|c|c|}
\hline $\begin{array}{l}\text { Etapa do processo de } \\
\text { decisão } \quad \text { (modelo } \\
\text { mixed scanning) }\end{array}$ & $\begin{array}{l}\text { Etapa correspondente ao processo de } \\
\text { decisão de adesão aos incentivos fiscais } \\
\text { de inovação tecnológica }\end{array}$ & $\begin{array}{l}\text { Informações contábeis } \\
\text { (item 2.1.5 deste trabalho) }\end{array}$ \\
\hline $\begin{array}{l}\text { Levantamento dos } \\
\text { problemas }\end{array}$ & $\begin{array}{l}\text { Identificação do incentivo fiscal. A } \\
\text { empresa toma conhecimento da existência } \\
\text { do incentivo. Concomitantemente à } \\
\text { obtenção desse conhecimento são } \\
\text { identificadas dificuldades e problemas que } \\
\text { dificultam a imediata e rápida adesão aos } \\
\text { incentivos. }\end{array}$ & $\begin{array}{l}\text { - Informações fiscais } \\
\text { - Regularidade fiscal }\end{array}$ \\
\hline $\begin{array}{l}\text { Análise } \\
\text { dificuldade }\end{array}$ & $\begin{array}{l}\text { Análise das dificuldades que existem na } \\
\text { aplicação dos incentivos de inovação } \\
\text { tecnológica. Trata-se de verificar como } \\
\text { podem ser vencidos os problemas } \\
\text { identificados na etapa anterior. }\end{array}$ & $\begin{array}{l}\text { - Regularidade fiscal } \\
\text { - Projeção de resultados } \\
\text { - Identificação dos dispêndios }\end{array}$ \\
\hline $\begin{array}{l}\text { Adoção de um curso } \\
\text { provisório como } \\
\text { tentativa de solução }\end{array}$ & $\begin{array}{l}\text { Realizar um experimento para verificar se } \\
\text { a adoção dos incentivos fiscais ocorre da } \\
\text { maneira esperada. }\end{array}$ & $\begin{array}{l}\text { - Identificação dos dispêndios } \\
\text { - Segregação em contas-contábeis } \\
\text { - Avaliação dos riscos fiscais } \\
\text { - Informação para registro das operações }\end{array}$ \\
\hline $\begin{array}{l}\text { Avaliação } \\
\text { resultado }\end{array}$ & $\begin{array}{l}\text { Verificação se o experimento ocorreu da } \\
\text { maneira como foi planejado, comparação } \\
\text { entre aquilo que se esperava e o que foi } \\
\text { obtido. Exemplo:se a relação custo x } \\
\text { incentivo foi a esperada }\end{array}$ & $\begin{array}{l}\text { - Avaliação dos riscos fiscais } \\
\text { - Comparação entre o custo da } \\
\text { implantação dos projetos e o resultado } \\
\text { desejado }\end{array}$ \\
\hline $\begin{array}{l}\text { Possível alteração no } \\
\text { curso tomado }\end{array}$ & $\begin{array}{l}\text { Inicio de um processo definitivo de } \\
\text { adesão aos incentivos fiscais }\end{array}$ & $\begin{array}{l}\text { - Identificação dos dispêndios } \\
\text { - Segregação das contas-contábeis } \\
\text { - Avaliação dos riscos fiscais } \\
\text { - Comparação entre o custo da } \\
\text { implantação dos projetos e o resultado } \\
\text { desejado }\end{array}$ \\
\hline
\end{tabular}

Entretanto, não se pode descartar que, tendo em vista a ampla difusão no meio empresarial e mesmo mo meio acadêmico do modelo clássico de decisão, denominado pelos autores classical, de fato as decisões relativas à utilização dos incentivos de inovação sejam realizadas segundo esse modelo.

De forma semelhante ao apresentado no Quadro 3, o Quadro 4 representa a relação entre as etapas existentes no modelo de decisão clássico e as informações contábeis. 
Quadro 4 - Relação entre as etapas de decisão do modelo optimizing e o processo de decisão de adesão aos incentivos fiscais de inovação tecnológica

\begin{tabular}{|c|c|c|}
\hline $\begin{array}{lr}\text { Etapa do } & \text { processo de } \\
\text { decisão } & \text { (modelo } \\
\text { classical) } & \end{array}$ & $\begin{array}{l}\text { Etapa correspondente do processo de } \\
\text { decisão de adesão aos incentivos fiscais } \\
\text { de inovação tecnológica }\end{array}$ & $\begin{array}{l}\text { Informações contábeis } \\
\text { (item 2.1.5 deste trabalho) }\end{array}$ \\
\hline Identificar o problema & 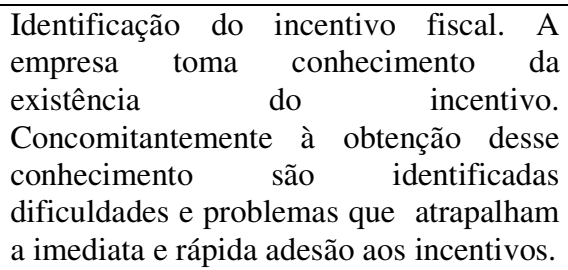 & $\begin{array}{l}\text { - Informações fiscais } \\
\text { - Regularidade fiscal }\end{array}$ \\
\hline $\begin{array}{l}\text { Diagnóstico } \\
\text { problema }\end{array}$ & $\begin{array}{l}\text { Análise das dificuldades que existem na } \\
\text { aplicação dos incentivos de inovação } \\
\text { tecnológica. Trata-se de verificar como } \\
\text { podem ser vencidos os problemas } \\
\text { identificados na etapa anterior. }\end{array}$ & $\begin{array}{l}\text { - Regularidade fiscal } \\
\text { - Projeção de resultados } \\
\text { - Identificação dos dispêndios }\end{array}$ \\
\hline $\begin{array}{l}\text { Definição } \\
\text { alternativas }\end{array}$ & $\begin{array}{l}\text { Verificar quais alternativas para a } \\
\text { aplicação do incentivo. Basicamente elas } \\
\text { se referem a uma escala em relação à } \\
\text { adoção do incentivo que vai desde a } \\
\text { adesão total dos incentivos até a sua não } \\
\text { utilização }\end{array}$ & $\begin{array}{l}\text { - Informações fiscais } \\
\text { - Identificação dos dispêndios }\end{array}$ \\
\hline $\begin{array}{l}\text { Exame das } \\
\text { consequências }\end{array}$ & $\begin{array}{l}\text { Exame de quais são as consequências da } \\
\text { aplicação do incentivo. }\end{array}$ & - Avaliação dos riscos fiscais \\
\hline Tomada de decisão & $\begin{array}{l}\text { Escolha da alternativa para a aplicação do } \\
\text { incentivo }\end{array}$ & $\begin{array}{l}\text { - Avaliação dos riscos fiscais } \\
\text { - Comparação entre o custo da } \\
\text { implantação dos projetos e o resultado } \\
\text { desejado }\end{array}$ \\
\hline $\begin{array}{l}\text { Implantação } \\
\text { decisão }\end{array}$ & Implementação do incentivo & $\begin{array}{l}\text { - Identificação dos dispêndios } \\
\text { - Segregação das contas-contábeis } \\
\text { - Avaliação dos riscos fiscais } \\
\text { - Comparação entre o custo da } \\
\text { implantação dos projetos e o resultado } \\
\text { desejado }\end{array}$ \\
\hline
\end{tabular}

Em vista da possibilidade da utilização desses dois modelos diferentes para a tomada de decisão na adesão aos incentivos fiscais de inovação tecnológica, no questionário utilizado para a coleta de dados foi incluída uma alternativa para o respondente indicar qual dos dois modelos de decisão é utilizado. 


\subsection{Fatores que podem influenciar o uso da informação contábil}

Nesse tópico, a partir dos conceitos apresentados anteriormente sobre a teoria da contingência, que atribui importância significativa aos aspectos ambientais e contextuais, serão identificados quais os fatores ambientais, estruturais e os atributos da informação contábil que, de acordo com os estudos e pesquisas já realizadas, podem induzir ou inibir a utilização da informação contábil, constituindo a base para a realização da pesquisa de campo deste trabalho.

Cabe aqui ressaltar que não se trata de indicar fatores que pudessem evidenciar se os incentivos governamentais para desenvolvimento de $\mathrm{P} \& \mathrm{D}$ produziram o resultado desejado como, por exemplo, no estudo realizado por Calzolaio (2011, p. 118), que procurou identificar se as empresas que se utilizaram dos incentivos fiscais da "lei do bem" incrementaram suas atividades inovativas.

\subsubsection{Estudos correlacionados}

Apesar de não ter sido identificado nenhum estudo específico que procurasse verificar quais os fatores indutores e inibidores que influenciam a utilização da informação contábil com relação à adesão a incentivos fiscais, alguns estudos foram desenvolvidos recentemente em áreas correlatas, considerando a realidade das empresas brasileiras e incluindo pesquisas internacionais que se utilizaram da teoria da contingência. Apresentam-se a seguir alguns desses estudos que mais se aproximam do escopo da pesquisa deste trabalho.

\subsubsection{Fatores condicionantes da gestão de custos interorganizacionais na cadeia de valor de hospitais privados no Brasil: uma abordagem à luz da Teoria da Contingência - Tese de Doutorado, Reinaldo Rodrigues Camacho, 2010}

A tese tem como objetivo investigar e identificar fatores que favorecem ou inibem a prática da Gestão de Custos Interorganizacionais (CGI) por parte de hospitais privados no Brasil e também utiliza como referência teórica a teoria da contingência. No trabalho são apresentados os fatores contingenciais que impactam no sistema de informações gerenciais com a respectiva hipótese de como ocorre esse impacto. Essas hipóteses estão relacionadas a seguir (CAMACHO, 2010, p. 73 a 77): 
a) Complexidade do sistema de informação: empresas com operações complexas utilizam sistemas contábeis mais complexos.

b) Porte: empresas maiores utilizam sistemas mais complexos.

c) Natureza privada ou pública ou fins lucrativos ou não: hospitais públicos e empresas não lucrativas têm menos interesse de controlar os custos.

d) Maior concorrência: quanto maior a concorrência mais detalhado é o sistema de custo.

\subsubsection{Arranjos entre fatores situacionais e sistema de contabilidade gerencial (SCG) sob a ótica da teoria da contingência - Dissertação de Mestrado, Almir Rogério Guerra, 2007}

O objetivo da dissertação, que como informado no próprio título do trabalho utiliza como referencial teórico a teoria da contingência, é identificar e analisar os arranjos promovidos pelo encaixe existente entre os fatores ambientais e organizacionais nas maiores empresas atuantes no mercado brasileiro. O termo 'encaixe' é utilizado no sentido de adaptação. Os fatores empregados para analisar esse encaixe são: ambiente e tecnologia, considerados atributos externos e estratégia, estrutura organizacional e atributos do Sistema Contábil de Gestão (SCG), considerados atributos internos.

Como fatores ambientais o autor relaciona três variáveis: dinamismo, heterogeneidade e hostilidade (GUERRA, 2007, p. 59 a 61)

- O dinamismo está relacionado com o fato de um ambiente poder ser estável ou não. No ambiente estável as preferências dos consumidores são previsíveis e a tecnologia sofre poucas alterações. À medida que o ambiente não é estável as previsões se tornam mais difíceis e a tecnologia sofre muitas alterações.

- Heterogeneidade ocorre em termos de características dos consumidores, quanto mais as características forem diferenciadas menos o ambiente será heterogêneo.

- Hostilidade reflete a atitude ameaçadora dos concorrentes ou de regulamentações governamentais ou, ainda, dificuldades de crédito.

Os atributos do SCG considerados pelo autor são (p. 69 a 72):

- Seleção de informação: refere-se aos instrumentos utilizados no SCG, que são divididos em dois grandes grupos (instrumentos gerenciais contemporâneos e instrumentos gerenciais tradicionais).

Como instrumentos contemporâneos o autor elenca os seguintes: custeio-alvo, relatórios de controle de qualidade, ABC/ABM, (Activity Based Costing e Actitvity based Management), EVA (Economic Value Added), BSC (Balanced Scorecard), análise de cenários para planejamento estratégico e indicadores de desempenho não-financeiros. Quanto mais esses instrumentos estiverem implantados mais será considerado um usuário de instrumentos contemporâneos.

Como instrumentos tradicionais o autor elenca os seguintes: demonstração de resultados mensais, custeio variável ou por absorção, orçamento não-participativo (diretoria impõe metas aos 
gerentes), orçamento participativo (gerentes participam ativamente do planejamento). Quanto mais estiverem implantados estes instrumentos mais será considerado como um usuário de instrumentos tradicionais.

- Apresentação da informação: dividida em quatro elementos: escopo, tempestividade, níveis de agregação e integração entre atividades.

O escopo é apresentado com três divisões:

a) Foco: o sistema é voltado para a parte interna ou externa da organização;

b) Quantificação: o sistema realiza mensuração apenas em termos financeiros ou inclui dados não-financeiros;

c) Horizonte temporal: as informações do sistema referem-se a fatos passados ou também futuros.

A tempestividade consiste em relatar a informação quando solicitada ou reportá-la sistematicamente.

O nível de agregação está relacionado à composição do somatório temporal e funcional, ou seja, esse elemento representa o nível em que a empresa consegue compactar informações sobre dimensões temporais e funcionais distintas.

- Integração de atividades refere-se ao fato de que o sistema de informações consiga avaliar a influência de um departamento sobre o desempenho do outro. Quanto mais essa avaliação for possível mais a informação será integrada.

\subsubsection{Fatores determinantes do nível de disclosure voluntário de companhias abertas no Brasil - Tese de Doutorado, Fernando Dal-Ri Murcia, 2009}

O objetivo desse trabalho foi identificar os fatores que explicam o nível de disclosure voluntário de companhias abertas no Brasil. Apesar de os fatores não serem os relacionados com a utilização da informação contábil, é provável que fatores que implicam um disclosure voluntário também influenciem a utilização da informação contábil.

O Quadro 5, representa as hipóteses de fatores que interferem no nível de disclosure (1 ${ }^{\mathrm{a}}$ coluna) com as respectivas variáveis utilizadas para identificar esse nível ( $2^{\mathrm{a}}$ coluna) e a respectiva fonte de dados utilizada ( $3^{\mathrm{a}}$ coluna). 
Quadro 5 - Fatores que influenciam no nível de disclosure voluntário de companhias abertas no Brasil

\begin{tabular}{|l|l|l|}
\hline \multicolumn{1}{|c|}{ Hipóteses } & \multicolumn{1}{|c|}{ Variáveis utilizadas } & \multicolumn{1}{c|}{ Fonte de Dados } \\
\hline I. Auditoria & Empresa de auditoria - Big Four & Maiores e Melhores - Exame \\
\hline II. Nível de Rentabilidade & Retorno sobre o PL médio & Maiores e Melhores - Exame \\
\hline III. Desempenho no mercado & Q de Tobin & Economática \\
\hline IV. Internacionalização & ADRs Nível II e II & $\begin{array}{l}\text { New York Stock Exchange } \\
\text { (NYSE) }\end{array}$ \\
\hline V. Tamanho & Receita Líquida & Maiores e Melhores - Exame \\
\hline VI. Governança Corporativa & Níveis diferenciados de GC & Bovespa \\
\hline VII. Nível de Endividamento & Passivo total sobre ativo total & Maiores e Melhores - Exame \\
\hline $\begin{array}{l}\text { VIII. Concentração } \\
\text { Controle }\end{array}$ & \% de ON do Acionista Principal & IAN - Bovespa \\
\hline IX. Emissão de Ações & Emissão de ações & Comissão de Valores Imobiliários \\
\hline $\begin{array}{l}\text { X. Oportunidade } \\
\text { Crescimento }\end{array}$ & de Variação da Receita Liquida & Maiores e Melhores - Exame \\
\hline XI. Setor & Setor Elétrico & Maiores e Melhores - Exame \\
\hline XII. Origem do Controle & Estatal - privado & Maiores e Melhores - Exame \\
\hline
\end{tabular}

Fonte: Murcia, 2009, p. 108

\subsubsection{Qualidades da informação contábil}

Não há um padrão único na literatura técnica que avalie, de forma objetiva, a qualidade das informações contábeis (ALMEIDA, 2010). Também não é objetivo deste trabalho um estudo nesse sentido. A literatura contábil apresenta em diversos trabalhos uma relação entre a qualidade da informação contábil e a tomada de decisão.

\footnotetext{
Por isso, os órgãos responsáveis pela emissão de pronunciamentos que compõem um determinado padrão contábil recomendam que as firmas produzam informações que atendam o maior número possível de usuários, como o próprio Pronuciamento da Estrutura Conceitual da Contabilidade (CPC) sugere no Brasil (ALMEIDA, 2010, p. 27).
}

Constata-se, assim, que a qualidade da informação contábil pode estar diretamente relacionada com a sua utilização. Do ponto de vista do usuário a qualidade dessa informação, que varia de empresa para empresa, pode ser um fator indutor ou inibidor da utilização dela.

Muitas são as classificações para a determinação das características da informação contábil. Neste trabalho optou-se por utilizar a classificação que é apresentada por Hendriksen (1999, p. 96) por meio de um quadro geral de dois grandes grupos:

- Qualidades específicas de usuários: compreensibilidade;

- Qualidades específicas de decisões: relevância e confiabilidade. 
Ainda, segundo Hendriksen (1999, p. 97), a relevância da informação é obtida se a informação atender aos seguintes requisitos:

\footnotetext{
- Valor preditivo: a informação deve auxiliar os usuários a prever corretamente eventos passados ou presentes;

- Valor de feedback: a informação deve ter um papel importante em termos de confirmação ou correção de expectativas anteriores.

- Oportunidade: a informação deve estar disponível para quem deseja tomar uma decisão antes que se perca a capacidade de influir sobre ela.
}

Em relação à confiabilidade Hendriksen (1999, p. 99 a 101) apresenta as seguintes características:

- Fidelidade de representação: consiste em que as informações contábeis representem fielmente o que pretendem representar;

- Neutralidade: não deve existir nenhum viés na informação contábil;

- Comparabilidade: a informação contábil deve permitir identificar semelhanças e diferenças em conjuntos de fenômenos econômicos.

Além da reconhecida importância, a adoção da classificação das qualidades da informação contábil de Hendriksen decorre do fato de os conceitos por eles apresentados se tornarem conhecidos no Brasil devido à publicação em livros didáticos.

\subsubsection{Legislação tributária}

Um fator ambiental que pode influenciar na utilização da informação contábil, sobretudo quando se trata de incentivos fiscais, é a própria legislação. As Leis 11.638/07 e 11.941/09 em seus artigos 37 e 38, regulamentadas pelos Pronunciamentos CPC (Comitê de Pronunciamentos Contábeis), estabeleceram novos critérios contábeis de escrituração e de elaboração das demonstrações contábeis, com vigência a partir de 01.01.2008, com a finalidade de uniformizar os critérios contábeis adotados no Brasil com padrões internacionais.

A alteração nos critérios de contabilização implicou alterações nos cálculos de impostos, principalmente no IRPJ e CSLL. Assim, para eliminar esse efeito foi instituído mediante o artigo 15 da Lei no 11.941/09 o RTT, regulamentado pela IN da RFB no 949/09.

Em vista dessa situação é possível que a adoção do RTT seja um fator indutor ou inibidor da utilização da informação contábil na adesão aos incentivos fiscais de inovação tecnológica. 


\subsubsection{Fatores considerados na pesquisa}

Com base na revisão realizada na literatura sobre fatores contábeis, tendo em vista os objetivos deste estudo, bem como toda a analise da utilização das informações contábeis na adesão aos incentivos fiscais de inovação tecnológica, foram considerados nesta pesquisa os seguintes fatores e suas respectivas variáveis:

- $\quad$ Características ambientais:

a) Dinamismo, com as seguintes variáveis: "tecnologia necessária para a produção", "atitudes da concorrência", "demanda do mercado", "características dos produtos lançados", "disponibilidade de insumos", "preço dos insumos", "regulamentação política do setor";

b) Heterogeneidade, com as seguintes variáveis: "características dos produtos encontrados no mercado", "tecnologia de produção/comercialização/serviço", "características dos fornecedores", "características dos concorrentes", "características dos clientes";

c) Hostilidade, com as seguintes variáveis: "mercado saturado", "mercado dominado" e "mercado restritivo";

d) Auditoria, com as seguintes variáveis: "Ernest Young", "Pricewaterhouse", "Deloitte", "KPMG", "outra empresa de auditoria estrangeira", "outra empresa de auditoria nacional, não é auditada".

e) Legislação tributária, com a variável "opção pelo RTT"

- Características organizacionais estruturais:

a) Natureza, com a variável "capital da empresa";

b) Tamanho, com a variável "porte da empresa".

- $\quad$ Características organizacionais de desempenho:

a) Rentabilidade, com a variável "margem de lucro";

b) Lucratividade, com a variável "crescimento do lucro";

c) Receita, com a variável "crescimento da receita".

- $\quad$ Atributos da Informação contábil:

a) Instrumentos gerenciais contemporâneos, com as variáveis "custeio-alvo", "relatório de controle de qualidade", "utilização de ABC/ABM", "utilização EVA", "uso sistemático de benchmarking", "utilização de balanced scorecard", "análise de cenários de planejamento estratégico", "utilização de indicadores não financeiros";

b) Instrumentos gerenciais tradicionais, com as variáveis: "demonstração de resultados mensais", "custeio variável ou por absorção", "orçamento não participativo", "orçamento participativo";

c) Escopo, com as variáveis: "temporal", "quantificação" "foco", "tempestividade"

d) Agregação, com as variáveis: "relatórios por divisão e filial", "análise sistemática de custo-lucro-volume", "preço de transferência interno".

Qualidade da informação contábil:

a) Relevância, com as variáveis "capacidade de avaliação", "capacidade de feedback", "disponibilidade";

b) Confiabilidade, com as variáveis "fidedignidade", "imparcialidade", "veracidade"; 
c) Comparabilidade, com as variáveis "equidade" e "consistência". 


\section{METODOLOGIA}

Definidos os fatores que podem ser indutores e inibidores da informação contábil, tendo como base o referencial teórico da teoria da contingência, bem como uma análise detalhada da utilização da informação contábil na adesão aos incentivos fiscais de inovação tecnológica, são apresentados, a seguir, a estratégia de pesquisa de campo adotada, com os respectivos meios técnicos da investigação, que incluem o tipo de pesquisa, a definição dos elementos da pesquisa e o processo de execução.

\subsection{Estratégia de pesquisa}

Martins (2007, p. 53) considera que nas ciências sociais é mais apropriada a utilização da expressão 'estratégia de pesquisa' para designar as diferentes maneiras de coletar e analisar dados empíricos. Diversos autores como Martins (2007, p. 74 a 81), Andrade (2007, p. 19 e 20), Diehi e Tatim (2004, p. 51 a 54) e Oliveira (2003, p. 62 e 63) enumeram uma série de estratégias de pesquisas que podem ser aplicadas aos temas técnico-sociais.

Com base na análise desses textos, no decorrer deste trabalho algumas dessas estratégias são aplicadas, a saber:

- Pesquisa descritiva: segundo Mattar (1996, p. 86) esse é um tipo de estratégia cujo propósito é:

[...] descrever as características de grupos, [...] descobrir ou verificar a existência de relação entre variáveis ou [...] estimar a proporção de elementos numa população específica que tenham determinadas características ou comportamentos

- Pesquisa bibliográfica: trata-se de uma estratégia indispensável em qualquer trabalho científico e segundo Martins (2007 p. 54)

[...] procura explicar e discutir um assunto, tema ou problema com base em referências publicadas em livros, periódicos, revistas, enciclopédias, dicionários, jornais, sites, CDs, anais de congressos etc.

- Pesquisa documental: é caracterizada pela utilização de documentos como fonte de informações e inclui a utilização de fontes primarias como, por exemplo, textos legais.

\subsection{População abrangida pela pesquisa}

A população ou universo é o conjunto de todos os elementos que poderiam ser objeto da pesquisa. Neste trabalho, o universo seriam todas as empresas que se propõem a analisar a 
viabilidade de utilização dos incentivos da 'lei de inovação'. É, sem dúvida, um trabalho inviável identificar essa população, para então ser definida uma amostra a ser examinada. Dessa forma, opta-se por uma amostra não probabilística, uma vez que é realizada de forma intencional.

A amostra da pesquisa é constituída pelas empresas que constam do relatório publicado anualmente pelo MCTI. A última publicação, até o momento do envio do questionário, ocorreu em dezembro de 2010 e refere-se ao aproveitamento dos incentivos fiscais utilizados pelas empresas no ano-base de 2009. Esse relatório é elaborado com base em um formulário eletrônico preenchido pelas empresas que se utilizaram dos incentivos físcais. $\mathrm{O}$ preenchimento e o envio é realizado via web. Exemplo desse formulário encontra-se no Apêndice 1.

A entrega do formulário deve ser feita até o dia 30 de julho e os dados referem-se ao ano anterior. Sendo o preenchimento um requisito obrigatório para a obtenção dos incentivos, é de supor que quase todas, senão a totalidade das empresas que se aproveitaram dos incentivos, enviaram o formulário ao MCTI.

Com base nos formulários preenchidos pelas empresas, o MCTI elabora um relatório que contém uma visão geral do universo das empresas que se utilizaram dos incentivos, assim como o montante da renúncia fiscal.

A relação das empresas que constam do relatório referente ao ano base de 2009, que é utilizado neste trabalho para a definição da população encontra-se no Apêndice 2.

As empresas relacionadas no referido relatório do MCTI são aquelas que se aproveitaram dos incentivos fiscais e foram consideradas como aptas a utilizar esses incentivos por analistas do referido ministério, constituindo-se em um universo de 542 empresas, cuja a razão social e respectiva inscrição no CNPJ (Cadastro Nacional da Pessoa Jurídica) do Ministério da Fazenda são relacionadas em anexo no relatório.

Note-se que enviaram formulários eletrônicos ao MCTI 635 empresas, das quais 93 não constam do relatório por apresentarem as seguintes situações: 
- 74 continham informações imprecisas sobre os projetos e o formulário não foi considerado como aprovado pelo MCTI;

- 16 apresentaram resultado fiscal negativo e portanto não puderam se aproveitar dos incentivos;

- 3 solicitaram a própria exclusão, podendo-se supor que optaram por não aproveitar os incentivos.

\subsection{Instrumentos de coleta de dados}

Os autores em geral que tratam de metodologia da investigação científica, e particularmente os anteriormente citados, são unânimes em apresentar o questionário como um importante instrumento na coleta de dados.

\footnotetext{
O questionário é um importante e popular instrumento de coleta de dados para uma pesquisa social. Trata-se de um conjunto ordenado e consistente de perguntas a respeito de variáveis e situações que se deseja medir ou descrever. O questionário é encaminhado para potenciais informantes, selecionados previamente, tendo que ser respondido por escrito e geralmente sem a presença do pesquisador (MARTINS, 2007, p. 90).
}

No presente trabalho, opta-se pela elaboração de um questionário estruturado, tendo em vista que esse é o que mais se adapta às exigências que devem ser levadas em consideração na elaboração de um questionário (MARTINS, 2007, p. 91), como clareza, precisão, codificação e padronização das respostas.

Conforme Martins (2007, p.90 a 95), a elaboração do questionário deve contemplar a estruturação, definição dos tipos de perguntas, elaboração de um pré-teste e definição de escalas para medir atitudes.

\subsubsection{Estruturação}

O questionário que se encontra no Apêndice 3 está dividido da seguinte forma:

A parte 1, considerada como uma parte introdutória é denominada 'informações preliminares'. Nela são coletados os dados que identificam características básicas da empresa, bem como o cargo do responsável pelo preenchimento e o setor em que a empresa atua. A identificação da empresa não é obrigatória para o preenchimento do questionário.

A parte 2, iniciada com a pergunta 'e', refere-se à identificação do modelo de decisão utilizado pela empresa para a adesão aos incentivos fiscais de inovação tecnológica. 
Uma vez escolhido se a adesão aos incentivos fiscais de inovação está mais condicionada aos objetivos organizacionais - o que corresponde ao modelo classical - ou se está mais condicionada às políticas empresariais - o que corresponde ao modelo mixed scanning automaticamente são apresentadas as etapas do respectivo modelo de decisão comentado no item 2.2.4 deste trabalho.

Para cada etapa do modelo de decisão, o respondente deve informar de forma segregada, a intensidade, a frequência e a importância da utilização da informação contábil, mediante uma escala de 0 a 4, sendo 0 nenhuma utilização da informação contábil e 4 grande utilização da informação contábil. O preenchimento dessas questões é obrigatório.

A parte 3, iniciada com a questão 2, refere-se à identificação dos fatores e, portanto, das variáveis da pesquisa que incentivam ou inibem a utilização da informação contábil. Cada pergunta, ou item de uma pergunta, está relacionada a uma variável, conforme discriminado no item 3.4 variáveis da pesquisa.

As questões são colocadas de tal forma que aquelas que apresentam o mesmo padrão de resposta fiquem próximas, o que facilita o preenchimento do questionário.

As respostas em todos os itens são obrigatórias.

\subsubsection{Escala de mensuração}

Segundo Martins (2007, p. 92), dois são os tipos de escalas encontradas em uma pesquisa social, quantitativas e qualitativas. As escalas qualitativas envolvem um grau de subjetividade e, normalmente, não envolvem fatores numéricos. 
Hair Jr. et al. (2005, p. 180) afirma que “A mensuração envolve a atribuição de números para uma variável de acordo com certas regras. Os números atribuídos devem refletir as características do fenômeno que está sendo mensurado".

O mesmo autor apresenta quatro tipos de mensuração para os diferentes tipos de escala: nominal, ordinal, intervalar e de razão. As escalas nominal e ordinal são consideradas não métricas e normalmente são chamadas de qualitativas ou comparativas. Ainda, segundo Hair Jr.,

\footnotetext{
Uma característica que distingue uma escala comparativa é que as respostas para as perguntas são avaliadas em relação umas com as outras e não de forma independente. Essas escalas são consideradas instrumentos de mensuração ordinal, pois os objetos são avaliados de uma maneira ordenada, quase sempre refletindo preferência ou importância (HAIR JR. et al., 2005, p. 191).
}

Constata-se, portanto, que, nesse tipo de escala, não há sentido em somar ou fazer uma média dos resultados obtidos entre os vários respondentes.

As escalas adotadas neste trabalho são não métricas, pois são escalas de opiniões com categorias de respostas.

\subsection{Variáveis da pesquisa}

As variáveis da pesquisa constituem dois grandes grupos: de um lado as variáveis dependentes relativas à utilização da informação contábil, que são três: intensidade, frequência e importância. Tendo em vista a dificuldade técnica do SPSS em atribuir o valor “0” a uma escala, os resultados dos questionários são apresentados em uma escala de 1 a 5.

De outro lado as variáveis independentes, que são aquelas que podem se constituir em fatores indutores ou inibidores da utilização da informação contábil. Essas variáveis são definidas conforme descrito no item 2.3 do presente trabalho.

Apresenta-se, a seguir, para cada uma das características um quadro com os respectivos fatores e variáveis relacionando-os às questões constantes do questionário e a escala de mensuração. 
Quadro 6 - Características ambientais, fatores e respectivas variáveis

\begin{tabular}{|c|c|c|c|c|}
\hline Fatores & Variáveis & Questão & Resultado & Fonte \\
\hline \multirow{7}{*}{ Dinamismo } & Tecnologia necessária para a produção & $2 \mathrm{a}$ & \multirow{7}{*}{$\begin{array}{l}\text { 1: muito estável } \\
\text { 2: estável } \\
\text { 3: intermediário } \\
\text { 4: dinâmico } \\
\text { 5: muito } \\
\text { dinâmico }\end{array}$} & \multirow{7}{*}{ (1) } \\
\hline & Atitudes da concorrência & $2 b$ & & \\
\hline & Demanda do mercado & $2 \mathrm{c}$ & & \\
\hline & Característica dos produtos lançados & $2 \mathrm{~d}$ & & \\
\hline & Disponibilidade de insumos & $2 \mathrm{e}$ & & \\
\hline & Preço dos insumos & $2 f$ & & \\
\hline & Regulamentação política do setor & $2 g$ & & \\
\hline \multirow{5}{*}{$\begin{array}{l}\text { Heteroge- } \\
\text { neidade }\end{array}$} & Características dos produtos no mercado & $3 a$ & \multirow{5}{*}{$\begin{array}{l}\text { 1: totalmente } \\
\text { homogêneos } \\
\text { 2: homogêneos } \\
\text { 3: intermediário } \\
\text { 4: heterogêneos } \\
\text { 5: totalmente } \\
\text { heterogêneos }\end{array}$} & \multirow{5}{*}{ (1) } \\
\hline & $\begin{array}{l}\text { Tecnologia de produção, comercialização e } \\
\text { serviço }\end{array}$ & $3 b$ & & \\
\hline & Características dos fornecedores & $3 \mathrm{c}$ & & \\
\hline & Características dos concorrentes & $3 d$ & & \\
\hline & Características dos clientes & $3 \mathrm{e}$ & & \\
\hline \multirow[b]{3}{*}{ Hostilidade } & Mercado saturado & $6 a$ & \multirow{3}{*}{$\begin{array}{l}\text { 1: não está } \\
\text { 2: está pouco } \\
\text { 3: está } \\
\text { razoavelmente } \\
\text { 4: está muito } \\
\text { 5: está } \\
\text { extremamente }\end{array}$} & \multirow[b]{3}{*}{ (1) } \\
\hline & Mercado dominado & $6 b$ & & \\
\hline & Mercado restritivo & $6 c$ & & \\
\hline \multirow{7}{*}{ Auditoria } & Ernest Young & \multirow{7}{*}{12} & \multirow{7}{*}{$\begin{array}{c}\text { Empresa de } \\
\text { auditoria }\end{array}$} & \multirow{7}{*}{ (2) } \\
\hline & Pricewaterhouse & & & \\
\hline & Deloitte & & & \\
\hline & KPMG & & & \\
\hline & Outra estrangeira & & & \\
\hline & Outra nacional & & & \\
\hline & Não é auditada & & & \\
\hline $\begin{array}{l}\text { Legislação } \\
\text { tributária }\end{array}$ & Opção pelo RTT & 9 & $\begin{array}{l}\text { 1- Não sei } \\
\text { 2- Não } \\
\text { 3-Sim }\end{array}$ & (5) \\
\hline
\end{tabular}

Referências: (1) Guerra (2007, p. 128 a 133) e (2) Murcia (2009, p.117), (5) Legislação tributária 
Quadro 7 - Características estruturais, fatores e respectivas variáveis

\begin{tabular}{|c|c|c|c|c|}
\hline Fatores & Variáveis & Questão & Resultado & Fonte \\
\hline Natureza & Capital da empresa & 10 & $\begin{array}{l}\text { 1: público } \\
\text { 2: privado brasileiro } \\
\text { 3: privado norte- } \\
\text { americano } \\
\text { 4: privado europeu } \\
\text { 5: privado outros }\end{array}$ & (2) \\
\hline Tamanho & Porte da empresa & 11 & $\begin{array}{l}\text { 1: grande porte } \\
\text { 2: médio porte } \\
\text { 3: pequeno porte }\end{array}$ & (2) \\
\hline
\end{tabular}

Referência: (2) Murcia (2009, p.117)

Quadro 8 - Características de desempenho, fatores e respectivas variáveis

\begin{tabular}{|c|c|c|c|c|}
\hline Fatores & Variáveis & Questão & Resultado & Fonte \\
\hline Rentabilidade & Margens de lucro & $4 a$ & \multirow{3}{*}{$\begin{array}{l}\text { 1: muito abaixo do } \\
\text { esperado } \\
\text { 2: abaixo do esperado } \\
\text { 3: esperado } \\
\text { 4: acima do esperado } \\
\text { 5: muito acima do } \\
\text { esperado }\end{array}$} & (3) \\
\hline Lucratividade & Crescimento do lucro & $4 \mathrm{~b}$ & & (3) \\
\hline Receita & Crescimento da receita & $4 \mathrm{c}$ & & (3) \\
\hline
\end{tabular}

Referência: (3) Camacho (2010, p.196 a 204) 
Quadro 9 - Atributos da informação contábil, fatores e respectivas variáveis

\begin{tabular}{|c|c|c|c|c|}
\hline Fatores & Variáveis & & Resultado & Fonte \\
\hline \multirow{8}{*}{$\begin{array}{c}\text { Instrumentos } \\
\text { gerenciais } \\
\text { contemporâneos }\end{array}$} & Custeio-alvo & $5 \mathrm{~h}$ & \multirow{8}{*}{$\begin{array}{l}\text { 1: não utiliza } \\
\text { 2: está estudando a } \\
\text { viabilidade } \\
\text { 3: está em fase inicial de } \\
\text { implantação } \\
\text { 4: está em fase final de } \\
\text { implantação } \\
\text { 5: conclui plenamente sua } \\
\text { implantação }\end{array}$} & \multirow{8}{*}{ (1) } \\
\hline & Relatório de controle de qualidade & $5 \mathrm{i}$ & & \\
\hline & $\mathrm{ABC} / \mathrm{ABM}$ & $5 \mathrm{j}$ & & \\
\hline & EVA & 51 & & \\
\hline & Uso sistemático de benchmarking & $5 \mathrm{~m}$ & & \\
\hline & Balanced scorecard & $5 n$ & & \\
\hline & Análise de cenários estratégicos & 50 & & \\
\hline & Indicadores não financeiros & $5 p$ & & \\
\hline \multirow{4}{*}{$\begin{array}{l}\text { Instrumentos } \\
\text { gerenciais } \\
\text { tradicionais }\end{array}$} & $\begin{array}{l}\text { Demonstração de } \\
\text { mensais }\end{array}$ & $5 d$ & \multirow{4}{*}{$\begin{array}{l}\text { 1: não utiliza } \\
\text { 2: está estudando a } \\
\text { viabilidade } \\
\text { 3: está em fase inicial de } \\
\text { implantação } \\
\text { 4: está em fase final de } \\
\text { implantação } \\
\text { 5: conclui plenamente sua } \\
\text { implantação }\end{array}$} & \multirow{4}{*}{ (1) } \\
\hline & Custeio variável ou por absorção & $5 e$ & & \\
\hline & Orçamento não participativo & $5 f$ & & \\
\hline & Orçamento participativo & $5 g$ & & \\
\hline \multirow{4}{*}{ Escopo } & Temporal & $8 \mathrm{a}$ & $\begin{array}{l}\text { 1: somente o passado } \\
\text { 2: principalmente o passado } \\
\text { 3: igualmente passado e } \\
\text { futuro } \\
\text { 4: principalmente o futuro } \\
\text { 5: somente o futuro }\end{array}$ & \multirow{3}{*}{ (1) } \\
\hline & Quantificação & $8 b$ & $\begin{array}{l}\text { 1:exclusivamente financeiras } \\
\text { 2: principalmente financeiras } \\
\text { 3: igualmente financeiras e } \\
\text { não-financeiras } \\
\text { 4: principalmente não finan. } \\
\text { 5: exclusivamente não finan. }\end{array}$ & \\
\hline & Foco & $8 \mathrm{c}$ & $\begin{array}{l}\text { 1: exclusivamente interno } \\
\text { 2: principalmente interno } \\
\text { 3: igualmente interno e ext. } \\
\text { 4: principalmente externo } \\
\text { 5: exclusivamente externo }\end{array}$ & \\
\hline & Tempestividade & $8 d$ & $\begin{array}{l}\text { 1: muito grande } \\
\text { 2: grande } \\
\text { 3: médio } \\
\text { 4: pequeno } \\
\text { 5: muito pequeno }\end{array}$ & (1) \\
\hline \multirow{3}{*}{ Agregação } & Relatórios por divisão e filial & $5 \mathrm{a}$ & \multirow{3}{*}{$\begin{array}{l}\text { 1: não utiliza } \\
\text { 2: está estudando a } \\
\text { viabilidade } \\
\text { 3: está em fase inicial de } \\
\text { implantação } \\
\text { 4: está em fase final de } \\
\text { implantação } \\
\text { 5: concluiu plenamente sua } \\
\text { implantação }\end{array}$} & (1) \\
\hline & $\begin{array}{l}\text { Análise sistemática de custo- } \\
\text { volume-lucro }\end{array}$ & $5 b$ & & (1) \\
\hline & Preço de transferência interno & $5 \mathrm{c}$ & & (1) \\
\hline
\end{tabular}

Referências: (1) Guerra (2007, p. 128 a 133) 
Quadro 10 - Qualidades da informação contábil, fatores e respectivas variáveis

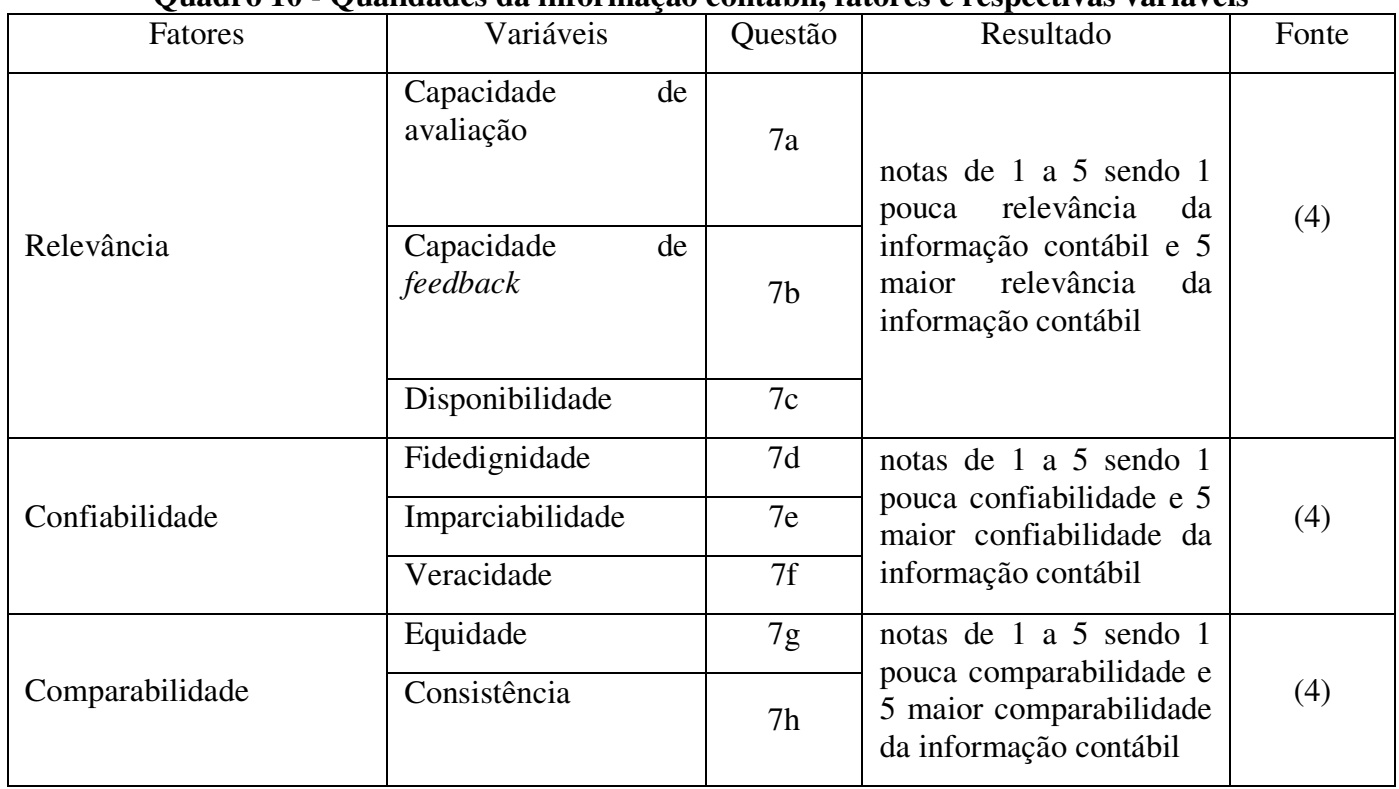

Referência: (4) Hendriksen (1999, p. 96 a 103)

Ressalte-se que as variáveis selecionadas podem se constituir em fatores indutores ou inibidores dependendo das diversas circunstâncias que se apresentem e que nem todas as variáveis relacionadas constituem obrigatoriamente fatores indutores ou inibidores da informação contábil, pois pode ocorrer que não exista relação entre a variável e a utilização da informação contábil.

\subsection{Pré-teste}

De acordo com Martins (2007, p. 92), depois de redigido, o questionário precisa ser avaliado mediante testes que consistem em aplicá-lo para uma pequena amostra de colaboradores. De acordo com Mattar (1996, p. 234), esse pré-teste tem como finalidade verificar se:

\footnotetext{
- os termos utilizados nas perguntas são de compreensão dos respondentes;

- as perguntas estão sendo entendidas como deveriam ser;

- as opções de respostas nas perguntas fechadas estão completas;

- a sequência das perguntas está correta;

- há objeção na obtenção das respostas;

- a forma de apresentar a pergunta está causando viés.
} 
Neste trabalho, o pré-teste é aplicado em seis analisadores distintos:

- um professor que atua na área de contabilidade com a finalidade de aproveitar sua experiência acadêmica e científica;

- quatro consultores especializados em auxiliar as empresas para a obtenção dos incentivos fiscais referentes à 'lei de inovação'. O conhecimento adquirido por eles no trabalho desenvolvido em várias empresas permite considerar essa consulta como uma espécie de modelo das impressões que os responsáveis nas empresas terão na leitura do questionário.

- Um controller de uma grande empresa nacional que aderiu à utilização do incentivo fiscal, desde o início de sua implantação e que, por essa razão, em muito pode contribuir na elaboração do questionário. Observe-se que, no ano-base 2009, sua empresa estava entre aquelas que tiveram prejuízo fiscal e, portanto, não está incluída no universo das empresas objeto da pesquisa.

\subsection{Aplicação e coleta de dados}

Os questionários foram aplicados por meio do software Web Form Builder, que é um aplicativo da informática específico para essa finalidade, mediante o qual a coleta de dados pode ser realizada via website.

As solicitações de preenchimento foram realizadas por e-mail, cujo texto se encontra no Apêndice 4. Posteriormente, nos casos para os quais o e-mail não é respondido, há um contato telefônico solicitando a cooperação dos participantes que não responderam ao questionário. Houve, ainda, um compromisso de divulgação do resultado da pesquisa, por meio de uma palestra àqueles que colaboraram com ela.

\subsection{Tratamento estatístico}

Ao tratar de técnicas para a avaliação quantitativa Martins (2007, p. 103) afirma que:

Durante o processo de construção de um trabalho científico, o pesquisador, dependendo da natureza das informações, dos dados e das evidências levantadas, poderá empreender uma avaliação quantitativa, isto é: organizar, sumarizar, caracterizar e interpretar os dados numéricos coletados. Para tanto poderá tratar os dados através da aplicação de métodos e técnicas da Estatística. 
Dentre as diversas técnicas estatísticas, optou-se por escolher a análise de homogeneidade (HOMALS), uma vez que ela permite identificar eventuais associações entre as variáveis qualitativas.

Segundo Fávero et al. (2009, p. 291),

A HOMALS é uma técnica de descrição de dados qualitativos, particularmente bem adaptada ao tratamento de dados de pesquisa em que as questões são relacionadas a respostas múltiplas. Formalmente, trata-se de uma simples aplicação da análise de correspondência a uma tabela com múltiplos níveis.

Ainda segundo os mesmos autores,

A análise de homogeneidade, ou HOMALS, consiste em uma análise dos componentes principais para dados qualitativos, permitindo a segregação das variáveis em grupos homogêneos, a partir da transformação de dados não-métricos por meio da atribuição de escores (quantificações ótimas). (FÁVERO et al., 2009, p. 292).

Para Pestana e Gageiro, (2008, p. 212), a análise de homogeneidade:

[...] permite estudar a relação entre mais do que duas variáveis nominais e representá-las em poucas dimensões, normalmente duas ou três. Considera-se uma análise equivalente à das componentes principais para dados nominais, que procede a uma partição das variáveis em grupos homogêneos.

Carvalho (2008, p. 19) recomenda a aplicação da analise de homogeneidade quando:

Existem muitas situações de pesquisa empírica, nas quais o investigador tem por referência modelos de análise que perspectivam, mesmo que não em exclusivo, uma abordagem mutifacetada e relacional sobre o objeto em estudo - traços da sua configuração complexa [...]. Um dos fatores deste tipo de abordagem consiste na identificação dos múltiplos fatores, considerados pertinentes para captar a estrutura dos fenômenos em estudo, do que os fenômenos sociais são somente um exemplo. Uma das premissas é, pois, a de que a complexidade é multidimensional .

Carvalho (2008, p. 21) ainda destaca a aplicabilidade desse método estatístico em relação a variáveis qualitativas.

O resultado da aplicação dessa técnica é a elaboração de um mapa perceptual que:

Pode ser entendido como a representação visual das percepções que um respondente tem sobre seus objetos em duas ou mais dimensões e, geralmente, em níveis opostos de dimensões nos extremos dos eixos $\mathrm{X}$ e Y. Cada objeto tem uma posição espacial que reflete a similaridade ou preferência relativa a outros objetos no que se refere às dimensões do mapa perceptual (FÁVERO et al., 2009, p. 272). 
Para a aplicação dessa técnica estatística foi utilizado o software SPSS. 


\section{ANÁLISE DOS RESULTADOS}

\subsection{Considerações iniciais}

Conforme comentado anteriormente, as empresas objeto da presente pesquisa são as que se utilizaram do incentivo fiscal de inovação tecnológica estabelecido pela Lei no 11.196/05, que constam do Relatório Anual da Utilização dos Incentivos Fiscais do ano-base 2009, publicado pelo MCTI, num total de 542 empresas.

Dentre essas, 77 empresas responderam ao questionário, conforme o 'resumo das respostas' que se encontra no Apêndice 5.

De acordo com Martins (2005), se a variável for qualitativa (nominal ou ordinal) e a população finita, o tamanho da amostra (n) aleatória simples pode ser calculado pela seguinte fórmula:

$$
\mathrm{n}=\frac{Z_{\mathrm{g}}^{2} \cdot \hat{p} \cdot \hat{q} \cdot \mathrm{N}}{e^{2}(\mathrm{~N}-1)+Z_{\mathrm{g}}^{2} \cdot \hat{p} \cdot \hat{q}}
$$

em que:

$Z_{g}$ = abscissa da distribuição normal padrão, fixado um nível de confiança g;

$\hat{\mathrm{p}}=$ estimativa da proporção de $\mathrm{p}$;

$\hat{\mathrm{q}}=1-\hat{\mathrm{p}}$

$\mathrm{N}=$ tamanho da população

$\boldsymbol{e}=$ erro amostral (máxima diferença permitida entre $\hat{\mathrm{p}}$ e $\hat{\mathrm{q}}$ )

Na equação acima, em que o grau de confiabilidade é dado por $\mathrm{Z}$, tem-se os seguintes valores fixos para as variáveis da equação; 
$\hat{p} . \hat{q}=0,25$, uma vez que, segundo Fávero el al (2009, p. 102),

[...] é comum que seja utilizado 0,25 para este termo, uma vez que o produto de duas probabilidades é maximizado quando elas assumem valores iguais a 0,5 . Isso propicia a maximização do dimensionamento amostral (a favor da segurança).

$\mathrm{N}=542$ total

$\mathrm{n}=77$, total de empresas que responderam ao questionário

Assim, aplicando-se a equação, tem-se o valor de $e=0,08$ e o valor de $\mathrm{Z}=1,43$.

O Valor $\mathrm{Z}=1,43$ corresponde, na tabela denominada tabela padrão normal, também chamada tabela Z, a um nível de confiança de $92 \%$.

\subsection{Análise descritiva dos resultados da pesquisa}

A seguir, são relacionados alguns dados obtidos na pesquisa que se apresentam como relevantes para fins da análise objeto desta tese.

\subsubsection{Funções exercidas pelos respondentes}

Conforme demonstra a Tabela 1, a grande maioria dos respondentes tem funções que implicam acesso aos dados contábeis de forma constante. Para uma melhor análise esse grupo de respondentes foi dividido em dois subgrupos.

O primeiro é referente àquelas funções que estão diretamente ligadas à atividade contábil, ou seja, aquelas que se envolvem na preparação ou análise das demonstrações contábeis, representadas pelas seguintes funções:

- contador/gerente contábil, denominado contador;

- controller;

- analista/assistente/coordenador/encarregado/especialista/supervisor contábil, denominado analista contábil;

- analista de custos;

- analista de controladoria.

O segundo subgrupo é referente às funções que se utilizam de forma constante das informações contábeis, sem entretanto terem responsabilidade pela sua elaboração, representadas pelas seguintes funções: 
- diretor/gestor administrativo e financeiro, denominado diretor administrativo;

- analista/encarregado financeiro ou administrativo, denominado analista financeiro;

- analista/coordenador fiscal, denominado analista fiscal.

O segundo grupo possui uma quantidade bastante reduzida de respondentes e refere-se às funções que não se utilizam de forma constante e rotineira das informações contábeis e são representadas pelas seguintes funções:

- $\quad$ presidente;

- $\quad$ gerente geral.

A Tabela 1 apresenta também o percentual de respondentes de cada função

Tabela 1 - Funções dos respondentes

\begin{tabular}{l|r|r}
\hline \multicolumn{1}{c|}{ Funções } & Quantidade & \multicolumn{1}{c}{ Perceptual } \\
\hline Contador & 40 & $51,95 \%$ \\
\hline Controller & 12 & $15,58 \%$ \\
\hline Analista contábil & 10 & $12,99 \%$ \\
\hline Analista de custos & 1 & $1,30 \%$ \\
\hline Analista de controladoria & 1 & $1,30 \%$ \\
\hline $\begin{array}{l}\text { Total Grupo 1A - Funções de usuários responsáveis pela } \\
\text { elaboração das demonstrações contábeis }\end{array}$ & $\mathbf{6 4}$ & $\mathbf{8 3 , 1 2 \%}$ \\
\hline Analista fiscal & 3 & $3,90 \%$ \\
\hline Analista financeiro & 2 & $2,60 \%$ \\
\hline Diretor financeiro & 5 & $6,49 \%$ \\
\hline $\begin{array}{l}\text { Total Grupo 1B - Funções de usuários que não } \\
\text { participam da elaboração das demonstrações contábeis }\end{array}$ & $\mathbf{1 0}$ & $\mathbf{1 2 , 9 9 \%}$ \\
\hline $\begin{array}{l}\text { Total do Grupo 1- Usuários que utilizam a informação } \\
\text { contábil rotineiramente }\end{array}$ & $\mathbf{7 4}$ & $\mathbf{9 6 , 1 1 \%}$ \\
\hline Gerente geral & 1 & $1,30 \%$ \\
\hline Presidente & 2 & $2,60 \%$ \\
\hline $\begin{array}{l}\text { Total Grupo 2 - Usuários que não utilizam a } \\
\text { informação contábil rotineiramente }\end{array}$ & $\mathbf{3}$ & $\mathbf{3 , 9 0 \%}$ \\
\hline TOTAL GERAL & $\mathbf{7 7}$ & $\mathbf{1 0 0 \%}$ \\
\hline
\end{tabular}

Verifica-se, portanto, que a grande maioria dos respondentes, ou seja, 96,11\% utilizam rotineiramente as informações contábeis. Tal constatação está de acordo com a visão de que esse tipo de incentivo fiscal envolve o pessoal da área contábil sendo a pesquisa adequada ao estudo que é desenvolvido. 


\subsubsection{Modelo de decisão utilizado}

Na respostas sobre o grau de utilização da informação contábil, o respondente, inicialmente, deveria optar entre dois modelos de decisão: "classical”, que tem por base os objetivos organizacionais ou "mixed scanning", que tem por base políticas empresariais.

A Tabela 2 demonstra, por função, a utilização de cada modelo.

Tabela 2 - Modelo de decisão utilizado

\begin{tabular}{|c|c|c|c|c|c|}
\hline \multirow[t]{2}{*}{$\begin{array}{l}\text { Quadro de função dos } \\
\text { respondentes }\end{array}$} & \multicolumn{2}{|c|}{$\begin{array}{c}\text { Modelo "classical" } \\
\text { (objetivos organizacionais) }\end{array}$} & \multicolumn{2}{|c|}{$\begin{array}{c}\text { Modelo "mixed scanning" } \\
\text { (políticas empresariais) }\end{array}$} & \multirow[t]{2}{*}{ Total } \\
\hline & quantidade & $\%$ & quantidade & $\%$ & \\
\hline Contador & 35 & $87,5 \%$ & 5 & $12,5 \%$ & 40 \\
\hline Controller & 9 & $75,0 \%$ & 3 & $25,0 \%$ & 12 \\
\hline Analista contábil & 10 & $100,00 \%$ & 0 & $0,00 \%$ & 10 \\
\hline Analista de custos & 1 & $100,00 \%$ & 0 & $0,00 \%$ & 1 \\
\hline Analista de controladoria & 1 & $100,00 \%$ & 0 & $0,00 \%$ & 1 \\
\hline Analista fiscal & 3 & $100,00 \%$ & 0 & $0,00 \%$ & 3 \\
\hline Analista financeiro & 2 & $100,00 \%$ & 0 & $0,00 \%$ & 2 \\
\hline Diretor financeiro & 5 & $100,00 \%$ & 0 & $0,00 \%$ & 5 \\
\hline Gerente geral & 0 & $0,00 \%$ & 1 & $100,00 \%$ & 2 \\
\hline Presidente & 2 & $100,00 \%$ & 0 & $0,00 \%$ & 2 \\
\hline TOTAL GERAL & 68 & $88,31 \%$ & 9 & $11,69 \%$ & 77 \\
\hline
\end{tabular}

$\mathrm{Na}$ Tabela 2, fica claro que a grande maioria dos respondentes, ou seja, 88,31\%, se orienta por objetivos organizacionais para a tomada de decisão, o que corresponde ao modelo "classical". Levando-se em consideração que a grande maioria dos respondentes é da área contábil, é razoável supor que os objetivos organizacionais se referiam à redução de impostos.

Apenas 11,69\% informaram que as decisões foram orientadas por políticas empresariais, o que corresponde ao modelo "mixed scanning”.

Este resultado contrariou a expectativa quando da elaboração da pesquisa, uma vez que claramente o modelo "mixed scanning" se adapta melhor aos requisitos de uma correta avaliação da decisão, no caso de adesão aos incentivos fiscais de inovação tecnológica, uma vez que, na presença de resultados incertos, não há como se estabelecer metas baseadas em resultados, devendo a decisão ser baseada em políticas empresarias.

Isso pode demonstrar que, apesar dos respondentes terem conhecimento da informação contábil e utilizá-la em seu processo decisório, o modelo de decisão, ao menos do ponto de 
vista teórico, que está sendo geralmente utilizado, é inadequado para o tipo de decisão que está sendo tomada.

Esse fato talvez seja um dos fatores que permitam explicar, a pequena quantidade de empresas que aderiram aos incentivos fiscais de inovação tecnológica, pois a utilização de um modelo inadequado de decisão possivelmente acarreta insegurança sobre o rumo a tomar.

Em vista da pequena quantidade de respostas que contemplam a opção do modelo de decisão “mixed scanning”, considera-se que não é adequada a análise desses dados mediante a análise de homogeneidade, uma vez que dificilmente poderia se concluir que os resultados indicam a formação de grupos, o que é um princípio fundamental para a aplicação da técnica estatística.

Seja qual for a natureza das unidades de análise, o que determina a opção pela Análise de Correspondências Múltiplas ou pela Análise de Homogeneidade é o propósito de realizar uma abordagem relacional sobre as múltiplas variáveis que caracterizam esses indivíduos, podendo vir a ser definidos diferentes grupos". (CARVALHO, 2008 p. 22)

Dessa forma, a aplicação da análise de homogeneidade com a elaboração dos respectivos gráficos perceptuais, foi realizada com os dados das empresas que contemplam a opção do modelo de decisão "classical”.

\subsubsection{Utilização atribuída à informação contábil}

Após a opção por um modelo de decisão, perguntou-se sobre a utilização da informação contábil no processo de decisão, dividida em três aspectos, de acordo com a escala já comentada anteriormente:

- Intensidade: quantidade de informação contábil;

- Frequência: periodicidade de utilização da informação contábil nas diversas etapas do processo de decisão;

- Importância: relevância da informação contábil para utilização nas diversas etapas do processo de decisão.

A finalidade dessa divisão foi precisar e esclarecer aos respondentes em que consiste a utilização da informação contábil.

A Tabela 3, a seguir, representa a quantidade de respostas atribuídas para cada um dos graus de utilização da informação contábil ( 0 a 4) de acordo com as funções dos respondentes. 
Tabela 3 - Grau de utilização da informação contábil: Geral

\begin{tabular}{|c|c|c|c|c|c|c|c|c|c|c|c|}
\hline \multirow{3}{*}{$\begin{array}{l}\text { Função dos } \\
\text { respondentes }\end{array}$} & \multicolumn{11}{|c|}{ Respostas } \\
\hline & \multicolumn{2}{|c|}{0} & \multicolumn{2}{|c|}{1} & \multicolumn{2}{|c|}{2} & \multicolumn{2}{|c|}{3} & \multicolumn{2}{|c|}{4} & \multirow{2}{*}{ Total } \\
\hline & qtde & $\%$ & qtde & $\%$ & qtde & $\%$ & qtde & $\%$ & qtde & $\%$ & \\
\hline Contador & 5 & 0,71 & 41 & 5,82 & 124 & 17,59 & 257 & 36,45 & 278 & 39,43 & 705 \\
\hline Controller & 5 & 2,42 & 9 & 4,35 & 46 & 22,22 & 67 & 32,37 & 80 & 38,65 & 207 \\
\hline Analista contábil & 3 & 1,67 & 14 & 7,78 & 19 & 10,56 & 85 & 47,22 & 59 & 32,78 & 180 \\
\hline Analista de custos & 0 & 0,00 & 0 & 0,00 & 0 & 0,00 & 4 & 22,22 & 14 & 77,78 & 18 \\
\hline $\begin{array}{ll}\text { Analista } & \mathrm{de} \\
\text { controladoria } & \end{array}$ & 0 & 0,00 & 0 & 0,00 & 1 & 5,56 & 0 & 0,00 & 17 & 94,44 & 18 \\
\hline Analista fiscal & 0 & 0,00 & 0 & 0,00 & 1 & 1,85 & 9 & 16,67 & 44 & 81,48 & 54 \\
\hline Analista financeiro & 0 & 0,00 & 2 & 5,56 & 6 & 16,67 & 10 & 27,78 & 18 & 50,00 & 36 \\
\hline Diretor financeiro & 3 & 3,33 & 2 & 2,22 & 11 & 12,22 & 13 & 14,44 & 61 & 67,78 & 90 \\
\hline Gerente geral & 15 & 100 & 0 & 0,00 & 0 & 0,00 & 0 & 0,00 & 15 & 0,00 & 15 \\
\hline Presidente & 4 & 11,1 & 4 & 11,1 & 8 & 22,22 & 8 & 22,22 & 12 & 33,33 & 36 \\
\hline TOTAL GERAL & $\underline{\underline{20}}$ & $\underline{\underline{1,47}}$ & $\underline{72}$ & $\underline{\underline{5,30}}$ & $\underline{\underline{216}}$ & 15,89 & $\underline{453}$ & 33,33 & $\underline{\underline{598}}$ & 44,00 & $\underline{\underline{1359}}$ \\
\hline
\end{tabular}

A quantidade de 1.359 respostas corresponde a 18 respostas de cada um dos 68 respondentes que optaram pelo modelo de decisão classical num total de 1.224 respostas, mais 15 respostas de cada um dos 9 respondentes que optaram pelo modelo de decisão mixed scanning, num total de 135 respostas, perfazendo, assim, o total de $1.359(1.224+135)$.

Constata-se, portanto, que com exceção da função de gerente geral, que é representada por uma única resposta, em todas as demais a utilização da informação contábil para a tomada de decisão é significativa.

Tais respostas demonstram, como comentado na parte teórica deste trabalho, que a decisão referente à adesão a esse incentivo envolve as informações contábeis.

Verifica-se, conforme Tabela 4, que as diferenças entre os três aspectos não são significativas em relação aos objetivos deste trabalho. A uniformidade apresentada nas respostas reforça a conclusão de que as informações contábeis são utilizadas no processo de decisão de utilização dos incentivos fiscais de inovação tecnológica. 
Tabela 4 - Grau de utilização da informação contábil por aspecto

\begin{tabular}{c|r|r|r|r|r|r|r}
\hline \multirow{2}{*}{$\begin{array}{c}\text { Aspectos/ } \\
\text { Escala }\end{array}$} & \multicolumn{2}{|c|}{ Intensidade } & \multicolumn{2}{|c|}{ Frequência } & \multicolumn{2}{|c|}{ Importância } & \multirow{2}{*}{ Total } \\
\cline { 2 - 7 } & qtde & \multicolumn{1}{c|}{$\%$} & qtde & $\%$ & qtde & \multicolumn{1}{c}{$\%$} & \\
\hline 0 & 10 & $2,21 \%$ & 15 & $3,31 \%$ & 10 & $2,21 \%$ & 35 \\
\hline 1 & 23 & $5,08 \%$ & 25 & $5,52 \%$ & 24 & $5,30 \%$ & 72 \\
\hline 2 & 74 & $16,34 \%$ & 84 & $18,54 \%$ & 58 & $12,80 \%$ & 216 \\
\hline 3 & 160 & $35,32 \%$ & 158 & $34,88 \%$ & 135 & $29,80 \%$ & 453 \\
\hline 4 & 186 & $41,06 \%$ & 171 & $37,75 \%$ & 226 & $49,89 \%$ & 583 \\
\hline Totais & 453 & & 453 & & 453 & & 1359 \\
\hline
\end{tabular}

\subsection{Análise dos fatores da utilização da informação contábil - observações gerais}

Conforme já mencionado anteriormente, para a análise estatística dos dados apurados por intermédio dos questionários foi utilizada a análise de homogeneidade (HOMALS) que é uma técnica que permite identificar a relação entre variáveis qualitativas.

De acordo com Fávero et al. (2009, p. 273), a finalidade dessa técnica é obter: “[...] as associações entre um conjunto de variáveis categóricas não-métricas em um mapa perceptual, permitindo, desta maneira, uma exame visual de qualquer padrão ou estrutura de dados."

Essa associação é realizada por meio de um mapa perceptual.

O mapa perceptual pode ser entendido como a representação visual das percepções que um respondente tem sobre seus objetos em duas a duas ou mais dimensões e, geralmente, em níveis opostos de dimensões nos extremos dos eixos X e Y. Cada objeto tem uma posição espacial que reflete a similaridade ou preferência relativa a outros objetos no que se refere às dimensões perceptuais (FÁVERO et al., 2009, p. 272).

Assim, cada eixo do gráfico é considerada uma dimensão.

Uma vez que o objetivo deste trabalho é identificar os fatores indutores e inibidores da utilização da informação contábil, tendo em vista o grande número de variáveis envolvidas na pesquisa, o referido mapa perceptual foi elaborado relacionando a utilização da informação contábil que consta da parte 2 do questionário, com cada variável individualmente. Essas variáveis constam da parte 3 do questionário e foram detalhadas no item 3.4.

Assim, por exemplo, o primeiro gráfico relacionou as variáveis relativas à utilização da informação contábil com a variável "atitudes da concorrência". 
De acordo com Fávero et al. (2009, p. 273 e 274), que desenvolveram e ampliaram as recomendações de Pestana e Gageiro (2008, p. 214 a 222), o método de análise deve seguir as seguintes etapas:

- Realização do teste qui-quadrado $\left(x^{2}\right)$ para verificar a existência da dependência entre duas variáveis. Nesse caso, segundo Fávero et al. (p. 284), quando há nível de significância inferior a $5 \%$ (p-valor), há indícios que levam à rejeição da hipótese nula de independência das variáveis, o que permite a aplicação da HOMALS.

- Definição da importância de cada dimensão através da apuração do valor da respectiva inércia. De acordo com Pestana e Gageiro (2008, p. 214), o quociente entre a inércia de cada dimensão e a inércia total dá a proporção da variância explicada por cada dimensão.

Os valores atribuídos ao resultados das dimensões é representado na tabela calculada por meio do SPSS, cujo título é 'modelSummary' na coluna ‘\% ofVariance'. O padrão de saída do SPSS são quatro dimensões.

Neste trabalho, devido ao grande número de variáveis para análise, optou-se por considerar sempre duas dimensões.

As tabelas relativas às dimensões foram incluídas no início da análise de cada fator. Acima de cada tabela, inseriram-se as variáveis que estão sendo analisadas. Estão sempre relacionadas as variáveis relativas à utilização da informação contábil com uma variável que pode se constituir em fator indutor ou inibidor da utilização da informação contábil. As variáveis são representadas por letras e números conforme será explicado no próximo item.

De acordo com os resultados transcritos nas tabelas, as duas dimensões explicam aproximadamente $80 \%$ da variação dos dados, sendo $48 \%$ na primeira e $32 \%$ na segunda. Devido à proximidade dos valores obtidos nas diversas tabelas que calculam a inércia, não foi necessário analisar individualmente os resultados sendo aplicado a todas as tabelas esse comentário geral.

A análise do gráfico é feita pela relação de proximidade geométrica das diversas variáveis, que simultaneamente se situam mais afastadas da origem, isto é da intersecção dos eixos do gráfico. (CARVALHO, 2008, p. 75 a 78) 
Para cada uma das variáveis que poderiam ser fatores indutores e inibidores da utilização da informação contábil e cujo teste do qui-quadrado apresentou nível de significância inferior a $5 \%$, foi elaborado um gráfico perceptual.

Tendo em vista o grande número de variáveis envolvidas em cada análise, foi elaborada uma codificação-padrão que é aplicada a todos os gráficos, a saber:

As variáveis que podem se constituir em fatores indutores e inibidores da utilização da informação contábil foram numeradas de acordo com o questionário enviado aos respondentes. Por exemplo, a variável b2 (questão no 2 letra b) corresponde à variável "atitudes da concorrência".

As variáveis relativas à utilização da informação contábil foram codificadas com o seguinte padrão:

Utilização da informação contábil:

I - Intensidade

II - Frequência

III - Importância

Fases do processo decisório

a - Identificação

b - Análise das dificuldades

c - Definição das alternativas

d - Exame de consequências

e - Escolha das alternativas

f - Implantação do incentivo

Para facilitar a compreensão dos gráficos, foi inserida uma legenda com todas as codificações.

Os resultados dos testes do qui-quadrado, das inércias e os gráficos são apresentados a seguir.

Cabe, por fim, lembrar que os resultados obtidos, conforme Fávero (2009, p. 299) "[...] não podem ser generalizados para observações não pertencentes à amostra utilizada pelo pesquisador". 


\subsection{Análise detalhada dos diversos fatores da utilização da informação contábil}

\subsubsection{Características ambientais - fator "dinamismo"}

Esse fator é identificado por meio da questão 2 da parte 3 do questionário.

a) Aplicação do teste do qui-quadrado fator "dinamismo".

$\mathrm{Na}$ aplicação do teste do qui-quadrado foi rejeitada a hipótese de independência nas seguintes variáveis:

\begin{tabular}{|c|c|c|c|}
\hline \multicolumn{4}{|c|}{ Quadro 11 - Teste do qui-quadrado fator "dinamismo" } \\
\hline $\begin{array}{c}\text { Itens da } \\
\text { questão } 2 \\
-2^{\mathrm{a}} \text {. parte }\end{array}$ & Variável & $\begin{array}{l}\text { Itens da parte } 1 \\
\text { - questões I a III }\end{array}$ & $\begin{array}{c}\text { p-valor } \\
\text { (teste qui-quadrado) }\end{array}$ \\
\hline Item b & Atitudes da concorrência & Item I C & 0,007 \\
\hline Item c & Demanda do mercado & Item I C & 0,015 \\
\hline Item d & $\begin{array}{l}\text { Características dos produtos } \\
\text { lançados }\end{array}$ & Item III F & 0,051 \\
\hline Item e & $\begin{array}{l}\text { Disponibilidades de } \\
\text { insumos }\end{array}$ & Item I a & 0,011 \\
\hline Item $\mathrm{f}$ & Preço dos insumos & Item I a & 0,028 \\
\hline Item $g$ & $\begin{array}{l}\text { Regulamentação política do } \\
\text { mercado }\end{array}$ & Item I c & 0,022 \\
\hline
\end{tabular}

Dessa forma, a variável "tecnologia necessária para a produção", por ter um resultado superior a 5\% no teste do qui-quadrado, não pode ser analisada com a aplicação da HOMALS.

b) Inércia das dimensões

b.1) Variável "atitudes da concorrência"

Tabela 5 - Inércia "atitudes da concorrência" MULTIPLE CORRES VARIABLES=IaIbIc Id Ie If IIaIIbIIcIIdIIeIIfIIIaIIIbIIIcIIIdIIIeIIIf b2 Model Summary

\begin{tabular}{c|c|c|c|c}
\hline \multirow{2}{*}{ Dimension } & \multirow{2}{*}{$\begin{array}{c}\text { Cronbach's } \\
\text { alpha }\end{array}$} & \multicolumn{3}{|c}{ Variance accounted for } \\
\cline { 3 - 5 } & $\begin{array}{c}\text { Total } \\
\text { (Eigenvalue) }\end{array}$ & Inertia & \% of variance \\
\hline 1 &, 941 & 9,202 &, 484 & 48,429 \\
2 &, 885 & 6,191 &, 326 & 32,584 \\
3 &, 836 & 4,809 &, 253 & 25,309 \\
4 &, 822 & 4,528 &, 238 & 23,830 \\
Total &, $885^{\text {a }}$ & 6,729 & 1,302 & \\
Mean & Cring & 6,325 & 32,538 \\
\hline
\end{tabular}

a. Mean Cronbach's Alpha is based on the mean Eigenvalue. 
b.2 ) Variável "demanda do mercado"

Tabela 6 - Inércia "demanda do mercado"

MULTIPLE CORRES VARIABLES=IaIbIc Id Ie If IIaIIbIIcIIdIIeIIfIIIaIIIbIIIcIIIdIIIIIIIIf c2

ModelSummary

\begin{tabular}{|c|c|c|c|c|}
\hline \multirow[b]{2}{*}{ Dimension } & \multirow{2}{*}{$\begin{array}{l}\text { Cronbach's } \\
\text { alpha }\end{array}$} & \multicolumn{3}{|c|}{ Variance accounted for } \\
\hline & & $\begin{array}{c}\text { Total } \\
\text { (Eigenvalue) }\end{array}$ & Inertia & $\%$ of variance \\
\hline 1 & ,940 & 9,123 & ,480 & 48,016 \\
\hline 2 & ,885 & 6,195 & ,326 & 32,603 \\
\hline 3 &, 833 & 4,747 & 250 & 24,987 \\
\hline 4 & ,822 & 4,519 & ,238 & 23,787 \\
\hline Total & & 24,585 & 1,294 & \\
\hline Mean &, $884^{\mathrm{a}}$ & 6,146 & ,323 & 32,348 \\
\hline
\end{tabular}

a. Mean Cronbach's Alpha is based on the mean Eigenvalue.

b.3) Variável "características dos produtos lançados"

Tabela 7 - Inércia "características dos produtos lançados"

MULTIPLE CORRES VARIABLES=IaIbIc Id Ie If IIaIIbIIcIIdIIIIIIIIIIIIIIbIIIcIIIdIIIIeIIIf d2 ModelSummary

\begin{tabular}{l|r|r|r|r}
\hline \multirow{2}{*}{ Dimension } & \multirow{2}{*}{$\begin{array}{c}\text { Cronbach's } \\
\text { alpha }\end{array}$} & \multicolumn{3}{|c}{ Variance accounted for } \\
\cline { 3 - 5 } &, 940 & 9,138 &, 481 & 48,096 \\
& Total & Inertia & \% of variance \\
\hline 1 &, 885 & 6,200 &, 326 & 32,633 \\
2 &, 836 & 4,810 &, 253 & 25,317 \\
3 &, 822 & 4,512 &, 237 & 23,747 \\
4 & & 24,661 & 1,298 & \\
Total &, $884^{\mathrm{a}}$ & 6,165 &, 324 & 32,448 \\
Mean &
\end{tabular}

a. Mean Cronbach's Alpha is based on the mean Eigenvalue.

b.4) Variável "disponibilidade de insumos"

Tabela 8 - Inércia "disponibilidade de insumos"

MULTIPLE CORRES VARIABLES=IaIbIc Id Ie If IIaIIbIIcIIdIIeIIfIIIaIIIbIIIcIIIdIIIeIIIf e2 ModelSummary

\begin{tabular}{|c|c|c|c|c|}
\hline \multirow[b]{2}{*}{ Dimension } & \multirow{2}{*}{$\begin{array}{l}\text { Cronbach's } \\
\text { alpha }\end{array}$} & \multicolumn{3}{|c|}{ Variance accounted for } \\
\hline & & $\begin{array}{c}\text { Total } \\
\text { (Eigenvalue) }\end{array}$ & Inertia & $\%$ of variance \\
\hline 1 & ,941 & 9,188 &, 484 & 48,359 \\
\hline 2 & ,887 & 6,272 & 330 & 33,012 \\
\hline 3 & ,837 & 4,829 &, 254 & 25,418 \\
\hline 4 & ,822 & 4,511 &, 237 & 23,744 \\
\hline Total & & 24,801 & 1,305 & \\
\hline Mean &, $885^{\mathrm{a}}$ & 6,200 & ,326 & 32,633 \\
\hline
\end{tabular}

a. Mean Cronbach's Alpha is based on the mean Eigenvalue. 
b.5) Variável "preço dos insumos"

Tabela 9 - Inércia "preço dos insumos"

MULTIPLE CORRES VARIABLES=IaIbIc Id Ie If IIaIIbIIcIIdIIeIIfIIIaIIIbIIIcIIIdIIIeIIIf f2

ModelSummary

\begin{tabular}{l|r|r|r|r}
\hline \multirow{2}{*}{ Dimension } & Cronbach's alpha & \multicolumn{3}{|c}{ Variance accounted for } \\
\cline { 3 - 5 } &, 940 & $\begin{array}{c}\text { Total } \\
\text { (Eigenvalue) }\end{array}$ & Inertia & \% of variance \\
\hline 1 &, 887 & 9,149 &, 482 & 48,155 \\
2 &, 841 & 6,247 &, 329 & 32,881 \\
3 &, 830 & 4,911 &, 258 & 25,846 \\
4 &, $887^{\mathrm{a}}$ & 4,681 &, 246 & 24,637 \\
Total & 24,989 & 1,315 & \\
Mean & 6,247 &, 329 & 32,880 \\
\hline
\end{tabular}

a. Mean Cronbach's Alpha is based on the mean Eigenvalue.

b.6) Inércia variável "regulamentação política do setor"

Tabela 10 - Inércia "regulamentação política do setor"

MULTIPLE CORRES VARIABLES=IaIbIc Id Ie If IIaIIbIIcIIdIIeIIfIIIaIIIbIIIcIIIdIIIeIIIf g2

ModelSummary

\begin{tabular}{|l|r|r|r|r|}
\hline \multirow{2}{*}{ Dimension } & \multirow{2}{*}{$\begin{array}{c}\text { Cronbach's } \\
\text { alpha }\end{array}$} & \multicolumn{3}{|c|}{\begin{tabular}{c} 
Variance accounted for \\
\cline { 3 - 5 }
\end{tabular}} \\
\cline { 3 - 5 } &, 940 & 9,165 &, 482 & 48,235 \\
\hline 1 &, 885 & 6,173 &, 325 & 32,492 \\
3 &, 837 & 4,827 &, 254 & 25,403 \\
4 &, 825 & 4,580 &, 241 & 24,103 \\
Total &, $885^{\mathrm{a}}$ & 24,744 & 1,302 & \\
Mean & & 6,186 &, 326 & 32,558 \\
\hline
\end{tabular}

a. Mean Cronbach's Alpha is based on the mean Eigenvalue. 
c) Mapas perceptuais

c.1) Mapa perceptual da variável "atitudes da concorrência" relacionada às variáveis "utilização da informação contábil"

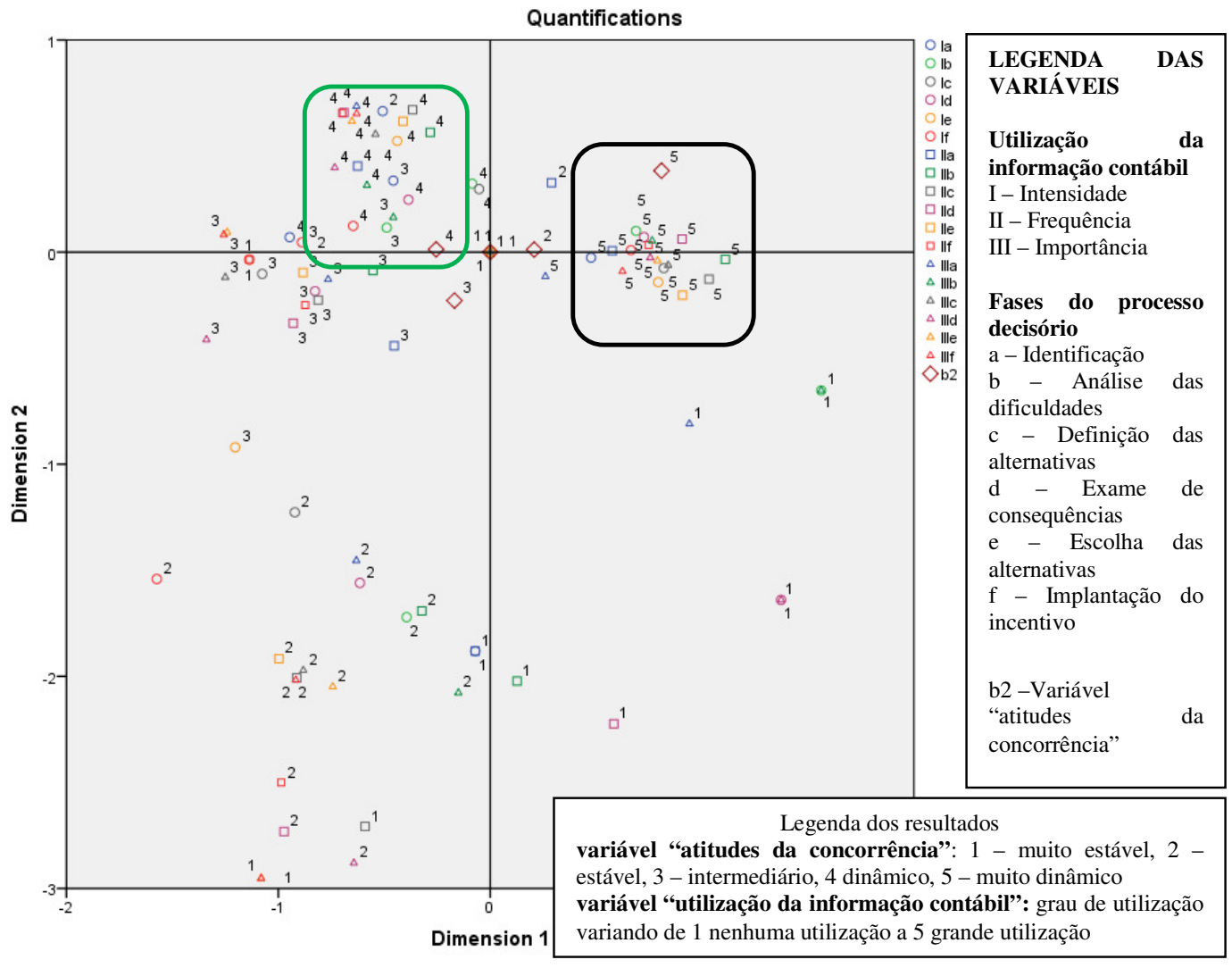

Gráfico 1 - Mapa perceptual "atitudes da concorrência"

O gráfico apresenta duas relações.

Na primeira, verifica-se que a variável "atitudes da concorrência", variável b2 com o número 5, que significa ambiente muito dinâmico, está relacionada com a utilização da informação contábil em todas as fases: intensidade, frequência e importância (variáveis I, II e III) com o número 5 que significa grande utilização. No gráfico, essa relação está assinalada com um quadrado na cor preta.

Na segunda, verifica-se que a variável "atitudes da concorrência", variável b2 com o número 4, que significa ambiente dinâmico, está relacionada com uma significativa utilização da informação contábil em todas as fases: intensidade, frequência e importância (variáveis I, II e II) com o número 4 e alguns números 3 que representam respectivamente significativa 
utilização da informação contábil e razoável utilização da informação contábil. No gráfico, essa relação está assinalada com um quadrado na cor verde.

c.2) Mapa perceptual da variável "demanda de mercado" relacionada às variáveis de "utilização da informação contábil"

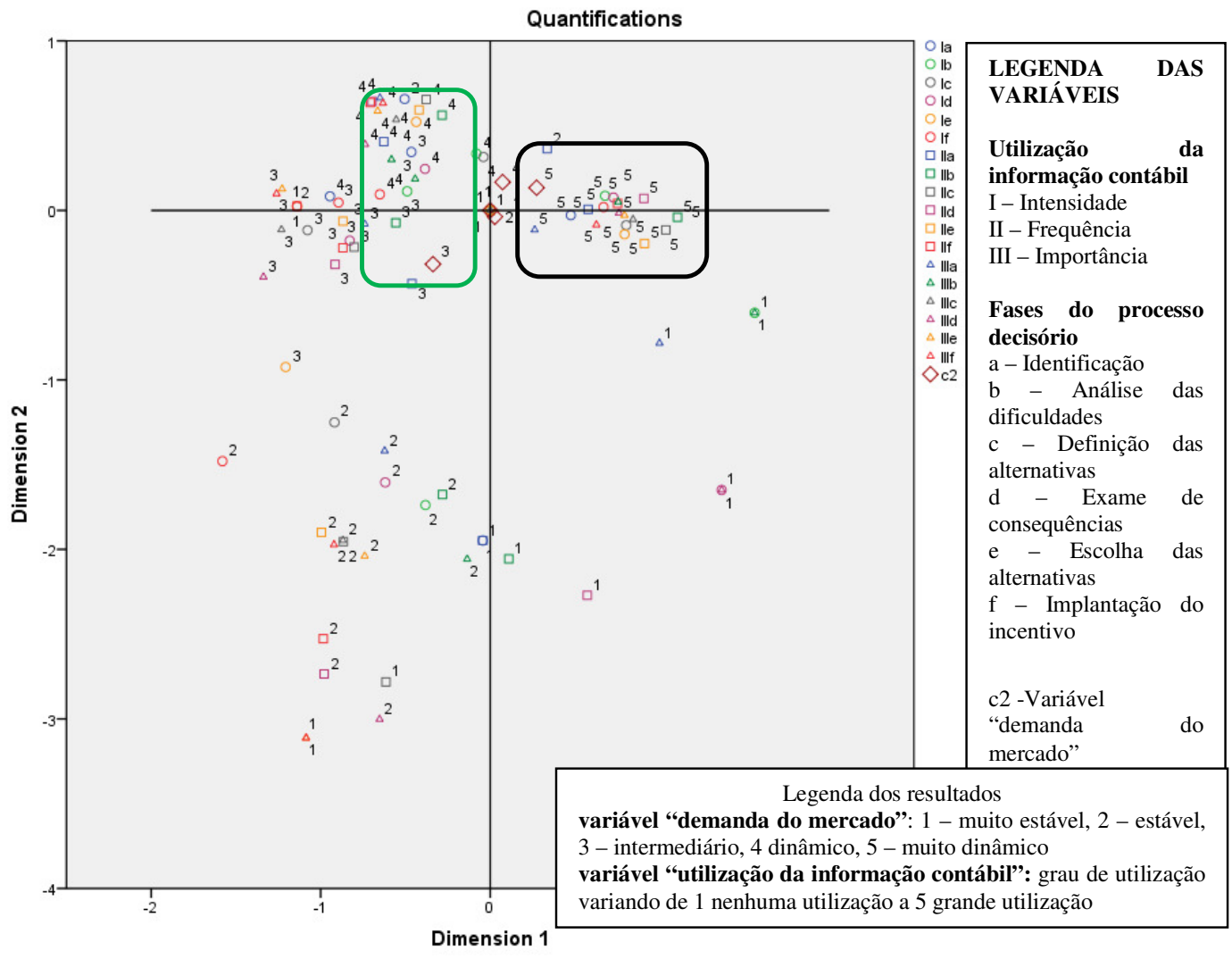

Gráfico 2 - Mapa perceptual "demanda de mercado"

O gráfico apresenta duas relações.

Na primeira, verifica-se que a variável "demanda de mercado", variável c2 com o número 5, que significa ambiente muito dinâmico, está relacionada com a utilização da informação contábil em todas as fases: intensidade, frequência e importância (variáveis I, II e III) com o número 5 como resultado que significa grande utilização. No gráfico, essa relação está assinalada com um quadrado na cor preta.

Na segunda, verifica-se que a variável "demanda de mercado", variável c2 com o número 3, que significa ambiente com dinamismo intermediário, está relacionada a uma utilização da informação contábil em todas as fases: intensidade, frequência e importância (variáveis I, II e 
III) com o número 4 e alguns números 3 que representam, respectivamente, significativa utilização da informação contábil e razoável utilização da informação contábil. No gráfico, essa correlação está assinalada com um quadrado na cor verde.

c.3) Mapa perceptual da variável "características dos produtos lançados no mercado" relacionada às variáveis de "utilização da informação contábil".

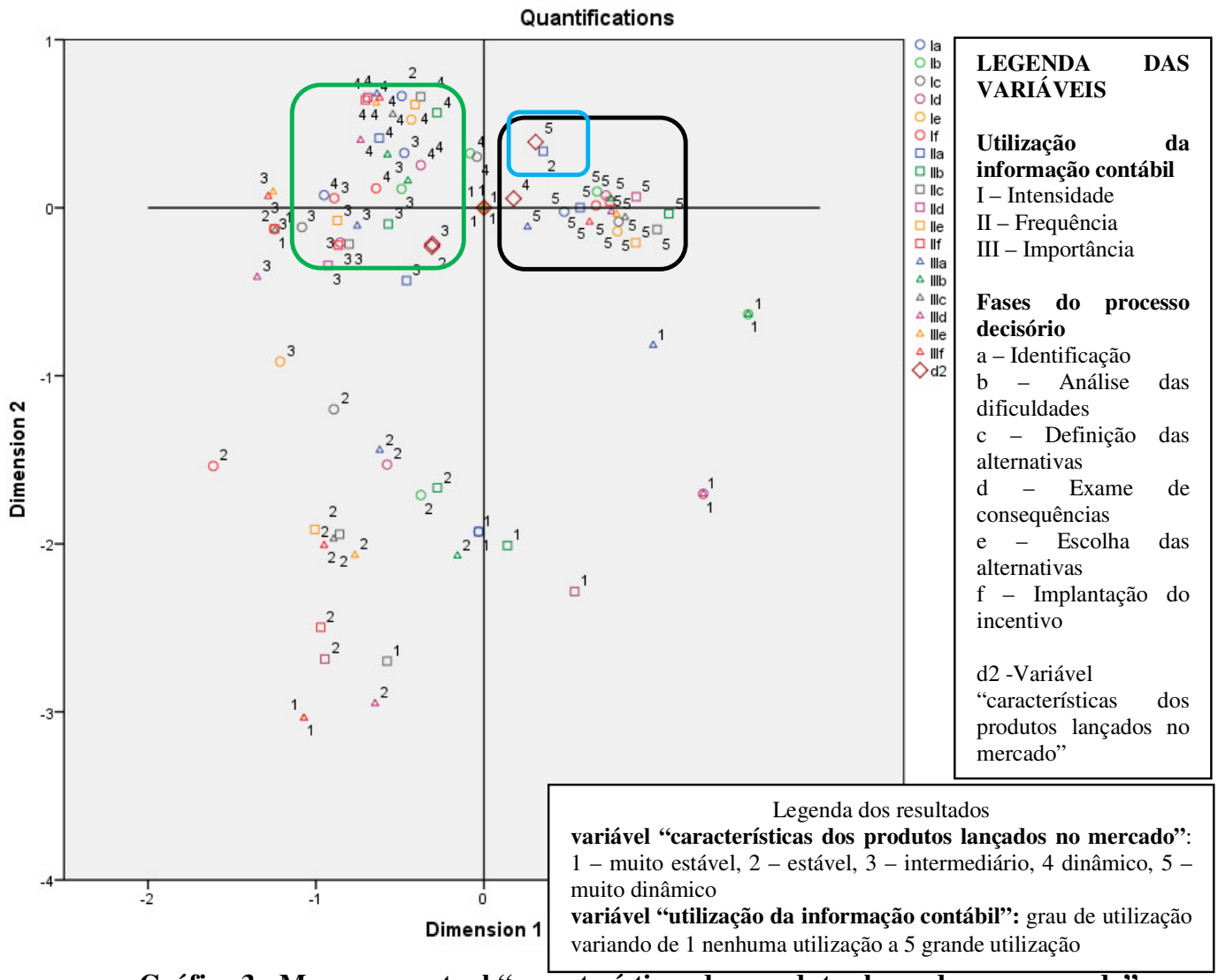

Gráfico 3 - Mapa perceptual "características dos produtos lançados no mercado"

O gráfico apresenta três relações.

Na primeira, verifica-se que a variável "características dos produtos lançados no mercado", variável d2 com os números 4 e 5 , que significam respectivamente ambiente dinâmico e muito dinâmico, está relacionada com a utilização da informação contábil em todas as fases: intensidade, frequência e importância (variáveis I, II e III), com o número 5 como resultado que significa grande utilização. No gráfico, essa relação está assinalada com um quadrado na cor preta. Note-se, ainda, que existe uma segunda relação diferente do padrão normal observado, uma vez que a variável d2 com o número 5 está muito próxima da variável "utilização da informação contábil" no aspecto da freqüência, na fase de identificação do 
incentivo com o número 2 que significa uma pequena utilização da informação contábil. Essa relação está destacada com um quadrado na cor azul.

$\mathrm{Na}$ terceira, relação verifica-se que a variável "demanda de mercado", variável d2 com os números 2 e 3 (as variáveis encontram-se praticamente sobrepostas), que significam ambiente estável e ambiente intermediário, está relacionada com a utilização da informação contábil em todas as fases: intensidade, frequência e importância (variáveis I, II e III) com o número 4 e alguns números 3 que representam respectivamente significativa utilização da informação contábil e razoável utilização da informação contábil. No gráfico, essa correlação está assinalada com um quadrado na cor verde.

c.4) Mapa perceptual da variável "disponibilidade de insumos" relacionada às variáveis de "utilização da informação contábil"

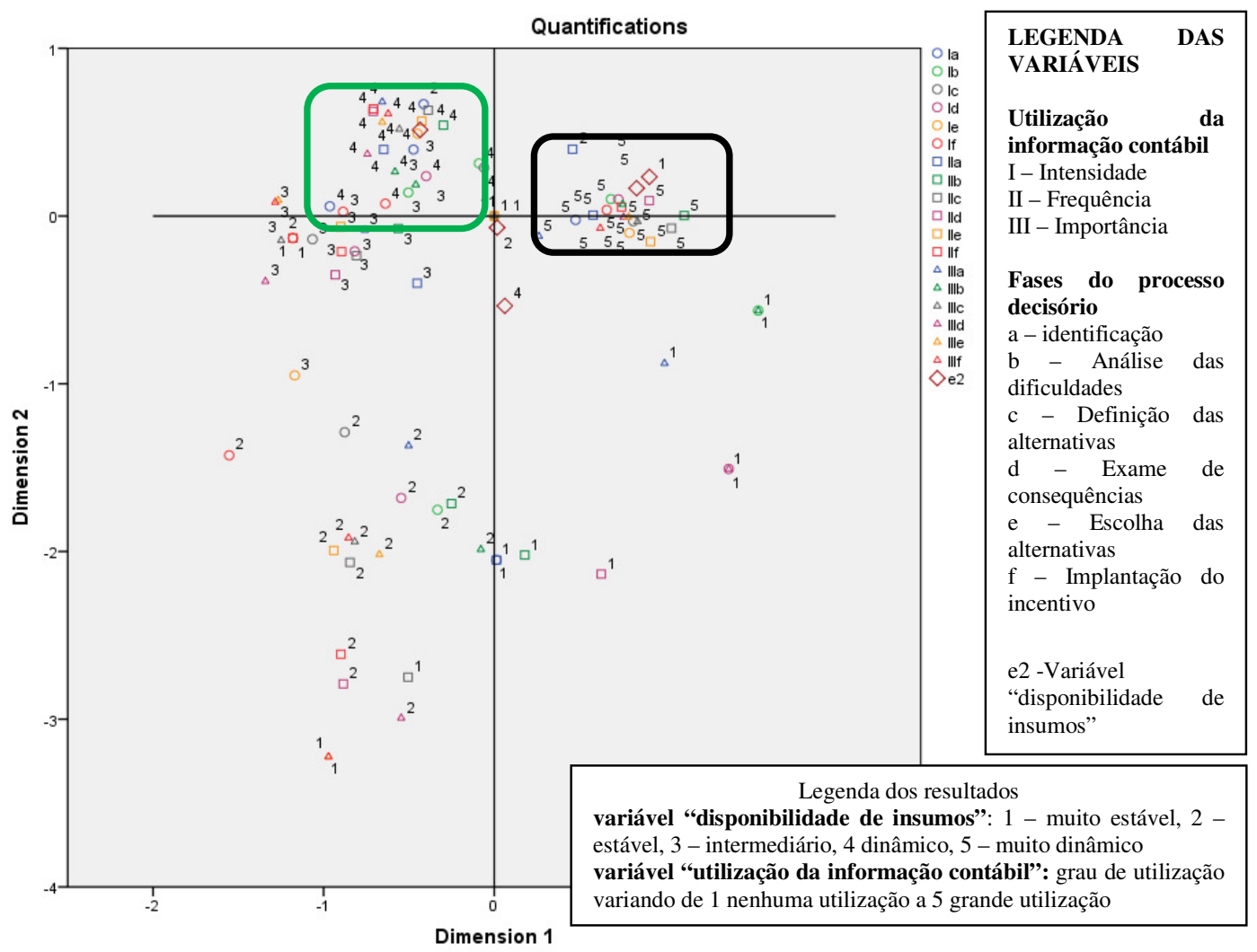

Gráfico 4 - Mapa perceptual "disponibilidade de insumos"

O gráfico apresenta duas relações.

Na primeira, verifica-se que a variável "disponibilidade de insumos", variável e2 com os números 5 e 1, que significam respectivamente disponibilidade de insumos muito dinâmica e 
disponibilidade de insumos muito estável, estão relacionadas à utilização da informação contábil em todas as fases: intensidade, frequência e importância (variáveis I, II e III) com o número 5 como resultado que significa grande utilização. Note-se que não se trata de um paradoxo, apenas se verifica que, em situações extremas, a informação contábil é utilizada. No gráfico, essa relação está assinalada com um quadrado na cor preta.

Na segunda, verifica-se que a disponibilidade de insumos, variável e2 com o número 3, que significa disponibilidade intermediária, está relacionada com a utilização da informação contábil em todas as fases: intensidade, frequência e importância (variáveis I, II e III) com o número 4 e alguns números 3 que representam respectivamente significativa utilização da informação contábil e razoável utilização da informação contábil. No gráfico, essa relação está assinalada com um quadrado na cor verde.

c.5) Mapa perceptual relação da variável "preço dos insumos" relacionada às variáveis de "utilização da informação contábil"

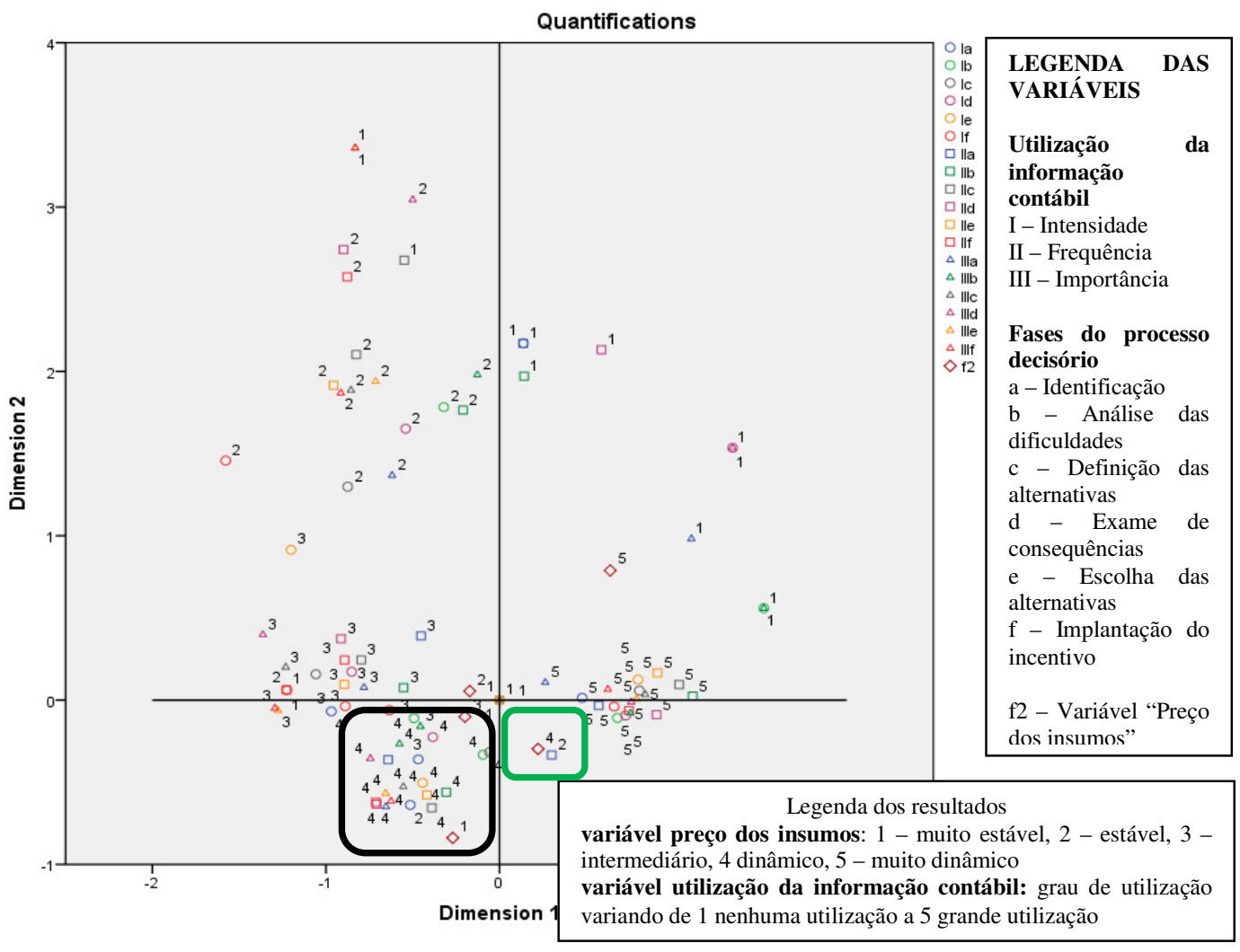

Gráfico 5 - Mapa perceptual "preço dos insumos"

O gráfico apresenta duas relações. 
Na primeira, verifica-se que a variável "preço dos insumos", variável f2 com o número 1, que significa preço dos insumos muito estável, está relacionada à utilização da informação contábil em todas as fases: intensidade, frequência e importância (variáveis I, II e III) com o número 4 que representa significativa utilização da informação contábil e com alguns números 3 que significa utilização mediana e um número 2 que significa pequena utilização, sendo que, nesse caso, se trata do aspecto da frequência na fase de definição de alternativas. No gráfico, essa relação está assinalada com um quadrado na cor preta.

$\mathrm{Na}$ segunda, existe uma relação diferente do padrão normal observado, uma vez que a variável f2 com o número 4 que significa preço dos insumos dinâmicos está muito próxima da variável utilização da informação contábil com o número 2 que significa uma pequena utilização da informação contábil, no aspecto da frequência, na fase de identificação. Essa relação está destacada com um quadrado na cor verde.

c.6) Mapa perceptual relação da variável "regulamentação política do setor" relacionada as variáveis de "utilização da informação contábil"

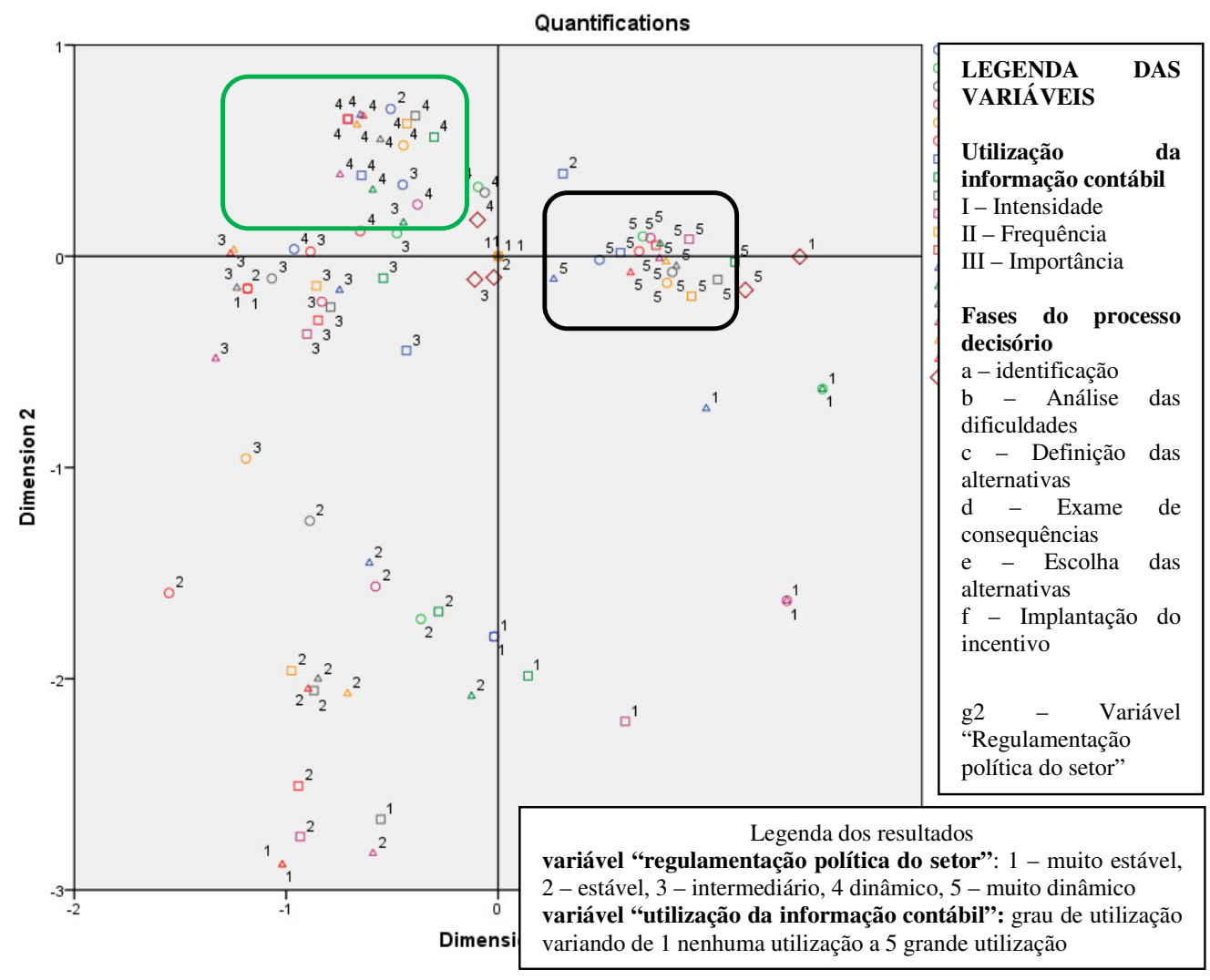

Gráfico 6 - Mapa perceptual "regulamentação política do setor" 
O gráfico apresenta duas relações.

Na primeira, verifica-se que a variável "regulamentação política do setor", variável g2 com o número 5 que significa regulamentação muito dinâmica, está relacionada com a utilização da informação contábil em todas as fases: intensidade, frequência e importância (variáveis I, II e III) com o número 5 como resultado que significa grande utilização.

Na segunda, verifica-se que a variável "regulamentação política do setor", variável f2 com o número 4, que significa regulamentação dinâmica do setor, está relacionada à utilização da informação contábil em todas as fases: intensidade, frequência e importância (variáveis I, II e III) com o número 4 e alguns números 3 que representam respectivamente significativa utilização da informação contábil e razoável utilização da informação contábil. No gráfico, essa relação está assinalada com um quadrado na cor verde.

\subsubsection{Características ambientais - fator "heterogeneidade"}

Esse fator é identificado por meio da questão 3 da parte 3 do questionário

a) Aplicação do teste do qui-quadrado

Na aplicação do teste do qui-quadrado, foi rejeitada a hipótese de independência nas variáveis apresentadas no Quadro 12.

Quadro 12 - Teste do qui-quadrado fator "heterogeneidade"

\begin{tabular}{|l|l|l|r|}
\hline $\begin{array}{c}\text { Itens da questão } \\
\text { 3- Parte 2 }\end{array}$ & \multicolumn{1}{|c|}{ Variável } & $\begin{array}{c}\text { Itens da parte 1 } \\
\text { - questões I a III }\end{array}$ & $\begin{array}{c}\text { p-valor (teste } \\
\text { qui-quadrado) }\end{array}$ \\
\hline Item a & Características dos produtos no mercado & Item I A & 0,000 \\
\hline Item d & Características dos concorrentes & Item III D & 0,004 \\
\hline Item e & Características dos clientes & Item I D & 0,035 \\
\hline
\end{tabular}

Dessa forma, as variáveis "tecnologia de produção/comercialização/serviço" e "características dos fornecedores", por terem um resultado superior a 5\% no teste do quiquadrado, não podem ser analisadas com a aplicação da HOMALS. 
b) Inércia das dimensões

b.1) Variável "característica dos produtos encontrados no mercado"

Tabela 11 - Inércia "características dos produtos encontrados no mercado" MULTIPLE CORRES VARIABLES=IaIbIc Id Ie If IIaIIbIIcIIdIIeIIfIIIaIIIbIIIcIIIdIIIeIIIf a3 ModelSummary

\begin{tabular}{|c|c|c|c|c|}
\hline \multirow[b]{2}{*}{ Dimension } & \multirow{2}{*}{$\begin{array}{c}\text { Cronbach's } \\
\text { alpha }\end{array}$} & \multicolumn{3}{|c|}{ Variance accounted for } \\
\hline & & $\begin{array}{c}\text { Total } \\
\text { (Eigenvalue) }\end{array}$ & Inertia & $\%$ of variance \\
\hline 1 & ,940 & 9,131 & ,481 & 48,058 \\
\hline 2 & ,885 & 6,187 & ,326 & 32,562 \\
\hline 3 & ,836 & 4,809 & ,253 & 25,311 \\
\hline 4 & ,820 & 4,486 & ,236 & 23,611 \\
\hline Total & & 24,613 & 1,295 & \\
\hline Mean &, $884^{\mathrm{a}}$ & 6,153 & ,324 & 32,386 \\
\hline
\end{tabular}

a. Mean Cronbach's Alpha is based on the mean Eigenvalue.

b.2) Variável "características dos concorrentes"

Tabela 12 - Inércia "características dos concorrentes" MULTIPLE CORRES VARIABLES=IaIbIc Id Ie If IIaIIbIIcIIdIIeIIfIIIaIIIbIIIcIIIdIIIeIIIf d3 ModelSummary

\begin{tabular}{l|r|r|r|r}
\hline \multirow{2}{*}{ Dimension } & \multirow{2}{*}{$\begin{array}{c}\text { Cronbach's } \\
\text { alpha }\end{array}$} & \multicolumn{3}{|c}{ Variance accounted for } \\
\cline { 3 - 5 } &, 940 & 9,127 &, 480 & 48,039 \\
&, 886 & 6,208 &, 327 & 32,675 \\
\hline 1 &, 836 & 4,818 &, 254 & 25,358 \\
2 &, 820 & 4,479 &, 236 & 23,576 \\
3 & & 24,633 & 1,296 & \\
4 &, $884^{\mathrm{a}}$ & 6,158 &, 324 & 32,412 \\
Total & Eigenvalue) & Inertia & \% variance \\
Mean &
\end{tabular}

a. Mean Cronbach's Alpha is based on the mean Eigenvalue.

b.3) Variável "característica dos clientes"

Tabela 13 - Inércia "características dos clientes" MULTIPLE CORRES VARIABLES=IaIbIc Id Ie If IIaIIbIIcIIdIIeIIfIIIaIIIbIIIcIIIdIIIeIIIf e3 ModelSummary

\begin{tabular}{l|r|r|r|r}
\hline \multirow{2}{*}{ Dimension } & \multirow{2}{*}{$\begin{array}{c}\text { Cronbach's } \\
\text { alpha }\end{array}$} & \multicolumn{3}{|c}{ Variance accounted for } \\
\cline { 3 - 5 } &, 941 & 9,205 &, 484 & 48,445 \\
& Total & Inertia & \% of variance \\
\hline 1 &, 886 & 6,222 &, 327 & 32,749 \\
2 &, 838 & 4,841 &, 255 & 25,480 \\
3 &, 825 & 4,587 &, 241 & 24,143 \\
4 & & 24,855 & 1,308 & 32,704 \\
Total &, $886^{\text {a }}$ & 6,214 &, 327 & 327 \\
Mean &
\end{tabular}

a. Mean Cronbach's Alpha is based on the mean Eigenvalue. 
c) Mapas perceptuais

c.1) Mapa perceptual da variável "características dos produtos encontrados no mercado" relacionada às variáveis de "utilização da informação contábil"

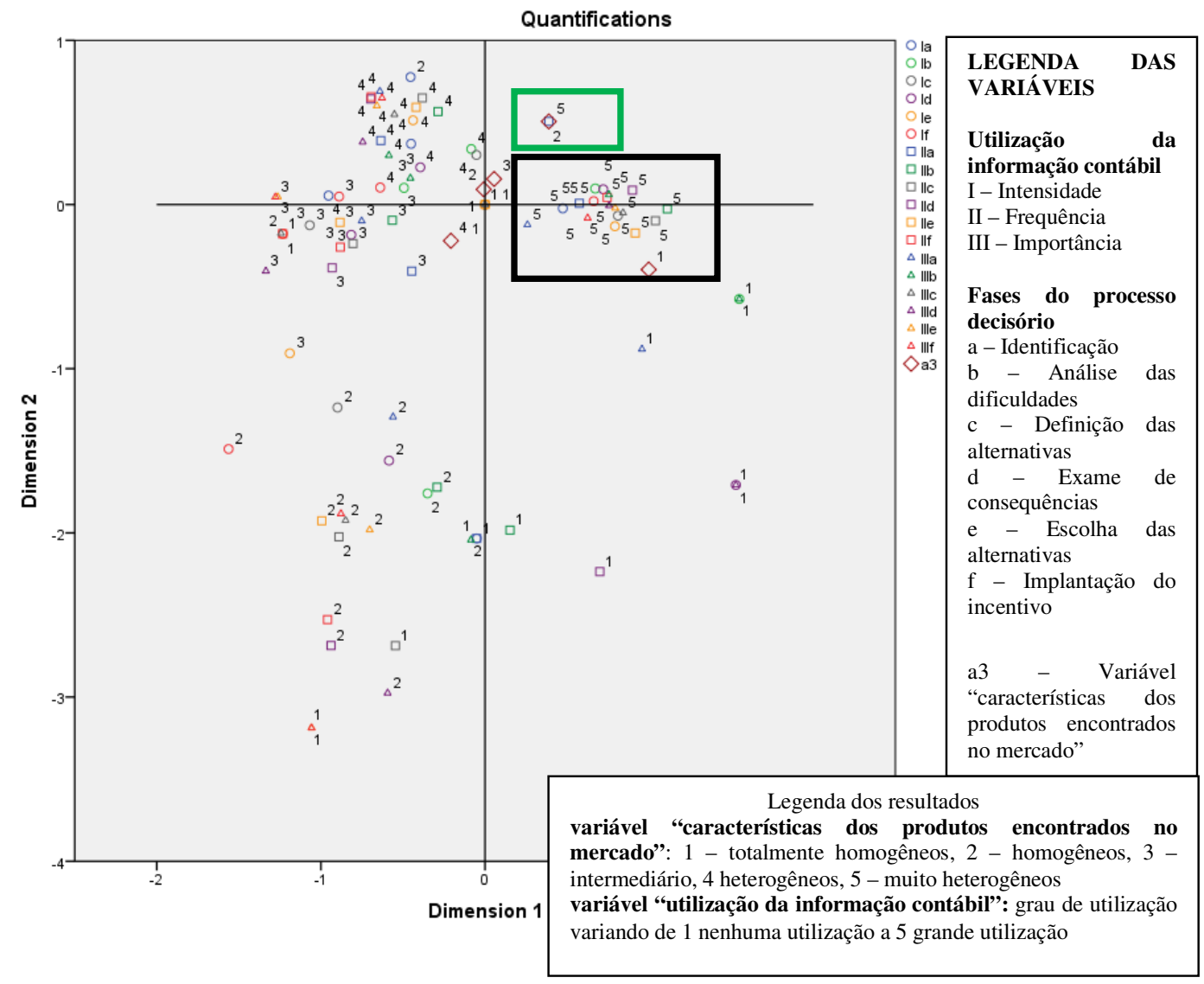

Gráfico 7 - Mapa perceptual "características dos produtos encontrados no mercado"

O gráfico apresenta duas relações.

Na primeira, verifica-se que a variável "características dos produtos lançados no mercado", variável a3 com o número 1, que significa produtos encontrados no mercado totalmente homogêneos, está relacionada à utilização da informação contábil em todas as fases: intensidade, frequência e importância (variáveis I, II e III) com o número 5 como resultado o que significa grande utilização. No gráfico, essa relação está assinalada com um quadrado na cor preta.

$\mathrm{Na}$ segunda, existe uma relação diferente do padrão normal observado, uma vez que a variável a3 com o número 5 que significa produtos encontrados no mercado muito heterogêneos está muito próxima da variável "utilização da informação contábil” com o 
número 2, que significa uma pequena utilização da informação contábil no aspecto da frequência na fase de identificação. Essa relação está destacada com um quadrado na cor verde.

c.2) Mapa perceptual da variável "características dos concorrentes" relacionada às variáveis de "utilização da informação contábil"

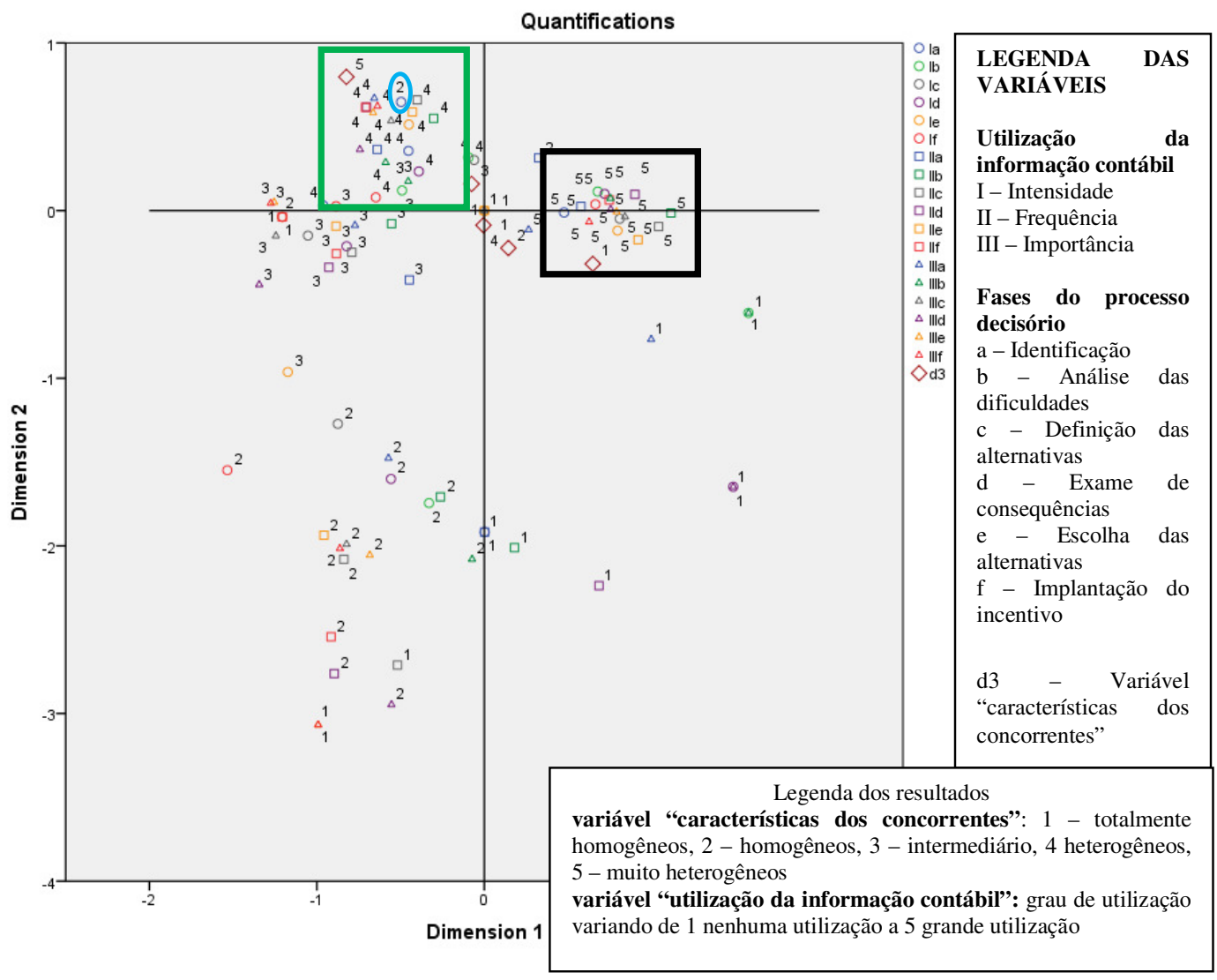

Gráfico 8 - Mapa perceptual "características dos concorrentes"

O gráfico apresenta duas relações.

Na primeira, verifica-se que a variável "características dos concorrentes”, variável d3 com o números 1 , que significa concorrentes totalmente homogêneos, está relacionada à utilização da informação contábil em todas as fases: intensidade, frequência e importância (variáveis I, II e III) com o número 5 como resultado que significa grande utilização. No gráfico, essa relação está assinalada com um quadrado na cor preta. 
$\mathrm{Na}$ segunda, verifica-se que a variável "características dos concorrentes", variável d3 com o números 5, que significa concorrentes muito heterogêneos, está relacionados com a utilização da informação contábil em todas as fases: intensidade, frequência e importância (variáveis I, II e III) com o número 4 e alguns números 3 que representam respectivamente significativa utilização da informação contábil e razoável utilização da informação contábil. No gráfico, essa relação está assinalada com um quadrado na cor verde.

Destaca-se, ainda, uma relação da variável d3 com o número 5 com a variável Ia que significa pequena utilização da informação contábil no aspecto da intensidade na fase de identificação do benefício Essa variável está destacada com a cor azul.

c.3) Mapa perceptual da variável "características dos clientes" relacionada às variáveis de "utilização da informação contábil".

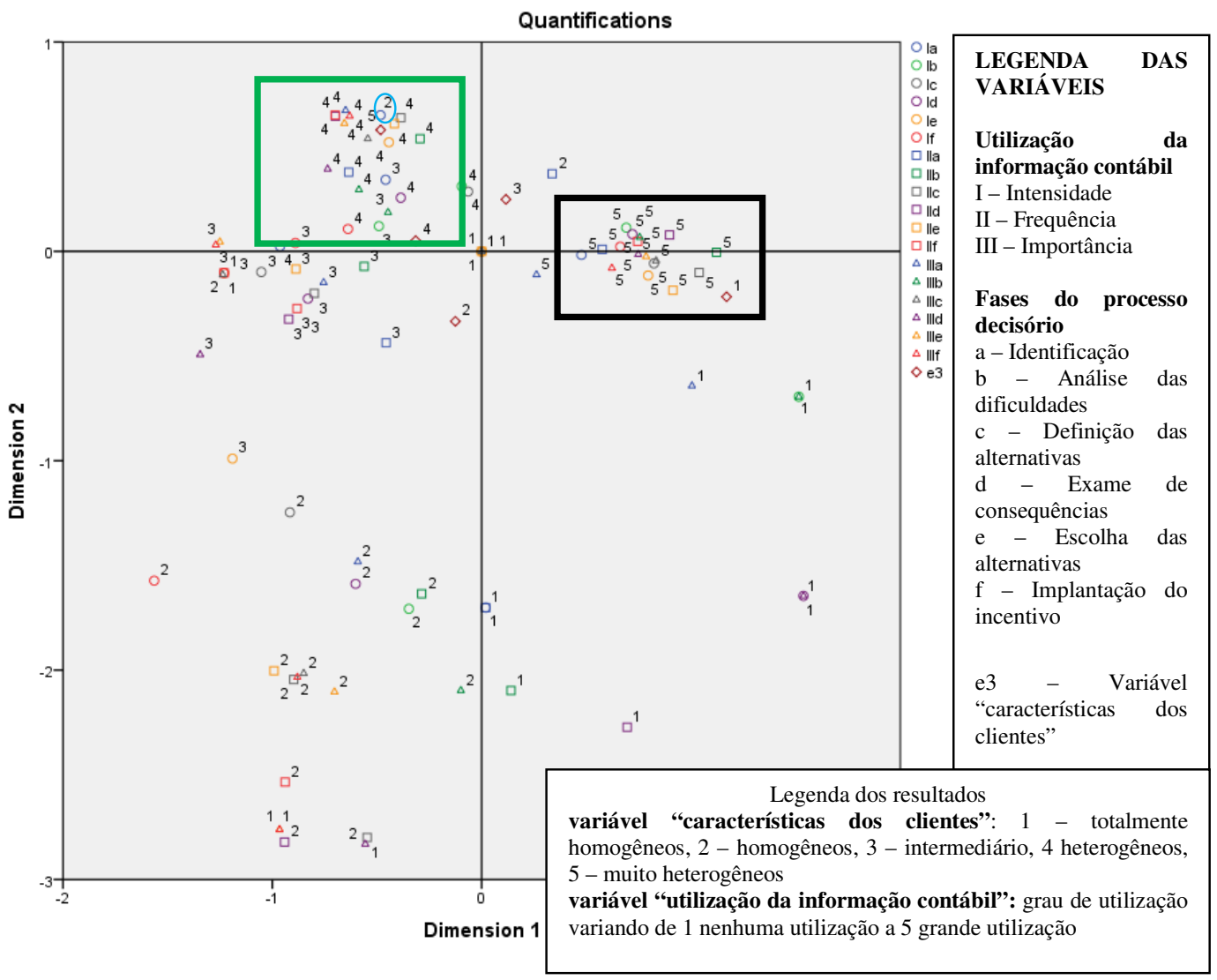

Gráfico 9 - Mapa perceptual “características dos clientes” 
O gráfico apresenta duas relações.

$\mathrm{Na}$ primeira, verifica-se que a variável "características dos clientes", variável e3 com o número 1, que significa clientes totalmente homogêneos, está relacionada à utilização da informação contábil em todas as fases: intensidade, frequência e importância (variáveis I, II e III) com o número 5 como resultado que significa grande utilização. No gráfico, essa correlação está assinalada com um quadrado na cor preta.

Na segunda, verifica-se que a variável "características dos clientes”, variável e3 com o número 5, que significa clientes muito heterogêneos, está relacionado com a utilização da informação contábil em todas as fases: intensidade, frequência e importância (variáveis I, II e III) com o número 4 e alguns números 3 que representam respectivamente significativa utilização da informação contábil e razoável utilização da informação contábil. No gráfico, essa relação está assinalada com um quadrado na cor verde.

Destaca-se, ainda, a relação da variável e3 número 5 com a utilização da informação contábil no aspecto intensidade na identificação do incentivo, variável Ia com o resultado de número 2 que representa pequena utilização. A variável Ia está destacada com a cor azul.

\subsubsection{Características ambientais - fator "hostilidade"}

Este fator é identificado através da questão 6 da parte 3 do questionário

a) Aplicação do teste do qui-quadrado fator "hostilidade"

Na aplicação do teste do qui-quadrado, foi rejeitada a hipótese de independência nas variáveis apontadas no Quadro 13.

Quadro 13 - Teste do qui-quadrado fator "hostilidade"

\begin{tabular}{|l|l|l|l|}
\hline $\begin{array}{c}\text { Itens da questão } \\
6-2^{\text {a }} \text {. parte }\end{array}$ & \multicolumn{1}{|c|}{ Variável } & $\begin{array}{c}\text { Itens da parte 1 - } \\
\text { questões I a III }\end{array}$ & P-valor (teste qui-quadrado) \\
\hline Item a & Mercado saturado & Item I A & 0,001 \\
\hline Item c & Mercado restritivo & Item I D & 0,004 \\
\hline
\end{tabular}

Dessa forma, a variável mercado dominado, por ter resultado superior a 5\% no teste do quiquadrado, não pode ser analisada com a aplicação da HOMALS. 
b) Inércia das dimensões

b.1) Variável mercado saturado

Tabela 14 - Inércia "mercado saturado" MULTIPLE CORRES VARIABLES=IaIbIc Id Ie If IIaIIbIIcIIdIIeIIfIIIaIIIbIIIcIIIdIIIeIIIf a6 ModelSummary

\begin{tabular}{l|r|r|r}
\hline \multirow{2}{*}{ Dimension } & \multirow{2}{*}{ Cronbach's alpha } & \multicolumn{2}{|c}{ Variance accounted for } \\
\cline { 3 - 4 } &, 940 & Total (Eigenvalue) & \multicolumn{1}{|c}{ Inertia } \\
\hline 1 &, 892 & 9,156 &, 482 \\
2 &, 858 & 6,444 &, 339 \\
3 &, 822 & 5,348 &, 281 \\
4 & & 4,512 &, 237 \\
Total &, $890^{\mathrm{a}}$ & 25,460 & 1,340 \\
Mean & & 6,365 &, 335 \\
\hline
\end{tabular}

a. Mean Cronbach's Alpha is based on the mean Eigenvalue.

b.2) Variável "mercado restritivo"

Tabela 15 - Inércia "mercado restritivo" MULTIPLE CORRES VARIABLES=IaIbIc Id Ie If IIaIIbIIcIIdIIeIIfIIIaIIIbIIIcIIIdIIIIIIIf c6 ModelSummary

\begin{tabular}{l|r|r|r}
\hline \multirow{2}{*}{ Dimension } & \multirow{2}{*}{ Cronbach's alpha } & \multicolumn{2}{|c}{ Variance accounted for } \\
\cline { 3 - 4 } & & Total (Eigenvalue) & Inertia \\
\hline 1 &, 940 & 9,124 &, 480 \\
2 &, 884 & 6,167 &, 325 \\
3 &, 838 & 4,847 &, 255 \\
4 &, 823 & 4,532 &, 239 \\
Total & & 24,670 & 1,298 \\
Mean &, $884^{\mathrm{a}}$ & 6,167 &, 325 \\
\hline \multicolumn{2}{r}{ a. Mean Cronbach's Alpha is based on the mean Eigenvalue. }
\end{tabular}

a. Mean Cronbach's Alpha is based on the mean Eigenvalue. 
c) Mapas perceptuais

c.1) Mapa perceptual variável "mercado saturado" relacionado às variáveis de "utilização da informação contábil”

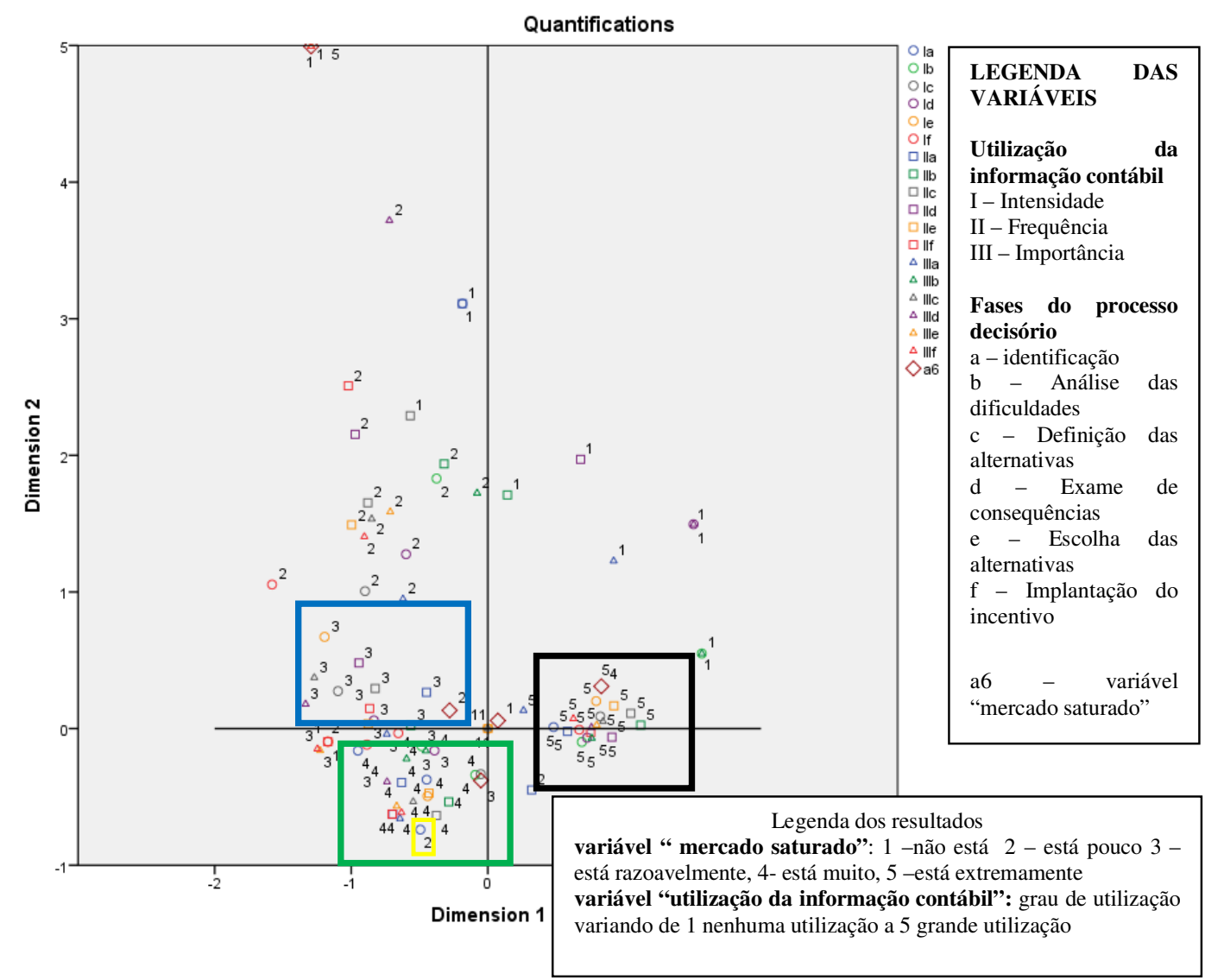

Gráfico 10 - Mapa perceptual "mercado saturado"

O gráfico apresenta três relações.

Na primeira, verifica-se que a variável "mercado saturado", variável a6 com os números 4 e 5 (os símbolos estão sobrepostos no gráfico), que significam respectivamente mercados muito e extremamente saturados, está relacionada à utilização da informação contábil em todas as fases: intensidade, frequência e importância, (variáveis I, II e III) com o número 5 como resultado que significa grande utilização. No gráfico, essa relação está assinalada com um quadrado na cor preta.

Na segunda, verifica-se que a variável “mercado saturado', variável a6 com o número 3, que significa mercado razoavelmente saturado, está relacionada com a utilização da informação 
contábil em todas as fases: intensidade, frequência e importância (variáveis I, II e III) com o número 4 e alguns números 3 que representam, respectivamente, significativa utilização da informação contábil e razoável utilização da informação contábil. No gráfico, essa relação está assinalada com um quadrado na cor verde.

Destaca-se, ainda, uma relação entre a variável a3 com o número 3 com a variável Ia com o número 2 que significa pequena utilização da informação contábil no aspecto de intensidade na identificação do incentivo. A variável Ia está destacada com a cor amarela.

$\mathrm{Na}$ terceira, verifica-se que a variável "mercado saturado", a6 com o número 2 como resultado que significa mercado pouco saturado, está relacionada com a utilização da informação contábil em todas as fases: intensidade, frequência e importância, (variáveis I, II e III) com o número 3 que representa razoável utilização da informação contábil. No gráfico, essa correlação está assinalada com um quadrado na cor azul.

c.2) Mapa perceptual da variável "mercado restritivo" relacionada às variáveis de "utilização da informação contábil"

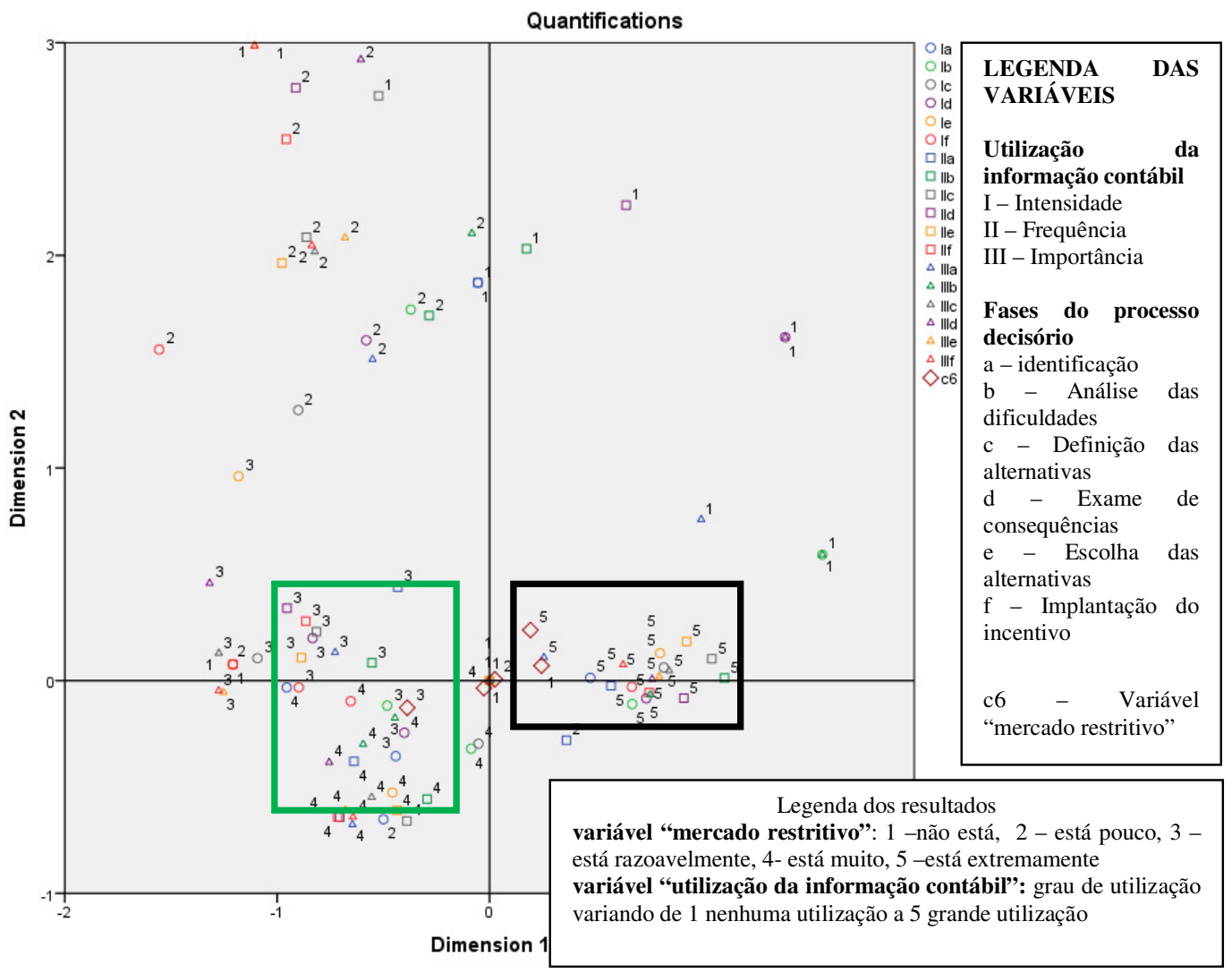

Gráfico 11 - Mapa perceptual "mercado restritivo" 
O gráfico apresenta duas relações.

Na primeira, verifica-se que a variável "mercado restritivo", variável c6 com os números 1 e 5, que significam respectivamente mercado extremamente restritivo e mercado não restritivo, está relacionada com a utilização da informação contábil em todas as fases: intensidade, frequência e importância, (variáveis I, II e III) com o número 5 como resultado, que significa grande utilização. No gráfico, essa relação está assinalada com um quadrado na cor preta.

Na segunda, verifica-se que a variável "mercado restritivo", variável c6 com o número 3, que significa mercado razoavelmente restritivo, está relacionada com a utilização da informação contábil em todas as fases: intensidade, frequência e importância, (variáveis I, II e III) com o número 4 e alguns números 3 que representam respectivamente significativa utilização da informação contábil e razoável utilização da informação contábil. No gráfico, essa relação está assinalada com um quadrado na cor verde.

\subsubsection{Características estruturais - fator "natureza"}

Esse fator é identificado mediante a questão 10 da parte 3 do questionário.

a) Aplicação do teste do qui-quadrado

Quadro 14 - Teste do qui-quadrado fator "natureza"

\begin{tabular}{|l|l|l|c|}
\hline $\begin{array}{c}\text { Itens da questão } \\
10-2^{\mathrm{a}} \text {. parte }\end{array}$ & \multicolumn{1}{|c|}{ Variável } & $\begin{array}{c}\text { Itens da parte } 1- \\
\text { questões I a III }\end{array}$ & $\begin{array}{c}\text { p-valor (teste qui- } \\
\text { quadrado) }\end{array}$ \\
\hline Item a & Capital da empresa & Item II A & 0,007 \\
\hline
\end{tabular}

Para essa única variável de característica estrutural, o teste do qui-quadrado apresenta que pode existir relação com a utilização da informação contábil. 
b) Inércia das dimensões Variável - Capital da empresa

Tabela 16 - Inércia "capital da empresa"

MULTIPLE CORRES VARIABLES=IaIbIc Id Ie If IIaIIbIIcIIdIIeIIfIIIaIIIbIIIcIIIdIIIeIIIf a10 ModelSummary

\begin{tabular}{l|r|r|r}
\hline Dimension & Cronbach's alpha & \multicolumn{2}{|c}{ Variance accounted for } \\
\cline { 3 - 4 } & & Total (Eigenvalue) & \multicolumn{1}{|c}{ Inertia } \\
\hline 1 &, 940 & 9,103 &, 479 \\
2 &, 886 & 6,225 &, 328 \\
3 &, 836 & 4,805 &, 253 \\
4 &, 819 & 4,467 &, 235 \\
Total & & 24,600 & 1,295 \\
Mean &, $884^{\mathrm{a}}$ & 6,150 &, 324 \\
\hline
\end{tabular}

a. Mean Cronbach's Alpha is based on the mean Eigenvalue.

c) Mapa perceptual da variável "capital da empresa" relacionada às variáveis de "utilização da informação contábil"

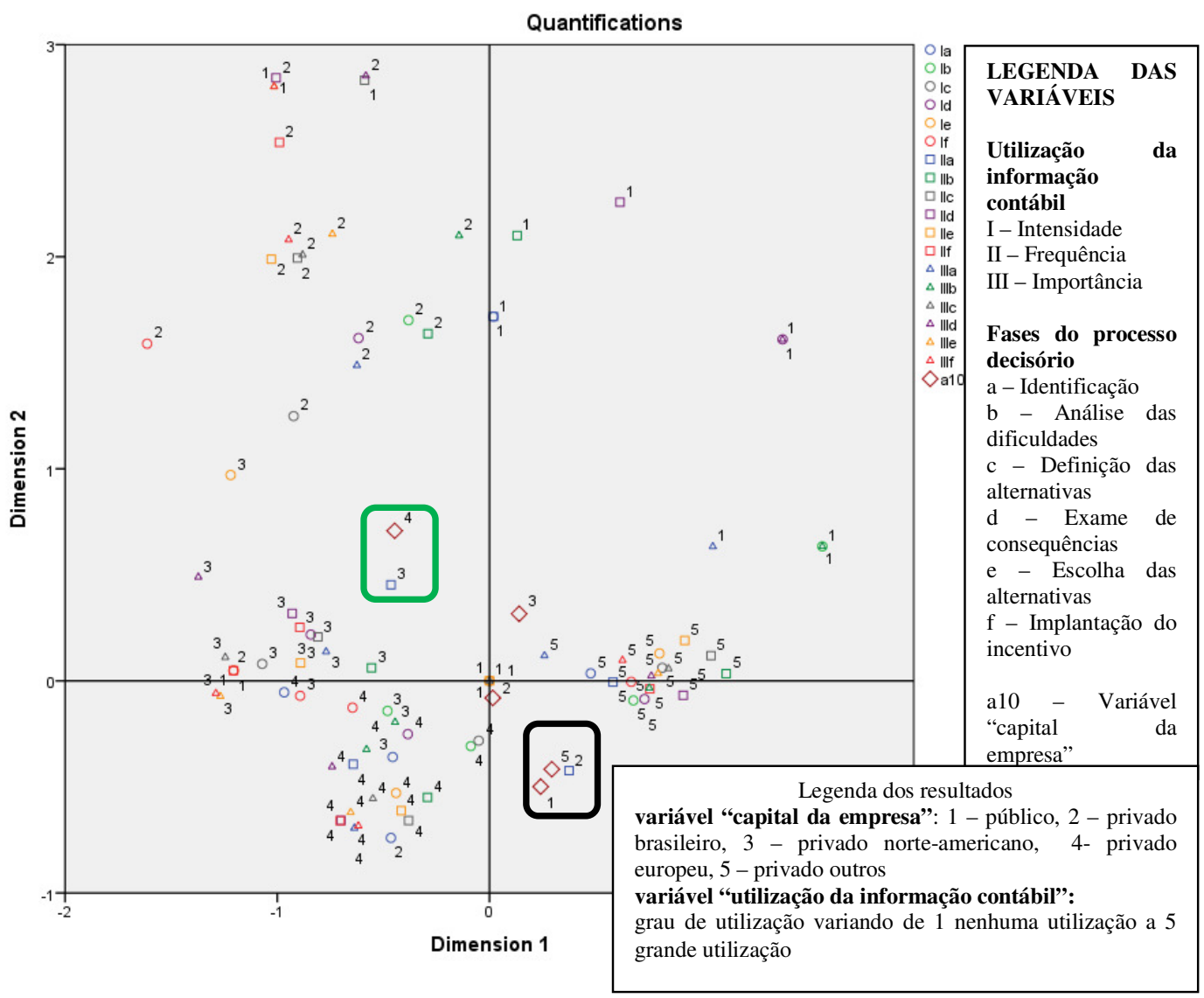

Gráfico 12 - Mapa perceptual "capital da empresa"

Por meio do gráfico perceptual da variável "capital da empresa" não foi possível estabelecer relações semelhantes aos padrões encontrados anteriormente, ou seja, a relação de uma 
variável com um grupo de variáveis relacionadas à informação contábil. Nesse caso, identificaram-se apenas as relações individuais, a saber:

A primeira relação refere-se a duas variáveis a10 com os números 5 e 1 que significam respectivamente empresa de capital público e empresa de capital privado outros com a variável IIa com o número 2 que significa pouca utilização da informação contábil no aspecto de intensidade na fase do processo de identificação do incentivo fiscal, assinalada no gráfico com um quadrado preto.

A segunda relação refere-se à variável a10 com o número 4 que significa capital privado europeu com a variável IIa com o número 3 que significa razoável utilização da informação contábil no aspecto de intensidade na fase do processo de identificação do incentivo fiscal, assinalada no gráfico com um quadrado verde.

\subsubsection{Características estruturais - fator "tamanho"}

Esse fator é identificado mediante a questão 11 da parte 3 do questionário.

a) Aplicação do teste do qui-quadrado

Quadro 15 - Teste do qui-quadrado fator "tamanho"

\begin{tabular}{|l|l|l|l|}
\hline $\begin{array}{c}\text { Itens da questão } \\
11-2^{\mathrm{a}} \text {. parte }\end{array}$ & \multicolumn{1}{|c|}{ Variável } & $\begin{array}{c}\text { Itens da parte 1 } \\
\text { questões I a III }\end{array}$ & $\begin{array}{c}\text { p-valor (teste qui- } \\
\text { quadrado) }\end{array}$ \\
\hline Item a & Porte da empresa & Item II A & 0,003 \\
\hline
\end{tabular}

Para essa única variável de característica estrutural, pelo teste do qui-quadrado foi rejeitada a hipótese de independência indicando relação com a utilização da informação contábil.

b) Inércia das dimensões - variável porte da empresa

Tabela 17 - Inércia "porte da empresa" MULTIPLE CORRES VARIABLES=IaIbIc Id Ie If IIaIIbIIcIIdIIeIIfIIIaIIIbIIIcIIIdIIIeIIIf a11

ModelSummary

\begin{tabular}{l|r|r|r}
\hline \multirow{2}{*}{ Dimension } & \multirow{2}{*}{ Cronbach's alpha } & \multicolumn{2}{|c}{ Variance accounted for } \\
\cline { 3 - 4 } & & Total (Eigenvalue) & \multicolumn{1}{|c}{ Inertia } \\
\hline 1 &, 939 & 9,090 &, 478 \\
2 &, 885 & 6,177 &, 325 \\
3 &, 832 & 4,731 &, 249 \\
4 &, 819 & 4,463 &, 235 \\
Total & & 24,462 & 1,287 \\
Mean &, $883^{\mathrm{a}}$ & 6,115 &, 322 \\
\hline
\end{tabular}

a. Mean Cronbach's Alpha is based on the mean Eigenvalue.

Fonte: elaborado pelo autor 
c) Mapa perceptual da variável "porte da empresa" relacionado às variáveis de "utilização da informação contábil”

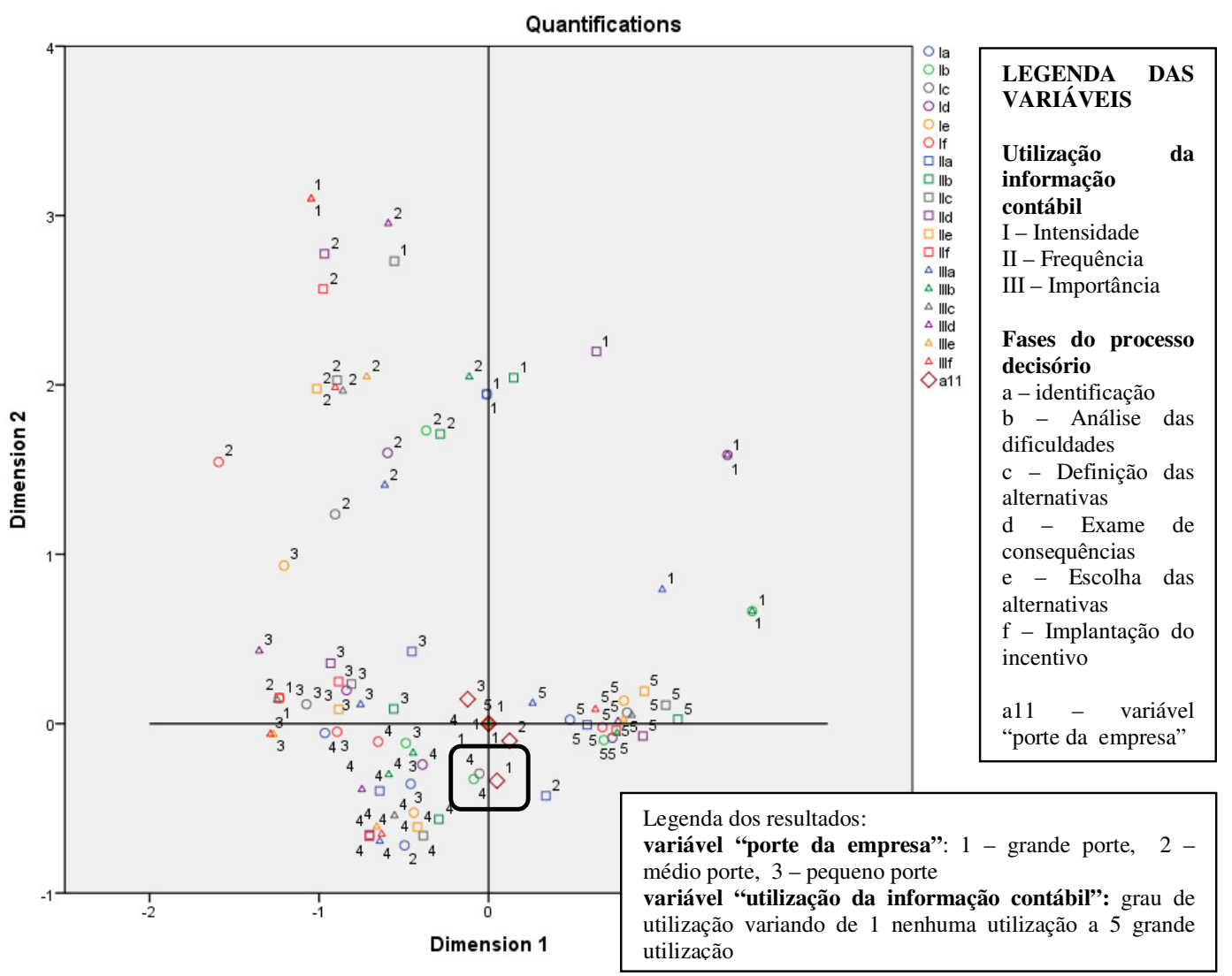

Gráfico 13 - Mapa perceptual "porte da empresa"

Por meio do gráfico perceptual da variável "porte da empresa" não foi possível estabelecer relações semelhantes aos padrões encontrados anteriormente, ou seja, a relação de uma variável com um grupo de variáveis relacionadas à informação contábil. Nesse caso identificou-se apenas uma relação individual que se refere à variável a11 "porte da empresa" com o número 1, que significa empresa de grande porte, com as variáveis da "utilização da informação contábil" Ib e Ic com o número 4, portanto ambas significando utilização da informação contábil no aspecto de intensidade com relação à fase do processo de decisão e representando respectivamente análise das dificuldades (letra b) e definição das alternativas (letra c). A relação está assinalada no gráfico com um quadrado preto. 


\subsubsection{Características de desempenho - fator "rentabilidade"}

Esse fator é identificado mediante a questão 4 letra a da parte 3 do questionário.

a) Aplicação do teste do qui-quadrado

Quadro 16 - Teste do qui-quadrado fator "rentabilidade"

\begin{tabular}{|l|l|l|c|}
\hline $\begin{array}{c}\text { Itens da questão } \\
4-2^{a} \text {. parte }\end{array}$ & \multicolumn{1}{|c|}{ Variável } & $\begin{array}{c}\text { Itens da parte 1 - } \\
\text { questões I a III }\end{array}$ & $\begin{array}{c}\text { p-valor (teste qui- } \\
\text { quadrado) }\end{array}$ \\
\hline Letra a & Margem de lucro & Item I A & 0,001 \\
\hline
\end{tabular}

Para essa única variável do fator rentabilidade, pelo teste do qui-quadrado pode-se rejeitar a hipótese de independência, o que significa que pode existir relação com a utilização da informação contábil.

b) Inércia das dimensões - variável "margem de lucro"

Tabela 18 - Inércia "margem de lucro" MULTIPLE CORRES VARIABLES=IaIbIc Id Ie If IIaIIbIIcIIdIIeIIfIIIaIIIbIIIcIIIdIIIeIIIf a4 ModelSummary

\begin{tabular}{l|r|r|r}
\hline Dimension & \multicolumn{1}{|c|}{$\begin{array}{c}\text { Cronbach's } \\
\text { alpha }\end{array}$} & \multicolumn{2}{|c}{ Variance accounted for } \\
\cline { 3 - 4 } & \multicolumn{1}{c}{$\begin{array}{c}\text { Total } \\
\text { (Eigenvalue) }\end{array}$} & Inertia \\
\hline 1 &, 940 & 9,133 &, 481 \\
2 &, 885 & 6,202 &, 326 \\
3 &, 823 & 4,898 &, 258 \\
4 &, $885^{\mathrm{a}}$ & 4,533 &, 239 \\
Total & 24,766 & 1,303 \\
Mean & 6,192 &, 326 \\
\hline
\end{tabular}

a. Mean Cronbach's Alpha is based on the mean Eigenvalue. 
c) Mapa perceptual da variável "margem de lucro" relacionado às variáveis de "utilização da informação contábil"

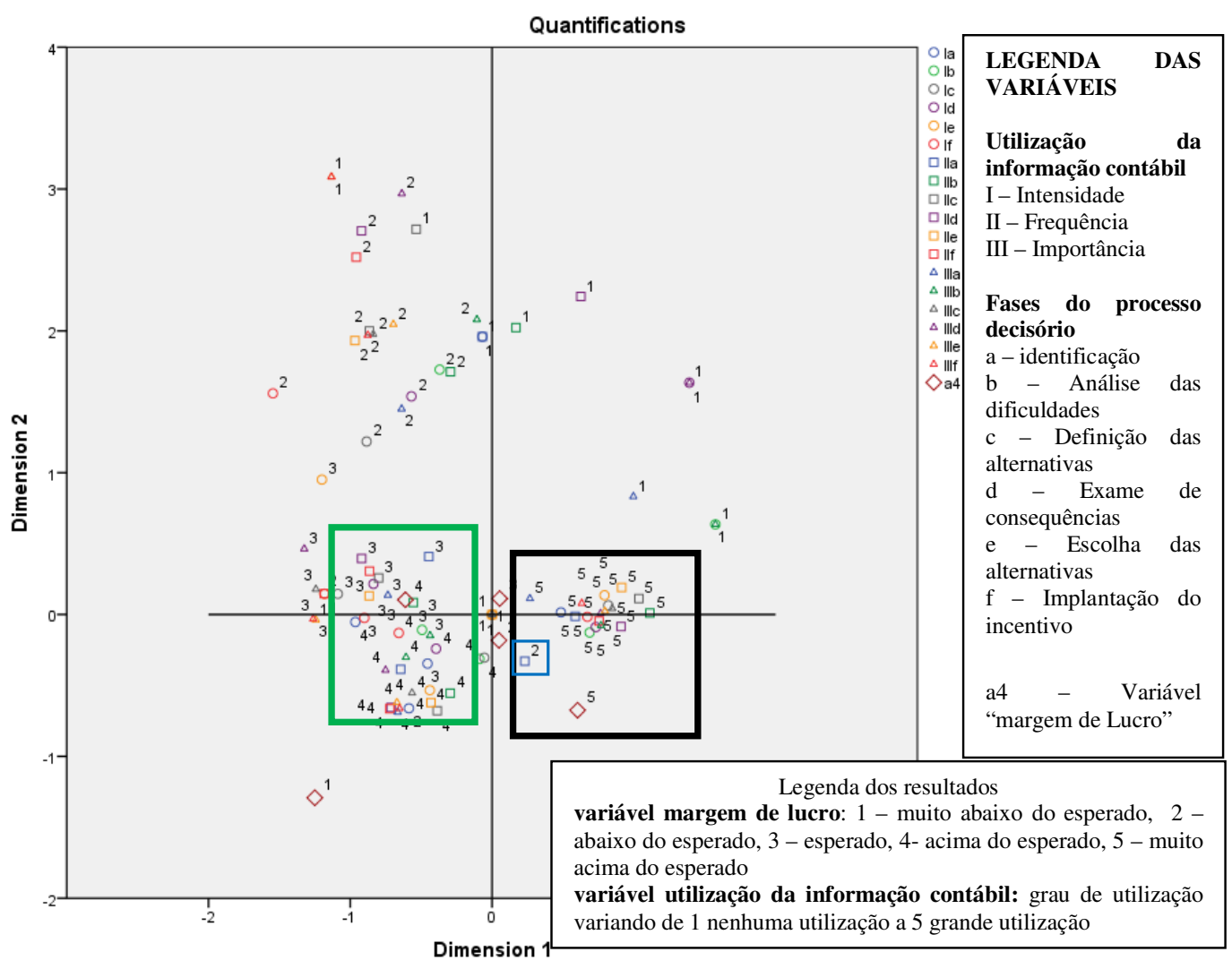

Gráfico 14 - Mapa perceptual "margem de lucro"

O gráfico apresenta duas relações.

Na primeira, verifica-se que a variável "margem de lucro", variável a4 com o número 5, que significa lucro muito acima do esperado está relacionada à utilização da informação contábil em todas as fases: intensidade, frequência e importância, (variáveis I, II e III) com o número 5, que significa grande utilização, destacado no gráfico no quadrado com a cor preta.

Verifica-se, ainda, a relação da variável "margem de lucro" a4 com o número 5, com a variável relativa à "utilização da informação contábil” Ia com o número 2, que significa baixa utilização da informação contábil no aspecto de intensidade na fase de identificação do benefício.

Na segunda, verifica-se que a variável "margem de lucro", variável a4 com o número 4, que significa margem de lucro acima do esperado, está relacionada com a utilização da 
informação contábil em todas as fases: intensidade, frequência e importância, variáveis I, II e II com o número 4 e também com o número 3 que representam, respectivamente, significativa utilização da informação contábil e razoável utilização da informação contábil. No gráfico, essa correlação está assinalada com um quadrado na cor verde.

\subsubsection{Características de desempenho - fator "lucratividade"}

Esse fator é identificado mediante a questão 4 letra b da parte 3 do questionário.

a) Aplicação do teste do qui-quadrado

Quadro 17 - Teste do qui-quadrado fator "lucratividade"

\begin{tabular}{|l|l|l|c|}
\hline $\begin{array}{c}\text { Itens da questão } \\
4-2^{\mathrm{a}} \text {. parte }\end{array}$ & \multicolumn{1}{|c|}{ Variável } & $\begin{array}{c}\text { Itens da parte 1 } \\
\text { questões I a III }\end{array}$ & $\begin{array}{c}\text { p-valor (teste qui- } \\
\text { quadrado) }\end{array}$ \\
\hline Letra b & Crescimento do lucro & Item I A & 0,026 \\
\hline
\end{tabular}

Para essa única variável do fator lucratividade, pelo teste do qui-quadrado foi rejeitada a hipótese de independência indicando relação com a utilização da informação contábil.

b) Inércia das dimensões - variável crescimento do lucro

Tabela 19 - Inércia "crescimento do lucro" MULTIPLE CORRES VARIABLES=IaIbIc Id Ie If IIaIIbIIcIIdIIeIIfIIIaIIIbIIIcIIIdIIIeIIIf b4 ModelSummary

\begin{tabular}{l|r|r|r}
\hline \multirow{2}{*}{ Dimension } & \multirow{2}{*}{ Cronbach's alpha } & \multicolumn{2}{|c}{ Variance accounted for } \\
\cline { 3 - 4 } & & Total (Eigenvalue) & \multicolumn{1}{|c}{ Inertia } \\
\hline 1 &, 940 & 9,124 &, 480 \\
2 &, 885 & 6,196 &, 326 \\
3 &, 834 & 4,768 &, 251 \\
4 &, 821 & 4,505 &, 237 \\
Total & & 24,592 & 1,294 \\
Mean &, $884^{\mathrm{a}}$ & 6,148 &, 324 \\
\hline
\end{tabular}

a. Mean Cronbach's Alpha is based on the mean Eigenvalue. 
c) Mapa perceptual variável crescimento do lucro relacionado às variáveis de utilização da informação contábil

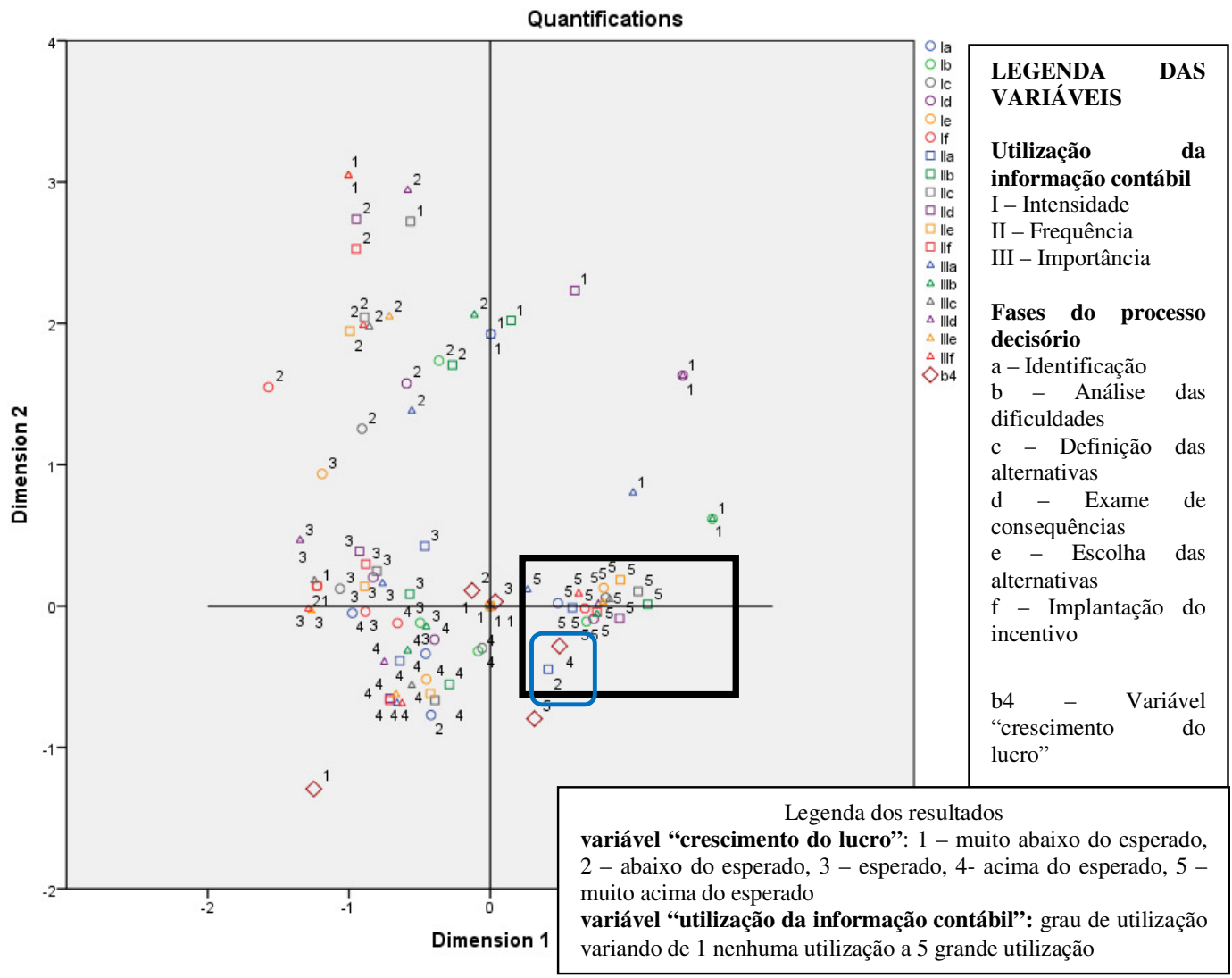

Gráfico 15 - Mapa perceptual "crescimento do lucro"

O gráfico apresenta apenas uma relação.

Verifica-se que a variável "crescimento do lucro", variável b4 com o número 4, que significa lucro acima do esperado está relacionada com a "utilização da informação contábil" em todas as fases: intensidade, frequência e importância, (variáveis I, II e III) com o número 5, que significa grande utilização da informação contábil, destacado no gráfico no quadrado com a cor preta. Note-se, ainda, uma relação com a variável "utilização da informação contábil" IIa com o número 2, que significa uma baixa utilização da informação contábil no aspecto da frequência na fase de identificação do incentivo. No gráfico, essa variável está assinalada com um quadrado na cor azul. 
Cabe, aqui, ressaltar que, no fator receita, com a única variável "crescimento da receita", o resultado obtido no teste qui-quadrado foi superior a 5\%, não sendo possível estabelecer relação entre a variável e a utilização da informação contábil.

\subsubsection{Atributos da informação - fator "instrumentos gerenciais contemporâneos"}

Esse fator é identificado mediante a questão 5 letras h, i, j, l, m, n, o e p da parte 3 do questionário.

a) Aplicação do teste do qui-quadrado

Apesar de esse fator ser composto por oito variáveis em apenas cinco, o teste de qui-quadrado apresentou resultado inferior a 5\%, o que permite rejeitar a hipótese de independência e, por isso, supor, uma relação entre a variável e a informação contábil, conforme apresentado a seguir.

Quadro 18 - Teste do qui-quadrado fator "instrumentos gerenciais contemporâneos"

\begin{tabular}{|l|l|l|l|}
\hline Itens da questão 5 & \multicolumn{1}{|c|}{ Variável } & $\begin{array}{l}\text { Itens da parte 1 - } \\
\text { questões I a III }\end{array}$ & p-valor (teste qui-quadrado) \\
\hline letra h & Custeio-alvo & Item I F & 0,025 \\
\hline Letra $\mathrm{i}$ & $\begin{array}{l}\text { Relatório de controle de } \\
\text { qualidade }\end{array}$ & Item III E & 0,013 \\
\hline letra j & Utilização do ABC/ABM & Item III D & 0,024 \\
\hline letra o & $\begin{array}{l}\text { Análise de cenários } \\
\text { estratégicos }\end{array}$ & Item II A & 0,046 \\
\hline letra p & Indicadores não financeiros & Item II A & 0,045 \\
\hline
\end{tabular}

As variáveis que apresentaram resultado do teste qui-quadrado superior a $5 \%$ foram: "utilização do EVA", "uso sistemático de benchmarking” e "utilização do balanced scorecard" e, por essa razão, não foram analisadas por meio da HOMALS. 
b) Inércia das dimensões

b.1) Variável "custeio-alvo"

Tabela 20 - Inércia "custeio-alvo"

MULTIPLE CORRES VARIABLES=IaIbIc Id Ie If IIaIIbIIcIIdIIeIIfIIIaIIIbIIIcIIIdIIIeIIIf h5

ModelSummary

\begin{tabular}{l|r|r|r}
\hline \multirow{2}{*}{ Dimension } & \multirow{2}{*}{ Cronbach's alpha } & \multicolumn{2}{|c}{ Variance accounted for } \\
\cline { 3 - 4 } &, 941 & Total (Eigenvalue) & \multicolumn{2}{|c}{ Inertia } \\
\hline 1 &, 888 & 9,200 &, 484 \\
2 &, 837 & 6,302 &, 332 \\
3 &, 823 & 4,819 &, 254 \\
4 & & 4,532 &, 239 \\
Total &, $886^{\mathrm{a}}$ & 24,854 & 1,308 \\
Mean & 6,213 &, 327 \\
\hline
\end{tabular}

a. Mean Cronbach's Alpha is based on the mean Eigenvalue.

b.2) Variável "relatório de controle de qualidade"

Tabela 21 - Inércia "relatório de controle de qualidade"

MULTIPLE CORRES VARIABLES=IaIbIc Id Ie If IIaIIbIIcIIdIIeIIfIIIaIIIbIIIcIIIdIIIeIIIf i5

ModelSummary

\begin{tabular}{l|r|r|r}
\hline \multirow{2}{*}{ Dimension } & \multirow{2}{*}{ Cronbach's alpha } & \multicolumn{2}{|c}{ Variance accounted for } \\
\cline { 3 - 4 } & & Total (Eigenvalue) & \multicolumn{1}{|c}{ Inertia } \\
\hline 1 &, 940 & 9,131 &, 481 \\
2 &, 885 & 6,192 &, 326 \\
3 &, 846 & 5,036 &, 265 \\
4 &, 824 & 4,560 &, 240 \\
Total & & 24,919 & 1,312 \\
Mean &, $886^{\mathrm{a}}$ & 6,230 &, 328 \\
\hline
\end{tabular}

a. Mean Cronbach's Alpha is based on the mean Eigenvalue.

b.3) Variável "custeio ABC/ABM"

Tabela 22 - Inércia "custeio ABC/ABM"

MULTIPLE CORRES VARIABLES=IaIbIc Id Ie If IIaIIbIIcIIdIIeIIfIIIaIIIbIIIcIIIdIIIeIIIf j5

ModelSummary

\begin{tabular}{l|r|r|r}
\hline \multirow{2}{*}{ Dimension } & \multirow{2}{*}{ Cronbach's alpha } & \multicolumn{2}{|c}{ Variance accounted for } \\
\cline { 3 - 4 } & & Total (Eigenvalue) & \multicolumn{1}{|c}{ Inertia } \\
\hline 1 &, 941 & 9,243 &, 486 \\
2 &, 885 & 6,205 &, 327 \\
3 &, 833 & 4,745 &, 250 \\
4 &, 822 & 4,518 &, 238 \\
Total & & 24,711 & 1,301 \\
Mean &, $885^{\mathrm{a}}$ & 6,178 &, 325 \\
\hline
\end{tabular}

a. Mean Cronbach's Alpha is based on the mean Eigenvalue. 
b.4) Variável "análise de cenários estratégicos"

Tabela 23 - Inércia "análise de cenários estratégicos"

MULTIPLE CORRES VARIABLES=IaIbIc Id Ie If IIaIIbIIcIIdIIeIIfIIIaIIIbIIIcIIIdIIIeIIIf o5 ModelSummary

\begin{tabular}{c|c|c|c}
\hline \multirow{2}{*}{ Dimension } & \multirow{2}{*}{ Cronbach's alpha } & \multicolumn{2}{|c}{ Variance accounted for } \\
\cline { 3 - 4 } & & Total (Eigenvalue) & Inertia \\
\hline 1 &, 940 & 9,131 &, 481 \\
2 &, 888 & 6,298 &, 331 \\
3 &, 842 & 4,942 &, 260 \\
4 &, 822 & 4,523 &, 238 \\
Total &, $886^{\mathrm{a}}$ & 24,894 & 1,310 \\
Mean & 6,223 &, 328 \\
\hline
\end{tabular}

a. Mean Cronbach's Alpha is based on the mean Eigenvalue.

b.5) Variável "indicadores não financeiros"

Tabela 24 - Inércia "indicadores não-financeiros" MULTIPLE CORRES VARIABLES=IaIbIc Id Ie If IIaIIbIIcIIdIIeIIfIIIaIIIbIIIcIIIdIIIeIIIf p5 ModelSummary

\begin{tabular}{l|r|r|r}
\hline \multirow{2}{*}{ Dimension } & \multirow{2}{*}{ Cronbach's alpha } & \multicolumn{2}{|c}{ Variance accounted for } \\
\cline { 3 - 4 } & & Total (Eigenvalue) & \multicolumn{1}{|c}{ Inertia } \\
\hline 1 &, 940 & 9,135 &, 481 \\
2 &, 885 & 6,182 &, 325 \\
3 &, 840 & 4,891 &, 257 \\
4 &, 826 & 4,596 &, 242 \\
Total & & 24,805 & 1,306 \\
Mean &, $885^{\mathrm{a}}$ & 6,201 &, 326 \\
\hline
\end{tabular}

a. Mean Cronbach's Alpha is based on the mean Eigenvalue. 
c) Mapas perceptuais

c.1) Mapa perceptual variável "custeio-alvo"

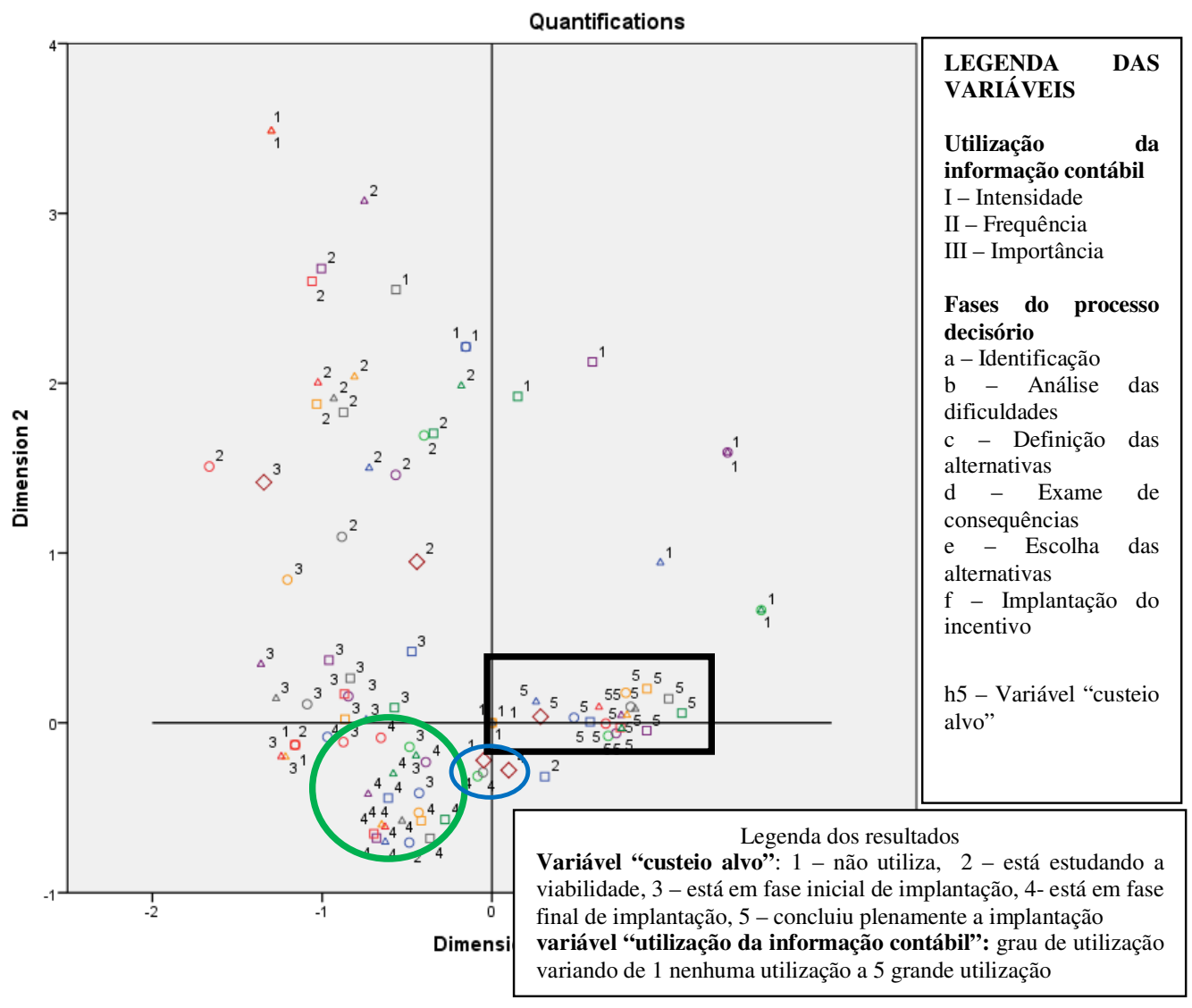

Gráfico 16 - Mapa perceptual "custeio-alvo"

O gráfico apresenta três relações.

Na primeira, verifica-se que a variável "utilização de custeio-alvo", variável h5 com o número 5, que significa concluiu plenamente a implantação, está relacionada com a utilização da informação contábil em todas os aspectos: intensidade, frequência e importância, (variáveis I, II e III) com o número 5 que representa grande utilização da informação contábil. Essa relação é destacada no gráfico no quadrado preto.

Na segunda, verifica-se que a variável "utilização do custeio-alvo", variável h5 com o número 1, que significa não utiliza, está relacionada à variável "utilização da informação contábil" em todas as formas de utilização, intensidade, frequência e importância, (variáveis I, II e III) com 
o número 4 que representa um grau significativo de utilização da informação contábil, uma vez que está com o número 4, em todas as fases do processo decisório. No gráfico, essa correlação está assinalada em uma forma oval na cor verde.

Na terceira relação, verifica-se que a variável "utilização do custeio-alvo", variável h5 com o número 4, que significa está em fase final de implantação, está relacionada com a variável "utilização da informação contábil" IIa, com o número 2 que representa um grau baixo de utilização da informação contábil no aspecto de frequência na identificação do incentivo fiscal. Essa relação está assinalada no mapa em uma forma oval azul.

c.2) Mapa perceptual variável "relatório de controle de qualidade"

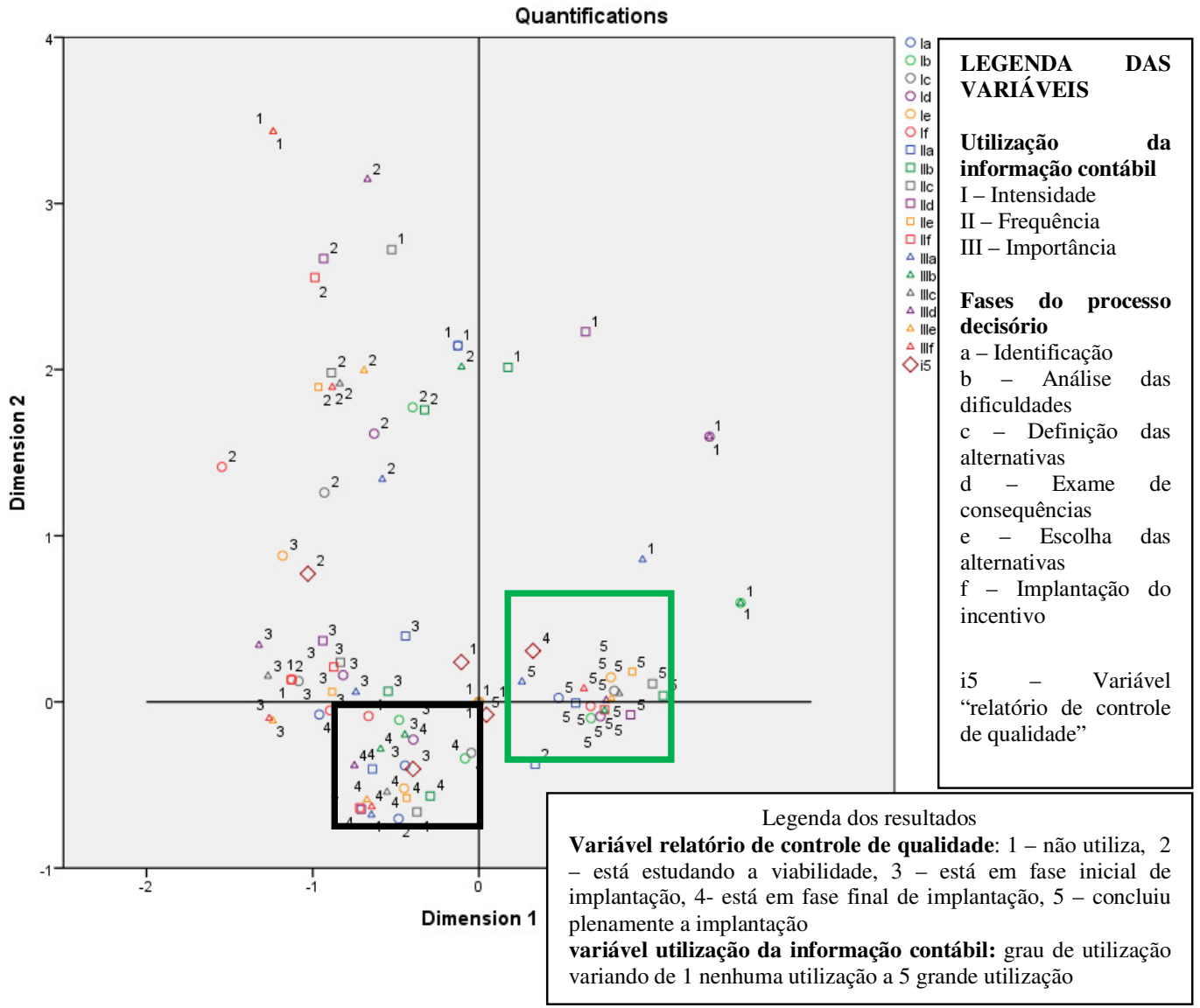

Gráfico 17 - Mapa perceptual "relatório de controle de qualidade"

O gráfico apresenta duas relações. 
Na primeira, verifica-se que a variável "utilização do relatório de controle de qualidade", variável i5 com o número 3, que significa está em fase inicial de implantação, está relacionada com a variável "utilização da informação contábil" em todos os aspectos: intensidade, frequência e importância, (variáveis I, II e III) com o número 4 que representa significativa utilização da informação contábil e algumas variáveis com o número 3 que representam uma razoável utilização da informação contábil. Essa relação é destacada no gráfico no quadrado preto.

Na segunda, verifica-se que a variável "utilização do relatório de controle de qualidade", variável i5 com o número 4 está em fase final de implantação, está relacionada com a "utilização da informação contábil", o número 5, que significa grande utilização da informação contábil em todas as formas de utilização, intensidade, frequência e importância, (variáveis I, II e III). No gráfico, essa relação está assinalada em um quadrado na cor verde.

c.3) Mapa perceptual variável "ABC/ABM" relacionada às variáveis de "utilização da informação contábil”

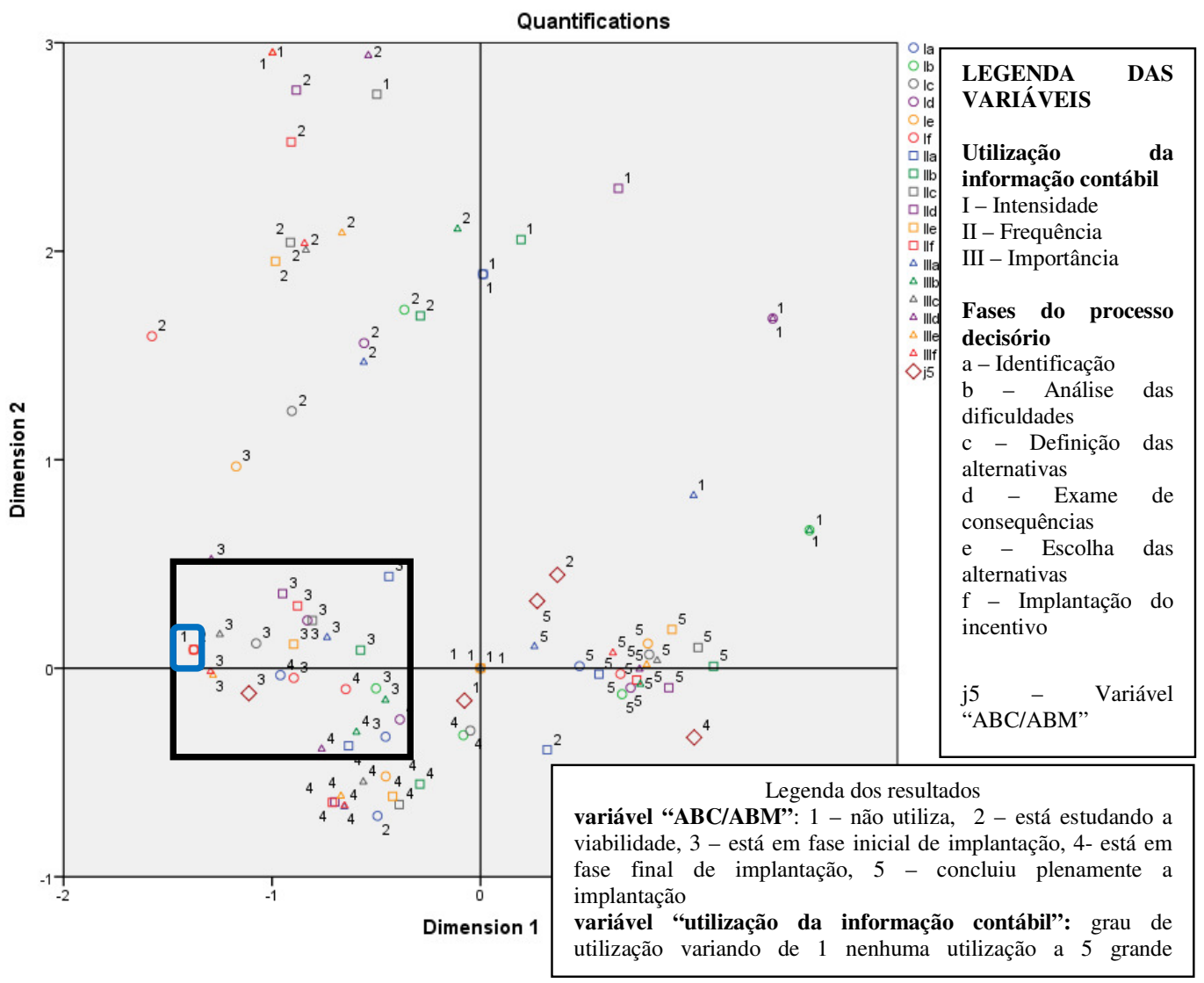

Gráfico 18 - Mapa perceptual “ABC/ABM" 
O gráfico apresenta a seguinte relação:

A variável "ABC/ABM", variável j5 com o número 3, que significa está em fase inicial de implantação está relacionada com a variável "utilização da informação contábil" em todas as fases: intensidade, frequência e importância, (variáveis I, II e III) com o número 3 que significa média utilização da informação contábil. Essa relação está destacada no gráfico no quadrado com a cor preta.

Note-se, ainda, uma relação da variável "ABC/ABM", variável j5 com a variável "utilização da informação contábil”, variável If com o número 1 que significa uma baixa utilização da informação contábil no aspecto da intensidade na fase de implantação do incentivo. No gráfico a variável está assinalada com a cor azul.

c.4) Mapa perceptual variável "cenários estratégicos" relacionada às variáveis de "utilização da informação contábil”

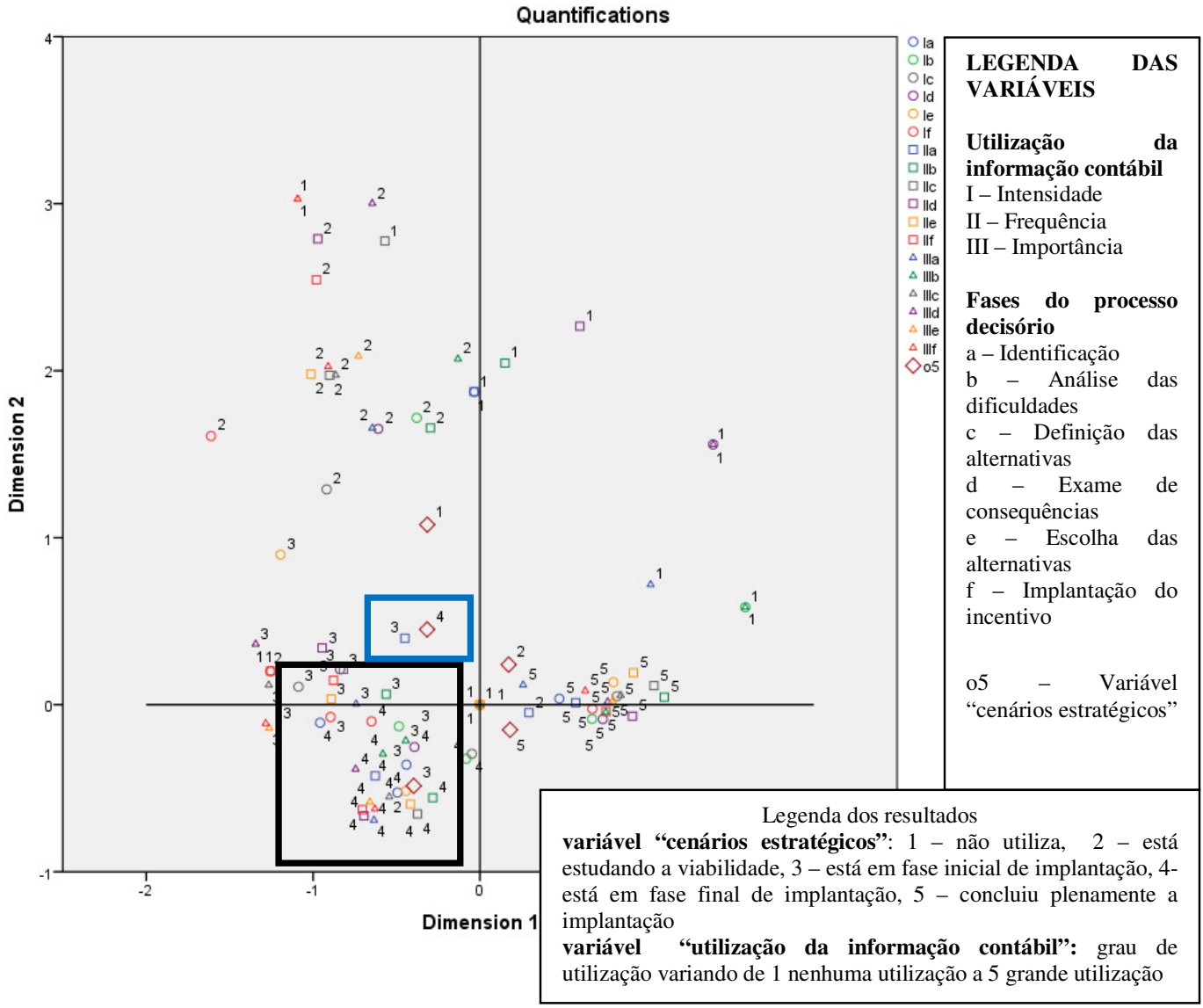

Gráfico 19 - Mapa perceptual "cenários estratégicos” 
O gráfico apresenta duas relações.

Na primeira, verifica-se que a variável "cenários estratégicos", variável o5 com o número 3, que significa está em fase inicial de implantação, está relacionada à variável "utilização da informação contábil" em todas as fases: intensidade, frequência e importância, (variáveis I, II e III) com o número 4 que representa significativa utilização da informação contábil, e alguns números 3, que representam razoável utilização da informação contábil, destacados no gráfico no quadrado com a cor preta.

A segunda relaciona a variável "cenários estratégicos" o5 com o número 4, que significa está em fase final de implantação, com a variável "utilização da informação contábil" variável IIa com o número 3 , que significa razoável utilização da informação contábil, no aspecto de frequência na fase de identificação do processo de decisão. Essa relação está marcada no gráfico com um quadrado na cor azul.

c.5) Mapa perceptual variável "indicadores não-financeiros", relacionada as variáveis de "utilização da informação contábil"

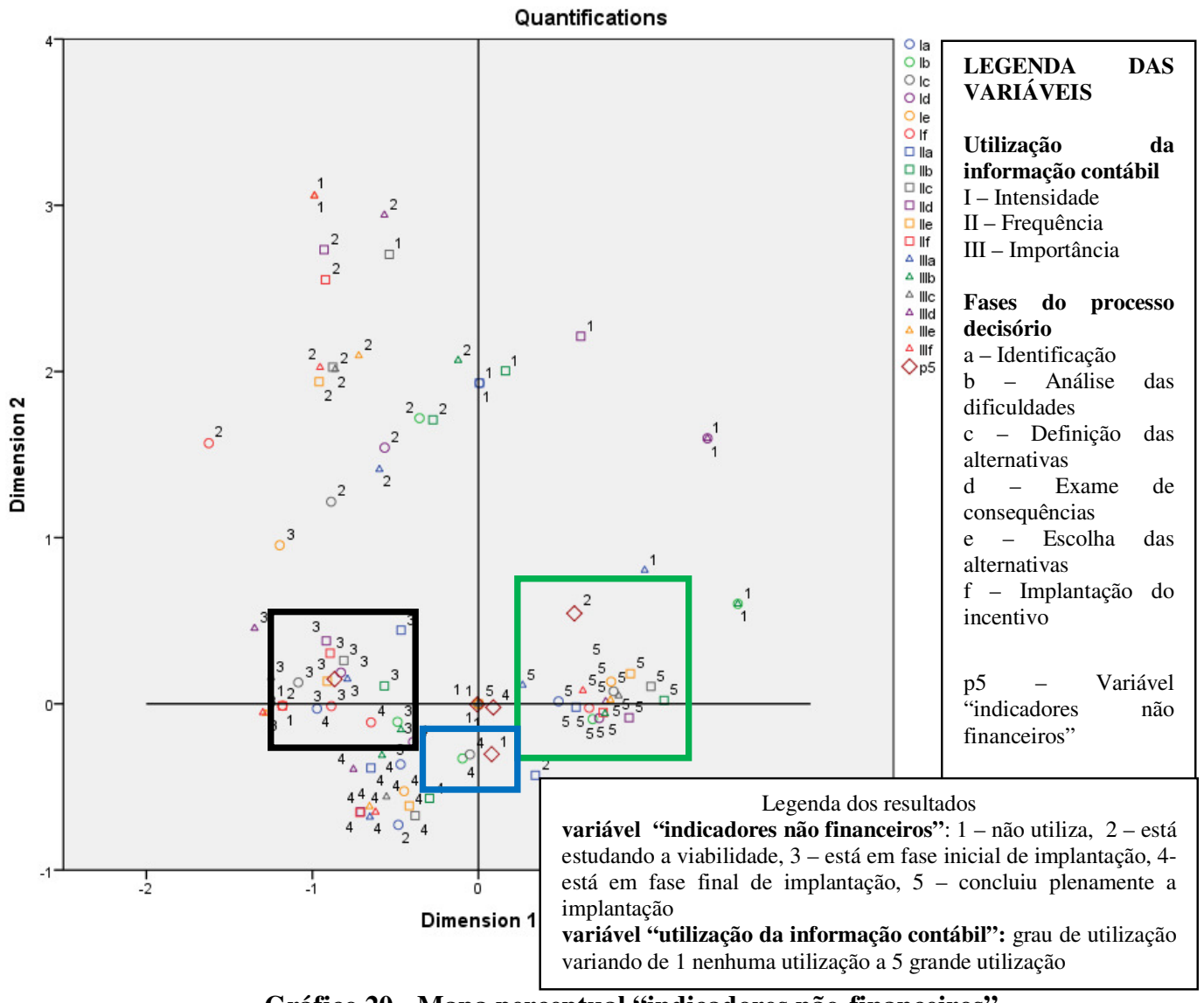

Gráfico 20 - Mapa perceptual "indicadores não-financeiros" 
O gráfico apresenta três relações.

$\mathrm{Na}$ primeira, verifica-se que a variável "indicadores não financeiros", variável p5 com o número 3, que significa está em fase inicial de implantação está relacionada com a variável "utilização da informação contábil" em todas as fases: intensidade, frequência e importância, (variáveis I, II e III) com o número 3 que representa razoável utilização da informação contábil, e alguns números 4 que representam significativa utilização da informação contábil, destacado no gráfico no quadrado com a cor preta.

$\mathrm{Na}$ segunda verifica-se que a variável "indicadores não financeiros", variável p5 com os números 2, que significa está estudando a viabilidade, está relacionada com a variável "utilização da informação contábil" em todas as fases: intensidade, frequência e importância,

(variáveis I, II e III) com o número 5, que significa grande utilização da informação contábil. No gráfico essa relação está assinalada em um quadrado na cor verde.

A terceira relaciona a variável "indicadores não financeiros", variável p5 com o número 1 que significa não utiliza, com a variável "utilização da informação contábil” representada por Ib e Ic com o número 4 que significa utilização da informação contábil no aspecto de intensidade nas fases do processo decisório, análise das dificuldades e escolha das alternativas respectivamente, com um significativo grau de utilização da informação contábil. Essa relação está marcada no gráfico com um quadrado na cor azul.

\subsubsection{Atributos da informação - fator "instrumentos gerenciais tradicionais"}

Esse fator é identificado mediante a questão 5 letras d, e, f, g, da parte 3 do questionário.

a) Aplicação do teste do qui-quadrado

Esse fator composto por quatro variáveis apresentou no teste do qui-quadrado três variáveis com resultado inferior a 5\%, o que permite rejeitar a hipótese de independência e, portanto, supor uma relação entre a variável e a informação contábil, conforme apresentado a seguir. 
Quadro 19 - Teste do qui-quadrado fator "instrumentos gerenciais tradicionais"

\begin{tabular}{|l|l|l|l|}
\hline \multicolumn{1}{|c|}{$\begin{array}{c}\text { Itens da questão } \\
5\end{array}$} & \multicolumn{1}{|c|}{ Variável } & \multicolumn{1}{|c|}{$\begin{array}{c}\text { Itens da parte 1 - } \\
\text { questões I a III }\end{array}$} & $\begin{array}{c}\text { p-valor (teste qui- } \\
\text { quadrado) }\end{array}$ \\
\hline letra d & $\begin{array}{l}\text { Demonstração de resultados } \\
\text { mensais }\end{array}$ & Item I A & 0,003 \\
\hline letra e & $\begin{array}{l}\text { Custeio variável ou por } \\
\text { absorção }\end{array}$ & Item I A & 0,049 \\
\hline letra g & Orçamento participativo & Item I F & 0,008 \\
\hline
\end{tabular}

A variável que apresentou resultado do teste qui-quadrado superior a 5\% relativa à utilização de instrumento gerenciais tradicionais foi apenas a utilização do orçamento não participativo.

b) Inércia das dimensões "instrumentos gerenciais tradicionais"

b.1) Variável "demonstração de resultados mensais

Tabela 25 - Inércia "demonstração de resultados mensais" MULTIPLE CORRES VARIABLES=IaIbIc Id Ie If IIaIIbIIcIIdIIeIIfIIIaIIIbIIIcIIIdIIIeIIIf d5 ModelSummary

\begin{tabular}{l|r|r|r}
\hline \multirow{2}{*}{ Dimension } & \multirow{2}{*}{ Cronbach's alpha } & \multicolumn{2}{|c}{ Variance accounted for } \\
\cline { 3 - 4 } & & Total (Eigenvalue) & \multicolumn{1}{|c}{ Inertia } \\
\hline 1 &, 940 & 9,136 &, 481 \\
2 &, 891 & 6,411 &, 337 \\
3 &, 858 & 5,336 &, 281 \\
4 &, 820 & 4,481 &, 236 \\
Total & & 25,365 & 1,335 \\
Mean &, $889^{\mathrm{a}}$ & 6,341 &, 334 \\
\hline
\end{tabular}

a. Mean Cronbach's Alpha is based on the mean Eigenvalue.

b.2) Variável "custeio variável ou por absorção"

Tabela 26 - Inércia "custeio variável ou por absorção" MULTIPLE CORRES VARIABLES=IaIbIc Id Ie If IIaIIbIIcIIdIIeIIfIIIaIIIbIIIcIIIdIIIIIIIf e5 ModelSummary

\begin{tabular}{l|r|r|r}
\hline \multirow{2}{*}{ Dimension } & \multirow{2}{*}{ Cronbach's alpha } & \multicolumn{2}{|c}{ Variance accounted for } \\
\cline { 3 - 4 } & & Total (Eigenvalue) & \multicolumn{1}{|c}{ Inertia } \\
\hline 1 &, 941 & 9,252 &, 487 \\
2 &, 885 & 6,190 &, 326 \\
3 &, 847 & 5,050 &, 266 \\
4 &, 821 & 4,505 &, 237 \\
Total & & 24,997 & 1,316 \\
Mean &, $887^{\mathrm{a}}$ & 6,249 &, 329 \\
\hline
\end{tabular}

a. Mean Cronbach's Alpha is based on the mean Eigenvalue. 
b.3) Variável "orçamento participativo"

Tabela 27 - Inércia "orçamento participativo" MULTIPLE CORRES VARIABLES=IaIbIc Id Ie If IIaIIbIIcIIdIIeIIfIIIaIIIbIIIcIIIdIIIeIIIf g5 ModelSummary

\begin{tabular}{l|r|r|r}
\hline \multirow{2}{*}{ Dimension } & \multirow{2}{*}{ Cronbach's alpha } & \multicolumn{2}{|c}{ Variance accounted for } \\
\cline { 3 - 4 } & & Total (Eigenvalue) & \multicolumn{1}{|c}{ Inertia } \\
\hline 1 &, 941 & 9,197 &, 484 \\
2 &, 886 & 6,213 &, 327 \\
3 &, 836 & 4,800 &, 253 \\
4 &, 821 & 4,502 &, 237 \\
Total & & 24,711 & 1,301 \\
Mean &, $885^{\mathrm{a}}$ & 6,178 &, 325 \\
\hline
\end{tabular}

a. Mean Cronbach's Alpha is based on the mean Eigenvalue.

c) Mapas perceptuais

c.1) Mapa perceptual variável "da demonstração de resultados mensais" relacionada às variáveis de "utilização da informação contábil"

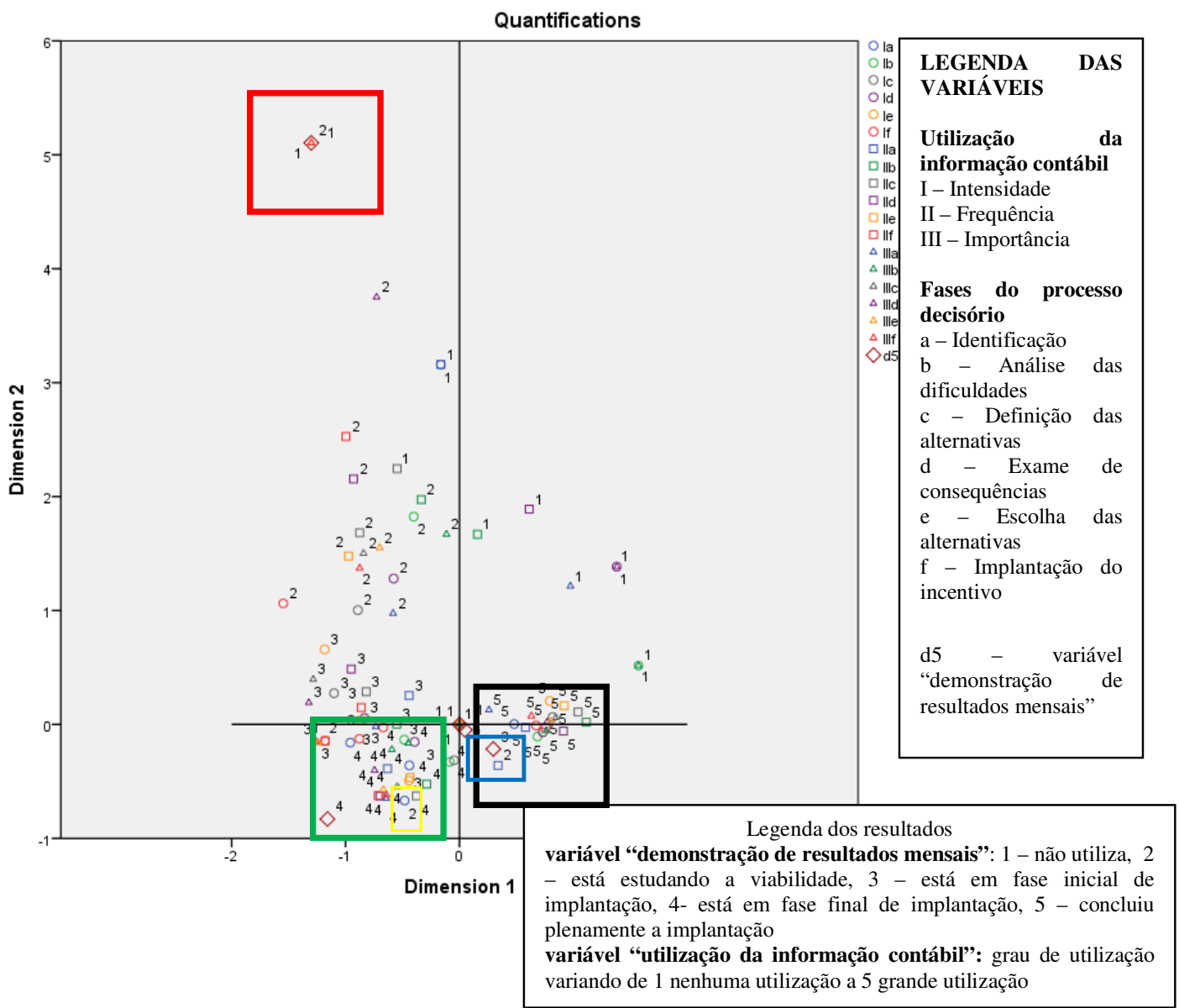

Gráfico 21 - Mapa perceptual "demonstração de resultados mensais" 
O gráfico apresenta três relações.

Na primeira, verifica-se que a variável "utilização de demonstração de resultados mensais", variável d5 com o número 3, que significa está em fase inicial de implantação está relacionada com a variável "utilização da informação contábil" em todas as fases: intensidade, frequência e importância, (variáveis I, II e III) com o número 5, que representa grande utilização da informação contábil. Essa relação é destacada no gráfico no quadrado preto. Note-se, ainda, que existe uma relação com a variável "utilização da informação contábil” IIa com número 2 que significa pequena utilização da informação contábil no aspecto da frequência na fase de identificação do incentivo. Essa variável está destacada no gráfico com o quadrado azul.

Na segunda, verifica-se que a variável "utilização de resultados mensais", variável d5 com o número 4, que significa está em fase final de implantação, está relacionada com a variável "utilização da informação contábil" em todas as fases: intensidade, frequência e importância, (variáveis I, II e III) com o número 4 e alguns números 3, que representam, respectivamente, significativa utilização da informação contábil e razoável utilização da informação contábil. No gráfico, essa relação está assinalada em um quadrado na cor verde. Note-se, ainda, que existe uma relação com a variável "utilização da informação contábil, variável Ia com o número 2 que significa a pequena utilização da informação contábil no aspecto da intensidade na fase de identificação do incentivo. Essa variável está destacada no gráfico com o quadrado amarelo.

A terceira relação aparece muita isolada em destaque no gráfico com um quadrado vermelho e relaciona a variável "utilização de demonstração de resultados mensais" d5 com o número 2 que significa está estudando a viabilidade com a variável "utilização da informação contábil" IIIf com o número 1 que significa nenhuma utilização da informação contábil no aspecto de importância no processo decisório de implantação do incentivo. 
c.2) Mapa perceptual variável "custeio variável ou por absorção" relacionada às variáveis de "utilização da informação contábil"

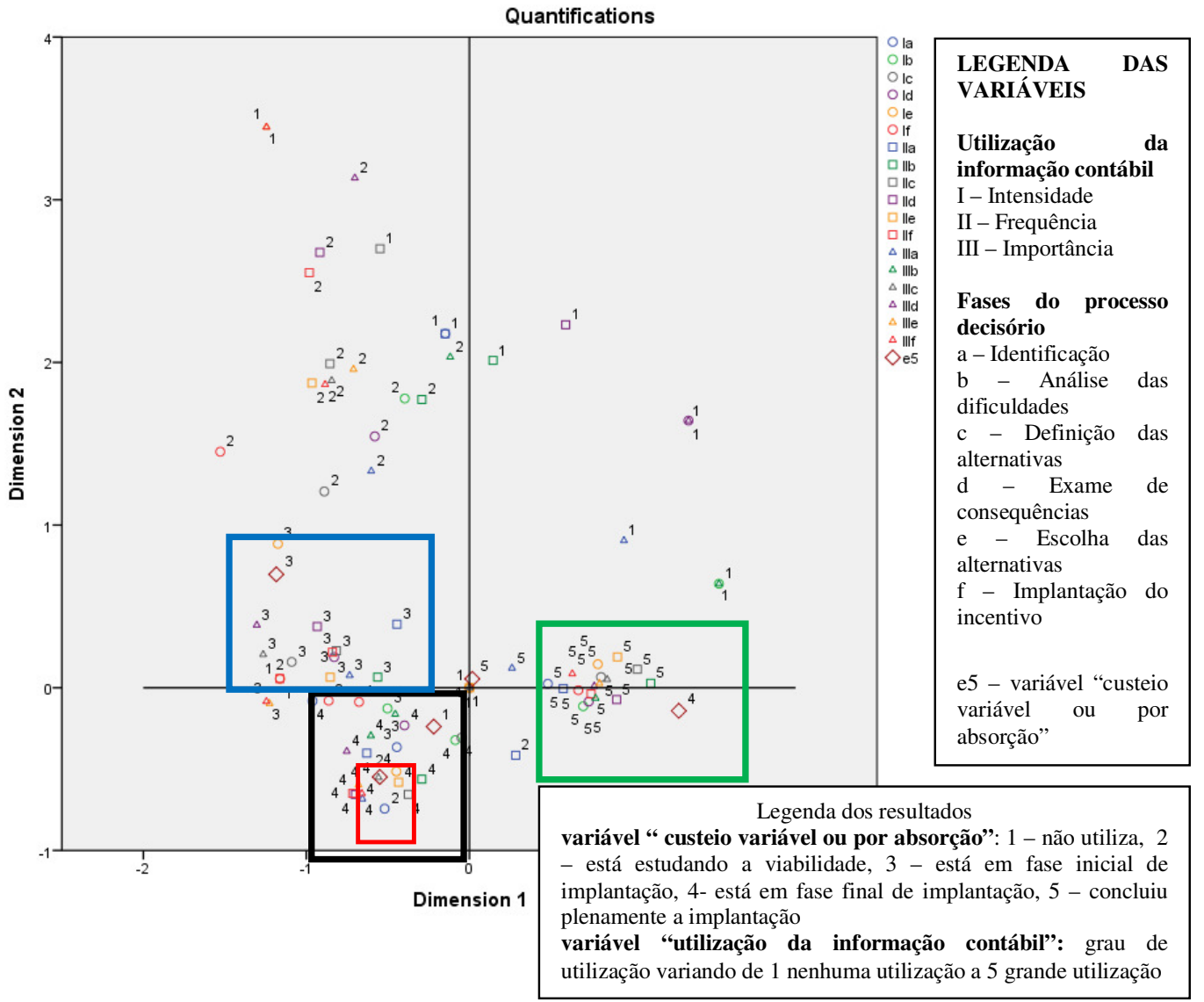

Gráfico 22 - Mapa perceptual "custeio variável ou por absorção"

O gráfico apresenta três relações.

Na primeira, verifica-se que as variáveis "utilização de custeio variável ou por absorção", variável e5 com os números 1 e 2, que significam não utiliza ou está estudando a viabilidade, estão relacionadas com a variável "utilização da informação contábil" em todas as fases: intensidade, frequência e importância, (variáveis I, II e III) com o número 4 que representam significativa utilização da informação contábil. Essa relação é destacada no gráfico no quadrado preto. Note-se, ainda, que existe uma relação com a variável "utilização da informação contábil" Ia com o número 2, que significa pequena utilização da informação contábil no aspecto da intensidade na fase de identificação do incentivo. Essa variável está destacada no gráfico com o quadrado vermelho. 
Na segunda, verifica-se que a variável "custeio variável ou por absorção", variável e5 com o número 4, que significa está em fase final de implantação, está relacionada com a variável "utilização da informação contábil" da em todas as fases: intensidade, frequência e importância, (variáveis I, II e III) com o número 5 que representa grande grau de utilização. No gráfico, essa correlação está assinalada em um quadrado na cor verde.

$\mathrm{Na}$ terceira relação, verifica-se que a variável "custeio variável ou por absorção" e5 com o número 3, que significa está em fase inicial de implantação, está relacionada com a variável "utilização da informação contábil" em todas as fases: intensidade, frequência e importância, (variáveis I, II e III) com o número 3 que significa um grau intermediário de utilização. Essa relação está assinalada no mapa em um quadrado azul.

c.3) Mapa perceptual variável "orçamento participativo", relacionada às variáveis de "utilização da informação contábil".

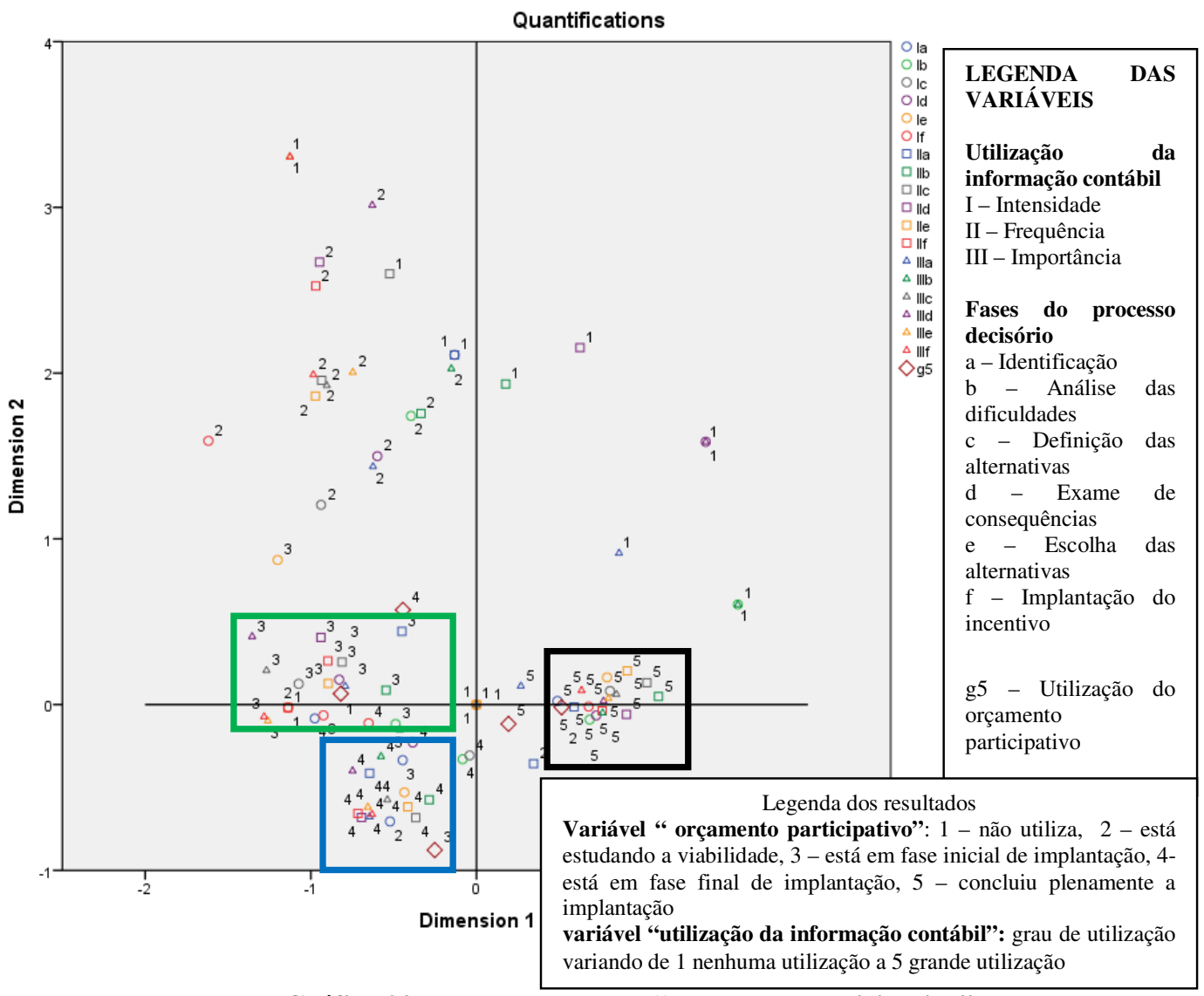

Gráfico 23 - Mapa perceptual "orçamento participativo" 
O gráfico apresenta três relações

Na primeira, verifica-se que a variável "orçamento participativo", variável g5 com o número 2, que significa está estudando a viabilidade está relacionada com a variável "utilização da informação contábil" em todas as fases: intensidade, frequência e importância, (variáveis I, II e III) com o número 5, que representa grande utilização da informação contábil. Essa relação é destacada no gráfico no quadrado preto. Note-se que devido à proximidade das variáveis se pode ter a impressão que a variável g5 com o número 5 está no quadrado preto, entretanto, não é isso que ocorre, uma vez que essa variável g5 com o número 5 está fora do quadrado próxima à intersecção dos eixos.

Na segunda, verifica-se que a variável "orçamento participativo", variável g5 com o número 1 que significa não utiliza orçamento participativo, está relacionada com a variável "utilização da informação contábil”, em todas as formas de utilização, intensidade, frequência e importância, (variáveis I, II e III) com o número 3 que representa um grau intermediário de utilização da informação contábil. No gráfico, essa correlação está assinalada em um quadrado na cor verde.

Na terceira relação, verifica-se que a variável "orçamento participativo", variável g5 com o número 3, que significa está em fase inicial de implantação, com a variável "utilização da informação contábil" e todas as fases do processo de decisão, (variáveis I, II e III) com o número 4, o que representa um grau significativo grau de utilização da informação contábil. Essa relação está assinalada no mapa em um quadrado azul. Note-se, ainda, que existe relacionamento com a variável "utilização da informação contábil" Ia, que se refere ao aspecto intensidade na fase de identificação do processo decisório e com o número 2 que significa pouca utilização da informação contábil.

\subsubsection{Atributos da informação contábil - fator "escopo"}

Esse fator é identificado mediante a questão 8 letras a, b, c, d, e da questão 9 da parte III do questionário. 
a) Aplicação do teste do qui-quadrado

Em todas as variáveis o teste de qui-quadrado apresentou resultado inferior a 5\%, o que permite rejeitar a hipótese de independência e, portanto, supor uma relação entre a variável e a informação contábil, conforme apresentado a seguir.

Quadro 20 - Teste do qui-quadrado fator "escopo"

\begin{tabular}{|l|l|l|l|}
\hline $\begin{array}{c}\text { Itens da questão } \\
8\end{array}$ & \multicolumn{1}{|c|}{ Variável } & \multicolumn{1}{|c|}{$\begin{array}{c}\text { Itens da parte 1 - } \\
\text { questões I a III }\end{array}$} & \multicolumn{1}{c|}{$\begin{array}{c}\text { p-valor (teste qui- } \\
\text { quadrado) }\end{array}$} \\
\hline letra a & Temporal & Item I A & 0,000 \\
\hline letra b & Quantificação & Item I A & 0,000 \\
\hline letra c & Foco & Item II A & 0,012 \\
\hline letra d & Tempestividade & Item I D & 0,022 \\
\hline
\end{tabular}

b) Inércia das dimensões

b.1) Variável "temporal”

Tabela 28 - Inércia "temporal"

MULTIPLE CORRES VARIABLES=IaIbIc Id Ie If IIaIIbIIcIIdIIeIIfIIIaIIIbIIIcIIIdIIIeIIIf a8 ModelSummary

\begin{tabular}{l|r|r|r}
\hline \multirow{2}{*}{ Dimension } & \multirow{2}{*}{ Cronbach's alpha } & \multicolumn{2}{|c}{ Variance accounted for } \\
\cline { 3 - 4 } & & Total (Eigenvalue) & \multicolumn{1}{|c}{ Inertia } \\
\hline 1 &, 940 & 9,124 &, 480 \\
2 &, 891 & 6,415 &, 338 \\
3 &, 857 & 5,324 &, 280 \\
4 &, 822 & 4,519 &, 238 \\
Total & & 25,382 & 1,336 \\
Mean &, $889^{\mathrm{a}}$ & 6,345 &, 334 \\
\hline
\end{tabular}

a. Mean Cronbach's Alpha is based on the mean Eigenvalue.

\section{b.2) Variável "quantificação"}

Tabela 29 - Inércia "quantificação" MULTIPLE CORRES VARIABLES=lalblc Id le If IlallbllclldllellflllalllblllcllldIlellif b8 ModelSummary

\begin{tabular}{l|r|r|r}
\hline \multirow{2}{*}{ Dimension } & \multirow{2}{*}{ Cronbach's alpha } & \multicolumn{2}{|c}{ Variance accounted for } \\
\cline { 3 - 4 } & & Total (Eigenvalue) & \multicolumn{1}{|c}{ Inertia } \\
\hline 1 &, 940 & 9,101 &, 479 \\
2 &, 891 & 6,421 &, 338 \\
3 &, 858 & 5,353 &, 282 \\
4 &, 820 & 4,488 &, 236 \\
Total & & 25,363 & 1,335 \\
Mean &, $889^{\mathrm{a}}$ & 6,341 &, 334 \\
\hline
\end{tabular}

a. Mean Cronbach's Alpha is based on the mean Eigenvalue. 
b.3) Variável "foco"

Tabela 30 - Inércia "foco"

MULTIPLE CORRES VARIABLES=IaIbIc Id Ie If IIaIIbIIcIIdIIeIIfIIIaIIIbIIIcIIIdIIIeIIIf c8 ModelSummary

\begin{tabular}{l|r|r|r}
\hline \multirow{2}{*}{ Dimension } & \multirow{2}{*}{ Cronbach's alpha } & \multicolumn{2}{|c}{ Variance accounted for } \\
\cline { 3 - 4 } &, 940 & Total (Eigenvalue) & \multicolumn{2}{|c}{ Inertia } \\
\hline 1 &, 885 & 9,109 &, 479 \\
2 &, 834 & 6,206 &, 327 \\
3 &, 821 & 4,768 &, 251 \\
4 & & 4,500 &, 237 \\
Total &, $884^{\mathrm{a}}$ & 24,585 & 1,294 \\
Mean & 6,146 &, 323 \\
\hline
\end{tabular}

a. Mean Cronbach's Alpha is based on the mean Eigenvalue.

b.4) Variável: "tempestividade"

Tabela 31 - Inércia "tempestividade"

MULTIPLE CORRES VARIABLES=IaIbIc Id Ie If IIaIIbIIcIIdIIeIIfIIIaIIIbIIIcIIIdIIIIIIIf d8 ModelSummary

\begin{tabular}{l|r|r|r}
\hline \multirow{2}{*}{ Dimension } & \multirow{2}{*}{ Cronbach's alpha } & \multicolumn{2}{|c}{ Variance accounted for } \\
\cline { 3 - 4 } & & Total (Eigenvalue) & \multicolumn{1}{|c}{ Inertia } \\
\hline 1 &, 941 & 9,212 &, 485 \\
2 &, 886 & 6,235 &, 328 \\
3 &, 833 & 4,751 &, 250 \\
4 &, 821 & 4,506 &, 237 \\
Total & & 24,704 & 1,300 \\
Mean &, $885^{\mathrm{a}}$ & 6,176 &, 325 \\
\hline
\end{tabular}

a. Mean Cronbach's Alpha is based on the mean Eigenvalue. 
c) Mapas perceptuais

c.1) Mapa perceptual variável "temporal", relacionada às variáveis de utilização da informação contábil.

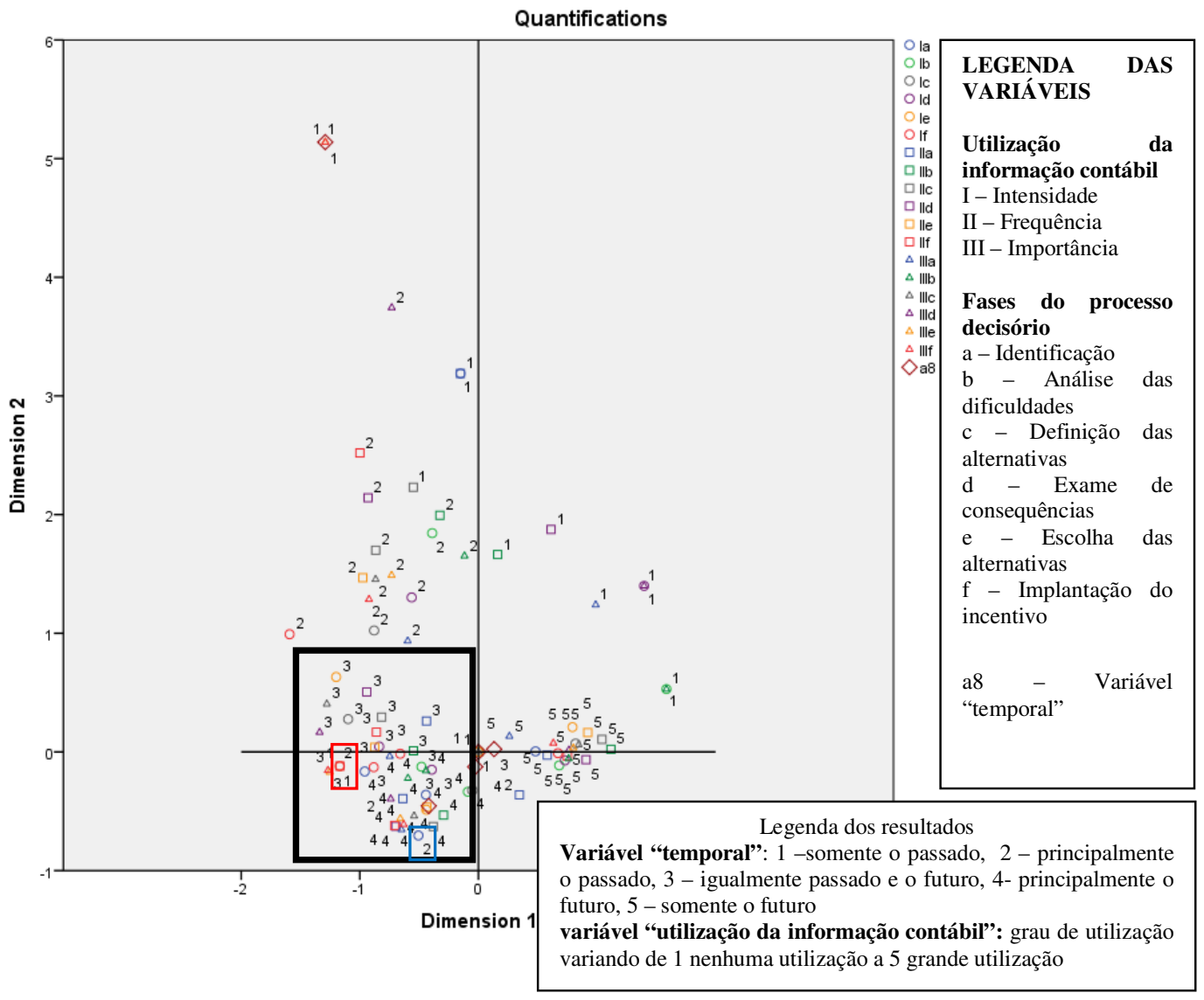

Gráfico 24 - Mapa perceptual "temporal”

O gráfico apresenta a variável "temporal", variável a8 com o número 4, que significa informações contábeis voltadas principalmente para o futuro e está relacionada com a variável "utilização da informação contábil" em todos os aspectos: intensidade, frequência e importância, (variáveis I, II e III) com o número 4 que representa significativa utilização da informação contábil e também com as variáveis com o número 3 que representa uma razoável utilização da informação contábil. Essa relação é destacada no gráfico no quadrado preto.

Verifica-se outra relação da variável "temporal" a8 com o número 4 com a variável "utilização da informação contábil" variável Ia com o número 2 que significa uma pequena utilização da informação contábil no aspecto de intensidade na fase de identificação do processo de decisão, essa variável está assinalada com a cor azul 
Uma terceira relação da variável "temporal" a8 com o número 4 verifica-se com a variável "utilização da informação contábil" variáveis If e IIf respectivamente com os número 1 e 2 (as variáveis estão sobrepostas no gráfico), que significam respectivamente nenhuma utilização da informação contábil e pouca utilização da informação contábil no aspecto de intensidade na fase de implantação do incentivo. Essas variáveis estão destacadas com a cor vermelha no gráfico.

c.2) Mapa perceptual da variável "quantificação", relacionada as variáveis de "utilização da informação contábil"

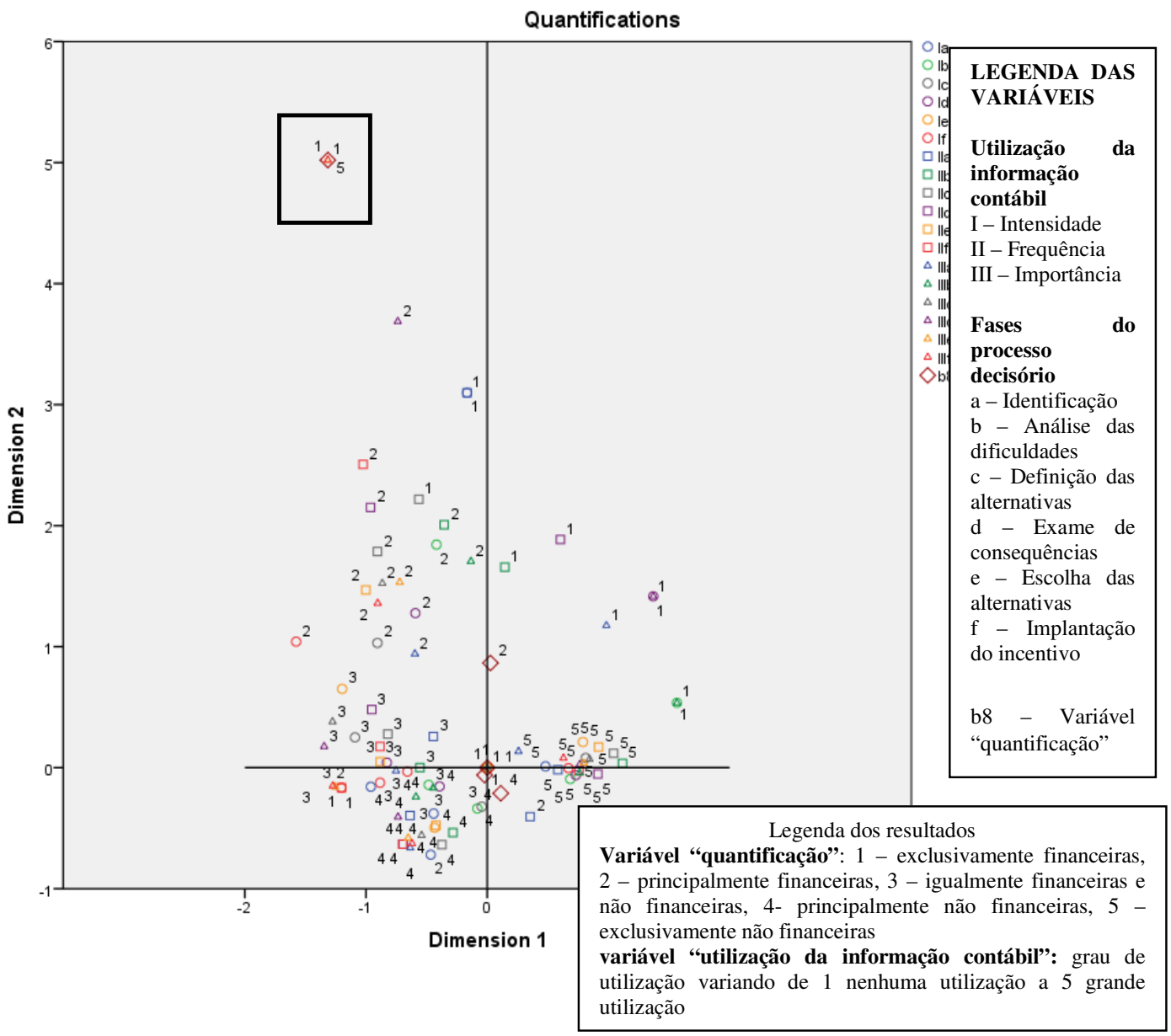

Gráfico 25 - Mapa perceptual "quantificação"

Não foram identificadas no mapa perceptual relações a variável "quantificação" e um grupo de variáveis da “utilização da informação contábil”. Contatou-se, apenas, a relação da variável "quantificação" b8 com o número 5, que significa informações exclusivamente nãofinanceiras, com as variáveis da utilização da informação contábil If e IIf com o número 1, 
que significam nenhuma utilização da informação contábil no aspecto de frequência na fase de identificação e de análise de dificuldades do processo de decisão. Essa relação está assinalada com a cor preta.

c.3) Mapa perceptual variável "foco" relacionada ás variáveis de "utilização da informação contábil"

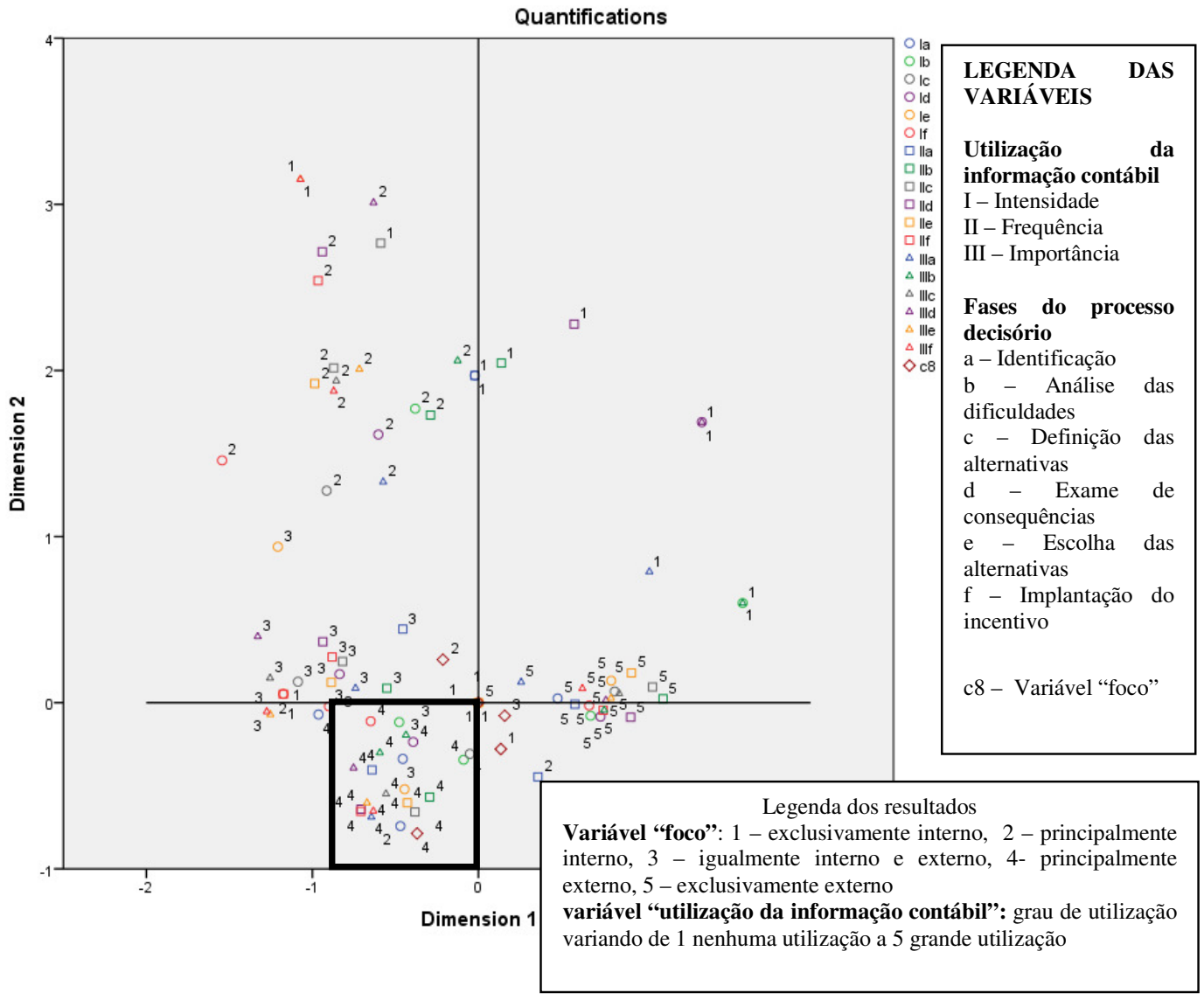

Gráfico 26 - Mapa perceptual "foco"

O gráfico apresenta a variável "foco", variável c8 com o número 4, que significa informações contábeis voltadas principalmente para o ambiente externo, está relacionada com a variável "utilização da informação contábil" em todos os aspectos: intensidade, frequência e importância, (variáveis I, II e III) com o número 4 que representa significativa utilização da informação contábil e também com algumas variáveis com o número 3 que representam uma razoável utilização da informação contábil. Essa relação é destacada no gráfico no quadrado preto. 
c.4) Mapa perceptual variável "tempestividade", relacionada as variáveis "utilização da informação contábil”.

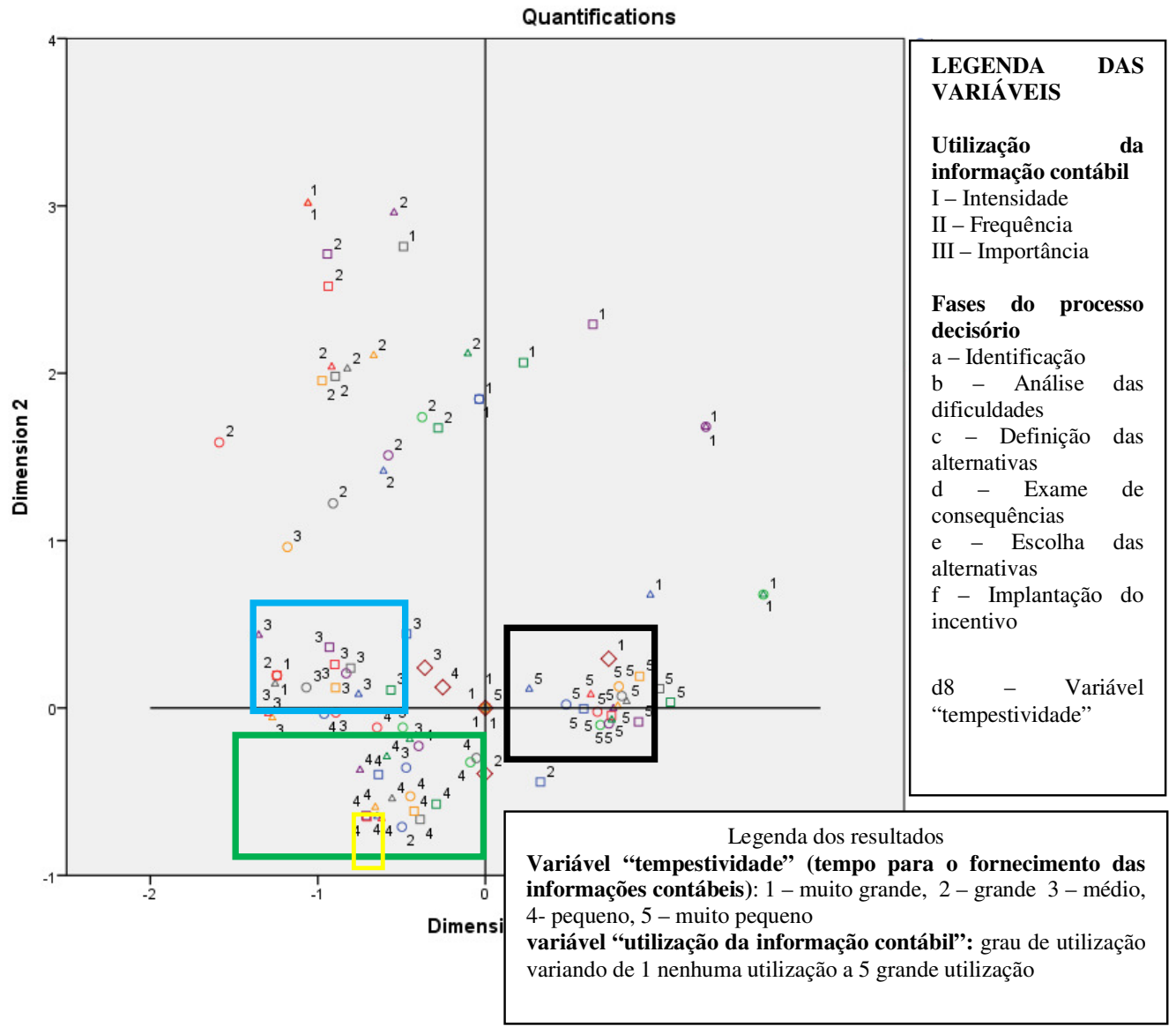

Gráfico 27 - Mapa perceptual "tempestividade"

O gráfico apresenta três relações.

Na primeira verifica-se que a variável "tempestividade", variável d8 com o número 1, que significa tempo muito grande para o fornecimento das informações contábeis, está relacionada com a variável "utilização da informação contábil" em todos os aspectos: intensidade, frequência e importância, (variáveis I, II e III) com o número 5 que representa significativa utilização da informação contábil. Essa relação é destacada no gráfico no quadrado preto.

$\mathrm{Na}$ segunda verifica-se que a variável 'tempestividade', variável d8 com o número 2, que significa tempo grande para o fornecimento das informações contábeis, está relacionada com a variável "utilização da informação contábil”, em todas as formas de utilização, intensidade, frequência e importância, (variáveis I, II e III) com o número 4 que significa grande utilização 
da informação contábil. No gráfico essa relação está assinalada em um quadrado na cor verde. Note-se que existe ainda uma relação com a variável Ia com o número 2 que significa pequena utilização da informação contábil no aspecto de intensidade na identificação do incentivo. No gráfico essa variável está assinalada em um retângulo da cor amarela.

Na terceira verifica-se que a variável "tempestividade", variável d8 com o número 3, que significam tempo médio e para o fornecimento das informações contábeis, estão relacionadas com a variável "utilização da informação contábil", com o número 3 que significa um grau médio, em todas as formas de utilização, intensidade, frequência e importância, (variáveis I, II e III). No gráfico essa correlação está assinalada em um quadrado na cor azul.

\subsubsection{Atributos da informação contábil - fator "agregação"}

Esse fator é identificado mediante a questão 5 letras a, b, c, da parte III do questionário.

a) Aplicação do teste do qui-quadrado

Das três variáveis envolvidas nesta análise a variável "análise sistemática custo-volumelucro" foi a única a apresentar resultado no teste do qui-quadrado superior a 5\%, o que permite rejeitar a hipótese de independência e portanto, supor que nos demais casos, há uma relação entre a variável e a informação contábil, conforme apresentado a seguir.

Quadro 21 - Teste do qui-quadrado fator "agregação"

\begin{tabular}{|l|l|l|l|}
\hline $\begin{array}{c}\text { Itens da questão } \\
5\end{array}$ & \multicolumn{1}{|c|}{ Variável } & $\begin{array}{c}\text { Itens da parte 1 - } \\
\text { questões I a III }\end{array}$ & $\begin{array}{c}\text { p-valor (teste qui- } \\
\text { quadrado) }\end{array}$ \\
\hline letra a & Relatório por divisão e filial & Item I A & 0,022 \\
\hline letra c & Preço de transferência interno & Item I C & 0,015 \\
\hline
\end{tabular}


b) Inércia das dimensões

b.1) Variável "relatório por divisão e filial"

Tabela 32 - Inércia "relatório por divisão e filial"

MULTIPLE CORRES VARIABLES=IaIbIc Id Ie If IIaIIbIIcIIdIIeIIfIIIaIIIbIIIcIIIdIIIeIIIf a5 ModelSummary

\begin{tabular}{l|r|r|r}
\hline \multirow{2}{*}{ Dimension } & \multirow{2}{*}{ Cronbach's alpha } & \multicolumn{2}{|c}{ Variance accounted for } \\
\cline { 3 - 4 } & & Total (Eigenvalue) & \multicolumn{1}{|c}{ Inertia } \\
\hline 1 &, 941 & 9,187 &, 484 \\
2 &, 886 & 6,238 &, 328 \\
3 &, 846 & 5,029 &, 265 \\
4 &, 822 & 4,512 &, 237 \\
Total & & 24,965 & 1,314 \\
Mean &, $886^{\mathrm{a}}$ & 6,241 &, 328 \\
\hline
\end{tabular}

a. Mean Cronbach's Alpha is based on the mean Eigenvalue.

b.2) Variável relatório "preço de transferência interno"

Tabela 33 - Inércia "relatório preço de transferência interno" MULTIPLE CORRES VARIABLES=IaIbIc Id Ie If IIaIIbIIcIIdIIeIIfIIIaIIIbIIIcIIIdIIIeIIIf c5 ModelSummary

\begin{tabular}{l|r|r|r}
\hline Dimension & Cronbach's alpha & \multicolumn{2}{|c}{ Variance accounted for } \\
\cline { 3 - 4 } & & Total (Eigenvalue) & \multicolumn{1}{|c}{ Inertia } \\
\hline 1 &, 940 & 9,111 &, 480 \\
2 &, 888 & 6,295 &, 331 \\
3 &, 851 & 5,157 &, 271 \\
4 &, 822 & 4,529 &, 238 \\
Total & & 25,092 & 1,321 \\
Mean &, $887^{\mathrm{a}}$ & 6,273 &, 330 \\
\hline
\end{tabular}

a. Mean Cronbach's Alpha is based on the mean Eigenvalue. 
c) Mapas perceptuais

c.1) Mapa perceptual da variável "relatórios por divisão e filial" relacionada com a variável de "utilização da informação contábil"

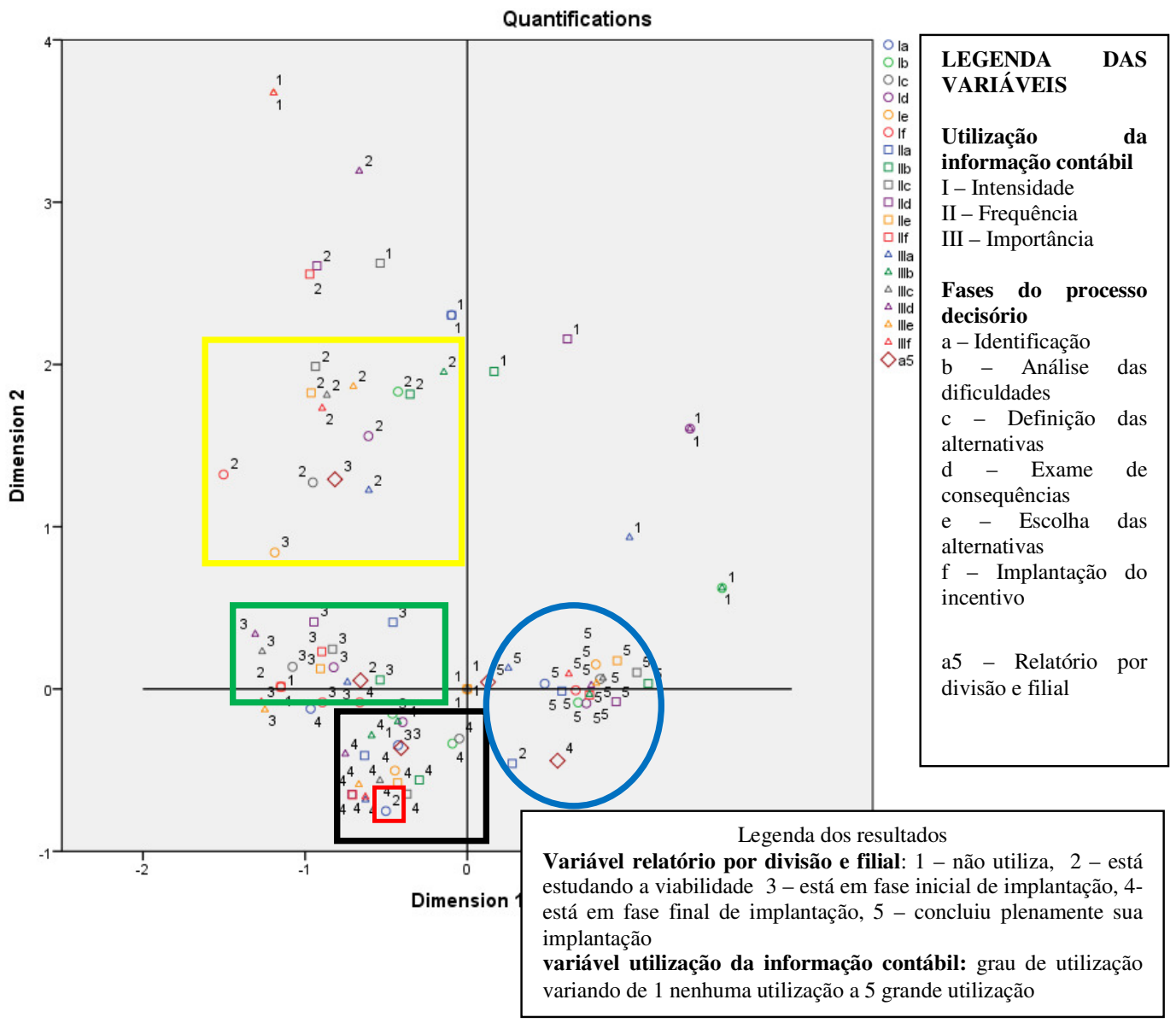

Gráfico 28 - Mapa perceptual "relatório por divisão e filial"

O gráfico apresenta quatro relações.

Na primeira, verifica-se que a variável "relatório por divisão e filial", variável a5 com o número 1, que representa não utiliza, está relacionada a variável "utilização da informação contábil" em todos os aspectos: intensidade, frequência e importância, (variáveis I, II e III) com o número 4 que representa significativa utilização da informação contábil. Essa relação é destacada no gráfico no quadrado preto. Note-se, ainda, uma relação com a variável “utilização da informação contábil” Ia com o número 2 que significa uma pequena utilização 
da informação contábil no aspecto de intensidade na fase de identificação do processo decisório. Essa variável está destaca com um retângulo na cor vermelha.

Na segunda, verifica-se que a variável "relatório por divisão e filial", variável a5 com o número 2, que significa está estudando a viabilidade, está relacionada com a variável "utilização da informação contábil" em todos os aspectos: intensidade, frequência e importância, (variáveis I, II e III) com o número 3 que representa um grau médio de utilização. Essa relação é destacada no gráfico no quadrado verde. Note-se ainda uma relação com a variável Ia com o número 1 que significa nenhuma utilização da informação contábil no aspecto de intensidade na fase de identificação do processo decisório.

Na terceira, verifica-se que a variável "relatório por divisão e filial", variável a5 com o número 4, que significa está em fase final de implantação, está relacionada com a variável "utilização da informação contábil" em todos os aspectos: intensidade, frequência e importância, (variáveis I, II e III) com o número 5 que significa uma grande utilização da informação contábil. Essa relação é destacada no gráfico no quadrado verde. Note-se, ainda, uma relação com a variável IIa com o número 2 que significa uma pequena utilização da informação contábil no aspecto frequência na fase de identificação do processo decisório. Essa relação está destacada no gráfico no quadrado com a cor violeta.

Na quarta, verifica-se que a variável "relatório por divisão e filial", variável a5 com o número 3, que significa está em fase inicial de implantação, está relacionada a variável "utilização da informação contábil" em todos os aspectos: intensidade, frequência e importância, (variáveis I, II e III) com o número 2 que significa um pequena utilização da informação contábil. Essa relação é destacada no gráfico no quadrado amarelo. 
c - 2) Mapa perceptual "preço de transferência interno"

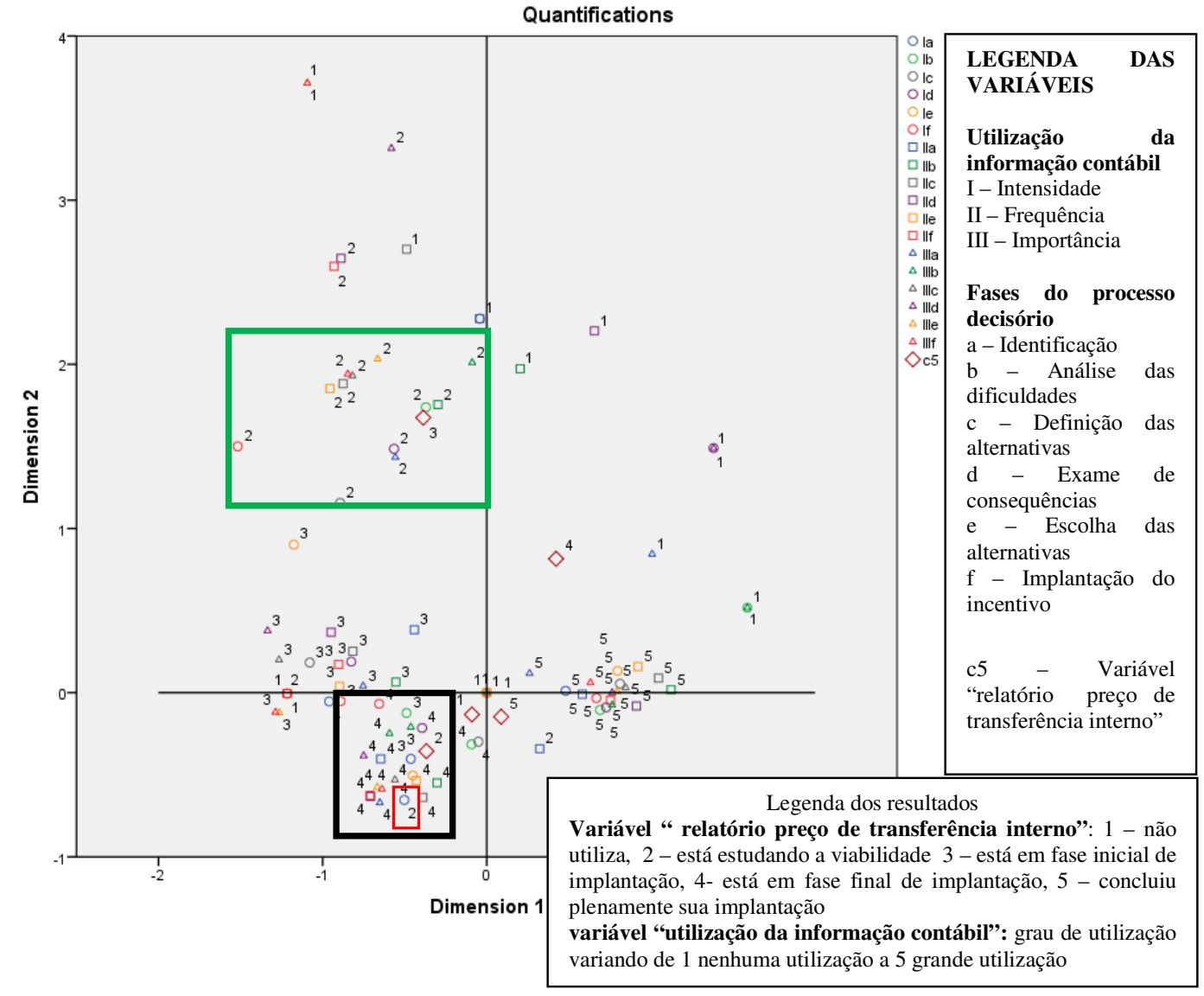

Gráfico 29 - Mapa perceptual "relatório preço de transferência interno"

O gráfico apresenta duas relações.

Na primeira, verifica-se que a variável "relatório preço de transferência interno", variável c5 com o número 2, que significa está estudando a viabilidade, está relacionada com a variável "utilização da informação contábil" em todos os aspectos: intensidade, frequência e importância, (variáveis I, II e III) com o número 4 que representa significativa utilização da informação contábil. Essa relação é destacada no gráfico no quadrado preto. Note-se ainda uma relação com a variável Ia com o número 2 que significa uma pequena utilização da informação contábil no aspecto de intensidade na fase de identificação do processo decisório. Essa variável está destaca com um retângulo na cor vermelha.

Na segunda, verifica-se que a variável "relatório preço de transferência interno", variável c5 com o número 3, que significa está em fase inicial de implantação, está relacionada com a 
variável "utilização da informação contábil" em todos os aspectos: intensidade, frequência e importância, (variáveis I, II e III) com o número 2 que significa pequena utilização da informação contábil. Essa relação é destacada no gráfico no quadrado verde.

\subsubsection{Qualidade da informação contábil - fator "relevância"}

Esse fator é identificado mediante a questão 7 letras a, b, c da parte III do questionário.

a) Aplicação do teste do qui-quadrado

Das três variáveis envolvidas nesta análise a variável "disponibilidade" foi a única a apresentar resultado no teste de qui-quadrado superior a 5\%, o que permite rejeitar a hipótese de independência e portanto supor que nos demais casos há uma relação entre a variável e a informação contábil, conforme apresentado a seguir.

Quadro 22 - Teste do qui-quadrado fator "relevância"

\begin{tabular}{|l|l|l|l|}
\hline Itens da questão 7 & \multicolumn{1}{|c|}{ Variável } & $\begin{array}{c}\text { Itens da parte 1 } \\
\text { questões I a III }\end{array}$ & $\begin{array}{c}\text { p-valor (teste qui- } \\
\text { quadrado) }\end{array}$ \\
\hline letra a & Capacidade de avaliação & Item III b & 0,045 \\
\hline letra b & Capacidade de feedback & Item III c & 0,055 \\
\hline
\end{tabular}

b) Inércia das dimensões

b.1) Variável "capacidade de avaliação"

Tabela 34 - Inércia "capacidade de avaliação" MULTIPLE CORRES VARIABLES=IaIbIc Id Ie If IIaIIbIIcIIdIIIIIfIIIaIIIbIIIcIIIdIIIIIIIIf a7 ModelSummary

\begin{tabular}{l|r|r|r}
\hline \multirow{2}{*}{ Dimension } & \multirow{2}{*}{ Cronbach's alpha } & \multicolumn{2}{|c}{ Variance accounted for } \\
\cline { 3 - 4 } &, 941 & Total (Eigenvalue) & \multicolumn{1}{|c}{ Inertia } \\
\hline 1 &, 889 & 9,225 &, 486 \\
2 &, 838 & 6,321 &, 333 \\
3 &, 821 & 4,860 &, 256 \\
4 & & 4,504 &, 237 \\
Total &, $886^{\mathrm{a}}$ & 24,911 & 1,311 \\
Mean & & 6,228 &, 328 \\
\hline
\end{tabular}

a. Mean Cronbach's Alpha is based on the mean Eigenvalue. 
b.2) Variável capacidade de "feedback"

Tabela 35 - Inércia "capacidade de feed-back"

MULTIPLE CORRES VARIABLES=IaIbIc Id Ie If IIaIIbIIcIIdIIeIIfIIIaIIIbIIIcIIIdIIIeIIIf b7

ModelSummary

\begin{tabular}{l|r|r|r}
\hline \multirow{2}{*}{ Dimension } & \multirow{2}{*}{ Cronbach's alpha } & \multicolumn{2}{|c}{ Variance accounted for } \\
\cline { 3 - 4 } &, 941 & Total (Eigenvalue) & \multicolumn{2}{|c}{ Inertia } \\
\hline 1 &, 886 & 9,200 &, 484 \\
2 &, 847 & 6,217 &, 327 \\
3 &, 821 & 5,069 &, 267 \\
4 & & 4,494 &, 237 \\
Total &, $887^{\mathrm{a}}$ & 24,979 & 1,315 \\
Mean & 6,245 &, 329 \\
\hline
\end{tabular}

a. Mean Cronbach's Alpha is based on the mean Eigenvalue.

c) Análise dos mapas perceptuais

c-1) Mapa perceptual da variável "capacidade de avaliação" relacionada às variáveis de "utilização da informação contábil"

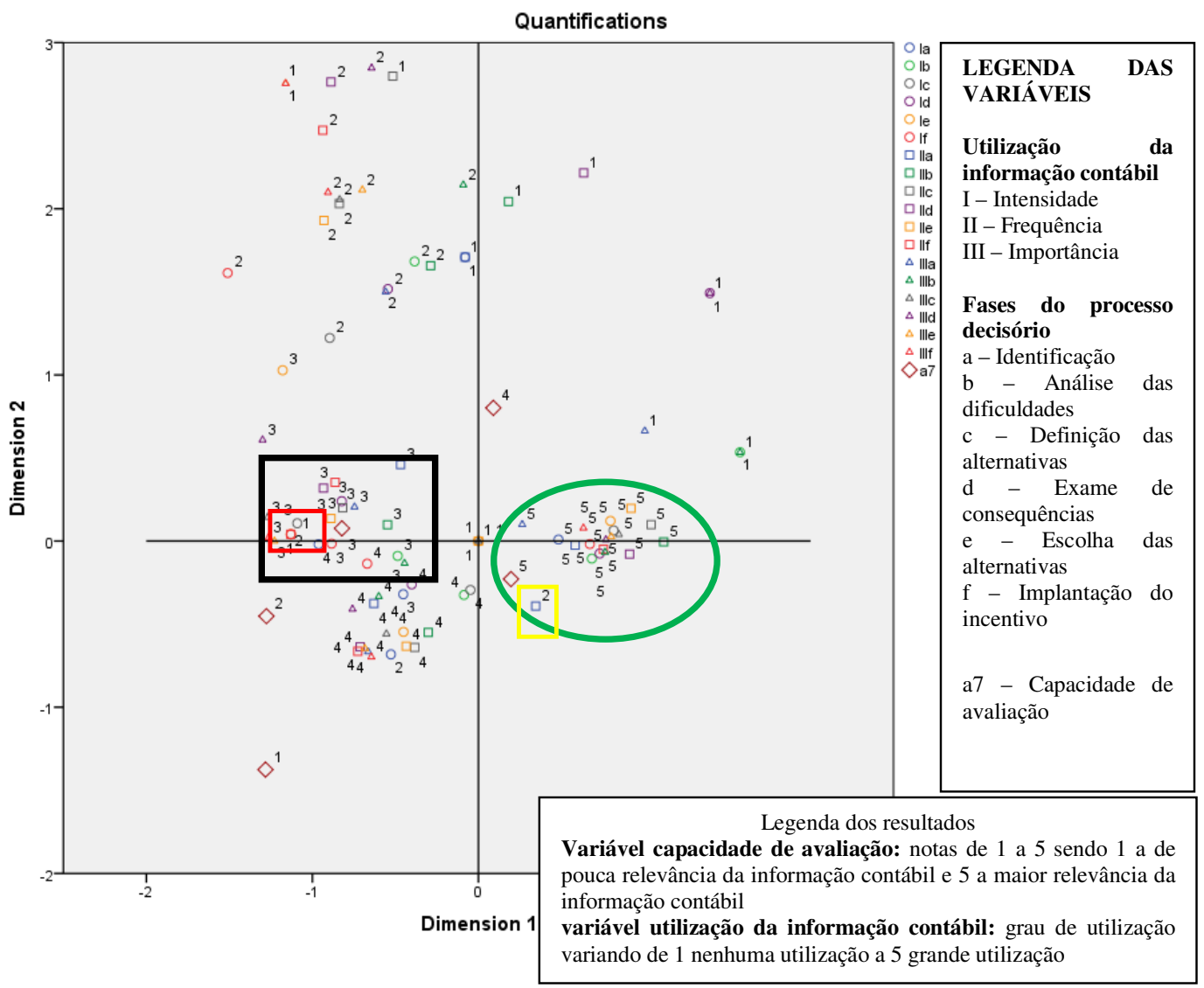

Gráfico 30 - Mapa perceptual "capacidade de avaliação" 
O gráfico apresenta duas relações.

Na primeira, verifica-se que a variável "capacidade de avaliação", variável c7 com o número 3, que significa uma capacidade média de avaliação, está relacionada com a variável "utilização da informação contábil" em todos os aspectos: intensidade, frequência e importância, (variáveis I, II e III), com o número 3 que representa razoável utilização e algumas com o número 4 que representa significativa utilização da informação contábil. Essa relação é destacada no gráfico no quadrado preto. Note-se, ainda, uma relação da variável "utilização da informação contábil" representada por Ia e If ambas respectivamente com o número 1 que significa nenhuma utilização da informação contábil no aspecto de intensidade na fase de identificação do incentivo, e número 2 que significa uma pequena utilização da informação contábil no aspecto de intensidade na fase de implantação do incentivo. Essas variáveis estão destacadas com um retângulo na cor vermelha.

Na segunda, verifica-se que a variável “capacidade de avaliação", variável c7 com o número 5, que significa uma grande capacidade de avaliação, está relacionada com a variável "utilização da informação contábil" em todos os aspectos: intensidade, frequência e importância, (variáveis I, II e III), com o número 5 que significa grande utilização da informação contábil. Essa relação é destacada no gráfico no quadrado verde. Note-se, ainda, uma relação com a variável "utilização da informação contábil" IIa com o número 2, que significa pequena utilização da informação contábil no aspecto de frequência na fase de identificação do incentivo. Essa variável está destacada com um retângulo na cor amarela. 
c-2) Mapa perceptual - "capacidade de feedback"

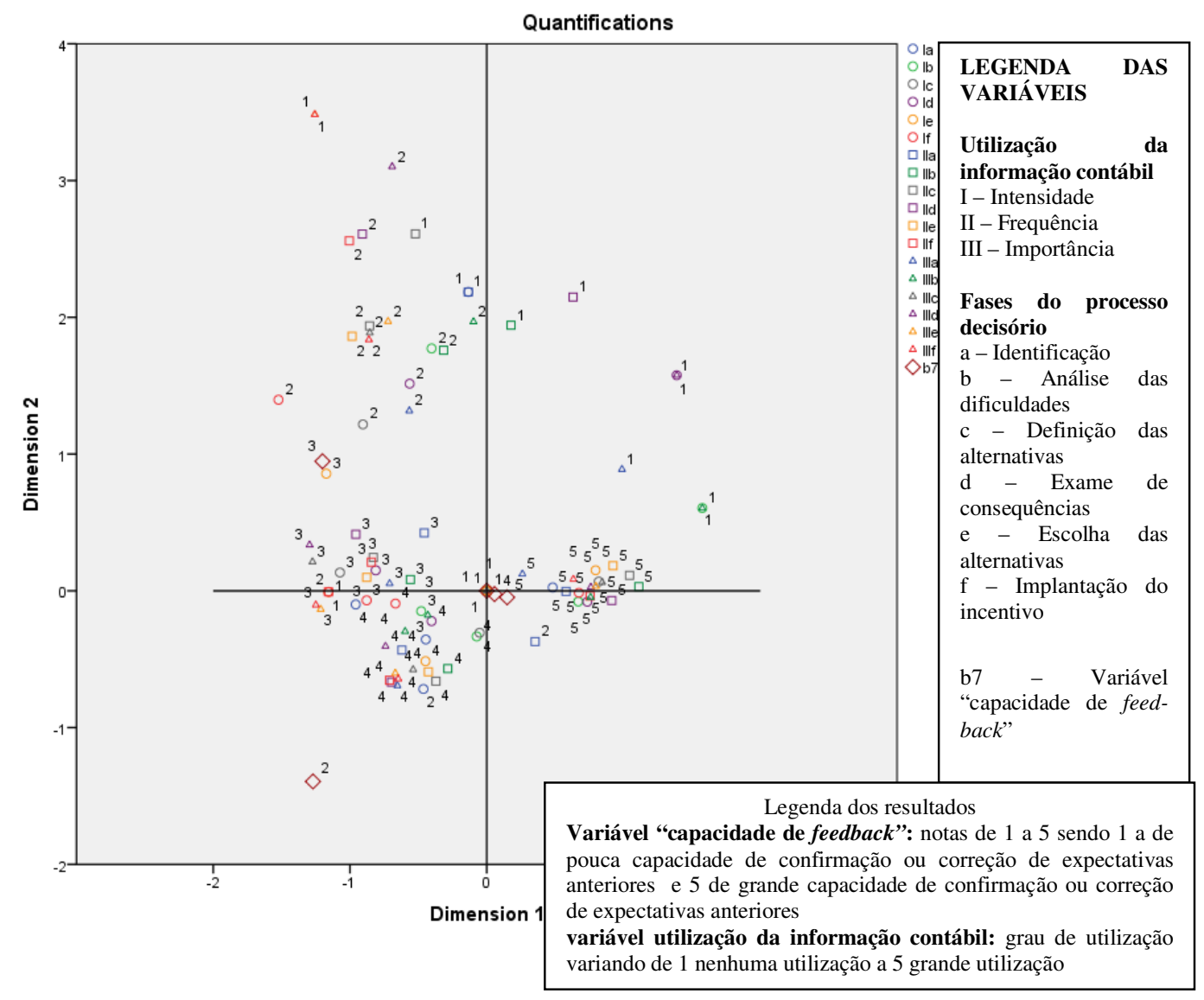

Gráfico 31 - Mapa perceptual "capacidade de feedback"

O mapa perceptual capacidade de feedback não apresenta relações claras entre a variável b7 “capacidade de feedback" em seus diversos graus de relevância com a variável "utilização da informação contábil".

As variáveis b7 "capacidade de feedback" com os números 1, 4 e 5 encontram-se muito próximas ao cruzamento dos eixos que representam as dimensões e, dessa forma, não possuem significado.

A variável b7 “capacidade de feedback" com o número 2 está isolada das variáveis "utilização da informação contábil".

A variável b7 "capacidade de feedback" com o número 3 está próxima da variável "utilização da informação contábil" Ie com o número 3 que significa uma razoável utilização da 
informação contábil no aspecto de intensidade na etapa do processo de decisão de escolha das alternativas. Entretanto, essa mesma variável b7 é equidistante das diversas variáveis da utilização da informação contábil com os números 2 e 3 que significam uma pequena e uma razoável utilização da informação contábil respectivamente.

\subsubsection{Qualidade da informação contábil - fator "confiabilidade"}

Esse fator é identificado mediante a questão 7 letras d, e, f, da parte III do questionário.

a) Aplicação do teste do qui-quadrado

As três variáveis envolvidas nesta análise apresentaram resultado no teste do qui-quadrado inferior a 5\%, o que permite rejeitar a hipótese de independência e portanto supor que há uma relação entre a variável e a informação contábil, conforme apresentado a seguir.

Quadro 23 - Teste do qui-quadrado fator "confiabilidade"

\begin{tabular}{|l|l|l|l|}
\hline Itens da questão 7 & \multicolumn{1}{|c|}{ Variável } & $\begin{array}{c}\text { Itens da parte 1 } \\
\text { questões I a III }\end{array}$ & \multicolumn{1}{c|}{$\begin{array}{c}\text { p-valor (teste qui- } \\
\text { quadrado) }\end{array}$} \\
\hline letra d & Fidedignidade & Item II A & 0,050 \\
\hline letra e & Imparcialidade & Item I A & 0,013 \\
\hline letra f & Veracidade & Item II A & 0,001 \\
\hline
\end{tabular}

b) Inércia das dimensões - fator confiabilidade

b.1) Variavel "fidedignidade"

Tabela 36 - Inércia "fidedignidade"

MULTIPLE CORRES VARIABLES=IaIbIc Id Ie If IIaIIbIIcIIdIIeIIfIIIaIIIbIIIcIIIdIIIeIIIf d7 ModelSummary

\begin{tabular}{l|r|r|r}
\hline \multirow{2}{*}{ Dimension } & \multirow{2}{*}{ Cronbach's alpha } & \multicolumn{2}{|c}{ Variance accounted for } \\
\cline { 3 - 4 } & & Total (Eigenvalue) & \multicolumn{1}{|c}{ Inertia } \\
\hline 1 &, 940 & 9,153 &, 482 \\
2 &, 888 & 6,296 &, 331 \\
3 &, 849 & 5,105 &, 269 \\
4 &, 823 & 4,534 &, 239 \\
Total & & 25,088 & 1,320 \\
Mean &, $887^{\mathrm{a}}$ & 6,272 &, 330 \\
\hline
\end{tabular}

a. Mean Cronbach's Alpha is based on the mean Eigenvalue. 
b.2) Variável "imparciabilidade"

Tabela 37 - Inércia "imparciabilidade"

MULTIPLE CORRES VARIABLES=IaIbIc Id Ie If IIaIIbIIcIIdIIeIIfIIIaIIIbIIIcIIIdIIIeIIIf e7 ModelSummary

\begin{tabular}{l|r|r|r}
\hline \multirow{2}{*}{ Dimension } & \multirow{2}{*}{ Cronbach's alpha } & \multicolumn{2}{|c}{ Variance accounted for } \\
\cline { 3 - 4 } &, 940 & Total (Eigenvalue) & \multicolumn{1}{|c}{ Inertia } \\
\hline 1 &, 887 & 9,150 &, 482 \\
2 &, 851 & 6,257 &, 329 \\
3 &, 820 & 5,162 &, 272 \\
4 & & 4,480 &, 236 \\
Total &, $887^{\mathrm{a}}$ & 25,049 & 1,318 \\
Mean & & 6,262 &, 330 \\
\hline
\end{tabular}

a. Mean Cronbach's Alpha is based on the mean Eigenvalue.

b.3) Variavel "veracidade"

Tabela 38 - Inércia "veracidade"

MULTIPLE CORRES VARIABLES=IaIbIc Id Ie If IIaIIbIIcIIdIIeIIfIIIaIIIbIIIcIIIdIIIIIIIf f7 Model Summary

\begin{tabular}{l|r|r|r}
\hline \multirow{2}{*}{ Dimension } & \multirow{2}{*}{ Cronbach's alpha } & \multicolumn{2}{|c}{ Variance accounted for } \\
\cline { 3 - 4 } & & Total (Eigenvalue) & \multicolumn{1}{|c}{ Inertia } \\
\hline 1 &, 940 & 9,157 &, 482 \\
2 &, 889 & 6,337 &, 334 \\
3 &, 842 & 4,952 &, 261 \\
4 &, 820 & 4,482 &, 236 \\
Total & & 24,927 & 1,312 \\
Mean &, $886^{\mathrm{a}}$ & 6,232 &, 328 \\
\hline
\end{tabular}

a. Mean Cronbach's Alpha is based on the mean Eigenvalue. 
c) Mapas perceptuais

c.1) Mapa perceptual variável "fidedignidade" relacionada às variáveis de "utilização da informação contábil”

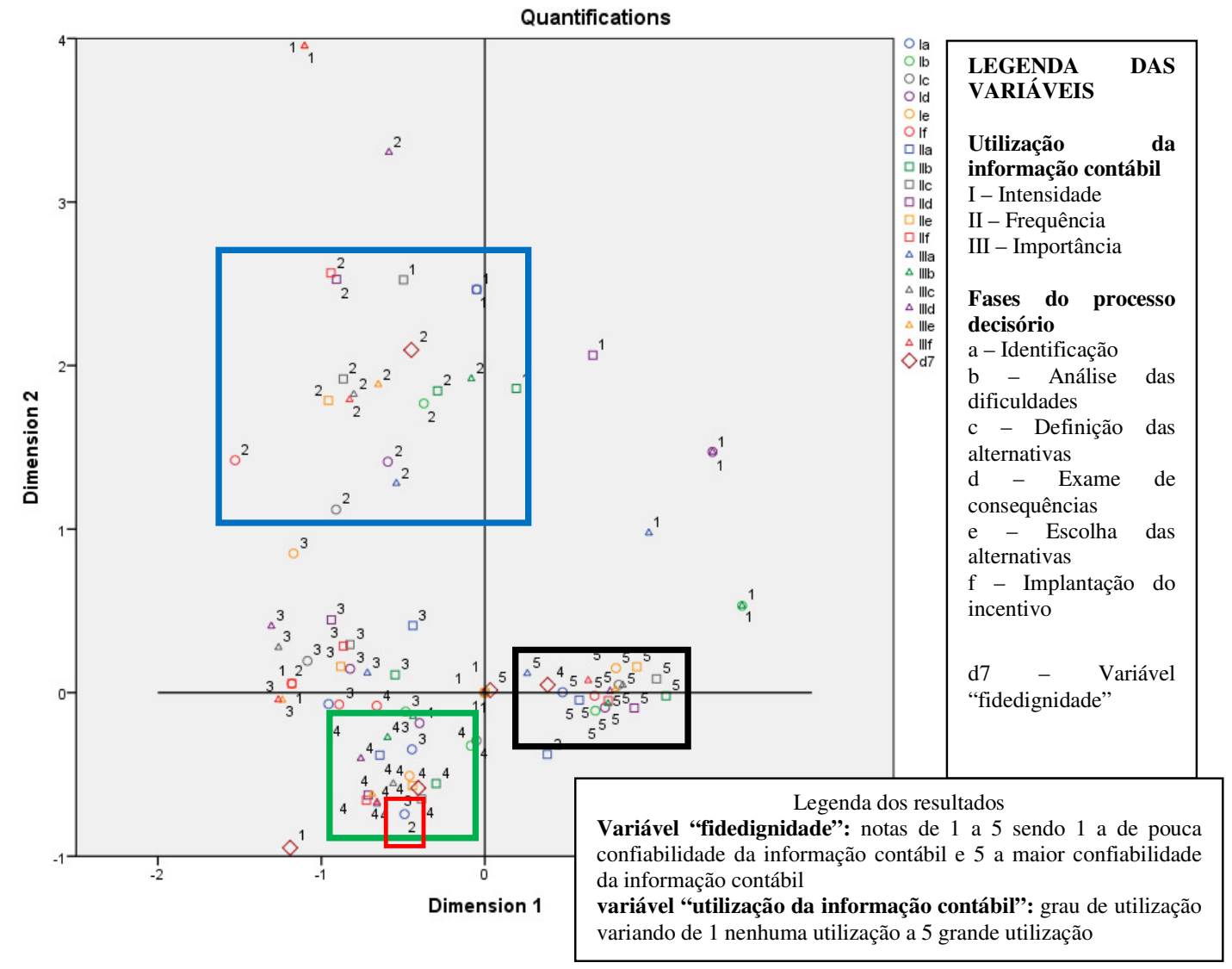

Gráfico 32 - Mapa perceptual "fidedignidade"

O gráfico apresenta três relações muito claras e definidas.

$\mathrm{Na}$ primeira, verifica-se que a variável "fidedignidade", variável d7 com o número 5, que significa uma grande fidedignidade na informação contábil, está relacionada a variável "utilização da informação contábil" em todos os aspectos: intensidade, frequência e importância, (variáveis I, II e III), com o número 5 que significa uma grande utilização da informação contábil. Essa relação é destacada no gráfico no quadrado preto.

Na segunda, verifica-se que a variável "fidedignidade", variável d7 com o número 4, que representa uma significativa fidedignidade na informação contábil, está relacionada a variável "utilização da informação contábil" em todos os aspectos: intensidade, frequência e importância, (variáveis I, II e III), com o número 4 que representa uma significativa utilização 
da informação contábil. Essa relação é destacada no gráfico no quadrado verde. Note-se, também, uma relação da variável d7 com o número 4 com a variável "utilização da informação contábil" Ia com o número 2 que significa uma pequena utilização da informação contábil no aspecto de intensidade na identificação do incentivo fiscal. Essa variável está destacada com um quadrado em vermelho no gráfico.

$\mathrm{Na}$ terceira, verifica-se que a variável "fidedignidade', variável d7 com o número 2, que significa uma pequena fidedignidade na informação contábil, está relacionada com a variável "utilização da informação contábil" em todos os aspectos: intensidade, frequência e importância, (variáveis I, II e III) as variáveis estão com o número 2 que significa uma pequena utilização e algumas com o número 1 , que significa nenhuma utilização da informação contábil. Essa relação é destacada no gráfico no quadrado azul.

c.2) Mapa perceptual variável "imparciabilidade" relacionada às variáveis de "utilização da informação contábil

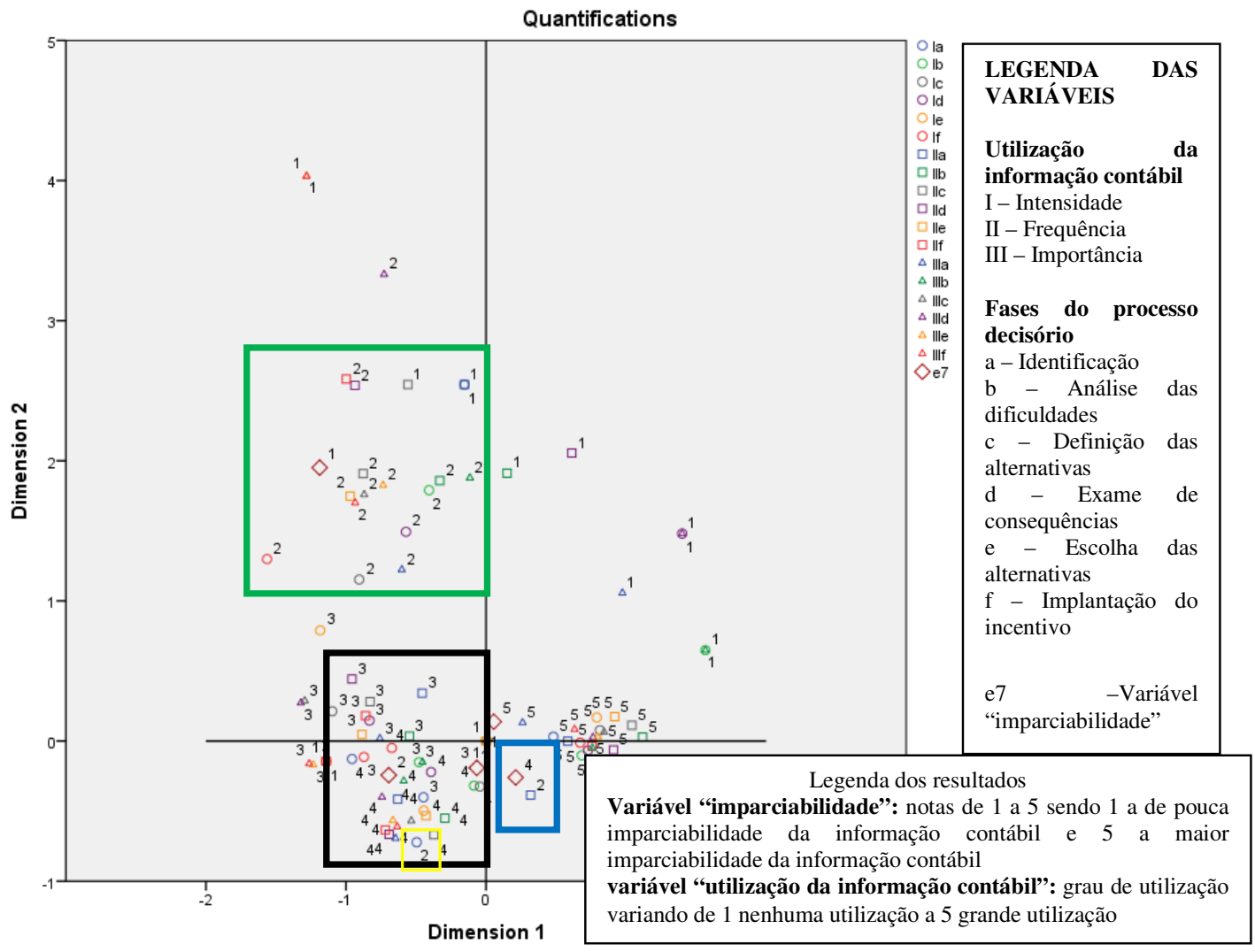

Gráfico 33 - Mapa perceptual "imparciabilidade” 
O gráfico apresenta três relações.

Na primeira, verifica-se que a variável "imparciabilidade", variável e7 com os números 2, que significam pequena imparciabilidade da informação contábil estão relacionadas a variável "utilização da informação contábil" em todos os aspectos: intensidade, frequência e importância, (variáveis I, II e III), as variáveis estão com o número 4 que representa uma significativa utilização da informação contábil e alguns números 3 que representam uma razoável utilização da informação contábil. Essa relação é destacada no gráfico no quadrado preto. Note-se, ainda, a relação com a variável "utilização da informação contábil" Ia com o número 2 que significa uma pequena utilização da informação contábil no aspecto de intensidade na fase de identificação do processo de decisão. Essa variável está destacada no quadrado amarelo.

Na segunda, verifica-se que a variável "imparciabilidade", variável e7 com o números 1, que significa pequena imparciabilidade, está relacionada com a variável “utilização da informação contábil" em todos os aspectos: intensidade, frequência e importância, (variáveis I, II e III), as variáveis estão com os números 2 que representam uma pequena utilização da informação contábil. Essa relação é destacada no gráfico no quadrado verde.

Na terceira, verifica-se que a variável "imparciabilidade", variável e7 com o número 4, que representa uma significativa imparciabilidade da informação contábil está relacionada a variável "utilização da informação contábil" variável IIa com o número 2 que significa uma pequena utilização da informação contábil no aspecto da frequência na fase de identificação do processo de decisão de adesão ao incentivo. 
c.3) Mapa perceptual variável "veracidade" relacionada às variáveis de "utilização da informação contábil”

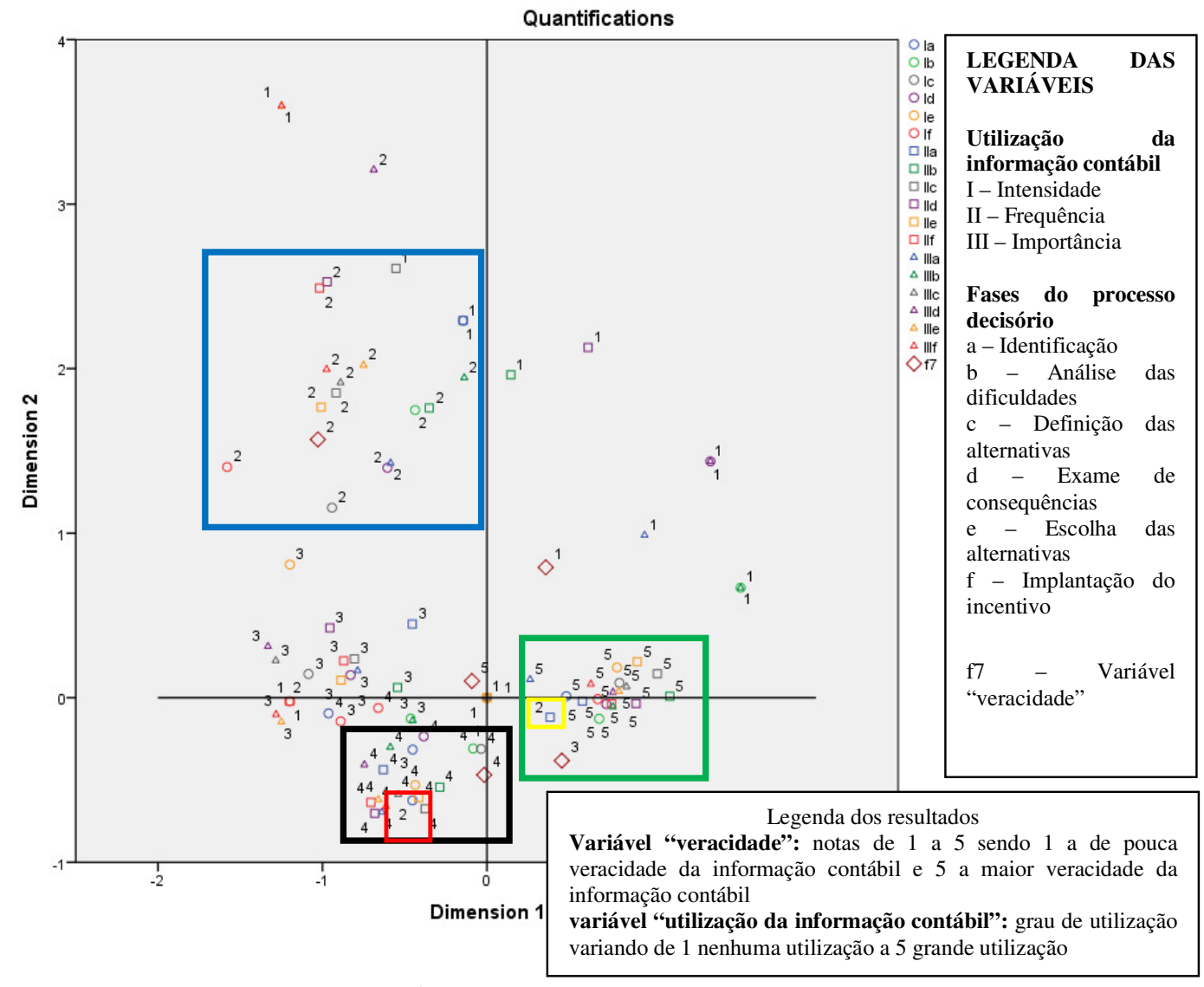

Gráfico 34 - Mapa perceptual "veracidade"

O gráfico apresenta três relações.

$\mathrm{Na}$ primeira, verifica-se que a variável "veracidade", variável f7 com o número 4, que representa uma significativa veracidade da informação contábil, está relacionada a variável "utilização da informação contábil" em todos os aspectos: intensidade, frequência e importância, (variáveis I, II e III). As variáveis estão com o número 4 que representam uma significativa utilização da informação contábil e uma variável de número 3 que representa uma razoável utilização da informação contábil. Essa relação é destacada no gráfico no quadrado preto. Note-se ainda a relação com a variável "utilização da informação contábil” Ia com o número 2 que significa uma pequena utilização da informação contábil no aspecto de intensidade na fase de identificação do processo de decisão. Essa variável está destacada no quadrado vermelho. 
$\mathrm{Na}$ segunda, verifica-se que a variável "veracidade", variável f7 com o número 3, que significa média veracidade da informação contábil, está relacionada a variável "utilização da informação contábil" em todos os aspectos: intensidade, frequência e importância, (variáveis I, II e III) com o número 5, que representa uma grande utilização da informação contábil Essa relação é destacada no gráfico no quadrado verde. Note-se, ainda, a relação com a variável "utilização da informação contábil" IIa com o número 2 que significa uma pequena utilização da informação contábil no aspecto de frequência na fase de identificação do processo de decisão. Essa variável está destacada no quadrado amarelo.

Na terceira, verifica-se que a variável "veracidade", variável f7 com o número 2, que significa pequena veracidade da informação contábil está relacionada com a variável "utilização da informação contábil" em todos os aspectos: intensidade, frequência e importância, (variáveis I, II e III) com o número 2, que representa uma pequena utilização da informação contábil. Esta relação é destacada no gráfico no quadrado azul.

\subsubsection{Qualidade da informação contábil - fator "comparabilidade"}

Esse fator é identificado mediante a questão 7 letras g, h da parte III do questionário.

a) Aplicação do teste do qui-quadrado

Apenas uma das variáveis envolvidas nesta análise apresentou resultado no teste de quiquadrado inferior a 5\%, o que permite rejeitar a hipótese de independência e, portanto, supor que há uma relação entre a variável e a informação contábil, conforme apresentado a seguir.

Quadro 24 - Teste do qui-quadrado fator "comparabilidade"

\begin{tabular}{|l|c|c|c|}
\hline Itens da questão 7 & Variável & $\begin{array}{c}\text { Itens da parte 1 - } \\
\text { questões I a III }\end{array}$ & $\begin{array}{c}\text { p-valor (teste qui- } \\
\text { quadrado) }\end{array}$ \\
\hline letra g & Equidade & Item II A & 0,008 \\
\hline
\end{tabular}


b) Inércia das dimensões - variável "equidade"

Tabela 39 - Inércia "equidade"

MULTIPLE CORRES VARIABLES=IaIbIc Id Ie If IIaIIbIIcIIdIIeIIfIIIaIIIbIIIcIIIdIIIeIIIf g7

ModelSummary

\begin{tabular}{l|r|r|r}
\hline \multirow{2}{*}{ Dimension } & \multirow{2}{*}{ Cronbach's alpha } & \multicolumn{2}{|c}{ Variance accounted for } \\
\cline { 3 - 4 } &, 941 & Total (Eigenvalue) & \multicolumn{1}{|c}{ Inertia } \\
\hline 1 &, 884 & 9,177 &, 483 \\
2 &, 845 & 6,164 &, 324 \\
3 &, 821 & 5,020 &, 264 \\
4 & & 4,497 &, 237 \\
Total &, $886^{\mathrm{a}}$ & 24,858 & 1,308 \\
Mean & 6,215 &, 327 \\
\hline
\end{tabular}

a. Mean Cronbach's Alpha is based on the mean Eigenvalue.

c) Mapa perceptual

c.1) Mapa perceptual da variável "equidade" relacionada às variáveis de "utilização da informação contábil"

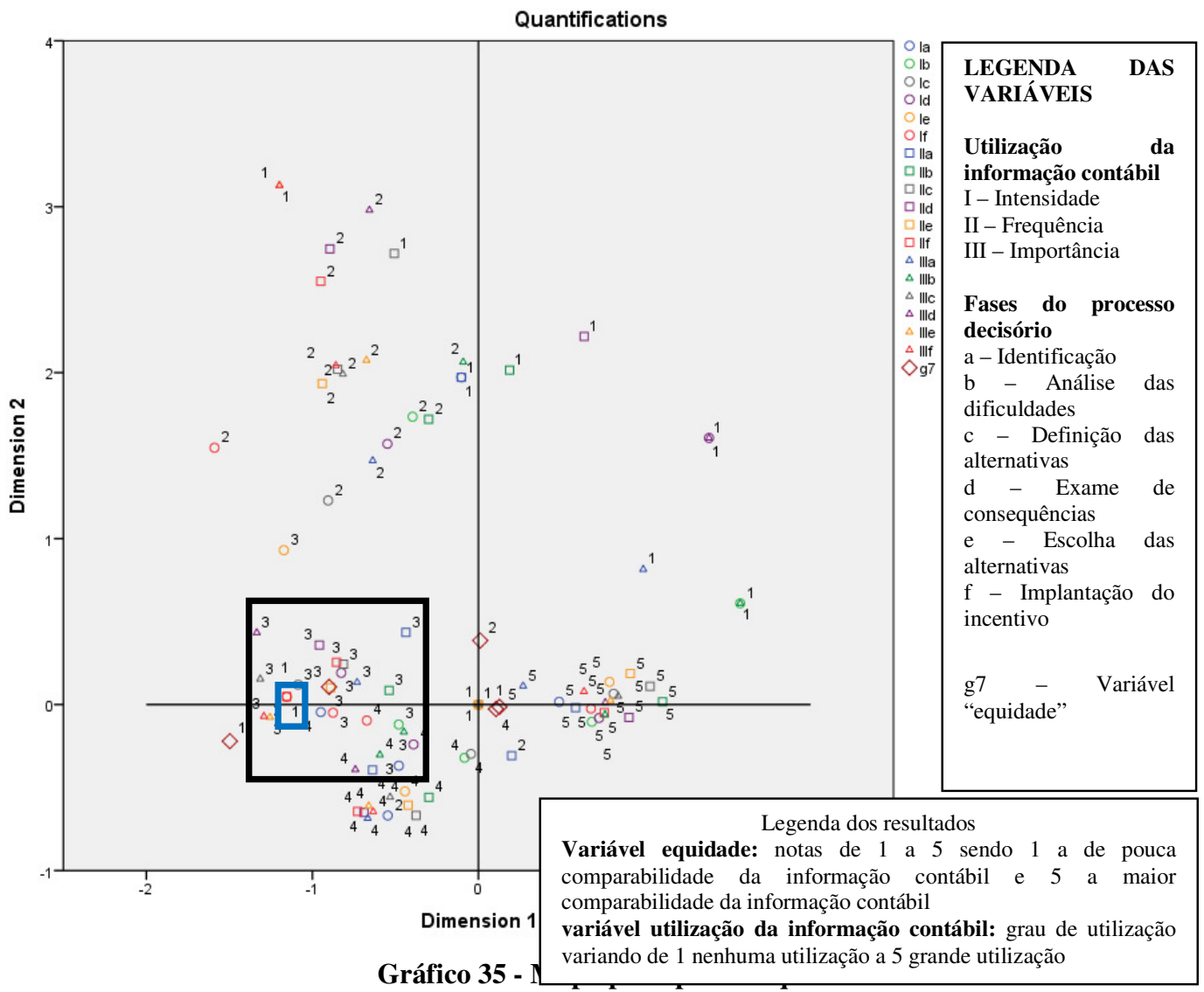

O gráfico apresenta a seguinte relação. 
A variável "equidade" g7 com os números 3, que representa média comparabilidade da informação contábil está relacionada com a variável "utilização da informação contábil" em todos os aspectos: intensidade, frequência e importância, (variáveis I, II e III) com o número 3 que representa uma razoável utilização da informação contábil e algumas variáveis de número 4, que representa significativa utilização da informação contábil. Essa relação é destacada no gráfico no quadrado preto. Note-se, ainda, a relação com a variável "utilização da informação contábil" If com o número 1 que significa nenhuma utilização no aspecto de intensidade na fase de implantação do incentivo, sendo que essa variável está destacada no quadrado azul.

\subsection{Resumo e discussão dos resultados}

\subsubsection{Resultados da pesquisa}

De acordo com os mapas perceptuais analisados, as principais e significativas relações apresentadas entre os diversos fatores e a indução ou inibição da informação contábil podem ser resumidos da seguinte forma:

\subsubsection{Características ambientais}

De forma geral, muitas vezes os fatores relativos às características ambientais se apresentam como indutores da informação contábil, conforme segue:

a) Fator "dinamismo"

a.1) Ambiente dinâmico - foram identificados oito relacionamentos dos ambientes muito dinâmico e dinâmico como fatores indutores da utilização da informação contábil nas variáveis: "atitudes da concorrência", "demanda do mercado", "características dos produtos lançados", “disponibilidades de insumos" e "regulamentação política do setor".

a.2) Ambiente estável - foram identificados três relacionamentos como fatores indutores da informação contábil nas variáveis: “características dos produtos lançados”, “disponibilidade dos insumos" e "preço dos insumos.

A única variável que não apresentou relação com a utilização da informação contábil foi a "tecnologia necessária para a produção". 
Verifica-se que um ambiente dinâmico, no geral é um fator indutor da utilização da informação contábil, enquanto o ambiente estável, no que se refere a características ambientais que se relacionam ao produto da empresa, é um fator inibidor da informação contábil.

b) Fator "heterogeneidade"

b.1) Homogeneidade - foram identificados como fatores indutores da informação contábil as seguintes variáveis: "características dos produtos", "características dos concorrentes" e "características dos clientes".

b.2) Heterogeneidade - foram identificados como fatores indutores da informação contábil as seguintes variáveis: "características dos concorrentes" e "características do clientes".

Não foram identificadas relações com a utilização da informação contábil nas variáveis "características dos fornecedores" e "tecnologia de produção comercialização e serviço". Essa é uma variável similar à "tecnologia necessária para a produção", analisada no fator dinamismo e para a qual também não foi identificada relação com a utilização da informação contábil.

Verifica-se que o fator "heterogeneidade" constitui um indutor da utilização da informação contábil, nos ambientes muito homogêneos ou muito heterogêneos, principalmente no que se refere a características de clientes e concorrentes.

c) Fator "hostilidade"

c.1) Ambiente do mercado hostil - foram identificadas quatro relações como fatores indutores da utilização da informação contábil, quando o ambiente do mercado se encontra hostil, ou seja, tendo como resposta 'está extremamente' ou 'está muito' nas variáveis "mercado saturado" e "mercado restritivo"

c.2) Ambiente do mercado não hostil - foi identificada uma relação como fator indutor da utilização da informação contábil, quando o ambiente do mercado não se encontra hostil, ou seja, tendo como resposta "não está' na variável "mercado restritivo" 
A variável "mercado dominado" não apresentou relação com a utilização da informação contábil.

De forma geral, o que se verifica é que o fator "hostilidade" nas situações em que os mercados são hostis é um fator indutor na utilização da informação contábil.

\subsubsection{Características estruturais}

Não foram identificadas, por meio dos gráficos, relações significativas entre as variáveis consideradas estruturais: "capital da empresa", que corresponde ao fator "natureza", e "porte da empresa", que corresponde ao fator "tamanho", e a variável "utilização da informação contábil”.

\subsubsection{Características de desempenho}

a) Fator "rentabilidade" - foram identificadas duas relações como fator indutor da utilização da informação contábil na variável "margem de lucro", quando esta se encontra muito acima ou acima do esperado.

b) Fator "lucratividade" - foi identificada uma relação como fator indutor da utilização informação contábil na variável "crescimento do lucro" quando esta se encontra acima do esperado.

Não foram identificadas relações com a utilização da informação contábil no que se refere a variável "crescimento da receita".

De forma geral, quando o desempenho se encontra acima do esperado os fatores correspondentes ao desempenho são indutores da informação contábil.

\subsubsection{Atributos da informação contábil}

Fator instrumentos gerenciais contemporâneos 
a.1) Foi identificada a relação como indutor da utilização da informação contábil nas variáveis: "indicadores não financeiros", na situação "está estudando a viabilidade de implantação"

a.2) Foi identificada a relação como indutor da utilização da informação contábil nas variáveis: "análise de cenários estratégicos", e "relatório de controle de qualidade" na situação "está na fase inicial de implantação".

a.3) Foi identificada a relação como indutor da utilização da informação contábil nas variáveis: "relatório de controle da qualidade" na situação "está em fase final da implantação".

a.4) Foi identificada a relação como indutor da informação contábil nas variáveis e "custeioalvo" na situação "concluiu plenamente a implantação".

a.5) Foi identificada a relação como indutor da utilização da informação contábil na variável "custeio-alvo" na situação "não utiliza”.

Dos oito instrumentos gerenciais contemporâneos objetos desta pesquisa em quatro deles, "ABC/ABM", "EVA", "uso sistemático de benchmarking" e "balanço scorecard" não houve relação com a utilização da informação contábil. Nos demais foram identificadas poucas relações que os caracterizassem como fatores indutores da informação contábil.

b) Fator instrumentos gerenciais tradicionais

b.1) Foi identificada a relação como indutor da utilização da informação contábil nas variáveis: "custeio variável ou por absorção" e "orçamento participativo" na situação "está estudando a viabilidade de implantação".

b.2) Foi identificada a relação como indutor da utilização da informação contábil nas variáveis "demonstração de resultados mensais" e "orçamento participativo" na situação "está na fase inicial de implantação". 
b.3) Foi identificada a relação como indutor da utilização da informação contábil nas variáveis "custeio variável ou por absorção" e "demonstração de resultados mensais" na situação "está em fase final da implantação" .

b.4) Foi identificada a relação como indutor da utilização da informação contábil na variável "custeio variável ou absorção" na situação "não utiliza”.

Dos quatro instrumentos gerenciais tradicionais apenas o "orçamento não participativo" não apresentou relação com a utilização da informação contábil.

Em relação ao instrumento "orçamento participativo" não foi identificada relação com a utilização da informação contábil quando este instrumento já está implantado ou em fase final de implantação.

Verifica-se que os instrumentos gerenciais tradicionais se constituem em diversas variáveis como indutores da informação contábil, de uma maneira mais destacada do que os instrumentos gerenciais contemporâneos.

c) Fator escopo

c.1) Foi identificada relação como indutor da utilização da informação contábil a variável "temporal" na situação em que as informações estão voltadas principalmente para o futuro.

c.2) Foi identificada relação como indutor da utilização da informação contábil a variável "foco" na situação em que "as informações estão voltadas para o ambiente externo".

c.3) Foram identificadas relações como indutor da informação contábil a variável "tempestividade" nas situações em que ocorre "um tempo muito grande" ou "um tempo grande" no fornecimento das informações

Verifica-se que em relação ao fator "escopo" ocorrem relações com a utilização da informação contábil. Estas relação são fatores indutores da utilização da informação contábil. 
d) Fator Agregação:

d.1) Foi identificada relação como indutor da utilização da informação contábil a variável "relatórios por divisão e filial" nas situações não utiliza e esta em fase final de implantação.

d.2) Foi identificada relação como indutor da utilização da informação contábil da variável "preço de transferência interno" na situação "está estudando a viabilidade de implantação".

d.3) Foi identificado como inibidor da utilização da informação contábil as variáveis "relatório por divisão e filial" e "preço de transferência interno" ambas na situação "está em fase inicial de implantação".

Não foram identificadas relações com a utilização da informação contábil na variável "análise sistemática de custo-volume-lucro".

Verifique-se que, em relação ao fator "agregação", existem alguns fatores indutores da informação contábil que dependem da fase de implantação dos relatórios que visam à agregação dentro da empresa. E como fator inibidor as variáveis "relatório por divisão e filial e preço de transferência interno, quando estão em fase de implantação. Ressalte-se que a análise do fator "agregação" foi realizada a partir de relatórios gerencias e que desta forma, o resultado deste fator está alinhado com o resultado dos dois fatores anteriores, "instrumentos gerenciais contemporâneos" e "instrumentos gerenciais tradicionais", ou seja, os atributos da informação contábil não apresentaram significativa relação como fator indutor da utilização da informação contábil.

\subsubsection{Qualidades da informação contábil}

a) Fator "relevância"

Foi identificada que na variável "grande capacidade de avaliação" há um relacionamento com um alto grau de utilização da informação contábil. Não foram identificadas relações na variável "capacidade de feedback" com a utilização da informação contábil. 
b) Fator "confiabilidade"

b.1) A variável "fidedignidade" foi identificada como indutora da utilização da informação contábil quando a informação é muito fidedigna e inibidora da utilização da informação contábil quando a fidedignidade é pequena.

b.2) A variável "imparciabilidade" foi identificada como inibidora e como indutora da utilização da informação contábil quando a imparciabilidade é pequena. A situação que aparentemente se constitui um paradoxo, pode demonstrar que as questões relativas a imparciabilidade em algumas situações são inibidoras da utilização da informação contábil, enquanto que em outras são indutoras.

b.3) A variável "veracidade" foi identificada como indutora da informação contábil quando há uma grande veracidade da informação, e inibidora quando há uma pequena veracidade da informação.

De forma geral, o fator confiabilidade está relacionado a utilização da informação contábil. Uma grande confiabilidade é um fator indutor e uma pequena confiabilidade um fator inibidor.

c) Fator "comparabilidade"

c.1) A variável "equidade" foi relacionada com indutora da informação contábil quando há uma pequena comparabilidade da informação.

Não foram identificadas relações com a utilização da informação contábil das variáveis "disponibilidade" e "consistência".

Algumas qualidades da informação contábil se relacionam com a utilização da informação contábil de forma direta. Assim, se houver uma grande imparciabilidade e veracidade nos dados contábeis, esses fatores serão indutores da utilização da informação contábil, mas se houver uma pequena imparciabilidade e veracidade da informação contábil esses fatores serão inibidores da utilização da informação contábil. Quanto à equidade a relação apresentada é que uma pequena comparabilidade da informação contábil é um fator indutor da mesma, o que não parece ser uma relação esperada do ponto de vista de decisões racionais, mas que 
talvez possa ser entendida sob uma perspectiva comportamental, que não constitui objeto do presente trabalho.

\subsubsection{Confrontação com outros estudos}

Conforme apresentado no item 2.3, os fatores que poderiam ser indutores ou inibidores da informação contábil são definidos por meio de três estudos. Apresenta-se, a seguir, uma comparação entre os resultados obtidos em cada um dos trabalhos e os resultados da pesquisa aqui realizada.

Ressalte-se que esses três trabalhos tem como objetivo verificar a relação de determinadas variáveis com a utilização da informação contábil em diferentes situações. Assim, apesar de semelhantes os objetivos desses três trabalhos não são idênticos ao do presente estudo que é determinar os fatores indutores e inibidores da utilização informação contábil na adesão aos incentivos fiscais de inovação tecnológica.

Dessa forma, essa comparação necessita ser vista muito mais como indicativa do que confirmativa, ou seja, se os resultados alcançados, neste trabalho, estão ou não alinhados com os de pesquisas anteriores.

\subsubsection{Arranjos entre fatores situacionais e sistema de contabilidade gerencial sob a ótica da teoria da contingência}

O autor apresenta uma ampla revisão de diversos estudos e pesquisas sobre a relação entre os fatores situacionais e o sistema de contabilidade gerencial - SCG. A seguir, são relacionadas algumas das conclusões, comparando-as com os resultados da pesquisa do presente trabalho.

a) ambiente competitivo aumenta a utilização de informações contábeis: "Pressão competitiva resulta no aumento da sofisticação e no uso de sistemas contábeis" (GUERRA, 2007 p. 36).

$\mathrm{Na}$ presente pesquisa, a pressão competitiva pode ser identificada pelo ambiente externo dinâmico que consta da pergunta $2 \mathrm{~b}$ e do dinamismo dos produtos lançados no mercado da pergunta 2d. Para ambos, identifica-se que o dinamismo tem relação com a grande utilização da informação contábil, estando, portanto, estes resultados alinhados. 
b) ambiente dinâmico aumenta a utilização de informações contábeis

com o aumento do dinamismo ambiental, cresce a necessidade de um sistema contábil com informações não financeiras e tempestivas. (GUERRA, 2007 p. 104)

incerteza ambiental percebida pelos gestores aumenta, eles tendem a utilizar mais informações não financeiras. (GUERRA, 2007 p.104)

quanto maior a incerteza do ambiente, mais informações devem ser processadas para os tomadores de decisão. (GUERRA, 2007 p. 107)

Na presente pesquisa, também, é identificado que, em diversas variáveis com um ambiente dinâmico, ocorre a relação com a indução para a utilização da informação contábil. Essas variáveis são: "demanda do mercado", "característica dos produtos lançados", "disponibilidade de insumos", "regulamentação política do setor". Entretanto, no que se refere a indicadores não financeiros se verifica que a variável "indicadores não financeiros", somente na situação "está em fase inicial de implantação" constitui-se em um fator indutor da utilização da informação contábil.

c) Os instrumentos da contabilidade gerencial contemporâneos seriam mais relacionados com o ambiente dinâmico e, portanto, seriam fatores indutores da utilização da informação contábil.

Analisando primeiramente o atributo seleção da informação percebe-se, no resultado, que o uso de instrumentos da contabilidade gerencial contemporâneos são os mais indicados nos casos de ambiente dinâmico. (GUERRA, 2007 p. 106)

Empresas com estratégia de diferenciação e estrutura descentralizada tendem, em contraposição a organizações com estratégia focada no baixo custo a estrutura centralizada, a usar mais intensamente um SCG que fornece medidas de satisfação do clientes, informações tempestivas, indicadores chaves de atividades de produção e qualidade, benchmarking e planos estratégicos. Em outras palavras, tais características estratégicas e estruturais contribuem para o uso de instrumentos de contabilidade gerencial mais contemporâneos (GUERRA, 2007 p. 104 e 105)

A presente pesquisa identifica uma situação diferente, uma vez que, dos oito instrumentos gerenciais contemporâneos, apenas, três são variáveis que induzem à utilização da informação contábil.

d) Os instrumentos gerenciais tradicionais estão mais relacionados com ambientes estáveis e assim, estariam menos relacionados com a utilização da informação contábil. 
Os instrumentos gerenciais tradicionais se ajustam melhor a outros fatores situacionais. Pois foram desenvolvidos sob um design que atendesse um contexto estável, onde a tecnologia segue processos com poucas exceções, a estratégia de custos focaliza a eficiência mais na produção interna e menos nas necessidades do mercado e, finalmente, a estrutura mecanicista favorece o fluxo padronizado de subordinação das tarefas. (GUERRA, 2007 P. 106).

A presente pesquisa também não confirma esta observação. Os instrumentos gerenciais tradicionais apresentam-se em um nível de indução da utilização da informação contábil ao menos semelhante aos instrumentos gerenciais contemporâneos, uma vez que, em metade deles, são identificados como indutores da utilização da informação

e) Um escopo amplo das informações está relacionado com um ambiente incerto e, portanto, com uma maior utilização da informação contábil

Em relação ao segundo atributo do $\mathrm{SCG}$, os resultados das pesquisas revelam que um escopo amplo (informações voltadas ao ambiente externo, mensuração não-financeira e projeção de eventos futuros) é compatível com ambiente incerto. (GUERRA, 2007 p. 136)

Por meio da presente pesquisa verificou-se que informações voltadas para o futuro, e voltadas para o ambiente externo são fatores indutores da utilização da informação contábil estando, portanto, no mesmo sentido do observado na pesquisa realizada por Guerra.

f) A heterogeneidade é um fator que agrega e integra informações e, dessa forma, está relacionada com uma maior utilização da informação contábil: "À medida que a heterogeneidade ambiental aumenta, o sistema de informações contábeis utiliza mais técnicas que agregam e integram informações” (GUERRA, 2007 p. 104)

Verifica-se, nesta pesquisa, que nos ambientes onde ocorre a heterogeneidade as variáveis “concorrentes" e "clientes", são indutoras da utilização da informação contábil, mas nas variáveis "características dos produtos no mercado", "tecnologia de produção e serviço" e “características dos fornecedores”, esta mesma relação não foi identificada.

\subsubsection{Fatores condicionantes de gestão de custos interorganizacionais na cadeia de valor de hospitais privados no Brasil}

A tese tem como objetivo investigar e identificar fatores que favorecem ou inibem a prática da Gestão de Custos Interorganizacionais (CGI) por parte de hospitais privados no Brasil. Pode- 
se presumir que a prática da CGI implica uma maior utilização de informações contábeis, sendo assim, variáveis que incentivem a prática da CGI, também, devem ser indutoras da utilização da informação contábil. As relações apresentadas pelo autor são:

a) Os artefatos gerenciais são necessários para a CGI, portanto, sua utilização deve ser um fator indutor da utilização informação contábil

A pesquisa de Kajuter e Kumlmala (2005) forneceu evidências empíricas que suportam a afirmação de que a existência de mecanismo, instrumentos ou artefatos gerenciais que dêem suporte à GCI é vital para o seu funcionamento. (CAMACHO, 2010, p.144)

A pesquisa mostra que dos doze instrumentos gerenciais analisados neste trabalho, apenas, cinco são fatores indutores da utilização da informação contábil. Ora, um artefato gerencial em sua essência e pela sua própria definição, deveria ser um fator indutor a utilização da informação contábil, afinal, é isso que justifica sua existência. Assim, analisados em seu conjunto os artefatos gerenciais não podem ser considerados como um fator indutor da utilização da informação contábil e, portanto, os resultados do presente trabalho estão alinhados, apenas, em parte à observação realizada por Camacho (2010).

b) Quanto maior for o lucro além do esperado, mais será a situação favorável para a CGI e, portanto, será um fator indutor para a utilização da informação contábil.

De acordo com a percepção dos hospitais, na escala de 0 a 10, na qual ' 0 ' significa muito distante do esperado e '10', muito próxima do esperado, a média do fator 'margem de lucro' é 4,78. Na matriz de análise, essa média se encontra no intervalo entre 2,5 a 5,0 e se classifica como provável, portanto, favorável à GCI. (CAMACHO, 2010 p. 170)

Conforme já comentado anteriormente, de acordo com a literatura pesquisada, quanto mais distante a margem de lucro se encontrar em relação ao esperado (margem orçada, planejada, desejada), mais favorável para a GCI. (CAMACHO, 2010 p. 170)

O presente estudo confirma esta situação, uma vez que é identificado que, a variável "lucro muito acima do esperado" está relacionada com a grande utilização da informação contábil, sendo um fator indutor da sua utilização. 


\subsubsection{Fatores determinantes no nível de disclosure voluntário de companhias abertas no Brasil.}

O autor trata dos fatores determinantes para o disclosure voluntário. É razoável estabelecer que à medida que existe um maior disclosure a informação contábil é mais utilizada. Os resultados deste trabalho são apresentados em um quadro resumo (MURCIA: 2009, p. 148), discriminando três tipos de disclosure: econômico, ambiental e total.

a) O tamanho da empresa não tem relação com o disclosure econômico, nem ambiental, nem total.

Também, neste trabalho, verifica-se que o tamanho da empresa, de forma, geral, não é um fator nem indutor nem inibidor da utilização da informação contábil. Identificam-se, apenas, relações da utilização da informação contábil como fator indutor em situações muito específicas, ou seja, em empresas de grande porte na definição de alternativas para o uso dos incentivos fiscais.

b) A natureza do capital é relacionada com o disclosure econômico, ambiental e total.

Igualmente ao item anterior, no presente trabalho, não foram identificadas relações entre a utilização da informação contábil e a natureza do capital, sendo, apenas, verificadas relações em casos específicos, nos quais a natureza se encontra como um fator inibidor da utilização da informação contábil.

O observado na presente pesquisa, portanto, diverge da conclusão do trabalho de Murcia (2009).

c) Oportunidade de crescimento, trata-se da variação da receita líquida, a qual não foi relacionada com disclosure econômico, nem ambiental nem total.

Também, neste trabalho, não é identificada relação do crescimento da receita com a utilização da informação contábil.

d) Empresa de auditoria, o trabalho de Murcia (2009) identificou disclosure econômico, mas não disclosure ambiental nem total. Mas no caso do disclosure econômico é adotado um nível 
de significância de $10 \%$, quando para todas as outras variáveis foi utilizado um nível de significância de $5 \%$.

Na presente pesquisa não foi identificada relação da empresa de auditoria com a utilização da informação contábil, sendo o nível de significância utilizado 5\%, como em todos as demais variáveis, indicando que muito possivelmente, se o nível de significância da pesquisa de Murcia fosse de $5 \%$ o resultado do trabalho dele seria o mesmo que o da presente pesquisa. 


\section{CONSIDERAÇÕES FINAIS}

Este estudo investigou a utilização da informação contábil no processo de adesão aos incentivos fiscais de inovação tecnológica estabelecidos pela Lei n- 11.196/2005, procurando identificar a existência de fatores indutores e/ou inibidores na utilização da informação contábil. Foram analisados dezessete fatores e cinquenta e cinco variáveis. A análise da utilização da informação contábil é bastante discutida na literatura, entretanto, de forma específica para fins de incentivos fiscais, não são identificados trabalhos semelhantes.

A adesão ao incentivo fiscal logicamente deve estar suportada por um modelo de decisão adequado. O referencial teórico utilizado neste trabalho para a definição desse modelo é a teoria da contingência, a qual estabelece uma importância significativa para o ambiente externo, bem como nega a existência de uma forma ideal de organização.

Assim, adota-se como referencial da forma de decisão a teoria apresentada por Trater e Hoy (1998), o qual estabelece seis modelos diferentes. Julga-se mais adequado para a decisão na adesão aos incentivos fiscais de inovação o modelo denominado mixed scanning, mas sendo incluído também na pesquisa o modelo normalmente utilizado, denominado classical.

O universo das empresas pesquisadas é obtido de um relatório publicado pelo MCTI, sendo utilizado um questionário estruturado. A técnica estatística adotada foi a análise de correspondência (HOMALS).

Um primeiro resultado da pesquisa que merece destaque foi a confirmação de que a informação contábil é muito utilizada no processo de adesão aos incentivos fiscais de inovação. Entretanto, ao contrário do esperado, os tomadores de decisão se utilizaram do modelo classical.

Isso pode, ao menos em parte, explicar a baixa adesão à utilização do incentivo, pois os tomadores de decisão estariam se utilizado de um modelo que não parece ser o adequado para a obtenção das respostas aos problemas levantados.

A questão de pesquisa apresentada "quais os fatores indutores e inibidores na utilização das informações contábeis para adesão aos incentivos fiscais de inovação tecnológica?" é respondida da seguinte forma: 
Os fatores indutores são: dinamismo; heterogeneidade; hostilidade; rentabilidade; lucratividade; alguns instrumentos gerenciais; escopo; agregação; confiabilidade e equidade.

Quanto aos fatores inibidores, com exceção da "confiabilidade" que se constitui em fator inibidor, quando esta qualidade não está presente, não foram encontrados outros fatores inibidores que se relacionassem com a utilização da informação contábil em todos os aspectos e em todas fases do processo decisório. Foram identificadas algumas variáveis específicas no fator heterogeneidade, no fator escopo, no fator agregação sempre na fase de identificação do benefício, que se apresentaram como inibidoras da utilização da informação contábil.

Quantos às hipóteses levantadas a pesquisa apresenta o seguinte resultado:

Hipótese 1 - Existem fatores indutores e inibidores na utilização da informação contábil, para a adesão dos incentivos fiscais de inovação tecnológica.

A hipótese é confirmada e os fatores são identificados. Ressalte-se que deixam de ser confirmados como fatores indutores da utilização da informação contábil algumas variáveis que são apresentadas como tal no referencial teórico. Nesse sentido, destacam-se diversos instrumentos gerenciais contemporâneos.

Hipótese 2 - A influência desses fatores varia de acordo com as características ambientais, empresariais e da própria informação contábil.

A hipótese é confirmada, uma vez que, nem todas as variáveis dos fatores mencionados se constituem em indutores e inibidores da utilização da informação contábil de modo uniforme em todas as organizações pesquisadas.

Uma situação clara da influência dessas variáveis ocorreu em relação ao fator "confiabilidade". A pesquisa demonstrou que informações confiáveis estão relacionadas a uma grande utilização da informação contábil, enquanto informações não confiáveis estão relacionadas à pequena utilização da informação contábil.

Cabe ressaltar que, como a maioria de respostas ao questionário indica uma grande utilização da informação contábil na adesão aos incentivos fiscais, alguns dos fatores inibidores da utilização da informação contábil podem não ter sido identificados. 
É importante destacar que com a utilização da HOMALS não há inferências de causa e efeito e nem se supõem efeitos de uma variável sobre a outra.

Hipótese 3 - As decisões sobre o aproveitamento dos incentivos fiscais podem ocorrer ignorando-se uma parcela significativa das informações contábeis.

A hipótese não foi confirmada. Quer seja devido às exigências da legislação, quer seja por iniciativa dos próprios gestores, a adesão aos incentivos fiscais de inovação tecnológica ocorre com o emprego da informação contábil.

Quanto aos objetivos do trabalho, foram identificados e associados os fatores indutores e inibidores da utilização da informação contábil na adesão aos incentivos fiscais de inovação tecnológica, a política e a legislação dos incentivos foram caracterizadas, o papel e a importância das informações contábeis foram descritos e analisados e o entendimento do processo de decisão de adesão é aprimorado.

Sendo assim, a tese proposta de que a utilização da informação contábil para decisão sobre aproveitamento dos incentivos fiscais não depende, apenas, de uma avaliação técnica é confirmada.

Como limitação do trabalho pode-se citar o fato de que a amostra obtida não alcançou a confiabilidade estatística de $95 \%$, e ao fato da pesquisa ter se aplicado somente a empresas que se utilizaram dos incentivos fiscais de inovação tecnológica. Ademais, a pesquisa foi realizada sobre apenas um ano calendário de utilização do incentivo.

Apesar dessas limitações, esta pesquisa contribui para uma melhor compreensão do processo de decisão para adesão aos incentivos fiscais de inovação tecnológica.

É natural que as empresas queiram aderir aos incentivos visando à redução da carga tributária, e, para tanto, estabelecem um processo decisório que, como se viu, necessita da utilização de informações contábeis. Ora, o conhecimento e a identificação dos fatores indutores e inibidores da utilização da informação contábil pode permitir aos gestores uma avaliação melhor da influência desses fatores sobre o processo de decisão e, dessa forma, o processo de adesão tem maiores possibilidades de atingir aos objetivos estabelecidos. 
Ainda, em relação à gestão empresarial, outra contribuição refere-se ao modelo de decisão que é utilizado para suportar a opção pela adesão aos incentivos fiscais.

Parece claro que o modelo de decisão utilizado, que, como foi verificado na pesquisa é o classical, não é o mais adequado, uma vez que, nas situações concretas que devem ser avaliadas, as decisões podem estar muito mais voltadas às políticas empresariais do que aos objetivos organizacionais. Conforme já mencionado anteriormente, este talvez seja um dos motivos que levem à baixa adesão das empresas, em termos quantitativos, aos incentivos fiscais de inovação tecnológica.

O trabalho apresenta, ainda, uma importante contribuição para os gestores da área pública. Em primeiro lugar, os gestores públicos desejam a adesão aos incentivos fiscais dentro da política estabelecida pelo governo e, para esse fim, foram estabelecidas diversas regras que incentivam e mesmo determinam a utilização da informação contábil.

Assim, do ponto de vista dos resultados das políticas estabelecidas, os gestores públicos devem levar em consideração nas avaliações do resultado da adesão ao incentivo físcal de inovação tecnológica, que não são somente os fatores econômicos que determinam a adesão aos incentivos fiscais, mas poderão ocorrer fatores diversos que inibam ou estimulem a utilização da informação contábil levando a uma adesão maior ou menor que a desejada.

Nesse sentido, merece destaque o artigo de autoria de Caroline Viriato Memória (2013), coordenadora dos incentivos fiscais ao desenvolvimento tecnológica do Ministério da Ciência, Tecnologia e Inovação, a qual ressalta que dentre os fatores necessários para uma maior adesão aos benefícios fiscais há uma necessidade de uma melhor gestão por parte do governo.

Do ponto de vista de controle, a ausência de fatores indutores da informação contábil pode indicar a necessidade de um maior acompanhamento sobre as empresas que aderiram aos incentivos.

Como exemplo dessas ações concretas é possível destacar que as informações concernentes à utilização da informação contábil poderiam ser incluídas no relatório anual do MCTI, que tem por finalidade orientar as empresas, nos mais variados aspectos, a aderirem os incentivos 
fiscais de uma forma correta, uma vez que há uma parte específica do relatório que analisa as empresas que aderiram aos incentivos. Seria ainda possível incluir no formulário que as empresas preenchem anualmente algumas informações que possibilitassem uma avaliação do ambiente onde elas estão inseridas.

A principal contribuição deste trabalho no campo teórico é o desenvolvimento de uma nova abordagem sobre os temas tratados, uma vez que não se encontram na literatura estudos que relacionem a utilização da informação contábil com a adesão a incentivos fiscais.

Normalmente, os temas tributários estão voltados quase exclusivamente à análise e redução da carga tributária ou impactos de caráter financeiros e econômicos dos tributos nas atividades empresariais.

Também, no campo da teoria da contingência, constitui-se uma novidade a aplicação do referencial teórico ao campo tributário e mais especificamente ao estudo dos incentivos fiscais.

O trabalho, portanto, do ponto de vista teórico demonstra a existência de um novo campo, bastante amplo para futuras pesquisas.

No que se refere ao referencial teórico da teoria da contingência, utilizado neste trabalho, de forma geral, este se mostra adequado e os principais conceitos teóricos são confirmados na pesquisa realizada, ou seja, a existência de fatores ambientais, de diversas naturezas, que exercem influência sobre as empresas. São identificados fatores inibidores e indutores na utilização da informação contábil.

Entretanto, o mesmo não ocorre em relação às características estruturais e aos atributos da informação contábil. O referencial teórico indica uma maior relação destas variáveis como fatores indutores com a utilização da informação contábil, no entanto, não são encontradas relações significativas entre as variáveis estruturais e os instrumentos gerenciais com a utilização da informação contábil na adesão aos incentivos de inovação tecnológica.

Em relação aos instrumentos gerenciais contemporâneos a situação identificada neste trabalho parece refletir bem o paradoxo relatado por Guerreiro $(2004$, p.1) e descrito no item 1.1.1 deste trabalho. 
Sem dúvida este trabalho abre perspectivas para futuros estudos, indicando que os incentivos de inovação tecnológica são uma atividade que poderá permitir uma pesquisa muito profícua sobre a utilização da informação contábil, ressaltando ser possível uma pesquisa que envolva vários anos de adesão aos incentivos e aumentando o universo de empresas envolvidas. 


\section{REFERÊNCIAS}

ALMEIDA, Francisco Carlos Ribeiro; Uma abordagem estruturada da renúncia de receita pública federal. Revista do Tribunal de Contas da União, Brasília, DF, v.31, n.84, p. 19-62, abr/jun. 2000. Disponível em: <http://portal2.tcu.gov.br/portal/pls/portal/docs/2055468>. Acesso em: 21/12/2011.

ALMEIDA, José Elias Feres de. Qualidade da informação contábil em ambientes competitivos. 2010. (Tese de Doutorado) - Programa de Pós-Graduação da Faculdade de Economia, Administração e Contabilidade, Universidade de São Paulo, São Paulo.

ANDRADE, Maria Margarida. Introdução a Metodologia do Trabalho Científico. 8. ed. São Paulo: Atlas, 2007.

BARREIROS, Reginaldo Ferreira et al. Processo decisório nas cooperativas agroindustriais do Paraná: uma análise comparativa utilizando o modelo racional e o modelo político de decisão. Revista de Contabilidade e Organizações (RCO), FEARP/USP, v. 2, n. 4, p. 3-22 set./dez. 2008.

BEUREN, I.M. Gerenciamento da Informação: um recurso estratégico no processo de gestão empresarial. São Paulo: Atlas, 1998.

BISPO, Jorge de Souza et al. A importância dos dados contábeis para a relação entre carga tributária, tamanho e setor econômico das empresas brasileiras. Revista da Informação Contábil, vol. 3, p. 25-43, jun-set/2009.

BRAIM - Brasil Inovação, Mercadante quer incluir empresas de lucro presumido na Lei de Inovação, 1 fev. 2011. Disponível em: <http://www.brasilinovacao.com.br/brainnews/noticias/mercadante-quer-incluir-empresas-de-lucro-presumido-na-lei-da-inovacao/>. Acesso em: 01 jul. 2011.

BRASIL. Decreto no 3.000. Regulamento do Imposto de Renda, de 26 de março de 1999. Disponível em: < http://www.receita.fazenda.gov.br/Legislacao/rir/default.htm>. Acesso em: 3 de junho de 2.011.

Decreto no 5.798, de 7 de junho de 2006. Disponível em: <http://www.receita.fazenda.gov.br/Legislacao/Decretos/2006/dec5798.htm>. Acesso em: 3 de junho de 2011.

Decreto no 6.909, de 22 de julho de 2009. Disponível em: <http://www.planalto.gov.br/ccivil_03/_Ato2007-2010/2009/Decreto/D6909.htm>. Acesso em: 3 de junho de 2011.

Lei no 8661, 2 de junho de 1993. Disponível em: <http://www.planalto.gov.br/ccivil_03/leis/L8661.htm>. Acesso em: 3 de junho de 2011. 
Lei no 9.352, de 10 de dezembro de 1997. Disponível em: <http://www.planalto.gov.br/ccivil_03/leis/L9532.htm>. Acesso em; 3 de junho de 2011.

Lei no 10.973, de 2 de dezembro de 2004. Disponível em: <http://www.receita.fazenda.gov.br/Legislacao/Leis/2004/lei10973.htm>. Acesso em: 03 de junho de 2011.

—. Lei no 11.196, de 25 de novembro de 2005. Disponível em: <http://www.receita.fazenda.gov.br/Legislacao/Leis/2005/lei11196.htm>. Acesso em: 3 junho de 2011.

Lei no 11.638, de 28 de dezembro de 2007. Disponível em: <http://www.planalto.gov.br/ccivil_03/_ato2007-2010/2007/lei/111638.htm>. Acesso em: 3 junho de 2011.

Lei no 11.941, de 27 de maio de 2009. Disponível em: <http://www.planalto.gov.br/ccivil_03/_ato2007-2010/2009/lei/111941.htm>. Acesso em: 3 de junho de 2011.

. Lei no 12.350, de 20 de dezembro de 2010. Disponível em: <http://www.planalto.gov.br/ccivil_03/_Ato2007-2010/2010/Lei/L12350.htm\#art63>. Acesso em: 3 de junho de 2011.

Lei no 11.774, de 17 de setembro de 2011. Disponível em: $\overline{<\mathrm{http}: / /}$ Www.planalto.gov.br/ccivil_03/_ato2007-2010/2008/lei/L11774.htm>. Acesso em: 30 de novembro de 2011.

BRONZINI, Rafaello; BALSIO, Guido. Evaluating the impact of investiment incentives: the case of Italy's Law 488/1992. Journal of Urban Economics, n. 60, p. 327-349, mai. 2006.

CALIJURI, Mônica Sionara Schpallir; LOPES, Alexsandro Broedel. Gestão Tributária: uma abordagem multidisciplinar. São Paulo: Atlas, 2011.

CALZOLAIO, Aziz E. Política de incentivo à inovação no Brasil: análise do desempenho inovativo das empresas que usufruíram benefícios da Lei 11.196/05 (lei do bem). 2011. (Dissertação de Mestrado) - Programa de Pós-Graduação em Economia. Faculdade de Ciências Econômicas da Universidade Federal do Rio Grande do Sul, Porto Alegre.

CAMACHO, Reinaldo R. Fatores condicionantes da gestão de custos interorganizacionais na cadeia de valor de hospitais privados no Brasil: uma abordagem à luz da contingência. 2010. (Tese de Doutorado) - Programa de Pós-Graduação em Contabilidade. Departamento de Contabilidade e Atuária da Faculdade de Economia, Administração e Contabilidade da Universidade de São Paulo. São Paulo.

CARVALHO, A.M.R.; NAKAGAWA, M. Informações contábeis: um olhar fenomenológico. $I n$ : $17^{\circ}$ Congresso Brasileiro de Contabilidade, Santos. Anais... Conselho Federal de Contabilidade, 2004. 
CARVALHO, Helena. Análise Multivariada de Dados Qualitativos: utilização da análise de correspondências múltiplas com o SPSS. Lisboa: Silabo, 2008.

CASTRO, Claudio de Moura. A prática da pesquisa. São Paulo: Mc Graw-Hill do Brasil, 1978.

CHIAVENATO, Idalberto. Introdução a Teoria Geral da Administração: uma visão abrangente da moderna administração das organizações. 7.ed. Rio de Janeiro: Elsevier, 2003.

COMITE DE PRONUNCIAMENTOS CONTÁBEIS (CPC), 07 - Subvenção e Assistência Governamentais. Disponível em: <http://www.cpc.org.br/pronunciamentosIndex.php>. Acesso em: 16 jun. 2012.

DIEHL, Astor Antonio; TATIM, Denise Carvalho. Pesquisa em Ciências Sociais Aplicadas, Métodos e Técnicas. São Paulo: Prentice Hall, 2004.

ESTACHE, Antonio; GASPAR Vitpr. Why tax incentives do not promote investiment in Brazil. In: Fiscal incentives for investment and innovation. New York, p. 309-340, 1995

FAGUNDES, Jair A. et al., Gestão do Curso de Administração Considerando o enfoque da Teoria da Contingência, Revista de Contabilidade do Mestrado em Ciências Contábeis da UERJ (online), Rio de Janeiro, v. 14, n. 3, p. 58-59, set./dez., 2009.

FÁVERO, Luiz Paulo et al. Análise de dados: modelagem multivariada para tomada de decisões. Rio de Janeiro: Elsevier/Campus, 2009.

FREZATTI, Fábio et al. Ciclo de Vida das Organizações e a Contabilidade Gerencial, I Congresso ANPCONT. Anais... Gramado, 17 a 19 jun. 2007.

Demandas Metodológicas, Monoparadigma e o desenvolvimento da Contabilidade Gerencial. II Congresso ANPCONT, Anais... Salvador - BA. 15 a 17 jun. 2008.

FERNANDES, Edison Carlos (Org.), Alterações tributárias da MP do Bem: Lei 11.196/05 - MP 255. São Paulo: Quartier Latin do Brasil, 2006.

FORMIGONI, Henrique. A influência dos incentivos fiscais sobre a estrutura de capital e a rentabilidade das companhias abertas brasileiras não-financeiras. 2008. Tese (Doutorado em Controladoria e Contabilidade: Contabilidade) - Faculdade de Economia, Administração e Contabilidade, Universidade de São Paulo, São Paulo, 2008. Disponível em: $<$ http://www.teses.usp.br/teses/disponiveis/12/12136/tde-13012009-155610/>. Acesso em: 08 jun. 2012.

GOLDRATT, Eliyahu M. Garimpando informação num oceano de dados: a síndrome do palheiro. São Paulo: C.Fullmann, 1991. 
GONTIJO, Colen A.; MAIA, Santos C. Tomada de decisão do modelo racional ao comportamental: uma síntese teórica. Caderno de Pesquisas em Administração, v. 11, p. 13-30, out./dez. 2004. Universidade Federal de Minas Gerais.

GUERRA, Almir R. Arranjos entre fatores situacionais e sistema de contabilidade gerencial sob a ótica da teoria da contingência. 2007. (Dissertação de Mestrado) Programa de Pós-Graduação em Contabilidade. Departamento de Contabilidade e Atuária da Faculdade de Economia, Administração e Contabilidade da Universidade de São Paulo. São Paulo.

GUERREIRO, Reinaldo. Um Modelo de Sistema de Informação Contábil para Mensuração do Desempenho Econômico das Atividades Empresariais. Caderno de Estudos, n. 4, São Paulo, FIPECAFI, mar. 1992.

; et al. Some reflections on the archetypes and the colletive unconscious in cost accouting: an exploratory study. Kobe, III Biennial International Accounting Research Conference of IAAER. Anais... Out. 2000.

; et al. Em busca do entendimento da formação dos hábitos, rotinas e instituições da contabilidade gerencial. In: 4. Congresso USP de Contabilidade. Anais... 07 e 08 out. 2004.

GUIMARÃES, Eduardo Augusto; NEGRI, João Alberto de (Org.). Políticas de Incentivo à Inovação Tecnológica no Brasil. Brasília: Instituto de Pesquisa Econômica e Aplicada (IPEA), 2008.

HAIR JR., Joseph F. et al. Fundamentos de Métodos de Pesquisa em Administração. Porto Alegre: Bookman, 2005.

HENDRIKSEN, Eldon S., BREDA, Michael F. Van. Teoria da Contabilidade. São Paulo: Atlas, 1999.

HORNGREN, Charles T. et al;. Contabilidade Gerencial. 12 ${ }^{\text {a }}$ ed. São Paulo: Pearson Prentice Hall, 2004.

HIGUCHI, Hiromi. et al. Imposto de Renda das Empresas. 34a ${ }^{\mathrm{a}}$ ed. São Paulo: IR Publicações, 2009.

$\begin{array}{lrr}\text { INSTITUTO BRASILEIRO DE GEOGRAFIA E ESTATÍSTICA. Séries Estatísticas e } \\ \text { históricas. } & 2011 . & \text { Disponível }\end{array}$ $<\mathrm{http}: / /$ seriesestatisticas.ibge.gov.br/series.aspx?vcodigo=SCN49\&t=carga-tributaria-bruta $>$.

IUDICIBUS, Sérgio et al. Manual de Contabilidade Societária. São Paulo: Atlas, 2010.

KERLINGER, Fred N. Metodologia da Pesquisa em Ciências sociais. São Paulo: EPU, 1980. 
LYRA, Flávio Torres. Os Incentivos Fiscais à Indústria da Zona Franca de Manaus: uma Avaliação (Relatório Final). Brasília: IPEA, 1995.

MARTINS, Gilberto de Andrade, THEÓPHILO, Carlos Renato. Metodologia da investigação científica para ciências sociais aplicadas. São Paulo: Atlas, 2007.

MATAllo JR. Heitor, Construindo o Saber Metodologia Científica: Fundamentos e Técnicas. CARVALHO, Maria Cecília M. de (org.). 4 ed. Campinas: Papirus, 1994.

MATTAR, Fauze N. Pesquisa de Marketing. São Paulo: Atlas, 1996.

MEMÓRIA, Caroline V. Poucas empresas usam incentivos fiscais à Inovação? Jornal Valor Econômico, p. A9 22/04/2013. Disponível em: <http://www.valor.com.br/ opiniao/3094898/poucas-empresas-usam-incentivos-fiscais-inovacao $>$. Acesso em: 22/04/2013.

MINISTÉRIO DA CIÊNCIA, TENCNOLOGIA E INOVAÇÃO - MCTI. Relatório anual da utilização dos incentivos fiscais, ano base 2006, Brasília, dezembro/2007.

Relatório anual da utilização dos incentivos fiscais, ano base 2007, Brasília, novembro/2008.

março/2010.

Relatório anual da utilização dos incentivos fiscais, ano base 2008, Brasília,

Relatório anual da utilização dos incentivos fiscais, ano base 2009, Brasília, novembro/2010.

Relatório anual da utilização dos incentivos fiscais, ano base 2010, Brasília, dezembro/2011.

MOLINARI, Sarah Kuwano Rodrigues; REINALDO, Guerreiro. Teoria da contingência e contabilidade gerencial: um estudo de caso sobre o processo de mudança na Controladoria do Banco do Brasil. In: $1^{\circ}$ Congresso USP de Iniciação Cientifica em Contabilidade FEA-USP. Anais... 7e 8 out. 2004.

MURCIA, Fernando Dal-Ri. Fatores determinantes do nível de disclosure voluntário de Companhias abertas no Brasil. 2009. (Tese de Doutorado) - Programa de Pós-Graduação em Controladoria e Contabilidade. Departamento de Contabilidade e Atuária da Faculdade de Economia, Administração e Contabilidade da Universidade de São Paulo. São Paulo.

NOGUEIRA, Ruy Barbosa. Extrafiscalidade e a intervenção do Estado na vida econômica e social por meio da tributação. Curso de Direito Tributário. 7 ed. São Paulo: Saraiva, 1986.

OLIVEIRA, Antônio Benedito da Silva. Métodos e Técnicas de pesquisa em Contabilidade. São Paulo: Atlas 2003. 
OLIVEIRA, Maurício Teixeira. A importância da Contabilidade no Processo de Decisão entre Lucro Real e Lucro Presumido. (Tese de Mestrado) - Programa de Pós-Graduação em Controladoria e Contabilidade. Departamento de Contabilidade e Atuária da Faculdade de Economia, Administração e Contabilidade da Universidade de São Paulo. São Paulo.

PESTANA, Maria H., GAGEIRO, João N. Análise de dados para ciências sociais: a complementaridade do SPSS. 5 ed. Lisboa: Sílabo, 2008.

PEREIRA, Carlos Alberto et al; As operações de fusão, incorporação e cisão e o planejamento tributário. In: $4^{\circ}$ Congresso USP de Contabilidade e Controladoria. Anais... 7 e 8 out. 2004.

; FORMIGONI, Henrique. A Influência dos Incentivos Fiscais sobre a Estrutura de Capital e a Rentabilidade das Companhias Abertas Brasileiras. In: III $^{\circ}$ Congresso IAAERANPCONT. Anais... 10 a 12 jun. 2009.

PORTAL DO SINDCONT, Lei do Bem será ampliada para pequenas empresas. Disponível em: <http://www.sindcontsp.org.br/view/paginas.php?idTexto=8927\&id=166, 13/05/2011>. Acesso em: 01/07/2011.

POSSAS, M. Ciência, tecnologia e desenvolvimento: referências para debate. UFRJ: Ciclo de seminário Brasil em Desenvolvimento, 2003.

RECEITA FEDERAL DO BRASIL. Instrução Normativa da Receita Federal do Brasil $\mathbf{n}^{\mathbf{0}}$ 949, de 16 de junho de 2.009. Disponível em: <http://www.receita.fazenda.gov.br/legislacao/ins/2009/in9492009.htm>. Acesso em: 03 de junho de 2011.

Instrução Normativa da Receita Federal do Brasil no 1.187 de 29 de agosto 2.011. Disponível em <http://www.receita.fazenda.gov.br/legislacao/ins/2011/in11872011.htm>. Acesso em 10 de novembro de 2011.

RODRIGUES JUNIOR. Manuel S. A DVA como instrumento para mensuração da relação custo-benefício na concessão de incentivos fiscais: um estudo de caso. 2003. (Tese de Mestrado) - Programa de Pós-Graduação em Controladoria e Contabilidade. Departamento de Contabilidade e Atuária da Faculdade de Economia, Administração e Contabilidade da Universidade de São Paulo. São Paulo.

RULLO, Carmine. Lucro real ou lucro presumido: por qual optar? 2008. (Dissertação de Mestrado) - Programa de Pós-Graduação em Ciências Contábeis. Departamento de Contabilidade e Atuaria, Faculdade Economia, Administração e Contabilidade da Universidade de São Paulo. São Paulo.

SEIXAS FILHO, Aurélio Pitanga. Teoria e prática das isenções tributárias. 2 ed. Rio de Janeiro: Forense, 1999. 
SOARES, Luiz Augusto de Carvalho Francisco. A divulgação de informações contábeis obrigatórias e as necessidades informacionais na área financeira. 1998. (Dissertação de Mestrado). Universidade Federal de Santa Catarina. Florianópolis.

SOUZA, Erica X. et al, Benefícios fiscais: um estudo sobre o nível de satisfação das empresas de grande porte em Pernambuco. In: X SEMEAD - Seminário em Administração - FEAUSP, Anais... 09 e 10 de agosto de 2007.

THOMAS H. Mapping strategic management research, Journal of General Management, 1984, vol. 9 9, p. 55-72. $<$ http://www.thebhc.org/publications/BEHprint/v012/p0013-p0028.pdf>. Acesso em: 17 jun. 2012.

TRATER, John C.; HOY, Wayne K. Toward a contingency theory of decision making. Journal of Education Administration, vol 36, n 3, 1998, p. 212-218.

YAMAMOTO, Marina Mitiyo; SALOTTI, Bruno Meirelles. Informação contábil: estudo sobre sua divulgação no mercado de capitais. São Paulo: Atlas, 2006.

ZANOTELI, Eduardo José. Sistemas de informações gerenciais: o uso da informação contábil como apoio à tomada de decisão. 2001. (Dissertação de Mestrado) - Universidade Federal de Minas Gerais, Belo Horizonte. 



\section{APÊNDICES}

\section{Apêndice 1 - Formulário MCTI}

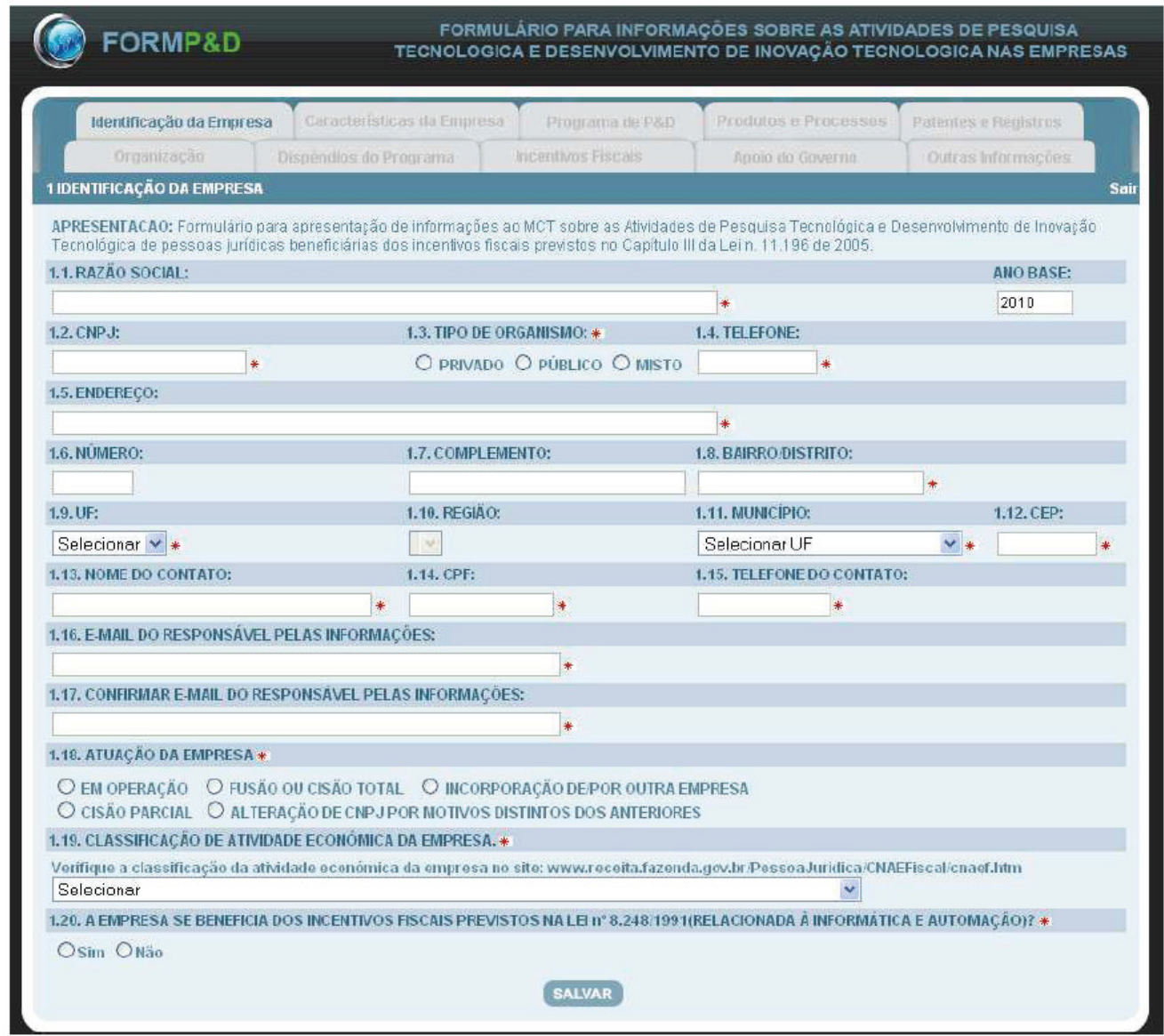




\begin{tabular}{|c|c|c|c|c|}
\hline Identincaçăo da Empresa & Caracteristicas da Empresa & \multirow{2}{*}{$\begin{array}{l}\text { Programa de P\&D } \\
\text { Incentivos Fisc-ais }\end{array}$} & \multirow{2}{*}{$\begin{array}{l}\text { Produtos e Processos } \\
\text { Apoio do Governo }\end{array}$} & \multirow{2}{*}{$\begin{array}{l}\text { Patentes e Registros } \\
\text { Outras informaçóes }\end{array}$} \\
\hline Organizaçắo & Dispêndios do Pragrama & & & \\
\hline
\end{tabular}

observaçeies:

Capital contr olador- - á quele que é ttular de uma participaçấo no capital social que lhe assegura a maioria dos votos e que, portanto, possui direitos

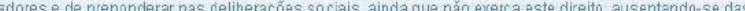
assembleias ou nelas se abstando de votar.

Origem do capital controlador- O capital controlador é nacional quando está sob titularidade direla ou indireta de pessoas físicas ou juricicas residentes domiciliadas no Pais. O capital controlador e estrangeiro quando està sob titulandade direta ou indireta de pessoas fisicas ou juridicas domiciliadas fora do Pais

Empresa controladora- $\dot{E}$ aquela que exerce, direta ou indiretamente, 0 peder (exercido nas trés uiltimas assemblélas ordinárias) de eleger a maioria dos administradores a de preponderar nas deliberaçōes soclais de outra(s) socledade(s).

Empresa coutrolada É acuela na qual a controladora possui, direta ou indiretamente (onr meio de outra controlada), condicắ considorada permanente de elecer a maioria dos administradores e de preponderar nas delliberaccöes socials.

Empresa coligada-E aquela na qual a investidora participa com pelo menoo $10 \%$ do sou capital, sem controlä.la.

2.1. ORIGEM DO CAPITAL CONTROLADOR DA EMPRESA: *

O Nacional $O$ Estrangeiro $O$ Mist

22. OUAL A SUA RELAÇAO COM 0 GRUPO?*

$O$ controlacora $O$ controlada $O$ coligada $O$ independente

23. OUAL O VALOR DA RECEITA LIOUIDA DA EMPRESA NO ANO BASE 2010? *

24. A EMPRESA FECHOU COMPREJUZZ FISCAL O ANO BASE?*

O sim O Nắo

25. O NÜMERO TOTAL DE FUNCIONÁRIOS COM VINCULO EMPREGATICIO COM A EMPRESA: *

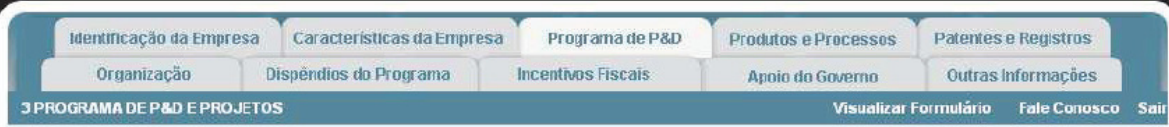

Observaçöes:

Descreva abaixo com ciareza no que consiste cada linha (projeto) da P\&D (PB, PA, DE) evidenciando: as objetivos do projeto. 0 elemento fecnologicamente nowo ou inovacor do projeto. Exste aplicaçáo de connecimento ou técrica de uma nova forma? Guals os axancos clentircos ou tecnológicos embutdos em cada projeto? Quais os métodos utilizados? Cite a dala inicio e fim da linha de projeto. Usa recursos próprios e de terceiros?

Na área de TIC cuais as competéncias exigidas no desenvolvimento de seus aplicativos? Quais técnicas ou metodologias foram empregadas? Ressalta-se que as atividades de informática de totina e que nắ impliquem avanços científicos ou técnicos ou nẵo resolkam incertezas tecnológicąs nẩo evem ser consideradas como PQD tais como:

- Software de aplicaçấo comercial e desenwolvimento de sistemas de informaçẫo que utilizem métodos conhecidos e ferramentas informáticas jả existentes

- A manutençấo dos sistemas existentes

A A conversáo ou tradiug o linguagens intormétteas.

A

- A cepuraço de sistemas informáticos.

- A preparaçăo de documentacăo para o utilizador.

3.1. LINHAS DE P8D:*

Observaçöes:

Descreva abaixe com clareza ne que consiste a pesquisa (PB, PA ou DE) e quais säo seus mar cos críticos e sens elementos tecnologicanente inovadores:

Inserir Linha:

Número Qual a linha de P\&D PB,PA oudE Valor despendido total Valor despedido en

bescriçăo da Lintra de P\&D

(rotal

Total $\quad 0,00$
0,00

NOTA: Caso a empresa entenda necessário prestar informaçöes complementares, poderá enviá-las para o MCT. no endereço: Esplanada dos Ministér ios, Bloco E, sala 398. Secretaria de desernotvimento Tecnolódico e Inovaçäo - SETEC

Coordenaçàa-Geral de lnovaçào Tecnofogica - CGI CEP 70067-900, Brasilia, DF. 


\begin{tabular}{|c|c|c|c|c|}
\hline Identificação đa Empresa & Caracteristicas da Empresa & Programa de P\&D & Produtos e Processos & Patemes e Registros \\
\hline Organizaçăo & Dispêndios do Programa & Incentivos fiscais & Apoio do Governo & Outras infermaçñes \\
\hline
\end{tabular}

4 PRODUTOS E PROCESSOS IECNOLOGICAMENTE NOVOS OU SUBSTAMCIALMENTE APERFELÇOADOS Visualizar Formulärio Fale Conosco Sa

4.1. INOVAÇÄO DE PRODUTO

Produto tecuologicamente novo rhem ou senico industial) é umproduto culas caracteristicas fundamentais (especificacöes técnicas, usos prefendidos,

softwate ou outro componente imaterial incorporado) diferem significativamente de todos os produtos previamente aroduzidos pala empresa.

Melhonla incremental de produto (bem ou serviço industria) retere-se a um produto prevamente existente, cujo desempenho tol substanclalmente

aumentado ou apeneiça do tecnologicamente. Um prosuto simples pode ser aperfeiçoado (no sentido de se obter um melhor de sempenho ou um meno custa) atraves da utilizaçaco de materias primas ou componentes de maior rendimento Um produto complexo, comvários componentes ou subsistemas

integrados, pode ser aperfeiçoado via mudanças parciais em um dos componentes ou subsistemas.

Hăo săo inchuidas: as mudanças puramente estáticas ou do estillo e a comerciallzaçăo do produtos novos integralmente desanwolvidos e produzidos por

4.1.1. NO ANO BASE, A EMPRESA INTRODUZIUPRODUTO TECNOLOGICAMENTE NOVO OU SIGNIFICATIVAMENTE APERFEICOADO PARA A EMPRESA, MAS JA EXISTENTE NO MERCADO HACIOHAL? *

O $\sin O$ Năo

4.1.2. NO ANO BASE, A EMPRESA INTRODUZIU PRODUTO TECNOLOGICAMENTE NOVO OU SIGNIFICATIVAMENTE APERFEIÇOADO PARA O MERCADO NACIONAL? *

O $\operatorname{sim} O$ Nẵo

4.13. DESCREVA BREVEMENTE O PRINCIPAL PRODUTO TECNOLOGICAMENTE NOVO OU SIGNIFICATIVAMENTE APERFECCOADO, LANÇADO PELA EMPRESA NO MERCADO NO ANO ANTERIOR.

12. NOVACCAOO DE PROCESSO

12.1. NO ANOBASE A EMOPRESAI

MAS JA EXISTENTE NO MERCADO NACIONAL?

$O \sin O$ Nắo

4.2.2. NO ANO BASE, A EMPRESA INTRODUZIUPROCESSO TECNOL OGICAMENTE NOVO OU SIGNIFICATIVAMENTE APERFEIC OADO PARA O MERCADO NACIONAL? *

$O \sin O$ Nă

4.2.3. DESCREVA BREVEMENTEO PRIICIPAL PROCESSO TECNOLOGICAMENTE NOVO OU SIGNIFICATIVAMENTE APERFEICOADO. LANÇADO PELA GMPRESA IIO MERCADO NO ANO ANTERIOR.

Você pode inserir 1000 caracteres.

4.3. INOVAÇÄO DE SERVIÇO

4.3.1. NO ANO BASE, A EMPRESA IITRODUZIU SERVIÇO TECNOLOGICAMENTE NOVO OU SIGNIFCATIVAMENTE APERFEÇOADO PARA A EMPRESA, MAS JÁ EXISTENTENO MERCADO NACIONAL? *

O $\operatorname{sim} O$ Nă̊

4.3.2. NO ANO BASE, A EMPRESA IITRODUZIU SERVIÇO TECNOLOGICAMENTENOVO OU SIGNIFCATIVAMENTE APERFEÇOADO PARA O MERCADO NACIONAL? *

O sim $O$ nẳo

4.3.3. DESCREVA BREVEMENTE O PRIICIPAL SERVIÇO TECNOLOGICAMENTE NOVO OU SIGMIIICATIVAMENTE APERFEIÇOADO, LANÇADO PELA EMIPRESA NO MERCADO NO ANO ANTERIOR.

Você pode inserir 1000 caractores.

4.4. O MCT ESTÁ AUTORIZADO A DIVULGAR ESSAS INFORIACÇÖES DO ITEM 4? *

O $\operatorname{sim} O$ Nã̃o

4.5. ESPECIFIOUE O OUE NÄO PODERÁ SER DIVULGADO * 


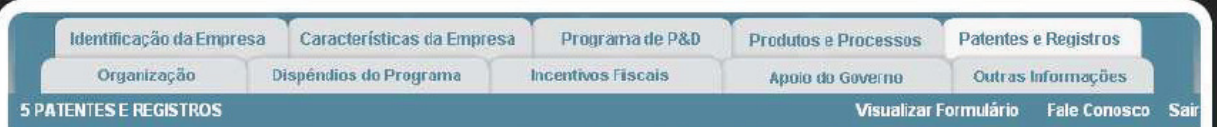

5.1. A EMPRESA TEM PATENTE REGISTRADA EM ESCRITÓRIO DEPATENTES NO BRASIL, NO EXTERIOR, OU ESTÁ PLETEANDO? *

O Sim O Não

5.2. NO ANOBASE, A EMPRESA PLEITEOU AL GUNS DOS ITENS A SEGUIR? *

Patente de invençăa

O $\operatorname{sim} O$ Nắ

Patente de modelo de utilidade

$O \operatorname{sim} O$ Nầ

Registro de cultivar

O $\operatorname{sim} O$ Nắ

Outros

O sim $O$ nắ

Especificar

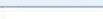

Voce pode inserir 500 caracteres.

5.3. NO ANOBASE A EMPRRESA OBTEVE ALGUMA PATENTE DO OUADRO 5.2? *

O $\operatorname{sim} O$ Nắ

No caso animativo, listi:

5.4. OCORREU PEDIDO DEPATENTE, REGISTRO DE CULTIVAR OU OUTROSDIREITOS DEPRROPRIFDMDEINTEL ECTUAL DURe pode Inserir 500 caranto INCENTIVOS FISCAIS DO ART. 19.A da Lein'. 11.19605? *

$O \operatorname{sim} O$ Nă

No caso afimativo, liste:

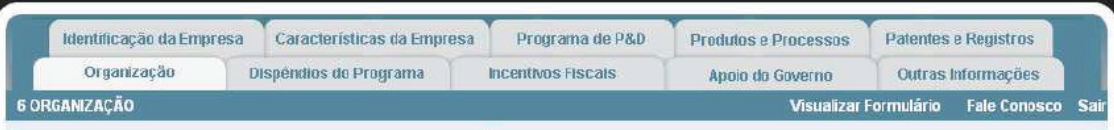

6.1 SUA EMPRESA POSSUI ALGUMA DAS NORMAS DECERTIFICACCOO ABAIXO? *

$\square$ NÃO POSBUI

$\square 1809000$

$\square 18014000$

$\square$ es

$\square$ OHSAS 1800

$\square$ AS 800

(1)

6. A EMPRESA POSSUI, EM SUA ESTRUTURA, UMA ÁREA FORMALMENTERESPONSÁVEL PELA GESTÁO DAS ATIVIDADES DE PESQUISA TECNOLÓGICA EDESENVOLVIIAENTO DE INOVAÇÁO TEC NOLOOGICA? *

O $\operatorname{sim} O$ Nấn

6.3. NO ANO BASE, OCORREU AL TERAÇÄO SIGNIFCATIVA NA EMPRESA NO OUE TANGE A CENTRO TECNOLÓGICO PRÓPRIO, LABORATÓRIOS, PLANTAS PLLOTO E OUTROSITENS DE NFRA-ESTRUTURA VOLTADOS PARA P\&D? *

O Sim $O$ Nầ

Comente soore a expertiencia da empresa no planelamento e execuçāo de attvidades de P\&D. incicando a existenncia de Centro Tecnotogico proprio ou

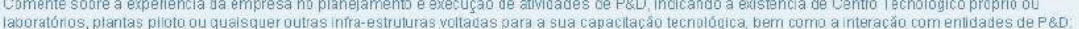

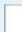




\begin{tabular}{|c|c|c|c|c|}
\hline Identificaçäo da Empresa & Caracteristicas da Empresa & Programa de P\&D & Produtos e Processos & Patentes e Registros \\
\hline Organizaçăe & Dispentios do Programa & Incentivos fiscais & Apoio de Governo & outras informaçö̀es \\
\hline
\end{tabular}

RECURSOS PRÓPRIOS: * FINANCIAMENTOS: * FONTE DO HINANCIAMENTO: *

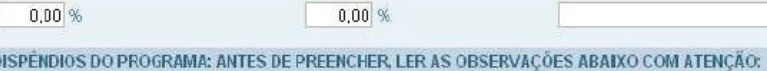

A. Todos os disnositivos lecalis citados (tens de A a D) estáo dispostos no Decreto nº 5.798 , de 7 de junho de 2006

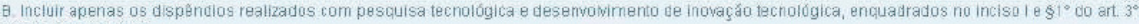
AXceto OERAS CIVIS

C. Nẵo Incluir RECURSOS NÄO REEMEOLSR̃VEIS onundos de órgẫos ou Entidades do Poder Público, conforme $\$ 2^{\circ}$ do art $3^{\circ}$.

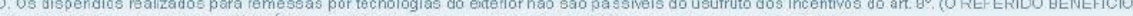
FOIINSTINTO PELA MEDIDA PROVISORIA 479 DO DIA 27 DE JULHO DE 2010 E CONVERTIDA EM LEI N"12350110)

E OS DISPENDIOS realizados deverẫo ser CONTROLADOS CONTABILMENTE am CONTAS ESPECIFICAS durante todo o periodo de execuräo do Programa, conforme art 10 , e anca somente noderás ser decuzidas se pagos a pessoas tisicas ou juridicas resinentes e domicilladas no pais.

F. Preencher o Quadro 7.1.1. com OS SERVIÇOS DE TERCEIROS, especificando os valores contratados ou transfendos, por entdade, no ANO BASE

Q. Preenchero Quadro 7.2. com OS EQUPAMVIENTOS, considerando as quantidades e os valores empolvidos, adquiridos no ANO BASE.

H. Preencher o Quadro 7 3. com os BENS INTANGIVEIS adquitidos no ANO BASE.

L. Todos us valores devern ser expressos em Reais $(R \$)$.

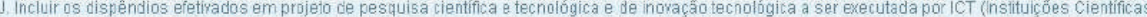
B Tecnológicas) conforme att $19-A$ da Lel no 11.196105 .

7.1.ITENS DE DISPENDIOS *

Ano Anterior ao

1. Recursos Humanos

2 Serviças de Terceiros Somatório $2.1+2.2+2.3$

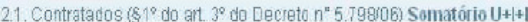

Universidades

Insituiçẫo de Pescuisa

Inventor Independente

22. Valores Transferidos (art $7^{\circ}$ e seus $1^{\circ}$ do Decrato $n^{*} 5.798,06$ ) Somatónio $M+E+1$

Microempresas:năo optantes do "SIMPLEG"

Empresas de Pequeno Porte(nẫo optantes do "SIMPLES")

Inventor Independente

Valor Total

23. Outros (DESPESAS DE ACORDO CON O art $2^{\circ}$, II a inea " $\theta^{\prime \prime}$ do Decreto $n^{\circ}$ 5.79806)

Especifique qual apoio técnico no subitem 7.1.3(OUTROS)

3. Material de Consumo

Sub Total de Custeio $-1+2+3$ (valor transferido para o item 8, subitem 1)

4. Remessa por Tecnologias do Exterior(Inciso V do art $3^{\circ}$ do decreto $\left.n^{\circ} 5798 / 06\right)$

5. Dispéndio de projetos de P\&D em ICT (art. 19-A da Lei n 11.19605)

Total do Custeio $(\mathrm{l})=\mathbf{1}+2+3+4+5$

6. Bens Intangiveis (art 17 IV da Lei $11196 / 05)$

7. Equipamentos Nacionais

8. Equipamentos Importados

9. Material Permanente

Total de Capital (III) $=6+7+8+9$

Total Geral (1+1)

\begin{tabular}{|c|c|}
\hline $\begin{array}{l}\text { Ano Auterior ao } \\
\text { Ano Base }\end{array}$ & Ano Base \\
\hline 0,00 & $12.345,67$ \\
\hline 0,00 & 0,00 \\
\hline 0,00 & 0,00 \\
\hline 0,00 & 0,00 \\
\hline 0,00 & 0,00 \\
\hline 0,00 & 0,00 \\
\hline 0,00 & 0,00 \\
\hline 0,00 & 0,00 \\
\hline 0,00 & 0,00 \\
\hline 0,00 & 0,00 \\
\hline 0,00 & 0,00 \\
\hline 0,00 & 0,00 \\
\hline 0,00 & $12.345,67$ \\
\hline 0,00 & 0,00 \\
\hline 0,00 & 0,00 \\
\hline 0,00 & $12.345,67$ \\
\hline 0,00 & 0,00 \\
\hline 0,00 & 0,00 \\
\hline 0,00 & 0,00 \\
\hline 0,00 & 0,00 \\
\hline 0,00 & 0,00 \\
\hline 0,00 & $12.345,67$ \\
\hline
\end{tabular}

7.1.1. SERVIÇOS DE TERCEIROS

OBSERVAÇÖES:

1. Em "LINHA DE PQD", selecionar o número correspondente a mesma (ver subitem 3.1 do Programa de P \&D)

2. Em "PRESTADOR DE SERVIÇO". incluir invertores independentes, ICTs e Microemoresas e Empresas de Pequeno Porte (conforme $\$ 1^{\circ} \mathrm{do}$ art. $3^{\circ} \mathrm{e}$ at. $7^{\circ}$ do Decreto $n^{\circ} .5 .798(06)$, se aplicáveis:

3. Incluir dispêndios efetivados em projeto a ser executado por ICT (conforme art. 19-A da Lei 11.196/05);

4. Ovalor anotado no subtem 2 do item 7 SERVICQO DE TERCEIRO, deve estar no seu total espec ficado. 


\begin{tabular}{|c|c|c|c|c|}
\hline \multicolumn{5}{|c|}{ 7.1.1. RFL AÇÄO DOS SERVIÇOS DE TERCEIROS - Contratados } \\
\hline \multicolumn{5}{|c|}{ Univer sidades $\oplus$} \\
\hline $\begin{array}{l}\text { Linha de P\&D } \\
\text { Total: }\end{array}$ & Situaçäo Prostador do Serviço & CNP J/CPF & Caracterizar o Sorviço Roalizado & $\begin{array}{r}\text { Valor } \\
0,00\end{array}$ \\
\hline \multicolumn{5}{|c|}{ Instituiçao do Pesquisa $\oplus$} \\
\hline $\begin{array}{l}\text { Linha de } P \text { zoD } \\
\text { Total: }\end{array}$ & Situaçäo Prestador de Serviço & CNPJICPF & Caracterizar 0 Serviço Realizado & $\begin{array}{r}\text { Valor } \\
0,00\end{array}$ \\
\hline \multicolumn{5}{|c|}{ Inventor Independente $\doteq$} \\
\hline $\begin{array}{l}\text { Linha de P\&D } \\
\text { Total: }\end{array}$ & Situaçäo Prestador de Serviço & CNPJ/CPF & Caracterizar 0 Serviço Realizado & $\begin{array}{r}\text { Valor } \\
0,00\end{array}$ \\
\hline \multicolumn{5}{|c|}{ 7.1.2. RELAÇÄO DOS SERVIÇOS DE TERCEIROS - Valores Transferidos } \\
\hline \multicolumn{5}{|c|}{ Micro Empresas +} \\
\hline $\begin{array}{l}\text { Linhta de P\&́D } \\
\text { Total: }\end{array}$ & Situaçăo Prestador de Serviço & CNPJ/CPF & Caracterizar o Serviço Realizado & $\begin{array}{r}\text { Valor } \\
0,00\end{array}$ \\
\hline \multicolumn{5}{|c|}{ Empresas de Pequeno Ponte $\dagger$} \\
\hline $\begin{array}{l}\text { Linha de PrD } \\
\text { Total: }\end{array}$ & Situaçäo Prostador de Serviço & CNPJ/CPF & Caractorizar o Sorviço Realizado & $\begin{array}{r}\text { Valor } \\
0,00\end{array}$ \\
\hline \multicolumn{5}{|c|}{ Inventor Independente +} \\
\hline $\begin{array}{l}\text { Linha de Pro } \\
\text { Total: }\end{array}$ & Situaçäo Prestador de Serviço & CNPJICPF & Caracterizar o Serviço Realizado & $\begin{array}{r}\text { Valor } \\
\mathbf{0 , 0 0}\end{array}$ \\
\hline \multicolumn{5}{|c|}{ 7.1.3. outros } \\
\hline \multicolumn{5}{|l|}{ observaçêes: } \\
\hline \multicolumn{5}{|c|}{ 1. Especifique quais sẫo os apoios técricos; } \\
\hline \multicolumn{5}{|c|}{ 2. Ovalor anotado para "outros, subitem 2.3 " deve ser especificado conforme solicitado a seguir. } \\
\hline $\begin{array}{l}N^{N} \\
\text { Total: }\end{array}$ & Especificaçäo & & & $\begin{array}{r}\text { Valor } \\
0,00\end{array}$ \\
\hline \multicolumn{5}{|c|}{ 7.2. MATERIAL DE CONSUMO $\doteq$} \\
\hline \multicolumn{5}{|l|}{ Observaçôes: } \\
\hline \multicolumn{5}{|c|}{ 1. Especifique quais são os Materiais de consumo; } \\
\hline \multicolumn{5}{|c|}{ 2. OValor anotado para "Material de Consumo, subitem $3^{\prime \prime}$ deve ser especificado conforme solicitado a seguir: } \\
\hline $\begin{array}{l}N^{N} \\
\text { Total: }\end{array}$ & Especificaçäe & & & $\begin{array}{r}\text { Valor } \\
0.00\end{array}$ \\
\hline
\end{tabular}


7.3.REMESSA POR TECNOLOGIA NO EXTERIOR $†$

Observaçöes:

1. Especifique quals são as Remessa Por Tecnologia no Exterior.

2. O Valor anotado para "Remessa Por Tecnologia no Exterior, subitem 4" deve ser especificado conforme solicilado a seyuir

$\begin{array}{lrr}\text { II }^{\circ} & \text { Especificaçăo } & \text { Valor } \\ \text { Total: } & 0,00\end{array}$

7.4. DISPÉNDIO DEPROJETOS DE P\&D EMICT †

Observaçöes:

1. Especiīque quais sẩo os Dispêndio de Projetos de P\&D em ICT,

2. O Valor anotado para "Dispêndio de Projetos de P\&D em ICT, subitem $5^{2}$ deve ser especificado conforme solicitado a seguir:

$\begin{array}{lll}N^{\circ} & \text { Especificaçäo } & \text { Valor } \\ 0,00 & \end{array}$

7.5. BENS INTANGIVEIS: †

Observaçöes:

1. Especinque quals săo as Relaçăo de Equipamentos Nacionals;

2. O Valor anotado para "Relaçăo de Equipamentos Nacionais, subitem 7" deve ser especificado conforme solicitado a seguin

№ de Ordem Especificaçăo

Total:

Especificaçāo

7.6. EQUIPAMENTOS POR LINHA DE P\&D †

OBSERVAÇÓES:

1. Relacionar os equipamentos, máquinas, aparelhos e instrumentos, bem como os acessórios sobressalentes e ferramentas que acompanham esses

bens, destinados a Pescuisa e Desenvolvimento Tecnológico.

2. Em "LINHA DE P\&D", selecionar o número correspondente à mesma (ver 4.1 do Programa de P\&D)

3. Especiñcar o produto, $n^{\circ}$ de património e o local da sua instalação, e o(s) projeto(s) a que se desina.

4. Tais eouipamentos nấo devem estar relacionados se estiverem na linha de produçẩo.

7.6.1. RELAÇAO DEEOUIPAMENTOS HACIONAIS

OBSERVAÇÓES

1. Especiñque quais sấo as Relaçấo de Equipamentos Nacionais

2. O Valo anotado para "Relaçăo de Equipamentos Nacionais, subitem 7" deve ser especific ado conforme solicitado a seguir.

Linha de P\&D Origem $\quad N^{\circ}$ Nota Fiscal Especificaca0 Valor Tota

Total:

7.6.2. REL AÇAO DEEOUIPAMENTOS INIPORTADOS

OBSERVAÇÕES:

1. Especifique quais são as Relaçấ de Equipamentos Importados

2. O Valor anotado para "Relaçăo de Equipamentos Importados, subitem 8" deve ser especificado conforne solicitado a seguir.

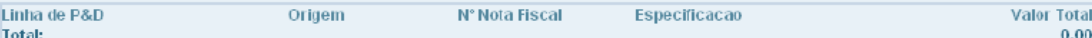

Total:

7.7. MATERIAL PERMANENITE +

Observaçöes:

1. Especifiqua quais săo as Material Permanente;

2. 0 Valor anotado para "Material Permanente, subitem 9" deve ser especificado conforme solictado a segur:

Notal:

Especificação

7.8. QUADRO DEPESSOAL (de acordo com art. $2^{\circ}$, III, Decreto 5798:06). *

Informe o número de pessoas do cuadro da empresa, de acordo com o maior nível de formaçẩo, normalmente ocupadas com as atividades de P\&D no Ano. Base, segundo o nivel de qualificasẫo e o tempo de dedicaşáo a essas atividades. Valor total, igual an item 3.1 Linhas de P\&D Nalor despedindo em Recursos Humanos no ANO BASE] e tem 7.1. liens de Dispendios, subiem 1. Recursos Humanos.

Titulo $\mathbb{N}^{\circ}$ de Pessoas com
Dedilcaçăo Parclal

Doutores

Mesires

Graduados

Técnicos

de Nivel

Medio

Outros de

Apoio

de Nivel

superlor

Total Dealcaçào Pact

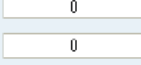

0

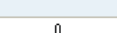

0

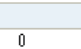

0,00

$\frac{1000}{0,000}$
Recursos Humanos

$N^{\circ}$ de Pessoas com Dedlicaçăo ExclusNa

Valor Gasto Dedlicaçăo Exclusina

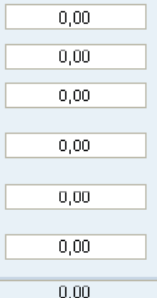

Total Valor Gasto

Ano Anterier ao Ano Base

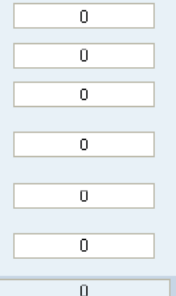

Valor Gasto

\begin{tabular}{|c|c|c|}
\hline 0,00 & 0,00 & 0 \\
\hline 0,00 & 0,00 & 0 \\
\hline 0,00 & 0,00 & 0 \\
\hline 0,00 & 0,00 & 0 \\
\hline 0,00 & 0,00 & 0 \\
\hline 0,00 & 0,00 & 0 \\
\hline 0.00 & 0,00 & 0 \\
\hline
\end{tabular}

7.9. OUTRAS INFORMAÇÖES SOBRE RECURSOS HUMANOS ENVOLVIDOS COMO PROGRAMA * 
7.9.1. A EMPRESA POSSUI ALGUM PROGRAMA DE FORMAÇĂO OU DESENVOLVIMENTO DE RH DESTINADO Ả P\&D? *

$\bigcirc \operatorname{sim} \odot$ Nầc

Em caso afirmativo, comente:

7.9.2. HOUVE CONTRATAÇÄO DENOVOS PESQUISADORES? *

Você pode inserir 500 caracteres.

○ $\sin \odot$ Nấ

Em caso afirmativo, comente

7.9.3. EXISTEN OUTROS INVESTIMENTOS DA EMPRESA EM P\&D, AL ÉM DOS PREVISTOS NOS PROGRAMAS DESCRITOS? *

Vacê pode inserir 500 caracteres.

$\bigcirc \operatorname{sim} \odot$ Nä́o

Em caso afirmativo, comente:

Você pode inserir 500 caracteres.

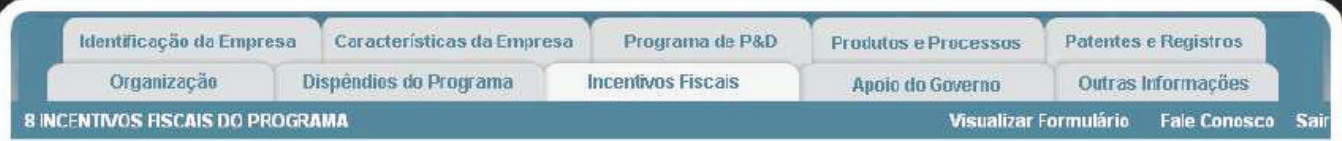

ANTES DE PREENCHER, LER AS OESERVAÇÓES ABAKO COM ATENÇÃO

1. Para efeito das deduçóes adicionais dos subitens 2.1 a 2.4 , os dispêndios realizados para remessas por tecnologias do exterior nắo sắo passixeis do usufuto dos incentivos do art. $8^{\circ}$ do Decreto 5798106 .

2. O incentivo especificado no subitem 2.5 näo pode ser acumulado com incentivos fiscais prexistos nos arts. 17 e 19 da Lai no. 11.196/05, conforme $\$ 11^{\circ}$ do art 19-A dessalei .

3. Todos os dispositivos legais citados estắo dispostos no Decreto $5.799 / 06$, com excęุẩo do subitem 2.5 .

4. As opçóes de depreciação acelerada incentivada, especificadas nos subitens 8.1 e 8.2 , năo podem ser aplicadas, cumulativamente, para um mesmo ativo, conforme $\$ 2^{\circ}$ do art $9^{\circ}$ do Decreto n $n^{\circ} 5.79808$.

5. As opçốes de amortizaçẩo acelerada, especificadas nos subitens 9.1 e 9.2 , nằ podem ser aplicadas, cumulativamente, para um bem intanóve conforme $\$ 2^{\circ} 00$ art $9^{\circ}$ do Decreto $r^{\circ} .5798 / 00$.

6. Pessoas juridicas que utilzarem os beneficios de que tratam as Leis $n=8.248$ de 23 de outubro de 1991.8387 de 30 de dezembro de 1991 e 10.176 de 11 de lanelro de 2001 relatwamente às attivades de informatica e automaçăo, só poderăo pletear os incentivos nscals previstos nos subitens $2.1 ; 2.2$

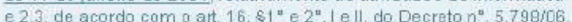

Rs(Reais)

Incentivos Fiscais

Ano Anterior ao Ano Base

Ano Base

1. DEDUÇÄ0, para efeito de apuraçäo do lucro liquido, da soma dos dispèndios de custeio realizados no

Ano Base (art. $\left.3^{\circ}, 1\right)$ - Pesquisadores, Serviço de Terceiro, Apoio Técrico e Material de Consumo.

$\begin{array}{r}\hline 0.00 \\ 11.377940,24 \\ \hline\end{array}$

2. DEDUCÓES ADICIONAIS

2.1. DEDUÇÃO, para efeito de apuraçăo do lucro liquido e da base de calculo da CSLL, de até $60 \%$ da soma dos di:spos

2.2. Mais $20 \%$, no casn de incremento do numero de pesquisadores contratados com dedicaçá exclusiva no Ano Ease acima de $5 \%$, em relaça a média des pesquisadares com contrato no ano anterior (inc. I do $\$ 1^{\circ}$ do art. $8^{\circ}$ ou an. 16 - caso de atividade de informática e automaçẩo) - se aplicâvel.

2.3. Mais $10 \%$, no caso de incremento do número de pesquisadores contratados com dedic açăo exclusiva no Ano Ease em aț $5 \%$, em relação ă média dos pesquisadores com contrato no ano anterio (inc. II do $\$ 1^{\circ}$ do art. $8^{\circ}$ ou art. 16 - caso de atividade de irformática e automaçăo) - se aplicável 
2.4. Sem prejuizo das deduçốes adicionais anteriores, mais $20 \%$, no caso de patente concedida ou cultivar registrado( $4^{\circ}$ do art. $8^{\circ}$ - se aplicável

2.5. De $50 \%$ a $250 \%$ dos dispêndios efetivados em projeto de pesquisa científica e tecnológica executada por ICT(Inc. I do \$ $1^{\circ}$ do Art. 19A da Lei $\left.\Pi^{\circ} 11.19605\right)$

3. TOTAL DE DEDUÇÖES $(3)=2.1+2.2+2.3+2.4+2.5$

4. REDUÇÓES DO IPI

4.1. $50 \%$ do IPI incidente sobre equipamentos, mácuinas, aparelhos $e$ instrumentos nacionais destinados à P\&D (inc. II do art. $\left.3^{\circ}\right)$

4.2.50\% do IPl incidente sobre equipamentos, máquinas, aparelhos e instrumentos importados destinados à P\&D (inc. II do art. $3^{\circ}$ )

TOTAL DA REDUÇÄO DO IPI $(4)=4.1+4.2$

5. CREDITO DEIR NA FONTE incidente sobre os pagamentos de tecnologia no exterior, conforme os limites ficados ( $\mathrm{n} \vee \mathrm{d}$ do art $3^{\circ}$. Despesas de acordo com 0 especificado no art $2^{\circ}$, II alínea ?e? do Decreto $n^{\circ}$ 5.798:06.).

6. REDUCĀO a zero da alíquota do IR na fonte incidente sobre as remessas ao exterior destinadas aos

pagamentos de registro e manutençẫo de marcas, patentes e cultivares (inc VI do art. $3^{\circ}$

7. TOTAL DOS INCENTIVOS $(7)=3+4+5+6$

8. DEPRECIACÁO ACELERADAINTEGRAL

8.1. Dos equipamentos, máquinas, aparelhos e instrumentos destinados á $P \& D$ (inc. III do art. $3^{\circ}$ )

8.2. Deduçẫo do saldo nẩo depreciado dos equipamentos, máquinas, aparelhos e instrumentos destinados à $\mathrm{P \& D}$, no ano em que for concluída a sua utilizaçẩ(art. $9^{\circ}$ )

TOTAL DE DEPRECIAÇÄO ACELERADA INCENTIVADA $(8)=8.1+8.2$

9. AMORTIZAÇÃO ACELERADA

9.1. Dedução dos dispèndios relatiros à aquisiçẫo de bens intangíveis destinados à $\mathrm{P} \& \mathrm{D}$, no Ano Base (inc. N do art. $3^{3}$ )

9.2. Dedução do saldo nẵo amortizado dos dispêndios relativos à aquisiçẵo de bens intangiveis destinados à $\mathrm{PQD}$, no ano em que ior concluída a sua utilizaçẫo (art. $9^{\circ}$ )

TOTAL DA AMORTIZAÇÄO ACELERADA $(9)-9.1+9.2$

TOTAL DE DIFERIMENTO $(10)=8+9$
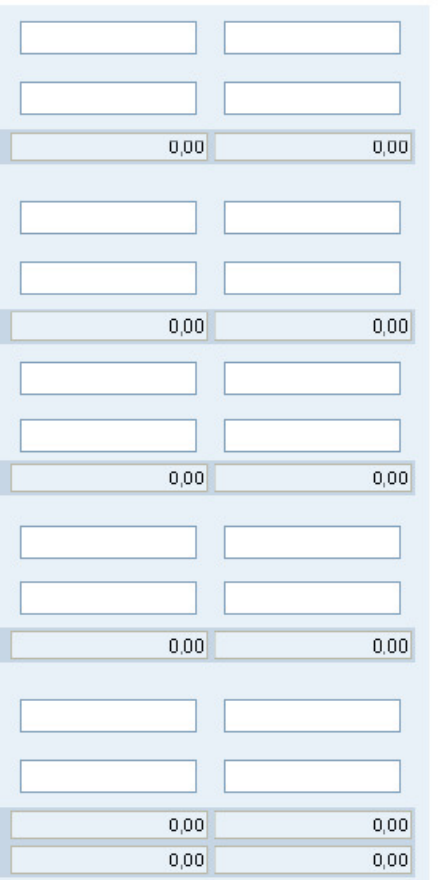

\begin{tabular}{|c|c|c|c|c|}
\hline Identificaçäo da Empresa & Características da Empresa & Proyrama de P\&D & Produtos e Processos & Patentes e Registros \\
\hline Organizaçào & Dispendios do Programa & incentwos fiscais & Apoio do Governo & Outras informaçöes \\
\hline \multicolumn{3}{|l|}{9 APOIO DO GOVERNO } & \multicolumn{2}{|c|}{ Visualizar Formulärio } \\
\hline
\end{tabular}

9.1. ALÉM DOS INCENTINOS DA LEIN: 11.196:05, A EMPRESA UTILIZOUUTILIZA ALGUM DOS PROGRAMAS, RELACIOHADOS A SEGUIR, DE APOIO DO GOVERNO PARA AS SUAS ATIMIDADES IMOVATIVAS? *

$\square$ Subwencẵo Ecanômica à P\&D (Lei no $10.973 / 2004)$

$\square$ Incentiyo fiscal à P\&D (Lei no. 8.661/93, Lei $n^{\circ} .10 .33212001$ )

$\square$ incentivo fiscal da Lei de informática (Lei no. 10.176/2001, Lei ñ. 10.664/2003)

$\square$ Financiamento a projetos de pesquisa em narceria com universidades e institutos de pesquisa

$\square$ Financiamento a projetos de pesquisa próprios

$\square$ Financiamento à compra de máquinas e equipamentos uilizados para inova

$\square$ Apoio oferecido pelas iundaçóes de amparo à pesquisa

$\square$ Apolo oferecido pelo RHAE

$\square$ Apone de capital de risco

$\square$ Financiamento a projetos de P\&D com equalizaça do duros (Lei $n^{\circ}$ 10.332/2001\}

$\square$ Outros (favor especificar)

$\square$ Näo se utilizou de nennum outro incentivo niscal 


\begin{tabular}{|c|c|c|c|c|}
\hline Identificação da Embres: & Características da Empresa & Prourama de P\&D & Produtos e Processos & Patentes \& Redistros \\
\hline Organizaçăo & Dispêndios de Programa & Incentivos Fiscais & Apoio to Governo & Outras intormaçöes \\
\hline \multicolumn{3}{|l|}{10 OUTRAS WNFORMAÇŌES } & \multicolumn{2}{|c|}{ Visualizar Formulário } \\
\hline
\end{tabular}

10.1. OUAL O ÚLTIHO PRÉMIO DE INOVAÇÄ́O TECNOLÓGICA OUE A EMPRESA OBTEVE?

Ano:

Qual:

10.2. EXPLICITAR OUTRAS INFORMAÇÖES JULGADAS RELEVANTES OU OUAISQUER SUGESTÖES VOLTADAS PARA 0 APERFEIÇOAMENTO DO SISTEMA DE CONCESSÄO DESSES INCENTIVOS FISCAIS.

Yocê pode inserir 500 caracteres. 10.3. OS RESPONSÁVEIS PEL AS EMPRESAS DEVERÄO CONARMAR AS INFORIMAÇÖES PRESTADAS E A REGUL ARIDADE DA EMPRESA EMRFL AÇÄO AOS TRIBUTOS ECONTRIBUIÇOES FEDERAIS:

"Declaro que a emaresa TESTE TONY, CNPJ 53.616.6200001-16, estă regular no que diz respeito aes tributos e contribuiçỗes féderais."

Nome: *

Cargo: *

CPF $*$

Observaçầ:

As certioóes que comprovema regularicade fiscal da empresa deverão estar à disposiçẩo de eventuais visitas do Ministério da ciência e Tecnologia au da Secretaria ca Receita Federal do Ministerio da Fazenda.

10.4. A PESSOA JURIDICA QUE PLEITEAR OS INCENTIVOS FISCAIS DEFINIDOS NO INCISO V DO ART. $3^{\circ}$ DO DECRETO 5.798 .05 TAMBEEM DEVERA DECLARAR:

"Declaro que a empresa IESIE IONY , CNPJ 53.516.620 0001-16, realizará dispendlos com atvidades de pesquisa e cesenvolvimento de inovaçăo

tecnológica nos percentuais definidos no inciso lou 11 do $\$ 3^{\circ}$ do art. $3^{\circ}$ do Docreto $n^{\circ} 5788$, de 7 de junho do 2006 , como contrapartida à fruçảo dos

incentivos previstos no inciso $\mathrm{V}$ do at. $3^{\circ}$ do mesmo decreto.

Nome:

Cargo:

CPF

10.5. "DECL ARO AINDA, QUE AS INFORMAÇÖES PRESTADAS CORRESPONDEM Ȧ EXPRESSẢO DA VERDADE E QUE CONHEÇO AS PENAL IDADES POR DESCUMPRIMENTO DEFIIIDAS NO ART. 13 DO DECRETO N' 5.798, DE 7 DE JUNHO DE 2006"

Nome:

Cargo:

CPF:

Atençăo:

* Se aplicável, a empresa deverá também manter cópia do registro ou averbacão do contrato de transferência de tecnologia, nos termos da Lei 9.279 de 14 de maio de 1996.

* Esse formulário só precisa ser enviado pelo sistema. Não sendo necessário o envio pelo correio.

NOTA: Caso a empresa entenda necessário prestar informaçốes complementares, poderá envia-las para o MCT, no endereço:

Esplanada dos Ministérios, Bloco E, sala 398

Secretaria de Desenvolvimento Tecnológico e Inovação - SETEC

Coordenaçẫo-Oeral de Inovaçẫo Tecnológica - ColT

CEP 70067-900, Erasília, DF

ANEXAR ARQUIVOS A EMPRESA: †

Descrição

Data 
Apêndice 2 - Empresas que aderiram aos benefícios fiscais de Inovação Tecnológica Relatório MCTI - ano base 2009

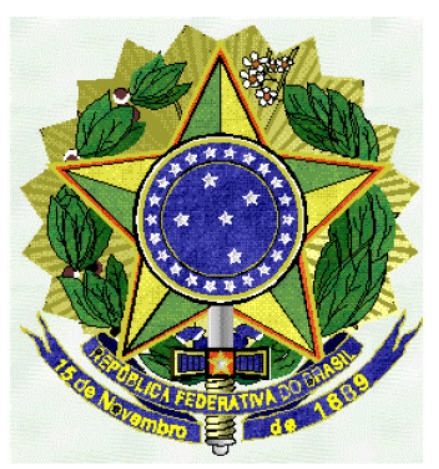

MINISTÉRIO DA CIÊNCIA E TECNOLOGIA - MCT

\section{RELATÓRIO ANUAL DA UTILIZAÇÃO DOS INCENTIVOS FISCAIS}

ANO BASE 2009

LEI No 11.196/05 - LEI DO BEM

BRASÍLIA - DF, NOVEMBRO 2010 


\section{ANEXO IV}

EMPRESAS BENEFICIÁRIAS DOS INCENTIVOS FISCAIS PREVISTOS NA Lei $n^{\circ}$ 11.196, de 21 de novembro de 2005 - Ordem Alfabética - ANO BASE 2009.

\begin{tabular}{|l|c|c|c|}
\hline \multicolumn{1}{|c|}{ RaZão Social } & CNPJ & MUNICIPIO & UF \\
\hline 3M DO BRASIL LTDA & $45.985 .371 / 0001-08$ & SUMARE & SP \\
\hline A RAYMOND BRASIL LTDA & $01.144 .384 / 0001-89$ & VINHEDO & SP \\
\hline A. GRINGS S.A. & $97.755 .177 / 0001-30$ & IGREJINHA & RS \\
\hline $\begin{array}{l}\text { ACE SCHMERSAL } \\
\text { ELETROELETRONICA } \\
\text { INDUSTRIAL LTDA }\end{array}$ & $61.854 .147 / 0001-33$ & BOITUVA & SP \\
\hline $\begin{array}{l}\text { ACHE LABORATORIOS } \\
\text { FARMACEUTICOS SIA }\end{array}$ & $60.659 .463 / 0001-91$ & GUARULHOS & SP \\
\hline $\begin{array}{l}\text { ACRILYS DO BRASIL } \\
\text { LAMINADOS PLASTICOS LTDA. }\end{array}$ & $93.831 .832 / 0001-30$ & CAXIAS DO SUL & RS \\
\hline ACUMULADORES MOURA S.A. & $09.811 .654 / 0001-70$ & BELO JARDIM & PE \\
\hline $\begin{array}{l}\text { ADRIA ALIMENTOS DO BRASIL } \\
\text { LTDA }\end{array}$ & $51.423 .747 / 0001-93$ & EUSÉBIO & CE \\
\hline AEROELETRONICA LTDA & $88.031 .539 / 0001-59$ & PORTO ALEGRE & RS \\
\hline $\begin{array}{l}\text { AES SUL DISTRIBUIDORA } \\
\text { GAUCHA DE ENERGIA SA. }\end{array}$ & $02.016 .440 / 0001-62$ & PORTO ALEGRE & RS \\
\hline $\begin{array}{l}\text { AETHRA SISTEMAS } \\
\text { AUTOMOTIVOS S.A. }\end{array}$ & $41.757 .527 / 0001-42$ & BETIM & MG \\
\hline $\begin{array}{l}\text { AGCO DO BRASIL COMÉRCIO E } \\
\text { INDÚSTRIA LTDA }\end{array}$ & $59.876 .003 / 0001-36$ & CANOAS & RS \\
\hline AGENCIA ESTADO LTDA & $62.652 .961 / 0001-38$ & SAO PAULO & SP \\
\hline AGRISTAR DO BRASIL LTDA. & $33.345 .950 / 0001-07$ & PETROPOLIS & RJ \\
\hline $\begin{array}{l}\text { AGRITECH LAVRALE S.A. } \\
\text { MAQUINARIOS AGRICOLAS E } \\
\text { COMPONENTES }\end{array}$ & $88.658 .984 / 0001-43$ & CAXIAS DO SUL & RS \\
\hline AIR LIQUIDE BRASIL LTDA & $00.331 .788 / 0001-19$ & SAOOPAULO & SP \\
\hline $\begin{array}{l}\text { ALCAN EMBALAGENS DO } \\
\text { BRASIL LTDA }\end{array}$ & $06.900 .974 / 0001-08$ & MAUA & SP \\
\hline ALCOA ALUMINIO S.A. & $23.637 .697 / 0001-01$ & POCOS DE CALDAS & MG \\
\hline $\begin{array}{l}\text { ALG AMERICA LATINA } \\
\text { GUINDASTES LTDA }\end{array}$ & $05.879 .042 / 0001-68$ & CAXIAS DO SUL & RS \\
\hline $\begin{array}{l}\text { ALSTOM HYDRO ENERGIA } \\
\text { BRASIL LTDA }\end{array}$ & $44.682 .318 / 0001-75$ & TAUBATE & SP \\
\hline $\begin{array}{l}\text { ALTUS SISTEMAS DE } \\
\text { INFORMATICA S.A. }\end{array}$ & $88.471 .578 / 0001-77$ & SÅO LEOPOLDO & RS \\
\hline AMBEV BRASIL BEBIDAS LTDA & $73.082 .158 / 0001-21$ & JAGUARIÚNA & SP \\
\hline
\end{tabular}




\begin{tabular}{|c|c|c|c|}
\hline $\begin{array}{l}\text { AMBEV- CIA DE BEBIDAS DAS } \\
\text { AMéRICAS }\end{array}$ & 02.808.708/0001-07| & SÃO PAULO & SP \\
\hline $\begin{array}{l}\text { ANGLO AMERICAN BRASIL } \\
\text { LTDA. }\end{array}$ & $42.184 .226 / 0001-30 \mid$ & SÃO PAULO & SP \\
\hline $\begin{array}{l}\text { ANJO QUIMICA DO BRASIL } \\
\text { LTDA }\end{array}$ & $02.921 .346 / 0001-58$ & CRICIÚMA & $S C$ \\
\hline $\begin{array}{l}\text { AP WINNER INDUSTRIA E } \\
\text { COMÉRCIO DE PRODUTOS } \\
\text { QUIMICOS LTDA }\end{array}$ & $00.101 .896 / 0001-03$ & PONTA GROSSA & PR \\
\hline APSEN FARMACËUTICA SA & $62.462 .015 / 0001-29$ & SAO PAULO & $\mathrm{SP}$ \\
\hline ARACRUZ CELULOSE S.A. & $42.157 .511 / 0001-61$ & ARACRUZ & ES \\
\hline ARAUCO FOREST BRASIL S.A. & $00.198 .057 / 0001-47$ & CURITIBA & PR \\
\hline ARAUPEL S.A. & $87.102 .810 / 0001-37$ & PORTO ALEGRE & RS \\
\hline $\begin{array}{l}\text { ARCELORMITTAL BIOENERGIA } \\
\text { LTDA. }\end{array}$ & $18.238 .980 / 0001-20$ & BELO HORIZONTE & MG \\
\hline ARCELORMITTAL BRASIL S.A. & $17.469 .701 / 0001-77$ & BELO HORIZONTE & MG \\
\hline $\begin{array}{l}\text { AREZZO INDÚSTRIA E } \\
\text { COMÉRCIO SIA. }\end{array}$ & $16.590 .234 / 0001-76$ & BELO HORIZONTE & MG \\
\hline ARJO WIGGINS LTDA & $45.943 .370 / 0001-09$ & SALTO & $\mathrm{SP}$ \\
\hline $\begin{array}{l}\text { AROSUCO - AROMAS E SUCOS } \\
\text { S.A. }\end{array}$ & $03.134 .910 / 0001-55$ & MANAUS & AM \\
\hline $\begin{array}{l}\text { ARTEGOR LAMINADOS } \\
\text { ESPECIAIS LTDA } \\
\end{array}$ & 03.133.678/0001-30| & TATUI & SP \\
\hline $\begin{array}{l}\text { ARVINMERITOR DO BRASIL } \\
\text { SISTEMAS AUTOMOTIVOS } \\
\text { LTDA. } \\
\end{array}$ & $56.689 .187 / 0001-75$ & OSASCO & SP \\
\hline $\begin{array}{l}\text { ARYSTA LIFESCIENCE DO } \\
\text { BRASIL IND QUIMICA E } \\
\text { AGROPECUARIA LTDA } \\
\end{array}$ & $62.182 .092 / 0001-25$ & SÃO PAULO & SP \\
\hline $\begin{array}{l}\text { ASA INDUSTRIAL E COMÉRCIO } \\
\text { DE ALIMENTOS LTDA }\end{array}$ & $01.551 .272 / 0001-42$ & RECIFE & PE \\
\hline ASGA SA & $59.694 .729 / 0001-58$ & PAULINIA & $\mathrm{SP}$ \\
\hline ASGA SISTEMAS LTDA & $05.287 .902 / 0001-74$ & PAULINIA & $\mathrm{SP}$ \\
\hline $\begin{array}{l}\text { ASTRAZENECA DO BRASIL } \\
\text { LTDA. }\end{array}$ & $60.318 .797 / 0001-00 \mid$ & COTIA & SP \\
\hline $\begin{array}{l}\text { ATOS SERVICOS EM } \\
\text { TECNOLOGIÁ DA INFORMAÇÅO } \\
\text { LTDA }\end{array}$ & $10.204 .178 / 0001-08$ & CAXIAS DO SUL & RS \\
\hline AURUS INDUSTRIAL S.A. & $56.992 .902 / 0001-06$ & TABOAO DA SERRA & $\mathrm{SP}$ \\
\hline $\begin{array}{l}\text { AUTROTRAC COMéRCIO E } \\
\text { TELECOMUNICAQ̄öES SA } \\
\end{array}$ & $40.281 .347 / 0001-74$ & BRASILIA & DF \\
\hline $\begin{array}{l}\text { AVERY DENNISON DO BRASIL } \\
\text { LTDA }\end{array}$ & 43.999.630/0001-24 & DO & SP \\
\hline AVON COSMÉTICOS LTDA. & $56.991 .441 / 0001-57$ & SAO PAULO & $\mathrm{SP}$ \\
\hline AVON INDUSTRIAL LTDA. & $00.680 .516 / 0001-24$ & SAO PAULO & $\mathrm{SP}$ \\
\hline
\end{tabular}




\begin{tabular}{|c|c|c|c|}
\hline AÇOS VILLARES S/A. & $60.664 .810 / 0001-74$ & SÅO PAULO & $\mathrm{SP}$ \\
\hline $\begin{array}{l}\text { BAHIA SPECIALTY CELLULOSE } \\
\text { S/A }\end{array}$ & $69.037 .133 / 0001-39$ & CAMAÇARI & BA \\
\hline BANCO JBS S.A. & $09.516 .419 / 0001-75$ & SAO PAULO & $\mathrm{SP}$ \\
\hline BANDEIRANTE ENERGIA S.A. & $02.302 .100 / 0001-06$ & SAO PAULO & $\mathrm{SP}$ \\
\hline BASELL POLIOLEFINAS LTDA & 13.583.323/0001-05 & PINDAMONHANGABA & $\mathrm{SP}$ \\
\hline BASF S.A. & $48.539 .407 / 0001-18$ & SAO PAULO & $\mathrm{SP}$ \\
\hline BAYER S.A & $18.459 .628 / 0001-15$ & SAO PAULO & $\mathrm{SP}$ \\
\hline BCM ENGENHARIA LTDA & $87.237 .830 / 0001-15$ & PORTO ALEGRE & RS \\
\hline $\begin{array}{l}\text { BEAULIEU DO BRASIL } \\
\text { INDÚSTRIA DE CARPETES LTDA }\end{array}$ & $02.305 .608 / 0001-60$ & PONTA GROSSA & PR \\
\hline $\begin{array}{l}\text { BECTON DICKINSON } \\
\text { INDUSTTRIAS CIRÚRGICAS } \\
\text { LTDA }\end{array}$ & $21.551 .379 / 0001-06$ & JUIZ DE FORA & MG \\
\hline $\begin{array}{l}\text { BELGO BEKAERT ARAMES } \\
\text { LTDA }\end{array}$ & $61.074 .506 / 0001-30$ & CONTAGEM & MG \\
\hline $\begin{array}{l}\text { BELGO BEKAERT NORDESTE } \\
\text { S.A }\end{array}$ & $14.044 .853 / 0001-30$ & FEIRA DE SANTANA & BA \\
\hline BENECKE IRMAOS \& CIA LTDA & $86.375 .656 / 0001-04$ & TIMBO & $\mathrm{SC}$ \\
\hline $\begin{array}{l}\text { BERACA SABARA QUIMICOS E } \\
\text { INGREDIENTES S/A }\end{array}$ & $12.884 .672 / 0001-96$ & ITAPISSUMA & PE \\
\hline $\begin{array}{l}\text { BETTANIN INDUSTRIAL } \\
\text { SOCIEDADE ANONIMA }\end{array}$ & $89.724 .447 / 0001-17$ & ESTEIO & RS \\
\hline $\begin{array}{l}\text { BIOLAB SANUS } \\
\text { FARMACEUTICA LTDA. }\end{array}$ & $49.475 .833 / 0001-06$ & SÃO PAULO & SP \\
\hline $\begin{array}{l}\text { BIOSINTETICA FARMACEUTICA } \\
\text { LTDA }\end{array}$ & $53.162 .095 / 0001-06$ & SÃO PAULO & SP \\
\hline BL INDUSTRIA OTICA LTDA & $27.011 .022 / 0001-03$ & PORTO ALEGRE & RS \\
\hline $\begin{array}{l}\text { BLUESTAR SILICONES BRASIL } \\
\text { LTDA }\end{array}$ & $07.790 .648 / 0001-58$ & SANTO ANDRE & SP \\
\hline $\begin{array}{l}\text { BMB-BELGO MINEIRA BEKAERT } \\
\text { ARTEFATOS DE ARAME LTDA }\end{array}$ & 18.786.988/0001-21 & VESPASIANO & MG \\
\hline $\begin{array}{l}\text { BORLEM S/A } \\
\text { EMPREENDIMENTOS } \\
\text { INDUSTRIAIS } \\
\end{array}$ & $60.943 .388 / 0001-96$ & GUARULHOS & SP \\
\hline BORRACHAS VIPAL S.A. & $87.870 .952 / 0001-44$ & NOVA PRATA & RS \\
\hline BOX PRINT GRUPOGRAF LTDA & $92.750 .629 / 0001-77$ & CAMPO BOM & RS \\
\hline BP BODE PROAR LTDA & $02.273 .865 / 0001-57$ & CAMPO NOVO & RS \\
\hline $\begin{array}{l}\text { BRAESI EQUIPAMENTOS PARA } \\
\text { ALIMENTACCAOO LTDA. }\end{array}$ & $88.833 .991 / 0001-34$ & CAXIAS DO SUL & RS \\
\hline BRASIL FOODS S.A. & $01.838 .723 / 0001-27$ & ITA.JAI & SC \\
\hline $\begin{array}{l}\text { BRASMETAL WAELZHOLZ S.A. } \\
\text { INDUSTRIA E COMERCIO }\end{array}$ & 43.7 & IA & SP \\
\hline
\end{tabular}




\begin{tabular}{|c|c|c|c|}
\hline $\begin{array}{l}\text { BREMIL INDÚSTRIA DE } \\
\text { PRODUTOS ALIMENTICIOS } \\
\text { LTDA }\end{array}$ & $91.897 .876 / 0001-38$ & ARROIO DO MEIO & RS \\
\hline BRINOX METALURGICA LTDA & $92.038 .108 / 0001-91$ & CAXIAS DO SUL & RS \\
\hline $\begin{array}{l}\text { BRISA INDUSTRIA DE TECIDOS } \\
\text { TECNOLOGICOS S.A }\end{array}$ & $02.036 .823 / 0001-00$ & SIMOES FILHO & BA \\
\hline $\begin{array}{l}\text { BRISTOL-MYERS SQUIBB } \\
\text { FARMACEUTICA S/A } \\
\end{array}$ & $56.998 .982 / 0001-07$ & SÃO PAULO & SP \\
\hline $\begin{array}{l}\text { BUN-TECH, TECNOLOGIA EM } \\
\text { INSUMOS LTDA. }\end{array}$ & $56.998 .438 / 0001-65$ & SÅO PAULO & SP \\
\hline $\begin{array}{l}\text { BUNDY REFRIGERAçÅO BRASIL } \\
\text { INDÚSTRIA E COMÉRCIO LTDA. }\end{array}$ & $08.320 .017 / 0001-38$ & CURITIBA & PR \\
\hline $\begin{array}{l}\text { CAB SISTEMA PRODUTOR } \\
\text { ALTO TIETE S/A }\end{array}$ & $09.538 .454 / 0001-95$ & SUZANO & SP \\
\hline $\begin{array}{l}\text { CAIMI E LIAISON IND. COM. } \\
\text { COUROS SINTÉTICOS LTDA }\end{array}$ & $7.443 .786 / 0001-60$ & CAMPO BOM & RS \\
\hline CALCCADOS BOTTERO LTDA. & $1-96$ & PAROBE & RS \\
\hline RIO SA. & $1-82$ & NOVO HAMBURGO & RS \\
\hline CAME & $1.088 .894 / 0001-08$ & SÄO PAULO & SP \\
\hline $\begin{array}{l}\text { CAMERA AGROA } \\
\text { S.A. }\end{array}$ & 88.248.644/0001-06 & SANTA ROSA & RS \\
\hline CAMERON DO BRASIL LTDA. & $01.505 .705 / 0001-23$ & RIO DE JANEIRO & $\mathrm{RJ}$ \\
\hline $\begin{array}{l}\text { CAOA } \\
\text { VEICU }\end{array}$ & $03.471 .344 / 0001-77$ & ANAPOLIS & GO \\
\hline $\begin{array}{l}\text { CARIOCA } \\
\text { ENGENHA }\end{array}$ & $0.450 .769 / 0001-26$ & EIRO & RJ \\
\hline CATERPILLAR BRASIL LTDA & $1 / 10001-77$ & PIRACICABA & $\mathrm{SP}$ \\
\hline CBPO ENGENHA & $61.156 .410 / 0001-10$ & SAO PAULO & $\mathrm{SP}$ \\
\hline $\begin{array}{l}\text { CELULOSE NIPO-BRASILEIRA } \\
\text { S.A. - CENIBRA }\end{array}$ & $1-99$ & $\mathrm{E}$ & MG \\
\hline CEMIG DISTRIBUICÅO S.A. & $06.981 .180 / 0001-16$ & BELO HORIZONTE & MG \\
\hline $\begin{array}{l}\text { CEMIG GERACCÃO E } \\
\text { TRANSMISSAO S.A. } \\
\end{array}$ & $06.981 .176 / 0001-58$ & BELO HORIZONTE & MG \\
\hline $\begin{array}{l}\text { CERAMICA E VELAS DE } \\
\text { IGNICCÅO NGK DO BRASIL LTDA }\end{array}$ & $52.541 .760 / 0001-00$ & MOGI DAS CRUZES & SP \\
\hline $\begin{array}{l}\text { CETREL S.A - EPRESA DE } \\
\text { PROTECA AO AMBIENTAL } \\
\end{array}$ & $14.414 .973 / 0001-81$ & CAMAÇARI & BA \\
\hline $\begin{array}{l}\text { CGMP - CENTRO DE GESTÃO } \\
\text { DE MEIOS DE PAGAMENTO SIA } \\
\end{array}$ & $04.088 .208 / 0001-65$ & OSASCO & SP \\
\hline $\begin{array}{l}\text { CHAPEMEC INDUSTRIA DE } \\
\text { CABINES LTDA. }\end{array}$ & $90.996 .281 / 0001-77$ & SANTA ROSA & RS \\
\hline $\begin{array}{l}\text { CHEMTECH SERVICOS DE } \\
\text { ENGENHARIA E SOFTWARE } \\
\text { LTDA. }\end{array}$ & $30.127 .872 / 0001-86$ & RIO DE JANEIRO & RJ \\
\hline CHOCOLATES GAROT & $28.053 .619 / 0001-83$ & VILA VELLHA & ES \\
\hline
\end{tabular}




\begin{tabular}{|c|c|c|c|}
\hline CHT BRASIL QUIMICA LTDA & $47.684 .386 / 0001-61$ & CAJAMAR & SP \\
\hline $\begin{array}{l}\text { CIA. IGUAÇU DE CAFÉ } \\
\text { SOLÚVEL }\end{array}$ & $76.255 .926 / 0001-90$ & CORNÉLIO PROCÓPIO & PR \\
\hline $\begin{array}{l}\text { CIA. INDUSTRIAL H. CARLOS } \\
\text { SCHNEIDER }\end{array}$ & $84.709 .955 / 0001-02$ & JOINVILLE & SC \\
\hline CIELO S/A & 01.027.058/0001-91 & BARUERI & $\mathrm{SP}$ \\
\hline $\begin{array}{l}\text { CIGAM SOFTWARE } \\
\text { CORPORATIVO LTDA. }\end{array}$ & 83.578.813/0001-44 & NOVO HAMBURGO & RS \\
\hline $\begin{array}{l}\text { CIMED INDUSTRIA DE } \\
\text { MEDICAMENTOS LTDA. }\end{array}$ & 02.814.497/0001-07 & SÃO PAULO & SP \\
\hline CLARIANT SA & $31.452 .113 / 0001-51$ & SÁO PAULO & $\mathrm{SP}$ \\
\hline $\begin{array}{l}\text { CLARIS INDÚSTRIA E } \\
\text { COMÉRCIO DE PORTAS E } \\
\text { JANELAS LTDA. }\end{array}$ & $10.768 .922 / 0001-05$ & INDAIATUBA & SP \\
\hline CNH LATIN AMERICA LTDA & $60.850 .617 / 0001-28$ & CONTAGEM & MG \\
\hline $\begin{array}{l}\text { COCAMAR COOPERATIVA } \\
\text { AGROINDUSTRIAL }\end{array}$ & $79.114 .450 / 0001-65$ & MARINGÁ & PR \\
\hline $\begin{array}{l}\text { COLGATE PALMOLIVE } \\
\text { INDUSTRIAL LTDA } \\
\end{array}$ & $03.816 .532 / 0001-90$ & $\begin{array}{c}\text { SAO BERNARDO DO } \\
\text { CAMPO }\end{array}$ & SP \\
\hline $\begin{array}{l}\text { COLIBRI INDUSTRIA E } \\
\text { COMERCIO DE MOVEIS LTDA. }\end{array}$ & $82.368 .283 / 0001-93$ & ARAPONGAS & PR \\
\hline $\begin{array}{l}\text { COMAU DO BRASIL INDÚSTRIA } \\
\text { E COMERRIO LTDA. } \\
\end{array}$ & $02.693 .750 / 0001-11$ & BETIM & MG \\
\hline $\begin{array}{l}\text { COMIL CARROCERIAS E } \\
\text { ONIBUS LTDA. }\end{array}$ & $00.940 .956 / 0001-73$ & ERECHIM & RS \\
\hline $\begin{array}{l}\text { COMPANHIA BRASILEIRA DE } \\
\text { METALURGIA E MINERAC } A O\end{array}$ & $33.131 .541 / 0001-08$ & ARAXA & MG \\
\hline $\begin{array}{l}\text { COMPANHIA BRASILEIRA DE } \\
\text { SOLUCOES E SERVICOS }\end{array}$ & $04.740 .876 / 0001-25$ & BARUERI & SP \\
\hline $\begin{array}{l}\text { COMPANHIA BRASILEIRA DO } \\
\text { ALUMINIO }\end{array}$ & $61.409 .892 / 0001-73$ & SÃO PAULO & SP \\
\hline $\begin{array}{l}\text { COMPANHIA DE GÁS DE SÅO } \\
\text { PAULO - COMGÁS }\end{array}$ & $61.856 .571 / 0001-17$ & SÃO PAULO & SP \\
\hline $\begin{array}{l}\text { COMPANHIA DE } \\
\text { TELECOMUNICAÇסES DO } \\
\text { BRASIL CENTRAL } \\
\end{array}$ & $71.208 .516 / 0001-74$ & UBERLANDIA & MG \\
\hline $\begin{array}{l}\text { COMPANHIA HEMMER } \\
\text { INDÚSTRIA E COMÉRCIO }\end{array}$ & $82.641 .986 / 0001-43$ & BLUMENAU & $S C$ \\
\hline $\begin{array}{l}\text { COMPANHIA PAULISTA DE } \\
\text { FORCAA E LUZ S.A. }\end{array}$ & $33.050 .196 / 0001-88$ & CAMPINAS & SP \\
\hline $\begin{array}{l}\text { COMPANHIA PIRATININGA DE } \\
\text { FORCAA E LUZ }\end{array}$ & $04.172 .213 / 0001-51$ & CAMPINAS & SP \\
\hline $\begin{array}{l}\text { COMPANHIA REFINADORA DA } \\
\text { AMAZONIA }\end{array}$ & $83.683 .484 / 0001-86$ & BELEM & PA \\
\hline
\end{tabular}




\begin{tabular}{|c|c|c|c|}
\hline $\begin{array}{l}\text { COMPANHIA SIDERURGICA } \\
\text { NACIONAL }\end{array}$ & $33.042 .730 / 0001-04$ & RIO DE JANEIRO & RJ \\
\hline $\begin{array}{l}\text { COMPANHIA TECIDOS } \\
\text { SANTANENSE }\end{array}$ & $21.255 .567 / 0001-89$ & MONTES CLAROS & MG \\
\hline $\begin{array}{l}\text { COMPANHIA VALE DO RIO } \\
\text { DOCE }\end{array}$ & $33.592 .510 / 0001-54$ & RIO DE JANEIRO & RJ \\
\hline $\begin{array}{l}\text { COMUNIQUE-SE } \\
\text { COMUNICACAO CORPORATIVA } \\
\text { LTDA. }\end{array}$ & $04.558 .476 / 0001-01$ & RIO DE JANEIRO & RJ \\
\hline CONDOR SIA & $86.046 .448 / 0001-61$ & SAO BENTO DO SUL & $\mathrm{SC}$ \\
\hline CONFAB INDUSTRIAL S/A & $60.882 .628 / 0001-90$ & $\begin{array}{c}\text { SAO CAETANO DO } \\
\text { SUL }\end{array}$ & SP \\
\hline IAS ODERICH S.A. & $97.191 .902 / 0001-94$ & $\begin{array}{l}\text { SAOO SEBASTIAO DO } \\
\text { CAI }\end{array}$ & RS \\
\hline CONSISTEM SISTEMAS LTDA & $79.500 .385 / 0001-06$ & JARAGUÁ DO SUL & $\mathrm{SC}$ \\
\hline $\begin{array}{l}\text { CONSTRUTORA ANDRADE } \\
\text { GUTIERREZ SA }\end{array}$ & $17.262 .213 / 0001-94$ & BELO HORIZONTE & MG \\
\hline $\begin{array}{l}\text { CONSTRUÇÅAO E COMÉRCIO } \\
\text { CAMARGO CORREA SIA } \\
\end{array}$ & $61.522 .512 / 0001-02$ & SÅO PAULO & SP \\
\hline $\begin{array}{l}\text { CONTINENTAL BRASIL } \\
\text { INDÚSTRIA AUTOMOTIVA LTDA }\end{array}$ & $48.754 .139 / 0001-57$ & GUARULHOS & SP \\
\hline CONTROLAR SIA & $01.015 .086 / 0001-99$ & SAOO PAULO & SP \\
\hline $\begin{array}{l}\text { COODETEC-COOPERATIVA } \\
\text { CENTRAL DE PESQUISA } \\
\text { AGRICOLA }\end{array}$ & $00.685 .383 / 0001-89$ & CASCAVEL & PR \\
\hline $\begin{array}{l}\text { COOPERATIVA DOS } \\
\text { SUINOCULTORES DE } \\
\text { ENCANTADO }\end{array}$ & $89.305 .239 / 0001-83$ & ENCANTADO & RS \\
\hline COPENER FLORESTAL LTDA & 15.692.999/0001-54 & ALAGOINHAS & $\mathrm{BA}$ \\
\hline $\begin{array}{l}\text { CORN PRODUCTS BRASIL } \\
\text { INGREDIENTES INDUSTRIAIS } \\
\text { LTDA }\end{array}$ & $01.730 .520 / 0001-12$ & SÅO PAULO & SP \\
\hline $\begin{array}{l}\text { COSMOTEC ESPECIALIDADES } \\
\text { COSMÉTICAS LTDA }\end{array}$ & $02.464 .838 / 0001-61$ & SÅO PAULO & SP \\
\hline $\begin{array}{l}\text { CPFL GERAçäO DE ENERGIA } \\
\text { S.A. }\end{array}$ & $03.953 .509 / 0001-47$ & CAMPINAS & SP \\
\hline CPW BRASIL LTDA & $01.446 .396 / 0002-49$ & CACAPAVA & $\mathrm{SP}$ \\
\hline CREMER S.A. & $82.641 .325 / 0001-18$ & BLUMENAU & $\mathrm{SC}$ \\
\hline $\begin{array}{l}\text { CRISTALIA PRODUTOS } \\
\text { QUIMICOS FARMACEUTICOS } \\
\text { LTDA } \\
\end{array}$ & $44.734 .671 / 0001-51$ & ITAPIRA & SP \\
\hline CRODA DO BRASIL LTDA & 44.144.293/0001-56 & CAMPINAS & $\mathrm{SP}$ \\
\hline CUMMINS BRASIL LTDA & $43.201 .151 / 0001-10$ & GUARULHOS & SP \\
\hline CVI REFRIGERANTES LTDA & $72.114 .994 / 0001-88$ & SANTA MARIA & RS \\
\hline
\end{tabular}




\begin{tabular}{|c|c|c|c|}
\hline $\begin{array}{l}\text { DAIICHI SANKYO BRASIL } \\
\text { FARMACEUTICA LTDA }\end{array}$ & $60.874 .187 / 0001-84$ & BARUERI & SP \\
\hline $\begin{array}{l}\text { DAIRY PARTNERS AMÉRICAS } \\
\text { BRASIL LTDA }\end{array}$ & $05.300 .331 / 0001-60$ & SÅO PAULO & SP \\
\hline $\begin{array}{l}\text { DAIRY PARTNERS AMÉRICAS } \\
\text { MANUFACTORING BRASIL } \\
\text { LTDA }\end{array}$ & $05.300 .340 / 0001-51$ & SÅO PAULO & SP \\
\hline $\begin{array}{l}\text { DAMBROZ S.A. IND. MECâNICA } \\
\text { E METALURGICA }\end{array}$ & $88.613 .716 / 0001-05$ & CAXIAS DO SUL & RS \\
\hline DANA INDÚSTRIAS LTDA. & $00.253 .137 / 0001-58$ & GRAVATAI & RS \\
\hline $\begin{array}{l}\text { DELPHI AUTOMOTIVE } \\
\text { SYSTEMS DO BRASIL LTDA }\end{array}$ & $00.857 .758 / 0001-40$ & $\begin{array}{l}\text { SAO CAETANO DO } \\
\text { SUL }\end{array}$ & $\overline{\mathrm{SP}}$ \\
\hline DENSO DO BRASIL LTDA & 43.375.830/0001-32 & CURITIBA & PR \\
\hline $\begin{array}{l}\text { DIGICON S A CONTROLE } \\
\text { ELETRONICO PARA MECANICA }\end{array}$ & $88.020 .102 / 0001-10 \mid$ & GRAVATAI & RS \\
\hline $\begin{array}{l}\text { DIGITEL S A INDUSTRIA } \\
\text { ELETRONICA } \\
\end{array}$ & $89.547 .269 / 0001-04$ & PORTO ALEGRE & RS \\
\hline $\begin{array}{l}\text { DINACON INÚSTRIA, COMéRCIO } \\
\text { E SERVIcOS LTDA. }\end{array}$ & $03.186 .880 / 0001-20$ & ESTRELA & RS \\
\hline DISTRIBUIDORA AMARAL LTDA & $21.759 .758 / 0001-88$ & DNINOPOLIS & $\overline{M G}$ \\
\hline DIXIE TOGA SA. & $60.394 .723 / 0001-44$ & SAO PAULO & $\mathrm{SP}$ \\
\hline DOCILE ALIMENTOS LTDA & $94.261 .534 / 0001-15$ & LAJEADO & RS \\
\hline $\begin{array}{l}\text { DOCOL METAIS SANITÁRIOS } \\
\text { LTDA }\end{array}$ & $75.339 .051 / 0001-41$ & JOINVILLE & SC \\
\hline $\begin{array}{l}\text { DSM ELASTOMEROS BRASIL } \\
\text { LTDA }\end{array}$ & $00.989 .799 / 0001-90$ & TRIUNFO & RS \\
\hline $\begin{array}{l}\text { DUAS RODAS INDUSTRIAL } \\
\text { LTDA }\end{array}$ & $84.430 .149 / 0001-09$ & JARAGUÁ DO SUL & $\mathrm{SC}$ \\
\hline $\begin{array}{l}\text { DUKE ENERGY } \\
\text { INTERNACIONAL GERAçäO } \\
\text { PARANAPANEMA S/A } \\
\end{array}$ & $02.998 .301 / 0001-81$ & SÅO PAULO & SP \\
\hline $\begin{array}{l}\text { DURA AUTOMOTIVE SYSTEMS } \\
\text { DO BRASIL LTDA }\end{array}$ & $57.501 .207 / 0001-67$ & $\begin{array}{l}\text { RIO GRANDE DA } \\
\text { SERRA }\end{array}$ & SP \\
\hline DURAFLORA SA. & $43.059 .559 / 0001-08$ & SAO PAULO & $\mathrm{SP}$ \\
\hline DURATEX S.A. & 97.837.181/0001-47 & SAO PAULO & $\mathrm{SP}$ \\
\hline DURATEX S.A. & $61.194 .080 / 0001-58$ & SAO PAULO & $\mathrm{SP}$ \\
\hline $\begin{array}{l}\text { DYNAPAC BRASIL INDUSTRIA E } \\
\text { COMERCIO LTDA } \\
\end{array}$ & $06.314 .429 / 0001-30$ & SOROCABA & SP \\
\hline DYNEA BRASIL S.A. & $02.854 .387 / 0001-79$ & ARAUCARIA & \begin{tabular}{|l|}
$\mathrm{PR}$ \\
\end{tabular} \\
\hline $\begin{array}{l}\text { E-COMMERCE MEDIA GROUP } \\
\text { INFORMAÇÅ̈O E TECNOLOGIA } \\
\text { LTDA }\end{array}$ & $03.437 .665 / 0001-55$ & SÅO PAULO & SP \\
\hline ELEB EQU & $55.763 .775 / 0001-00$ & $\begin{array}{l}\text { SAOO JOSÉ DOS } \\
\text { CAMPOS }\end{array}$ & SP \\
\hline ELECTROLUX DO BRASIL S/A & $76.487 .032 / 0001-25$ & CURITIBA & 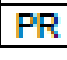 \\
\hline
\end{tabular}




\begin{tabular}{|c|c|c|c|}
\hline $\begin{array}{l}\text { ELEKTRO ELETRICIDADE E } \\
\text { SERVIÇOS S.A. }\end{array}$ & $02.328 .280 / 0001-97$ & CAMPINAS & SP \\
\hline $\begin{array}{l}\text { ELETROFRIO REFRIGERAÇÅO } \\
\text { LTDA. }\end{array}$ & 76.498.179/0001-10 & CURITIBA & PR \\
\hline $\begin{array}{l}\text { ELETROPAULO } \\
\text { METROPOLITANA } \\
\text { ELETRICIDADE DE SäO PAULO } \\
\text { SA }\end{array}$ & $61.695 .227 / 0001-93$ & SÃO PAULO & SP \\
\hline ELETRONICA SELENIUM SIA & $88.315 .379 / 0001-70$ & TABAI & RS \\
\hline $\begin{array}{l}\text { ELEVADORES ATLAS } \\
\text { SCHINDLER SA }\end{array}$ & $00.028 .986 / 0001-08$ & SÃO PAULO & SP \\
\hline $\begin{array}{l}\text { ELO SISTEMAS ELETRONICOS } \\
\text { S.A. }\end{array}$ & $87.332 .342 / 0001-97$ & PORTO ALEGRE & RS \\
\hline $\begin{array}{l}\text { EMBRAER EMPRESA } \\
\text { BRASILEIRA DE AERONÁUTICA } \\
\text { SA } \\
\end{array}$ & $07.689 .002 / 0001-89$ & $\begin{array}{l}\text { SÅO JOSÉ DOS } \\
\text { CAMPOS }\end{array}$ & SP \\
\hline $\begin{array}{l}\text { EMICOL ELETRO ELETRONICA } \\
\text { S.A. }\end{array}$ & $61.685 .723 / 0001-66$ & ITU & SP \\
\hline EMS S.A. & 57.507.378/0001-01 & $\begin{array}{c}\text { SAO BERNARDO DO } \\
\text { CAMPO }\end{array}$ & SP \\
\hline $\begin{array}{l}\text { ENGEMASA ENGENHARIA E } \\
\text { MATERIAIS LTDA }\end{array}$ & $47.034 .509 / 0001-19$ & SÃO CARLOS & SP \\
\hline $\begin{array}{l}\text { ENGENHARIA E COMéRCIO } \\
\text { BANDEIRANTES LTDA } \\
\end{array}$ & $59.598 .029 / 0001-60$ & SÃO CARLOS & SP \\
\hline EQUIPALCOOL SISTEMAS LTDA & $52.853 .181 / 0001-00$ & SERTÃOZINHO & SP \\
\hline $\begin{array}{l}\text { ERICSSON } \\
\text { TELECOMUNICACöES S.A. }\end{array}$ & $33.067 .745 / 0001-27$ & SÅO PAULO & SP \\
\hline $\begin{array}{l}\text { ESAB INDUSTRIA E COMERCIO } \\
\text { LTDA }\end{array}$ & $29.799 .921 / 0001-48$ & CONTAGEM & MG \\
\hline $\begin{array}{l}\text { ESMALGLASS DO BRASIL } \\
\text { FRITAS, ESMALTES E } \\
\text { CORANTES CERÅMICOS LTDA } \\
\end{array}$ & $86.981 .966 / 0001-72$ & MORRO DA FUMACA & $\mathrm{SC}$ \\
\hline $\begin{array}{l}\text { ESPIRITO SANTO CENTRAIS } \\
\text { ELETRICAS S.A. } \\
\end{array}$ & $28.152 .650 / 0001-71$ & VITÓRIA & ES \\
\hline $\begin{array}{l}\text { ESPUMATEC INJETADOS EM } \\
\text { POLIURET IND COM LTDA } \\
\end{array}$ & 93.628.188/0001-06 & CAXIAS DO SUL & RS \\
\hline $\begin{array}{l}\text { ET BRASIL INDÚSTRIA E } \\
\text { COMÉRCIO DE SISTEMAS } \\
\text { AUTOMOTIVOS LTDA. } \\
\end{array}$ & $08.515 .211 / 0001-79$ & LIMEIRA & SP \\
\hline ETERNIT SIA & $61.092 .037 / 0001-81$ & SAO PAULO & $\mathrm{SP}$ \\
\hline $\begin{array}{l}\text { EUROFARMA LABORATORIOS } \\
\text { LTDA. }\end{array}$ & $61.190 .096 / 0001-92$ & SÅO PAULO & SP \\
\hline $\begin{array}{l}\text { EXATRON INDUSTRIA } \\
\text { ELETRONICA LTDA }\end{array}$ & $90.191 .529 / 0001-22$ & PORTO ALEGRE & RS \\
\hline
\end{tabular}




\begin{tabular}{|c|c|c|c|}
\hline $\begin{array}{l}\text { FAMASTIL TAURUS } \\
\text { FERRAMENTAS SIA. }\end{array}$ & $80.260 .985 / 0001-87$ & GRAMADO & RS \\
\hline $\begin{array}{l}\text { FAST GONDOLOAS } \\
\text { EQUIPAMENTOS LTDA }\end{array}$ & $76.902 .204 / 0001-80$ & LONDRINA & PR \\
\hline $\begin{array}{l}\text { FAST ONE SISTEMAS } \\
\text { TECNOLÓGICOS }\end{array}$ & $06.056 .163 / 0001-72$ & RIO DE JANEIRO & RJ \\
\hline $\begin{array}{l}\text { FATOR S.A. CORRETORA DE } \\
\text { VALORES }\end{array}$ & $63.062 .749 / 0001-83$ & SÃO PAULO & SP \\
\hline $\begin{array}{l}\text { FCC FORNECEDORA } \\
\text { COMPONENTES QUIMICOS E } \\
\text { COUROS LTDA. }\end{array}$ & $88.065 .321 / 0001-15$ & CAMPO BOM & RS \\
\hline $\begin{array}{l}\text { FELTRIN IMPRA DE SEMENTES } \\
\text { LTDA }\end{array}$ & $89.844 .922 / 0001-99$ & FARROUPILHA & RS \\
\hline FERTILIZANTES HERINGER S.A. & $22.266 .175 / 0001-88$ & PAULINIA & $\mathrm{SP}$ \\
\hline FESTO AUTOMACAO LTDA. & $57.582 .793 / 0001-11$ & SAO PAULO & $\mathrm{SP}$ \\
\hline FIAT AUTOMOVEIS SIA & $16.701 .716 / 0001-56$ & BETIM & $\overline{\mathrm{MG}}$ \\
\hline $\begin{array}{l}\text { FIBAM COMPANHIA } \\
\text { INDUSTRIAL }\end{array}$ & $61.410 .395 / 0001-95$ & $\begin{array}{c}\text { SAO BERNARDO DO } \\
\text { CAMPO }\end{array}$ & SP \\
\hline FIRMENICH \& CIA LTDA & $61.360 .574 / 0001-65$ & COTIA & $\mathrm{SP}$ \\
\hline FLEURY S.A. & $60.840 .055 / 0001-31$ & SAOO PAULO & $\mathrm{SP}$ \\
\hline $\begin{array}{l}\text { FLEXIBASE INDUSTRIA E } \\
\text { COMERCIO DE MOVEIS LTDA }\end{array}$ & $04.869 .711 / 0001-58$ & $\begin{array}{l}\text { APARECIDA DE } \\
\text { GOIANIA }\end{array}$ & GO \\
\hline $\begin{array}{l}\text { FLEXIBRAS TUBOS FLEXIVEIS } \\
\text { LTDA }\end{array}$ & $28.910 .529 / 0001-61$ & VITORIA & ES \\
\hline FMC QUIMICA DO BRASIL LTDA & $04.136 .367 / 0001-98$ & CAMPINAS & $\mathrm{SP}$ \\
\hline $\begin{array}{l}\text { FMC TECHNOLOGIES DO } \\
\text { BRASIL LTDA }\end{array}$ & $48.122 .295 / 0001-03$ & RIO DE JANEIRO & RJ \\
\hline FORJAS TAURUS S.A. & 92.781.335/0001-02 & PORTO ALEGRE & RS \\
\hline FORJASUL ELETRIK S/A & $88.674 .080 / 0001-01$ & CARLOS BARBOSA & RS \\
\hline FRAS-LE S/A. & $88.610 .126 / 0001-29$ & CAXIAS DO SUL & RS \\
\hline FRATELLI VITA BEBIDAS S.A. & $73.626 .293 / 0001-90$ & JAGUARIÚNA & SP \\
\hline $\begin{array}{l}\text { FREEDDOM TECNOLOGIA E } \\
\text { SERVICOS SA }\end{array}$ & $07.209 .188 / 0001-21$ & SÃO PAULO & SP \\
\hline $\begin{array}{l}\text { FUNDAÇÃO CPQD CENTRO DE } \\
\text { PESQUISA E } \\
\text { DESENVOLVIMENTO EM } \\
\text { TELECOMUNICACCOES }\end{array}$ & $02.641 .663 / 0001-10$ & CAMPINAS & SP \\
\hline $\begin{array}{l}\text { FUNDIMISA FUNDIÇÅO E } \\
\text { USINAGEM LTDA }\end{array}$ & $07.032 .076 / 0001-48$ & SANTO ANGELO & RS \\
\hline FUSOPAR PARAFUSOS LTDA & 89.135.073/0001-02 & CAXIAS DO SUL & RS \\
\hline $\begin{array}{l}\text { FÁBRICA CARIOCA DE } \\
\text { CATALISADORES S.A. }\end{array}$ & $28.944 .734 / 0001-48$ & RIO DE JANEIRO & RJ \\
\hline $\begin{array}{l}\text { FáBRICA DE MóVEIS } \\
\text { FLORENSE LTDA }\end{array}$ & $89.962 .294 / 0001-46$ & FLORES DA CUNHA & RS \\
\hline
\end{tabular}




\begin{tabular}{|c|c|c|c|}
\hline GE BETZ DO BRASIL LITDA & $01.009 .681 / 0001-11$ & COTIA & SP \\
\hline GE CELMA LTDA & $33.435 .231 / 0001-87$ & PETROPOLIS & RJ \\
\hline $\begin{array}{l}\text { GEA DO BRASIL } \\
\text { INTERCAMBIADORES LTDA. }\end{array}$ & $47.344 .197 / 0001-40$ & FRANCO DA ROCHA & SP \\
\hline GELITA DO BRASIL LTDA & $12.199 .337 / 0001-59$ & COTIA & SP \\
\hline $\begin{array}{l}\text { GEMALTO DO BRASIL } \\
\text { CARTŐES E TERMINAIS LTDA. }\end{array}$ & $01.586 .633 / 0001-96$ & PINHAIS & PR \\
\hline $\begin{array}{l}\text { GENERAL MOTORS DO BRASIL } \\
\text { LTDA }\end{array}$ & $59.275 .792 / 0001-50$ & $\begin{array}{l}\text { SAKO CAETANO DO } \\
\text { SUL }\end{array}$ & SP \\
\hline GERDAU ACOS ESPECIAIS S.A. & $07.359 .641 / 0001-86$ & PORTO ALEGRE & RS \\
\hline GERDAU ACOS LONGOS S.A. & $07.358 .761 / 0001-69$ & RIO DE JANEIRO & RJ \\
\hline GESTAMP PARANA S/A & $02.147 .467 / 0001-94$ & $\begin{array}{l}\text { SAOO JOSE DOS } \\
\text { PINHAIS } \\
\end{array}$ & PR \\
\hline $\begin{array}{l}\text { GLOBAL VILLAGE TELECOM } \\
\text { LTDA }\end{array}$ & $03.420 .926 / 0001-24$ & MARINGÁ & PR \\
\hline $\begin{array}{l}\text { GLOBO COMUNICAÇAO E } \\
\text { PARTICIPACOES SA }\end{array}$ & $27.865 .757 / 0001-02$ & RIO DE JANEIRO & RJ \\
\hline $\begin{array}{l}\text { GOODYEAR DO BRASIL } \\
\text { PRODUTOS DE BORRACHA } \\
\text { LTDA. }\end{array}$ & $60.500 .246 / 0001-54$ & SÃO PAULO & SP \\
\hline $\begin{array}{l}\text { GRAFFO PARANAENSE DE } \\
\text { EMBALAGENS LTDA }\end{array}$ & $04.676 .488 / 0001-22$ & PINHAIS & PR \\
\hline GRAMMER DO BRASIL LTDA & $60.395 .233 / 0001-62$ & ATIBAIA & $\mathrm{SP}$ \\
\hline $\begin{array}{l}\text { GRANOLAB DO BRASIL S.A } \\
\text { TECNOLOGIA PARA INDUSTRIA } \\
\text { ALIMENTICIA }\end{array}$ & $06.895 .723 / 0001-82$ & CURITIBA & PR \\
\hline GRENDENE S.A. & $89.850 .341 / 0001-60$ & SOBRAL & $\mathrm{CE}$ \\
\hline GRUPO A TARDE & 15.111.297/0001-30 & SALVADOR & BA \\
\hline $\begin{array}{l}\text { GUARANY INDUSTRIA E } \\
\text { COMERCIO LTDA }\end{array}$ & $61.089 .835 / 0001-54$ & ITU & SP \\
\hline GVDASA INFORMATICA LTDA & $91.626 .572 / 0001-36$ & SAOLEOPOLDO & RS \\
\hline $\begin{array}{l}\text { HERGEN S.A. MÁQUINAS E } \\
\text { EQUIPAMENTOS }\end{array}$ & $83.141 .507 / 0001-92$ & RIO DO SUL & SC \\
\hline $\begin{array}{l}\text { HEXION QUIMICA INDUSTRIA E } \\
\text { COMERCIO LTDA }\end{array}$ & $61.460 .150 / 0001-72$ & CURITIBA & PR \\
\hline $\begin{array}{l}\text { HIPOLABOR FARMACéUTICA } \\
\text { LTDA }\end{array}$ & $19.570 .720 / 0001-10$ & SABARA & MG \\
\hline $\begin{array}{l}\text { HITER IND. E COM. DE } \\
\text { CONTROLES TERMO } \\
\text { HIDRAULICOS LTDA. } \\
\end{array}$ & $61.507 .844 / 0001-18$ & SÃO PAULO & SP \\
\hline $\begin{array}{l}\text { HONDA AUTOMóVEIS DO } \\
\text { BRASIL LTDA }\end{array}$ & $01.192 .333 / 0001-22$ & SUMARE & SP \\
\hline $\begin{array}{l}\text { HSBC BANK BRASIL S.A. - } \\
\text { BANCO MÚLTIPLO }\end{array}$ & $01.701 .201 / 0001-89$ & शITIBA & PR \\
\hline
\end{tabular}




\begin{tabular}{|c|c|c|c|}
\hline $\begin{array}{l}\text { IBEMA INDUSTRIA BRASILEIRA } \\
\text { DE PAPEL }\end{array}$ & $80.228 .885 / 0001-10$ & TURVO & PR \\
\hline $\begin{array}{l}\text { IHARABRAS SIA INDUSTRIAS } \\
\text { QUIMICAS }\end{array}$ & $61.142 .550 / 0001-30$ & SOROCABA & SP \\
\hline $\begin{array}{l}\text { MOBRAS INDÚSTRIA DE } \\
\text { MOTORES ELETTRICOS LTDA }\end{array}$ & $04.333 .355 / 0001-53$ & ALTO FELIZ & RS \\
\hline $\begin{array}{l}\text { MPRESSORA PARANAENSE } \\
\text { S/A }\end{array}$ & $76.501 .253 / 0001-00$ & CURITIBA & PR \\
\hline INCARD DO BRASIL LTDA & $05.591 .856 / 0001-00$ & SANTO ANDRE & $\mathrm{SP}$ \\
\hline $\begin{array}{l}\text { INCEPA REVESTIMENTOS } \\
\text { CERAMICOS LTDA. }\end{array}$ & $76.610 .062 / 0001-87$ & CAMPO LARGO & PR \\
\hline IND DE CALCADOS VIVO LTDA & $08.909 .818 / 0001-33$ & FARROUPILHA & RS \\
\hline $\begin{array}{l}\text { INDUSSCAR INDÚSTRIA E } \\
\text { COMÉRCIO DE CARROCERIAS } \\
\text { LTDA }\end{array}$ & $02.907 .841 / 0001-02$ & BOTUCATU & SP \\
\hline $\begin{array}{l}\text { INDUSTRIA DE ALIMENTOS } \\
\text { BOMGOSTO LTDA }\end{array}$ & $35.603 .679 / 0001-98$ & $\begin{array}{l}\text { JABOATAO DOS } \\
\text { GUARARAPES }\end{array}$ & $\mathrm{PE}$ \\
\hline $\begin{array}{l}\text { INDUSTRIA DE MEIAS SCALINA } \\
\text { LTDA }\end{array}$ & $61.149 .886 / 0001-24$ & GUARULHOS & SP \\
\hline $\begin{array}{l}\text { INDUSTRIA ELETRICA } \\
\text { MARANGONI MARETTI LTDA }\end{array}$ & $52.770 .005 / 0001-05$ & MOJI MIRIM & SP \\
\hline $\begin{array}{l}\text { INDUSTRIA ELETROMECANICA } \\
\text { BALESTRO LTDA } \\
\end{array}$ & $52.770 .948 / 0001-20$ & MOJI MIRIM & SP \\
\hline $\begin{array}{l}\text { INDUSTRIAL AGRICOLA } \\
\text { FORTALEZA IMPORTACAO E } \\
\text { EXPORTACAO LTDA. }\end{array}$ & $88.152 .517 / 0001-47$ & IBIRUBA & RS \\
\hline INDUSTRIAL PAGE LTDA & $82.563 .321 / 0001-69$ & ARARANGUA & $\mathrm{SC}$ \\
\hline $\begin{array}{l}\text { INDUSTRIAS SANTA CLARA } \\
\text { S.A. }\end{array}$ & $17.156 .696 / 0001-42$ & CONTAGEM & MG \\
\hline $\begin{array}{l}\text { INDÚSTRIA DE CALÇADOS } \\
\text { WEST COAST LTDA }\end{array}$ & 91.938.712/0001-01 & IVOTI & RS \\
\hline INDÚSTRIAS ROMI S.A. & $56.720 .428 / 0001-63$ & $\begin{array}{l}\text { SANTA BARBARA } \\
\text { D'OESTE }\end{array}$ & SP \\
\hline $\begin{array}{l}\text { INERGY AUTOMOTIVE } \\
\text { SYSTEMS DO BRASIL LTDA. }\end{array}$ & $02.814 .286 / 0001-74$ & SÅO PAULO & SP \\
\hline $\begin{array}{l}\text { INOQUIMICA INDUSTRIA E } \\
\text { COMERCIO LTDA. }\end{array}$ & $07.292 .680 / 0001-03$ & SIMOES FILHO & BA \\
\hline NTECNIAL SA & $89.432 .702 / 0001-58$ & ERECHIM & RS \\
\hline $\begin{array}{l}\text { INTERNATIONAL PAPER DO } \\
\text { BRASIL LTDA. }\end{array}$ & $52.736 .949 / 0001-58$ & MOGI GUACU & SP \\
\hline $\begin{array}{l}\text { INTERNET GROUP DO BRASIL } \\
\text { S.A. }\end{array}$ & $03.368 .522 / 0001-39$ & SÅO PAULO & SP \\
\hline $\begin{array}{l}\text { INTRAL SIA INDÚSTRIA DE } \\
\text { MATERIAIS ELÉTRICOS }\end{array}$ & $88.611 .264 / 0001-22$ & CAXIAS DO SUL & RS \\
\hline
\end{tabular}




\begin{tabular}{|c|c|c|c|}
\hline IOCHPE-MAXION S/A & $61.156 .113 / 0001-75$ & CRUZEIRO & SP \\
\hline $\begin{array}{l}\text { IRWIN INDUSTRIAL TOOL } \\
\text { FERRAMENTAS DO BRASIL } \\
\text { LTDA }\end{array}$ & $90.049 .289 / 0001-26$ & CARLOS BARBOSA & RS \\
\hline ISP DO BRASIL LTDA. & 62.432.778/0001-27 & SÁO PAULO & SP \\
\hline ITABUNA TEXTIL S/A & $01.933 .349 / 0001-49$ & ITABUNA & BA \\
\hline ITAP/BEMIS LTDA & $00.216 .758 / 0001-61$ & SAO PAULO & $\mathrm{SP}$ \\
\hline $\begin{array}{l}\text { ITAUTEC S.A. - GRUPO } \\
\text { ITAUTEC }\end{array}$ & $54.526 .082 / 0001-31$ & SÃO PAULO & SP \\
\hline ITAÚ UNIBANCO S.A. & $60.701 .190 / 0001-04$ & SAO PAULO & $\mathrm{SP}$ \\
\hline $\begin{array}{l}\text { ITRON SOLUÇסES PARA } \\
\text { ENERGIA E AGUA LTDA }\end{array}$ & $60.882 .719 / 0001-25$ & CAMPINAS & SP \\
\hline NECO LATIN AMERICA LTDA & $01.844 .555 / 0001-82$ & NOVA LIMA & MG \\
\hline JOHN DEERE BRASIL LTDA. & $89.674 .782 / 0001-58$ & HORIZONTINA & RS \\
\hline $\begin{array}{l}\text { JOHNSON \& JOHNSON DO } \\
\text { BRASIL INDUSTRIA E } \\
\text { COMERCIO DE PRODUTOS } \\
\text { PARA SAUDE LTDA }\end{array}$ & $54.516 .661 / 0001-01$ & SÅO PAULO & SP \\
\hline $\begin{array}{l}\text { JOHNSON \& JOHNSON } \\
\text { INDUSTRIAL LTDA }\end{array}$ & $59.748 .988 / 0001-14$ & $\begin{array}{l}\text { SAO JOSE DOS } \\
\text { CAMPOS }\end{array}$ & SP \\
\hline $\begin{array}{l}\text { JOST BRASIL SISTEMAS } \\
\text { AUTOMOTIVOS LTDA. }\end{array}$ & $|00.843 .966 / 0001-90|$ & CAXIAS DO SUL & RS \\
\hline $\begin{array}{l}\text { JP INDUSTRIA FARMACEUTICA } \\
\text { S/A }\end{array}$ & $55.972 .087 / 0001-50$ & SÅO PAULO & SP \\
\hline KEKO ACESSORIOS S.A. & $91.013 .698 / 0001-35$ & CAXIAS DO SUL & RS \\
\hline $\begin{array}{l}\text { KEPLER WEBER INDUSTRIAL } \\
\text { S.A }\end{array}$ & $87.288 .940 / 0001-06$ & PANAMBI & RS \\
\hline $\begin{array}{l}\text { KLEY HERTZ SIA INDUSTRIA E } \\
\text { COMERCIO }\end{array}$ & $92.695 .691 / 0001-03$ & PORTO ALEGRE & RS \\
\hline $\begin{array}{l}\text { KLL EQUIPAMENTOS PARA } \\
\text { TRANSPORTE LTDA }\end{array}$ & $92.327 .410 / 0001-60$ & PORTO ALEGRE & RS \\
\hline $\begin{array}{l}\text { KNORR BREMSE SISTEMAS } \\
\text { PARA VEICULOS COMERCIAIS } \\
\text { BRASIL LTDA. }\end{array}$ & $00.416 .170 / 0001-51$ & SÅO PAULO & SP \\
\hline $\begin{array}{l}\text { KOSTAL ELETROMECấNICA } \\
\text { LTDA. }\end{array}$ & $|60.852 .274 / 0001-30|$ & $\begin{array}{l}\text { SÅO BERNARDO DO } \\
\text { CAMPO }\end{array}$ & SP \\
\hline KRAFT FOODS BRASIL SIA & $33.033 .028 / 0001-84$ & CURITIBA & $\mathrm{PR}$ \\
\hline $\begin{array}{l}\text { KRATON POLYMERS DO } \\
\text { BRASIL SIA }\end{array}$ & $03.528 .802 / 0001-67$ & PAULIINIA & SP \\
\hline $\begin{array}{l}\text { KäRCHER INDUSTRIA E } \\
\text { COMéRCIO LTDA }\end{array}$ & $47.110 .960 / 0001-78$ & PAULIINIA & SP \\
\hline LABORATORIO BIO-VET SA & $60.411 .527 / 0001-30 \mid$ & $\begin{array}{l}\text { VARGEM GRANDE } \\
\text { PAULISTA }\end{array}$ & SP \\
\hline
\end{tabular}




\begin{tabular}{|c|c|c|c|}
\hline $\begin{array}{l}\text { LABORATORIO INDUSTRIAL } \\
\text { FARMACEUTICO LIFAR LTDA }\end{array}$ & $92.928 .951 / 0001-43$ & PORTO ALEGRE & RS \\
\hline $\begin{array}{l}\text { LABORATORIO TEUTO } \\
\text { BRASILEIRO SIA }\end{array}$ & $17.159 .229 / 0001-76$ & ANAPOLIS & GO \\
\hline $\begin{array}{l}\text { LABORATÓRIO NEO QUIMICA } \\
\text { COMÉRCIO E INDÚSTRIA LTDA. }\end{array}$ & $29.785 .870 / 0001-03$ & ANAPOLIS & Go \\
\hline LABTEST DIAGNOSTICA SA. & $16.516 .296 / 0001-38$ & LAGOA SANTA & MG \\
\hline $\begin{array}{l}\text { LANDIS+GYR EQUIPAMENTOS } \\
\text { DE MEDIção LTDA. }\end{array}$ & $58.900 .754 / 0001-88$ & CURITIBA & PR \\
\hline $\begin{array}{l}\text { LATINA ELETRODOMESTICOS } \\
\text { S.A. }\end{array}$ & $00.217 .622 / 0001-76$ & SÃO CARLOS & SP \\
\hline LBS LOCAL SA & $03.980 .538 / 0001-06$ & SAO PAULO & $\mathrm{SP}$ \\
\hline $\begin{array}{l}\text { LEAR DO BRASIL INDUSTRIA E } \\
\text { COMERCIO INTERIORES } \\
\text { AUTOMOTIVOS LTDA }\end{array}$ & $01.998 .585 / 0001-43$ & CACAPAVA & SP \\
\hline $\begin{array}{l}\text { LHS AMERICAS SISTEMAS DE } \\
\text { COMUNICAcäO LTDA }\end{array}$ & $06.944 .304 / 0001-93$ & SÅO PAULO & SP \\
\hline $\begin{array}{l}\text { LIFEMED INDUSTRIAL DE } \\
\text { EQUIPAMENTOS E ARTIGOS } \\
\text { MéDICOS E HOSPITALARES SIA }\end{array}$ & $02.357 .251 / 0001-53$ & PELOTAS & RS \\
\hline LIGHT ENERGIA S.A. & $01.917 .818 / 0001-36$ & RIO DE JANEIRO & RJ \\
\hline $\begin{array}{l}\text { LIGHT SERVICOS DE } \\
\text { ELETRICIDADE SA. }\end{array}$ & $60.444 .437 / 0001-46$ & RIO DE JANEIRO & RJ \\
\hline $\begin{array}{l}\text { LINX SISTEMAS E } \\
\text { CONSULTORIA LTDA }\end{array}$ & $54.517 .628 / 0001-98$ & SÅO PAULO & SP \\
\hline $\begin{array}{l}\text { LOCALFRIO S.A.ARMAZÉNS } \\
\text { GERAIS FRIGORIFICOS }\end{array}$ & $58.317 .751 / 0001-16$ & SÅO PAULO & SP \\
\hline $\begin{array}{l}\text { LOCAWEB SERVICOS DE } \\
\text { INTERNET S.A. }\end{array}$ & $02.351 .877 / 0001-52$ & SÅO PAULO & SP \\
\hline LOGICTEL SIA & $03.430 .070 / 0001-78$ & SAO PAULO & $\mathrm{SP}$ \\
\hline $\begin{array}{l}\text { LUBRIZOL DO BRASIL } \\
\text { ADITIVOS LTDA }\end{array}$ & $42.593 .962 / 0001-41$ & BELFORD ROXO & RJ \\
\hline LUPO S.A. & $43.948 .405 / 0001-69$ & ARARAQUARA & $\mathrm{SP}$ \\
\hline M D MÓVEIS LTDA & $89.042 .642 / 0001-67$ & BOM PRINCIPIO & RS \\
\hline M.A. BORRACHAS LTDA & 80.429.168/0001-00 & CARLOS BARBOSA & RS \\
\hline MACCAFERRI DO BRASIL LTDA & $43.876 .960 / 0001-22$ & JUNDIAI & SP \\
\hline MADEIREIRA HERVAL LTDA & $89.237 .911 / 0016-27$ & DOIS IRMAOS & RS \\
\hline $\begin{array}{l}\text { MAGNETI MARELLI SISTEMAS } \\
\text { AUTOMOTIVOS INDÚSRIA E } \\
\text { COMÉRCIO LTDA. }\end{array}$ & $02.990 .605 / 0001-00$ & CONTAGEM & MG \\
\hline $\begin{array}{l}\text { MAHLE COMPONENTES DE } \\
\text { MOTORES DO BRASIL LTDA. }\end{array}$ & $03.002 .935 / 0001-03$ & ITAJUBA & M \\
\hline
\end{tabular}




\begin{tabular}{|c|c|c|c|}
\hline $\begin{array}{l}\text { MAN Latin America Industria e } \\
\text { Comercio de Veiculos Ltda }\end{array}$ & $06.020 .318 / 0001-10$ & SÃO PAULO & SP \\
\hline $\begin{array}{l}\text { MANGELS INDÚSTRIA E } \\
\text { COMÉRCIO LTDA }\end{array}$ & $17.958 .315 / 0001-49$ & SÃO PAULO & SP \\
\hline MAQ SAZI LTDA & $90.064 .288 / 0001-50$ & FARROUPILHA & RS \\
\hline MAQUINAS SANMARTIN LTDA & $89.086 .672 / 0001-75$ & CAXIAS DO SUL & RS \\
\hline $\begin{array}{l}\text { MAR- GIRIUS CONTINENTAL } \\
\text { ICE LTDA }\end{array}$ & 61.093.001/0001-12 & PORTO FERREIRA & SP \\
\hline MARCOPOLO S/A. & $88.611 .835 / 0001-29$ & CAXIAS DO SUL & RS \\
\hline $\begin{array}{l}\text { MAREL INDÚSTRIA DE MÓVEIS } \\
\text { S.A. }\end{array}$ & $77.808 .640 / 0001-57$ & FRANCISCO BELTRAO & PR \\
\hline $\begin{array}{l}\text { MARELLI MÓVEIS PARA } \\
\text { ESCRITORIO LTDA. }\end{array}$ & $88.766 .936 / 0001-79$ & CAXIAS DO SUL & RS \\
\hline MARSUL PROTEINAS LTDA & $91.271 .718 / 0001-78$ & MONTENEGRO & RS \\
\hline $\begin{array}{l}\text { MASCARELLO CARROCERIAS E } \\
\text { ONIBUS LTDA }\end{array}$ & $05.440 .065 / 0001-71$ & CASCAVEL & PR \\
\hline $\begin{array}{l}\text { MASTER SISTEMAS } \\
\text { AUTOMOTIVOS LTDA. }\end{array}$ & $90.852 .914 / 0001-73$ & CAXIAS DO SUL & RS \\
\hline $\begin{array}{l}\text { MASTERFOODS BRASIL } \\
\text { ALIMENTO LTDA } \\
\end{array}$ & 29.737.368/0001-19 & MOJI MIRIM & SP \\
\hline $\begin{array}{l}\text { MATERA SYSTEMS } \\
\text { INFORMáTICA SA } \\
\end{array}$ & $57.040 .040 / 0001-84$ & CAMPINAS & SP \\
\hline $\begin{array}{l}\text { MAUSA SA EQUIPAMENTOS } \\
\text { INDUSTRIAIS }\end{array}$ & $54.363 .072 / 0001-22$ & PIRACICABA & SP \\
\hline $\begin{array}{l}\text { MAXICORTE IND E COM DE } \\
\text { ACOS LTDA }\end{array}$ & $91.960 .971 / 0001-39$ & BENTO GONCALVES & RS \\
\hline $\begin{array}{l}\text { MB METALBAGES DO BRASIL } \\
\text { LTDA }\end{array}$ & $00.615 .041 / 0001-92$ & TAUBATE & SP \\
\hline $\begin{array}{l}\text { MECALOR SOLUÇठరES EM } \\
\text { ENGENHARIA TÉRMICA LTDA. }\end{array}$ & $49.031 .776 / 0001-68$ & SÃO PAULO & SP \\
\hline $\begin{array}{l}\text { MEDABIL SISTEMAS } \\
\text { CONSTRUTIVOS SIA. }\end{array}$ & $94.638 .392 / 0001-62$ & NOVA BASSANO & RS \\
\hline MEGA EMBALAGENS LTDA & $72.535 .115 / 0001-91$ & SALVADOR DO SUL & RS \\
\hline MEMPHIS S.A. INDUSTRIAL & $92.697 .010 / 0001-46$ & PORTO ALEGRE & RS \\
\hline $\begin{array}{l}\text { MERCEDES-BENZ DO BRASIL } \\
\text { LTDA }\end{array}$ & $58.104 .273 / 0001-29$ & $\begin{array}{c}\text { SAOO BERNARDO DO } \\
\text { CAMPO }\end{array}$ & SP \\
\hline $\begin{array}{l}\text { MERCK SHARP \& DOHME } \\
\text { FARMACËUTICA LTDA }\end{array}$ & $45.987 .013 / 0001-34$ & CAMPINAS & SP \\
\hline MERCUR SIA & $93.896 .397 / 0001-22$ & SANTA CRUZ DO SUL & RS \\
\hline MERIAL SAÚDE ANIMAL LTDA & $57.600 .249 / 0001-55$ & PAULINIAA & $\mathrm{SP}$ \\
\hline $\begin{array}{l}\text { MERITOR COMERCIO E } \\
\text { INDUSTRIA DE SISTEMAS } \\
\text { AUTOMOTIVOS LTDA. }\end{array}$ & $09.603 .244 / 0001-33$ & LIMEIRA & SP \\
\hline METALFRIO SOLUTIONS S.A. & $04.821 .041 / 0001-08$ & SAOO PAULO & $\mathrm{SP}$ \\
\hline METALURGICA FEY S/A & $84.229 .624 / 0001-75$ & INDAIAL & $\mathrm{SC}$ \\
\hline
\end{tabular}




\begin{tabular}{|c|c|c|c|}
\hline $\begin{array}{l}\text { METALURGICA METAL MASTER } \\
\text { LTDA. }\end{array}$ & $00.125 .485 / 0001-40$ & SANTA ROSA & RS \\
\hline $\begin{array}{l}\text { METASA SIA INDÚSTRIA } \\
\text { METALÚRGICA }\end{array}$ & $88.416 .482 / 0001-06$ & MARAU & RS \\
\hline MICROVIX SOFTWARE SIA & $02.339 .928 / 0001-20$ & JOINVILLE & $\mathrm{SC}$ \\
\hline MK QUIMICA DO BRASIL LTDA & 82.315.332/0001-83 & PORTAO & RS \\
\hline $\begin{array}{l}\text { MODINE DO BRASIL SISTEMAS } \\
\text { TERMICOS LTDA }\end{array}$ & $03.310 .685 / 0002-41$ & GUARULHOS & SP \\
\hline $\begin{array}{l}\text { MONIER TEGULA SOLUÇסES } \\
\text { PARA TELLHADOS LTDA }\end{array}$ & $02.014 .622 / 0001-02$ & ATIBAIA & SP \\
\hline MONSOY LTDA. & $00.901 .864 / 0001-84$ & SÅO PAULO & $\mathrm{SP}$ \\
\hline $\begin{array}{l}\text { MOTO HONDA DA AMAZONIA } \\
\text { LTDA }\end{array}$ & $04.337 .168 / 0001-48$ & MANAUS & AM \\
\hline MOVEIS SANDRIN LTDA. & $87.845 .368 / 0001-39$ & BENTO GONCALVES & RS \\
\hline MRS LOGISTICA SIA & $01.417 .222 / 0001-77$ & RIO DE JANEIRO & RJ \\
\hline $\begin{array}{l}\text { MULTILAB IND. E COMÉRCIO } \\
\text { DE PRODUTOS } \\
\text { FARMACÉUTICOS LTDA. }\end{array}$ & $92.265 .552 / 0001-40$ & SÅO JERONIMO & RS \\
\hline $\begin{array}{l}\text { MULTINOVA IND DE } \\
\text { EMBALAGENS PLASTICAS }\end{array}$ & $92.475 .250 / 0001-04$ & FARROUPILHA & RS \\
\hline $\begin{array}{l}\text { MULTITÉCNICA INDUSTRIAL } \\
\text { LTDA }\end{array}$ & $71.013 .916 / 0001-24$ & SETE LAGOAS & MG \\
\hline $\begin{array}{l}\text { MUNTERS BRASIL INDUSTRIA E } \\
\text { COMERCIO LTDA }\end{array}$ & $00.385 .090 / 0001-86$ & CURITIBA & PR \\
\hline $\begin{array}{l}\text { MVC COMPONENTES } \\
\text { PLASTICOS LTDA }\end{array}$ & $81.424 .962 / 0001-70$ & $\begin{array}{l}\text { SÅO JOSÉ DOS } \\
\text { PINHAIS }\end{array}$ & PR \\
\hline $\begin{array}{l}\text { MÁQUINAS AGRICOLAS JACTO } \\
\text { SA }\end{array}$ & $55.064 .562 / 0001-90$ & POMPEIA & SP \\
\hline MÓVEIS KAPPESBERG LTDA. & $00.912 .882 / 0001-61$ & TUPANDI & RS \\
\hline $\begin{array}{l}\text { NATIONAL STARCH \& } \\
\text { CHEMICAL INDUSTRIALLTDA } \\
\end{array}$ & $64.777 .691 / 0001-17$ & JUNDIAI & SP \\
\hline NATURA COSMÉTICOS SIA & $71.673 .990 / 0001-77$ & $\begin{array}{l}\text { ITAPECERICA DA } \\
\text { SERRA }\end{array}$ & SP \\
\hline $\begin{array}{l}\text { NESTLE WATERS BRASIL - } \\
\text { BEBIDAS E ALIMENTOS LTDA }\end{array}$ & $33.062 .464 / 0001-81$ & SÅO PAULO & SP \\
\hline NESTLé BRASIL LTDA & $60.409 .075 / 0001-52$ & SÅO PAULO & $\mathrm{SP}$ \\
\hline $\begin{array}{l}\text { NESTLé NORDESTE } \\
\text { ALIMENTOS E BBEBIDAS }\end{array}$ & $08.334 .818 / 0001-52$ & FEIRA DE SANTANA & BA \\
\hline NET SăO PAULO LTDA & $65.697 .161 / 0001-21$ & SAO PAULO & $\mathrm{SP}$ \\
\hline \begin{tabular}{|l|} 
NETZSCH DO BRASIL \\
INDUSTRIA E COMERCIO LTDA
\end{tabular} & $82.749 .987 / 0001-06$ & POMERODE & $\mathrm{SC}$ \\
\hline $\begin{array}{l}\text { NEUMAYER TEKFOR } \\
\text { AUTOMOTIVE BRASIL LTDA }\end{array}$ & $61.096 .996 / 0001-75$ & JUNDIAI & SP \\
\hline $\begin{array}{l}\text { NINFA INDÚSTRIA DE } \\
\text { ALIMENTOS LTDA }\end{array}$ & $78.099 .777 / 0001-42$ & MEDIANEIRA & PR \\
\hline
\end{tabular}




\begin{tabular}{|c|c|c|c|}
\hline $\begin{array}{l}\text { NISSAN DO BRASIL } \\
\text { AUTOMOVEIS LTDA. }\end{array}$ & $04.104 .117 / 0001-76$ & $\begin{array}{l}\text { SÅO JOSÉ DOS } \\
\text { PINHAIS }\end{array}$ & PR \\
\hline NORTEC QUIMICA S. A. & $29.950 .060 / 0001-57$ & DUQUE DE CAXIAS & R.J \\
\hline $\begin{array}{l}\text { NOVA ROCHA INDUSTRIA DE } \\
\text { TINTAS LTDA }\end{array}$ & $03.005 .123 / 0001-03$ & $\begin{array}{l}\text { APARECIDA DE } \\
\text { GOIANIA }\end{array}$ & GO \\
\hline NOVARTIS BIOCIÉNCIAS SIA & $56.994 .502 / 0001-30$ & SAO PAULO & SP \\
\hline NOVELIS DO BRASIL LTDA. & $60.561 .800 / 0001-03$ & SÁO PAULO & SP \\
\hline $\begin{array}{l}\text { NOVO NORDISK PRODUCAO } \\
\text { FARMACEUTICA DO BRASIL } \\
\text { LTDA }\end{array}$ & $16.921 .603 / 0001-66$ & MONTES CLAROS & MG \\
\hline NUTRON ALIMENTOS LTDA & $01.961 .898 / 0001-27$ & ITAPIRA & SP \\
\hline $\begin{array}{l}\text { ORBISAT DA AMAZóNIA } \\
\text { INDÚSTRIA E } \\
\text { AEROLEVANTAMENTO SIA } \\
\end{array}$ & $02.807 .737 / 0001-46$ & MANAUS & AM \\
\hline $\begin{array}{l}\text { ORIGINAL INDÚSTRIA } \\
\text { ELETROELETRONICA LTDA }\end{array}$ & $03.058 .852 / 0001-28$ & $\begin{array}{l}\text { SAO JOSÉ DOS } \\
\text { PINHAIS }\end{array}$ & PR \\
\hline $\begin{array}{l}\text { OURO FINO SAúDE ANIMAL } \\
\text { LTDA }\end{array}$ & $57.624 .462 / 0001-05$ & CRAVINHOS & SP \\
\hline $\begin{array}{l}\text { OXFORD SIA INDUSTRIA E } \\
\text { COMERCIO }\end{array}$ & $86.046 .463 / 0001-00$ & SÅO BENTO DO SUL & SC \\
\hline OXICAP IND. DE GASES LTDA & $43.117 .399 / 0001-06$ & SAO PAULO & $\mathrm{SP}$ \\
\hline PADTEC SIA & $03.549 .807 / 0001-76$ & CAMPINAS & $\mathrm{SP}$ \\
\hline PANDURATA ALIMENTOS LTDA & $70.940 .994 / 0001-01$ & GUARULHOS & $\mathrm{SP}$ \\
\hline PARATI S.A. & $82.945 .932 / 0001-71$ & $\begin{array}{l}\text { SAAO LOURENCO DO } \\
\text { OESTE }\end{array}$ & SC \\
\hline $\begin{array}{l}\text { PARKS S/A - COMUNICAÇס́ES } \\
\text { DIGITAIS }\end{array}$ & 92.679 .331 & $\mathrm{CAC}$ & RS \\
\hline PC INFORMATICA LTDA & $22.003 .149 / 0001-67$ & BELO HORIZONTE & MG \\
\hline PEDRO SANZ CLIMA LTDA & $05.403 .856 / 0001-21$ & CAXIAS DO SUL & RS \\
\hline PEROXIDOS DO BRASIL LTDA. & $51.784 .262 / 0001-25$ & CURITIBA & PR \\
\hline PETROQUIMICA TRIUNFO S/A. & $80.751 .025 / 0001-10$ & TRIUNFO & RS \\
\hline PETRÓLEO BRASILEIRO S.A & $33.000 .167 / 0001-01$ & RIO DE JANEIRO & R.J \\
\hline $\begin{array}{l}\text { PEUGEOT CITROEN DO BRASIL } \\
\text { AUTOMOVEIS LTDA }\end{array}$ & $67.405 .936 / 0001-73$ & PORTO REAL & RJ \\
\hline $\begin{array}{l}\text { PHILIP MORRIS BRASIL } \\
\text { INDÚSTRIA E COMÉRCIO LTDA. }\end{array}$ & $04.041 .933 / 0001-88$ & CURITIBA & PR \\
\hline $\begin{array}{l}\text { PILECCO NOBRE ALIMENTOS } \\
\text { LTDA. }\end{array}$ & $88.944 .558 / 0001-76$ & ALEGRETE & RS \\
\hline PINCEIS TIGRE SIA & $61.182 .606 / 0001-80$ & CASTRO & PR \\
\hline PINCélS ATLAS SA & $89.723 .837 / 0001-72$ & ESTEIO & RS \\
\hline PIRELLI PNEUS LTDA & $59.179 .838 / 0001-37$ & SANTO ANDRE & $\mathrm{SP}$ \\
\hline PISANI PLASTICOS S.A & $87.833 .737 / 0001-73$ & CAXIAS DO SUL & RS \\
\hline $\begin{array}{l}\text { PK CABLES DO BRASIL } \\
\text { INDUSTRIA E COMERCIO LTDA }\end{array}$ & $01.691 .944 / 0001-15$ & CURITIBA & PR \\
\hline
\end{tabular}




\begin{tabular}{|c|c|c|c|}
\hline $\begin{array}{l}\text { PLASTIC OMNIUM DO BRASIL } \\
\text { LTDA. }\end{array}$ & $02.645 .941 / 0001-08$ & TAUBATE & SP \\
\hline $\begin{array}{l}\text { PLP PRODUTOS } \\
\text { PREFORMADOS LTDA }\end{array}$ & 61.831.244/0001-00 & CANAMAR & SP \\
\hline PLáSTICOS CREMER S.A. & $2.726 .316 / 0001-20$ & BLUMENAU & $\mathrm{SC}$ \\
\hline $\begin{array}{l}\text { POLENGHI INDUSTRIA } \\
\text { ALIMENTICIAS LTDA } \\
\end{array}$ & $24.949 .232 / 0001-59$ & SÃO PAULO & SP \\
\hline POLI NUTRI ALIMENTOS LTDA & $60.210 .515 / 0001-48$ & OSASCO & $\mathrm{SP}$ \\
\hline POSITIVO INFORMATICA S.A. & $81.243 .735 / 0001-48$ & CURITIBA & $\overline{P R}$ \\
\hline ZII \& CIA LTDA & $73.856 .593 / 0001-68$ & TOLEDO & PR \\
\hline PRIMAFE & $87.230 .553 / 0001-19$ & ESTEIO & RS \\
\hline PRINT LA & $67.996 .520 / 0001-77$ & SAO PAULO & $\mathrm{SP}$ \\
\hline PROCAD SOFTWARES LTDA & $00.141 .463 / 0001-73$ & CAXIAS DO SUL & $\overline{R S}$ \\
\hline $\begin{array}{l}\text { PROMINA } \\
\text { EQUIPAN }\end{array}$ & 50.50 & $S A$ & SP \\
\hline $\begin{array}{l}\text { PRYSMIAN ENERGIA CABOS E } \\
\text { SISTEMAS DO BRASIL S.A. } \\
\end{array}$ & 9 & So & SP \\
\hline PST ELETRONICA SIA & $10001-04$ & & AM \\
\hline PURA & $10001-43$ & $\mathrm{HOS}$ & $\mathrm{SP}$ \\
\hline L INDUSTRIA & $00.999 .042 / 0001-88$ & RIO DE JANEIRO & RJ \\
\hline QUIM & $1-90$ & & $\mathrm{SP}$ \\
\hline QUIR & $10001-70$ & UE & $\mathrm{SC}$ \\
\hline $\begin{array}{l}\text { RAND } \\
\text { O TR }\end{array}$ & $09.479 .233 / 0001-93$ & GUARULHOS & SP \\
\hline NTOS E & $89.086 .144 / 0001-16$ & CAXIAS DO SUL & RS \\
\hline RANDON VEICCULOS LTDA. & $.740 / 0001-08$ & CAXI & RS \\
\hline $\begin{array}{l}\text { RASSINI NHK AUTO PEÇAS } \\
\text { LTDA }\end{array}$ & $61.142 .063 / 0001-77$ & $\begin{array}{c}\text { SÅO BERNARDO DO } \\
\text { CAMPO }\end{array}$ & SP \\
\hline $\begin{array}{l}\text { RAZÅO SOCIAL: STEMAC S/A } \\
\text { GRUPOS GERADORES }\end{array}$ & $2.753 .268 / 0001-12$ & PORTO ALEGRE & RS \\
\hline RED & -04 & & $\mathrm{SP}$ \\
\hline REI & $10002-37$ & MOGI L & $\mathrm{SP}$ \\
\hline RELTHY LABOR & $58.884 .735 / 0001-05$ & $\mathbb{I N D F}$ & $\mathrm{SP}$ \\
\hline REI & 0 & $\begin{array}{l}\text { SAO JOSE DOS } \\
\text { PINHAIS }\end{array}$ & PR \\
\hline RENNER SAYERLACK SIA. & 61.142.865/0006-91 & CAJAMAR & $\mathrm{SP}$ \\
\hline $\begin{array}{l}\text { REPINHO REFLORESTADORA } \\
\text { MADEIRAS E COMPENSADOS } \\
\text { LTDA }\end{array}$ & $82.196 .510 / 0001-40$ & GUARAPUAVA & PR \\
\hline & 02.261 .78 & JUR & SP \\
\hline RHODIA BR & $57.507 .626 / 0001-06$ & SAOO PAULO & $\mathrm{SP}$ \\
\hline
\end{tabular}




\begin{tabular}{|c|c|c|c|}
\hline $\begin{array}{l}\text { RIGESA, CELULOSE, PAPEL E } \\
\text { EMBALAGENS LTDA }\end{array}$ & $45.989 .050 / 0001-81$ & CAMPINAS & SP \\
\hline RIMA INDUSTRIAL S/A & 18.279.158/0001-08 & BOCAIUVA & $\overline{M G}$ \\
\hline RIO GRANDE ENERGIA S.A. & $02.016 .439 / 0001-38$ & CAXIAS DO SUL & $\overline{R S}$ \\
\hline ROBERT BOSCH LIMITADA & $45.990 .181 / 0001-89$ & CAMPINAS & $\mathrm{SP}$ \\
\hline $\begin{array}{l}\text { ROYAL CANIN DO BRASIL } \\
\text { INDUSTRIAE COMERCIO LTDA }\end{array}$ & $62.527 .619 / 0001-06$ & DESCALVADO & SP \\
\hline SADIA S.A. & $20.730 .099 / 0001-94$ & CONCORDIA & $\mathrm{SC}$ \\
\hline $\begin{array}{l}\text { SAINT-GOBAIN DO BRASIL } \\
\text { PRODUTOS INDUSTRIAIS E } \\
\text { PARA CONSTRUÇÄO LTDA. }\end{array}$ & $61.064 .838 / 0001-33$ & SÃO PAULO & SP \\
\hline $\begin{array}{l}\text { SAN MARINO ONIBUS E } \\
\text { MPLEMENTOS LTDA. }\end{array}$ & $83.785 .822 / 0001-06$ & CAXIAS DO SUL & RS \\
\hline SANREMO S/A & $89.738 .173 / 0001-15$ & ESTEIO & RS \\
\hline $\begin{array}{l}\text { SARA LEE } \\
\text { LTDA. } \\
\end{array}$ & $02.333 .707 / 0001-45$ & BARUERI & SP \\
\hline $\begin{array}{l}\text { SASCAR TECNOLOGIA E } \\
\text { SEGURANCA AUTOM S/A }\end{array}$ & $03.112 .879 / 0001-51$ & $\begin{array}{l}\text { SAOO JOSÉ DOS } \\
\text { PINHAIS }\end{array}$ & PR \\
\hline SAUR EQUIPAMENTOS SIA. & $92.253 .095 / 0001-73$ & PANAMBI & RS \\
\hline$S C A$ & -76 & $\begin{array}{l}\text { SAOO BERNARDO DO } \\
\text { CAMPO } \\
\end{array}$ & SP \\
\hline ASIL LTDA & $57.000 .036 / 0001-92$ & SOROCABA & $\mathrm{SP}$ \\
\hline $\begin{array}{l}\text { SCHNEIDER } \\
\text { LTDA. } \\
\end{array}$ & $82.743 .287 / 0001-04$ & SÃO PAULO & SP \\
\hline $\begin{array}{l}\text { SCM GROUP TECMATIC } \\
\text { MAQUINAS E EQUIPAMENTOS } \\
\text { LTDA }\end{array}$ & 78.977.451/0001-70 & SÅO BENTO DO SUL & $\mathrm{SC}$ \\
\hline SCOPUS TECNOLOGIA LTDA. & $47.379 .565 / 0001-95$ & SÁO PAULO & $\mathrm{SP}$ \\
\hline $\begin{array}{l}\text { SEGMENTA FARMACÉUTICA } \\
\text { LTDA }\end{array}$ & $1-99$ & ETO & SP \\
\hline SISTEMAS S/A & $0001-81$ & BLUMENAU & $\mathrm{SC}$ \\
\hline SER & $62.173 .620 / 0001-80$ & SAO PAULO & $\mathrm{SP}$ \\
\hline SERT & $24.144 .040 / 0001-75$ & RECIFE & $\mathrm{PE}$ \\
\hline $\begin{array}{l}\text { SEVA } \\
\text { ELETR }\end{array}$ & 71.336.218/00 & TAGEM & MG \\
\hline SIAC DO BRASIL LTDA & $.225 .317 / 0001-14$ & ANESIA & MG \\
\hline $\begin{array}{l}\text { SIAGRI SISTEMAS DE GESTAO } \\
\text { LTDA }\end{array}$ & $02.435 .301 / 0001-73$ & E & GO \\
\hline SILA DO BRASIL LTDA & $01.360 .869 / 0001-00$ & CONTAGEM & MG \\
\hline $\begin{array}{l}\text { SILGAN WHITE CAP DO BRASIL } \\
\text { LTDA }\end{array}$ & $00.543 .035 / 0001-77$ & SÅO PAULO & SP \\
\hline $\begin{array}{l}\text { SMS TECNOLOGIA } \\
\text { ELETRONICA LTDA. }\end{array}$ & $48.715 .759 / 0001-87$ & DIADEMA & SP \\
\hline SOFTEXPERT SOFTWA & $00.449 .824 / 0001-43$ & JOINVILLE & $\mathrm{SC}$ \\
\hline
\end{tabular}




\begin{tabular}{|c|c|c|c|}
\hline $\begin{array}{l}\text { SOFTRAN INFORMáTICA DO } \\
\text { TRANSPORTE LTDA }\end{array}$ & $00.194 .584 / 0001-83$ & JOINVILLE & SC \\
\hline $\begin{array}{l}\text { SOGEFI FILTRATION DO } \\
\text { BRASIL LTDA. }\end{array}$ & $68.975 .699 / 0001-13$ & SÅO PAULO & SP \\
\hline SOUZA CRUZ SA & $001-39$ & RIO DE JANEIRO & R.J \\
\hline $\begin{array}{l}\text { SPF DO BRASIL INDÚSTRIA E } \\
\text { COMÉRCIO LTDA. }\end{array}$ & $00.981 .411 / 0001-05$ & /ADO & SP \\
\hline $\begin{array}{l}\text { SPHEROS CLIMATIZAÇ.ÅO DO } \\
\text { BRASIL S/A }\end{array}$ & $04.576 .105 / 0001-44$ & CAXIAS DO SUL & RS \\
\hline $\begin{array}{l}\text { STARA S/A INDÚSTRIA DE } \\
\text { MPLEMENTOS AGRICOLAS }\end{array}$ & 91.495.499/0001-00 & NAO-ME-TOQUE & RS \\
\hline $\begin{array}{l}\text { STEFANINI CONSULTORIA E } \\
\text { ASSESSORIA EM INFORMáTICA } \\
\text { S.A. } \\
\end{array}$ & $58.069 .360 / 0001-20$ & JAGUARIÚNA & SP \\
\hline STOLLER DO BRASIL LTDA. & $001-18$ & COSMOPOLIS & SP \\
\hline $\begin{array}{l}\text { SUL } \\
\text { CON }\end{array}$ & $87.861 .324 / 0001-00$ & GUAPORE & RS \\
\hline $\begin{array}{l}\text { SUM } \\
\text { INDL }\end{array}$ & $01.965 .363 / 0001-24$ & POUSO ALEGRE & MG \\
\hline SURTEC DO BRASIL LTDA & $03.117 .903 / 0001-45$ & $\begin{array}{c}\text { SAO BERNARDO DO } \\
\text { CAMPO }\end{array}$ & SP \\
\hline $\begin{array}{l}\text { SUSP } \\
\text { AUTT }\end{array}$ & 10.523.280/0001-76 & CAXIAS DO SUL & RS \\
\hline $\begin{array}{l}\text { SUZAI } \\
\text { SIA }\end{array}$ & $16.404 .287 / 0001-55$ & SALVADOR & BA \\
\hline $\begin{array}{l}\text { SYMRIS } \\
\text { FRAGR, }\end{array}$ & $43.940 .758 / 0001-12$ & AULO & SP \\
\hline $\begin{array}{l}\text { SYNC } \\
\text { CULT }\end{array}$ & $60.744 .463 / 0001-90$ & SÅO PAULO & SP \\
\hline ITRA & $1-00$ & $S A O$ & SP \\
\hline$S A C$ & $01-05$ & AULO & $\mathrm{SP}$ \\
\hline IS LTDA. & $3 / 0001-18$ & RITUBA & $\mathrm{PR}$ \\
\hline $\begin{array}{l}\text { TECE } \\
\text { COM }\end{array}$ & 93.293.736/0001-86 & CAXIA & RS \\
\hline HARIA & $68.915 .891 / 0001-40$ & RIO DE JANEIRO & RJ \\
\hline $\begin{array}{l}\text { TECNOMOTOR ELETRŌNICA } \\
\text { DO BRASIL S.A }\end{array}$ & $44.762 .458 / 0001-53$ & SÃO CARLOS & SP \\
\hline LTDA & $1-14$ & & MG \\
\hline TELA & $1-86$ & $\overline{\mathrm{LDI}}$ & RS \\
\hline $\begin{array}{l}\text { TELCO } \\
\text { TELEC }\end{array}$ & 5 & SOROCABA & $P$ \\
\hline $\begin{array}{l}\text { TENNECO AUT } \\
\text { BRASIL LTDA }\end{array}$ & $44.023 .471 / 0001-90$ & MOJI MIRIM & SP \\
\hline
\end{tabular}




\begin{tabular}{|c|c|c|c|}
\hline $\begin{array}{l}\text { TEREX CIFALI EQUIPAMENTOS } \\
\text { LTDA }\end{array}$ & $87.960 .167 / 0001-82$ & NHA & RS \\
\hline $\begin{array}{l}\text { TERMOMECÅNICA SÅO PAULO } \\
\text { S/A }\end{array}$ & $59.106 .666 / 0001-71$ & $\begin{array}{c}\text { SAOO BERNARDO DO } \\
\text { CAMPO }\end{array}$ & SP \\
\hline $\begin{array}{l}\text { THYSSENKRUPP AUTOMOTIVE } \\
\text { SYSTEMS DO BRASIL LTDA }\end{array}$ & $02.093 .897 / 0001-70$ & $\begin{array}{c}\text { SÅO BERNARDO DO } \\
\text { CAMPO }\end{array}$ & SP \\
\hline $\begin{array}{l}\text { THYSSENKRUPP ELEVADORES } \\
\text { S/A. }\end{array}$ & $80.347 .840 / 0001-18$ & GUAIBA & RS \\
\hline JPP PRESTA DO & $02.720 .313 / 0001-40$ & $\begin{array}{l}\text { SÅO JOSÉ DOS } \\
\text { PINHAIS } \\
\end{array}$ & PR \\
\hline & $84.684 .455 / 0001-63$ & JOINVILLE & SC \\
\hline \begin{tabular}{|l|} 
TIVIT \\
PRO \\
TEC \\
\end{tabular} & $07.073 .027 / 0001-53$ & MOGI DAS CRUZES & SP \\
\hline $\begin{array}{l}\text { TMS } \\
\text { MOV }\end{array}$ & $2.782 .705 / 0001-26$ & PORTO ALEGRE & RS \\
\hline TNLC & $001-48$ & RIO DE JANEIRO & RJ \\
\hline TNLF & $1-59$ & RIO DE JANEIRO & RJ \\
\hline $\begin{array}{l}\text { TOLP } \\
\text { DE B }\end{array}$ & $59.704 .510 / 0001-92$ & $\begin{array}{c}\text { SAOO BERNARDO DO } \\
\text { CAMPO }\end{array}$ & SP \\
\hline TONDO SI & -70 & CAXIAS DO SUL & RS \\
\hline $\begin{array}{l}\text { TOT } \\
\text { SIST }\end{array}$ & $92.205 .368 / 0001-04$ & PORTO ALEGRE & RS \\
\hline TOTVS S.A. & $1-22$ & SAO PAULO & $\mathrm{SP}$ \\
\hline & $1-40$ & JOINVILLE & $\mathrm{SC}$ \\
\hline TQT & $1-40$ & RIO DE JANEIRO & RJ \\
\hline & $0.286 .105 / 0001-41$ & $\mathrm{Al}$ & RS \\
\hline $\begin{array}{l}\text { TRA } \\
\text { POP }\end{array}$ & $0002-03$ & SÅO PAULC & SP \\
\hline $\begin{array}{l}\text { TRóPICD } \\
\text { TELECO } \\
\text { AMAZÓN }\end{array}$ & $84.534 .254 / 0001-80$ & MANAUS & AM \\
\hline TUPY SA. & $84.683 .374 / 0001-49$ & SAO PAULO & SP \\
\hline $\begin{array}{l}\text { TUTT } \\
\text { DE FI }\end{array}$ & $07.236 .290 / 0001-16$ & CAXIAS D & RS \\
\hline $\begin{array}{l}\text { TYCO ELECTRONICS BRASIL } \\
\text { LTDA }\end{array}$ & $00.907 .845 / 0001-65$ & PAULO & SP \\
\hline & $45.517 .000 / 0001-00$ & ULO & SP \\
\hline DÚSTRIA DE & 80.4 & ES & RS \\
\hline $\begin{array}{l}\text { UNILEVER BR } \\
\text { LTDA. }\end{array}$ & $01.615 .814 / 0001-01$ & SÃO PAULO & SP \\
\hline
\end{tabular}




\begin{tabular}{|c|c|c|c|}
\hline UNILEVER BRASIL LTDA. & 61.068.276/0001-04 & SÅO PAULO & SP \\
\hline $\begin{array}{l}\text { UNIVERSAL INDÚSTRIAS } \\
\text { GERAIS LTDA. }\end{array}$ & $50.948 .819 / 0001-53$ & JUNDIAI & SP \\
\hline $\begin{array}{l}\text { USINA TERMELETRICA NORTE } \\
\text { FLUMINENSE S/A }\end{array}$ & 03.258.983/0001-59| & RIO DE JANEIRO & RJ \\
\hline $\begin{array}{l}\text { USINAS SIDERÚRGICAS DE } \\
\text { MINAS GERAIS S.A. - USIMINAS }\end{array}$ & $60.894 .730 / 0001-05$ & BELO HORIZONTE & MG \\
\hline V\&M DO BRASIL SA. & $17.170 .150 / 0001-46$ & BELO HORIZONTE & MG \\
\hline $\begin{array}{l}\text { VACCINAR INDUSTRIA E } \\
\text { COMERCIO LTDA }\end{array}$ & $21.820 .014 / 0001-21$ & BELO HORIZONTE & MG \\
\hline $\begin{array}{l}\text { VALE SOLUÇOEES EM ENERGIA } \\
\text { S.A. - VSE }\end{array}$ & $09.327 .793 / 0001-22$ & RIO DE JANEIRO & RJ \\
\hline $\begin{array}{l}\text { VALEO SISTEMAS } \\
\text { AUTOMOTIVOS LTDA. }\end{array}$ & $57.010 .662 / 0001-60$ & ITATIBA & SP \\
\hline VALLéE S.A & $20.557 .161 / 0001-98$ & MONTES CLAROS & MG \\
\hline VALTRA DO BRASIL LTDA & $61.076 .055 / 0001-70$ & MOGI DAS CRUZES & $\mathrm{SP}$ \\
\hline $\begin{array}{l}\text { VAMOL INDUSTRIA MOVELEIRA } \\
\text { LTDA. }\end{array}$ & $73.368 .243 / 0001-50$ & ARAPONGAS & PR \\
\hline $\begin{array}{l}\text { VENAX ELETRODOMESTICOS } \\
\text { LTDA }\end{array}$ & $90.295 .338 / 0001-00$ & VENANCIO AIRES & RS \\
\hline $\begin{array}{l}\text { VETCO GRAY OLEO E GAS } \\
\text { LTDA }\end{array}$ & $05.635 .291 / 0001-08$ & JANDIRA & $\mathrm{SP}$ \\
\hline $\begin{array}{l}\text { VIAçäO SANTA TEREZA DE } \\
\text { CAXXIAS DO SUL LTDA }\end{array}$ & $90.467 .424 / 0001-53$ & CAXIAS DO SUL & RS \\
\hline $\begin{array}{l}\text { VIQUA INDUSTRIA PLASTICOS } \\
\text { LTDA }\end{array}$ & $00.477 .761 / 0001-39$ & JOINVILLE & $\mathrm{SC}$ \\
\hline $\begin{array}{l}\text { VISUM SISTEMAS } \\
\text { ELETRONICOS SIA }\end{array}$ & $72.164 .734 / 0001-17$ & CURITIBA & PR \\
\hline VOITH HYDRO LTDA & $03.400 .080 / 0001-60$ & SAOO PAULO & SP \\
\hline $\begin{array}{l}\text { VOITH PAPER MáQUINAS E } \\
\text { EQUIPAMENTOS LTDA }\end{array}$ & 61.243.119/0001-80 & SÃO PAULO & SP \\
\hline $\begin{array}{l}\text { VOLKSWAGEN DO BRASIL } \\
\text { INDÚSTRIA DE VEICULOS } \\
\text { AUTOMOTORES LTDA }\end{array}$ & $59.104 .422 / 0001-50$ & $\begin{array}{l}\text { SÅO BERNARDO DO } \\
\text { CAMPO }\end{array}$ & SP \\
\hline $\begin{array}{l}\text { VOLVO DO BRASIL VEICULOS } \\
\text { LTDA }\end{array}$ & $43.999 .424 / 0001-14$ & CURITIBA & PR \\
\hline VOTORANTIM SIDERURGIA SIA & $60.892 .403 / 0001-14$ & RESENDE & RJ \\
\hline $\begin{array}{l}\text { VULCABRáS DO NORDESTE } \\
\text { S.A. }\end{array}$ & $00.954 .394 / 0001-17$ & HORIZONTE & $\mathrm{CE}$ \\
\hline $\begin{array}{l}\text { WABCO DO BRASIL INDUSTRIA } \\
\text { E COMERCIO DE FREIOS LTDA } \\
\end{array}$ & $08.779 .349 / 0001-85$ & SUMARE & $\mathrm{SP}$ \\
\hline $\begin{array}{l}\text { WALTEC EQUIPAMENTOS } \\
\text { ELETRICOS LTDA. }\end{array}$ & $83.241 .349 / 0001-42$ & MENAU & SC \\
\hline WEG AUTOMACAO S.A. & $08.520 .338 / 0001-86$ & JARAGUA DO SUL & $\mathrm{SC}$ \\
\hline
\end{tabular}




\begin{tabular}{|c|c|c|c|}
\hline $\begin{array}{l}\text { WEG EQUIPAMENTOS } \\
\text { ELÉTRICOS SA. }\end{array}$ & $07.175 .725 / 0001-60$ & JARAGUÁ DO SUL & SC \\
\hline $\begin{array}{l}\text { WELLSTRREAM DO BRASIL } \\
\text { INDÚSTRIA E SERVICOS LTDA. }\end{array}$ & $05.379 .542 / 0001-30$ & NITEROI & RJ \\
\hline WHIRLPOOL SA & $58.105 .999 / 0001-86$ & SAOO PAULO & SP \\
\hline YOKI ALIMENTOS S/A & $61.586 .558 / 0013-29$ & $\begin{array}{c}\text { SÅO BERNARDO DO } \\
\text { CAMPO }\end{array}$ & SP \\
\hline $\begin{array}{l}\text { ZEN S.A. INDUSTRIA } \\
\text { METALURGICA } \\
\end{array}$ & $57.006 .264 / 0001-70$ & BRUSQUE & SC \\
\hline $\begin{array}{l}\text { ZF SISTEMAS DE DIREÇÅO } \\
\text { LTDA }\end{array}$ & $01.930 .685 / 0001-38$ & SOROCABA & SP \\
\hline $\begin{array}{l}\text { ZIEMANN LIESS MáQUINAS E } \\
\text { EQUIPAMENTOS LTDA. }\end{array}$ & $92.765 .833 / 0001-61$ & CANOAS & RS \\
\hline ZMSA & $76.812 .379 / 0001-04$ & BRUSQUE & $\mathrm{SC}$ \\
\hline $\begin{array}{l}\text { ZOLLERN TRANSMISSöES } \\
\text { MECâNICAS LTDA }\end{array}$ & $18.222 .877 / 0001-92$ & CATAGUASES & MG \\
\hline
\end{tabular}





\section{Apêndice 3 - Questionário enviado às empresas para coleta de dados}

Parte 1 - Informações Preliminares

A - Nome da Empresa *

B - CNPJ da Matriz

C - Cargo/ Função na Empresa do respondedor *

- Presidente

- Superintendente

- Diretor Administrativo

- Diretor Financeiro

- Controller

- Contador

- Outro

D - Qual o setor de atuação de sua empresa? Escolha apenas o considerado principal *

- Agroindústria

- Alimentos

- Bens de Consumo

- Construção Civil

- Eletro-Eletrônica

- Farmacêutica

- Mecânica e Transportes

- Metalurgia

- Mineração

- Moveleira

- Papel e Celulose

- Petroquímica

- Química

- Software

- Telecomunicações

- Textil

- Outras Indústrias

E - A decisão relativa à adesão de sua empresa aos benefícios fiscais de inovação estão mais condicionados a: *(escolha apenas 1 opção)

- OBJETIVOS ORGANIZACIONAIS, ou seja, a decisão estava incluída no conjunto de objetivos que a organização pretendia atingir, como por exemplo, metas relativas à redução da carga tributária.

- POLÍTICAS EMPRESARIAIS, ou seja, a decisão estava subordinada principalmente ao conjunto de políticas estabelecidas pela empresa, como por exemplo, a avaliação de riscos fiscais.

Parte 2 - Utilização da Informação contábil no processo de decisão. (a)

1 - Para cada um dos itens abaixo, informe o grau de utilização da informação contábil para as diversas fases do processo decisório na adesão aos benefícios fiscais de Inovação de Tecnologia. Considerando 0 como nenhuma utilização e 4 como grande utilização. 
I - INTESIDADE: a quantidade de informação contábil utilizada nas diversas etapas do processo de decisão. *

a) Identificação do benefício

b) Análise das dificuldades de utilização do benefício

c) Definição das alternativas para aplicação do benefício

d) Exame das consequências para aplicação do benefício

e) Escolha das alternativas na aplicação do benefício

f) Implantação do benefício

II - FREQUÊNCIA: a periodicidade de utilização da informação contábil nas diversas etapas do processo de decisão. *

a) Identificação do benefício

b) Análise das dificuldades de utilização do benefício

c) Definição das alternativas para aplicação do benefício

d) Exame das consequências para aplicação do benefício

e) Escolha das alternativas na aplicação do benefício

f) Implantação do benefício

III - IMPORTÂNCIA: relevância da informação contábil para utilização nas diversas etapas do processo de decisão. *

a) Identificação do benefício

b) Análise das dificuldades de utilização do benefício

c) Definição das alternativas para aplicação do benefício

d) Exame das consequências para aplicação do benefício

e) Escolha das alternativas na aplicação do benefício

f) Implantação do benefício

Parte 2 - Utilização da Informação contábil no processo de decisão. (b)

1 - Para cada um dos itens abaixo, informe o grau de utilização da informação contábil para as diversas fases do processo decisório na adesão aos benefícios fiscais de Inovação de Tecnologia. Considerando 0 como nenhuma utilização e 4 como grande utilização

I - INTENSIDADE: a quantidade de informação contábil utilizada nas diversas etapas do processo de decisão. *

a) Identificação do benefício

b) Análise das dificuldades da utilização do benefício

c) Início de uma ação experimental para verificar se o benefício deve ser utilizado

d) Exame se na ação experimental houve alguma falha

e) Início de um processo definitivo de adesão

II - FREQUÊNCIA: a periodicidade de utilização da informação contábil nas diversas etapas do processo de decisão. * 
a) Identificação do benefício

b) Análise das dificuldades da utilização do benefício

c) Início de uma ação experimental para verificar se o benefício deve ser utilizado

d) Exame se na ação experimental houve alguma falha

e) Início de um processo definitivo de adesão

III - IMPORTÂNCIA: a periodicidade de utilização da informação contábil nas diversas etapas do processo de decisão. *

a) Identificação do benefício

b) Análise das dificuldades da utilização do benefício

c) Início de uma ação experimental para verificar se o benefício deve ser utilizado

d) Exame se na ação experimental houve alguma falha

e) Início de um processo definitivo de adesão

Parte 3 - Informações Gerais

2 - Em relação a cada um dos aspectos da tabela abaixo, quão previsível é o ambiente externo no qual a sua empresa está inserida? *

(Classificar entre: Muito estável; Estável; Intermediário; Dinâmico; Muito Dinâmico, mudanças rápidas e imprevisíveis)

a) Tecnologia necessária para a produção

b) Atitudes da concorrência

c) Demanda do mercado

d) Características dos produtos lançados no mercado

e) Disponibilidades de insumos

f) Preço dos insumos

g) Regulamentação política do setor

3 - O quanto a heterogeneidade é uma característica marcante no meio em que sua empresa atua? *

(Classificar entre: Totalmente homogêneos/semelhantes; Homogêneos/semelhantes; Intermediário; Heterogêneos/diferenciados; Totalmente heterogêneos/diferenciados)

a) Características dos produtos encontrados no mercado

b) Tecnologia de produção/ comercialização/ serviço adotada

c) Características dos fornecedores

d) Características dos Concorrentes

e) Características dos Clientes

4 - Quanto aos resultados atingidos pela empresa: *

(Classificar entre: Muito acima do esperado; Acima do esperado; Esperado; Abaixo do esperado; Muito abaixo do esperado)

a) As margens de lucro de seus principais produtos/ serviços como estão na média

b) O crescimento do lucro como se comportou

c) $\mathrm{O}$ crescimento da receita como se comportou 
5 - Em que nível sua empresa utiliza os seguintes instrumentos ou práticas gerenciais? *

(Classificar como: Não utiliza; Está estudando a viabilidade de sua adoção; Está em fase inicial de implantação; Está em fase final de implantação; Concluiu plenamente sua implantação)

a) Relatórios por divisão e/ ou filial

b) Análise sistemática (rotineira e automática) de custo-volume-lucro

c) Preço de transferência interno entre divisões de negócios

d) Demonstrações de resultados mensais

e) Custeio variável ou por absorção

f) Orçamento não participativo (diretoria impões metas aos gerentes)

g) Orçamento participativo (gerentes participam ativamente no planejamento)

h) Custeio alvo - uso sistemático

i) Relatórios de controle de qualidade

j) $\mathrm{ABC} / \mathrm{ABM}$

1) EVA

m) Uso sistemático de Benchmarking

n) Balanço Scorecard

o) Análise de cenários de planejamento estratégico

p) Indicadores não financeiros como: índice de satisfação dos clientes, $n^{\circ}$ de novos produtos lançados, tempo de processamento dos produtos defeituosos, etc.

6 - Você acredita que o setor no qual sua empresa compete está *

(Classificar entre: Não está; Está pouco; Está razoavelmente; Está muito; Está extremamente)

a) Saturado (quantidade de empresas muito grande para o tamanho do setor

b) Dominado (poucas empresas dominam e ditam regras)

c) Restritivo (regulamentações, tecnologias exigidas e outras implicações dificultam a entrada de novos competidores no setor)

7 - Avalie cada uma das proposições e responda atribuindo notas de 1 a 5 o que melhor representa a situação da informação contábil na sua empresa. *

a) A informação contábil ajuda a avaliar corretamente o resultado de eventos, o sistema de informações gerenciais de sua empresa é capaz de fornecer informações precisas de custos em nível de departamentos

b) A informação contábil desempenha um papel importante em termos de confirmação ou correção de expectativas anteriores

c) A informação contábil está disponível para quem deseja tomar uma decisão antes que se perca a capacidade de tomas a decisão

d) a informação contábil representa fielmente as operações que pretende representar

e) A informação contábil mensura sem erro ou viés as operações

f) A informação contábil não é modificada para adequação a metas ou políticas empresariais 
g) A informação contábil representa eventos iguais de maneira idêntica

h) As informações contábeis são suportadas por conceitos contábeis que não variam no decorrer do tempo nem em mensurações diferentes

8 - Escolha o nível em que cada característica está presente nas informações contábeis de sua empresa.

a) Horizonte Temporal: as informações estão voltadas *

- Somente ao passado

- Principalmente ao passado

- Igualmente ao passado e ao futuro

- Principalmente ao futuro

- Somente ao futuro

b) Quantificação: as informações são *

- Exclusivamente financeiras

- Principalmente financeiras

- Igualmente financeiras e não financeiras

- Principalmente não financeiras

- Exclusivamente não financeiras

c) Foco: as informações estão voltadas ao ambiente *

- Exclusivamente interno

- Principalmente interno

-Igualmente interno e externo

- Principalmente externo

- Exclusivamente externo

d) Tempestividade: o tempo em que o sistema de informações gerenciais demora a gerar as informações requeridas é *

- Muito grande

- Grande

- Médio

- Pequeno

- Muito pequeno

9 - A empresa optou pela utilização do RTT (regime tributário de transição)? *

- Sim

- Não

- Não sei

Parte 4 - Características da empresa

10 - O capital da empresa é principalmente *

- Público 
- Privado - brasileiro

- Privado - norte-americano

- Privado - europeu

- Privado - outros

11 - Comparando com o setor onde sua empresa atua, ela é considerada de: * - Grande porte

- Médio porte

- Pequeno porte

12 - Sua empresa é auditada por: *

- Ernest Young

- Price Waterhouse

- Deloitte

- KPMG

- outra empresa de auditoria de origem estrangeira

- outra empresa de auditoria de origem nacional

- não é auditada 


\section{Apêndice 4 - Email solicitando as empresas que participassem da pesquisa}

Bom dia!

Meu nome é Alberto Luiz Zucchi e curso o programa de doutorado na FEA-USP, no departamento de contabilidade. Alguns dias atrás solicitei sua participação em uma pesquisa cientifica com o objetivo de entender o papel das informações contábeis na adesão dos benefícios fiscais para inovação tecnológica estabelecidos pela lei 11.196/05. Certamente devido ao grande volume de suas atividades meu pedido não pode ser atendido. Assim sendo, venho novamente solicitar a sua valiosíssima colaboração ou de algum outro membro de sua organização, para que responda um questionário através do link abaixo:

https://docs.google.com/spreadsheet/embeddedform?formkey=dFZScVotXzYwMFVKVUlk UUlhamtHN1E6MQ

São apenas 15 questões, todas de múltipla escolha, e seu preenchimento não demandará mais que quinze minutos de seu tempo. Lembro novamente que todos aqueles que responderem ao questionário estão convidados a participar de uma palestra na Câmara de Comércio França Brasil, possivelmente no mês de outubro de 2.012 na cidade de São Paulo, na qual serão apresentados os resultados da pesquisa, e que temos certeza, será extremamente útil como auxilio para a tomada de decisão na adesão ao referido benefício fiscal.

Caso seja necessário algum esclarecimento adicional este pode ser

obtido através de: Email: alberto.zucchi@usp.br

Telefone: (11) 9970-4355

Por fim, salientamos que os dados serão tratados com o devido sigilo e agradecemos antecipadamente sua contribuição.

Alberto Luiz Zucchi

Doutorando em Contabilidade e Controladoria

Orientador: Prof. Dr. Carlos Pereira

Departamento de Contabilidade e Atuaria da FEA/USP

UNIVERSIDADE DE SÃO PAULO

FACULDADE DE ECONOMIA, ADMINISTRAÇÃO E CONTABILIDADE

DEPARTAMENTO DE CONTABILIDADE E ATUÁRIA 



\section{Apêndice 5 - Respostas obtidas através dos questionários}

\begin{tabular}{|c|c|c|}
\hline & C - Cargo/ Função na Empresa & D - Qual o setor de atuação de sua empresa? \\
\hline 1 & Analista Contábil & Bens de Consumo \\
\hline 2 & Analista Contábil & Software \\
\hline 3 & Analista Contábil & Química \\
\hline 4 & ANALISTA CONTÁBIL SR. & Outras Indústrias \\
\hline 5 & Analista custos & Outras Indústrias \\
\hline 6 & ANALISTA DE CONTROLADORIA & Outras Indústrias \\
\hline 7 & Analista Financeiro & Outras Indústrias \\
\hline 8 & ANALISTA FISCAL SR & Metalurgia \\
\hline 9 & Assistente de Contabilidade & Outras Indústrias \\
\hline 10 & Contador & Outras Indústrias \\
\hline 11 & Contador & Farmacêutica \\
\hline 12 & Contador & Moveleira \\
\hline 13 & Contador & Outras Indústrias \\
\hline 14 & Contador & Química \\
\hline 15 & Contador & Outras Indústrias \\
\hline 16 & Contador & Mecânica e Transportes \\
\hline 17 & Contador & Textil \\
\hline 18 & Contador & Outras Indústrias \\
\hline 19 & Contador & Farmacêutica \\
\hline 20 & Contador & Metalurgia \\
\hline 21 & Contador & Eletro-Eletrônica \\
\hline 22 & Contador & Outras Indústrias \\
\hline 23 & Contador & Outras Indústrias \\
\hline 24 & Contador & Software \\
\hline 25 & Contador & Metalurgia \\
\hline 26 & Contador & Química \\
\hline 27 & Contador & Alimentos \\
\hline 28 & Contador & Metalurgia \\
\hline 29 & Contador & Software \\
\hline 30 & Contador & Metalurgia \\
\hline 31 & Contador & Química \\
\hline 32 & Contador & Outras Indústrias \\
\hline 33 & Contador & Bens de Consumo \\
\hline 34 & Contador & Farmacêutica \\
\hline 35 & Contador & Outras Indústrias \\
\hline 36 & Contador & Mineração \\
\hline 37 & Contador & Outras Indústrias \\
\hline 38 & Contador & Química \\
\hline 39 & Contador & Eletro-Eletrônica \\
\hline 40 & Contador & Metalurgia \\
\hline 41 & Contador & Agroindústria \\
\hline 42 & Contador & Bens de Consumo \\
\hline 43 & Contador & Química \\
\hline 44 & Contador & Química \\
\hline 45 & Contador & Farmacêutica \\
\hline 46 & Contador & Agroindústria \\
\hline 47 & Contador & Mecânica e Transportes \\
\hline 48 & Contador & Química \\
\hline 49 & Controller & Mineração \\
\hline 50 & Controller & Telecomunicações \\
\hline 51 & Controller & Outras Indústrias \\
\hline 52 & Controller & Bens de Consumo \\
\hline 53 & Controller & Moveleira \\
\hline 54 & Controller & Metalurgia \\
\hline 55 & Controller & Farmacêutica \\
\hline 56 & Controller & Eletro-Eletrônica \\
\hline 57 & Controller & Alimentos \\
\hline 58 & Controller & Eletro-Eletrônica \\
\hline
\end{tabular}




$\begin{array}{lll}59 & \text { Controller } & \text { Construção Civil } \\ 60 & \text { Controller } & \text { Mecânica e Transportes } \\ 61 & \text { Coordenador Contábil } & \text { Farmacêutica } \\ 62 & \text { Coordenador Fiscal } & \text { Metalurgia } \\ 63 & \text { Coordenador Fiscal } & \text { Outras Indústrias } \\ 64 & \text { Diretor Adm./Financeiro } & \text { Eletro-Eletrônica } \\ 65 & \text { Diretor Administrativo } & \text { Software } \\ 66 & \text { Diretor Financeiro } & \text { Metalurgia } \\ 67 & \text { Diretor Financeiro } & \text { Química } \\ 68 & \text { Encarregada Administrativa } & \text { Química } \\ 69 & \text { Encarregado da Contabilidade } & \text { Metalurgia } \\ 70 & \text { Especialista Contábil } & \text { Outras Indústrias } \\ 71 & \text { Gerente Contábil } & \text { Outras Indústrias } \\ 72 & \text { Gerente Geral } & \text { Metalurgia } \\ 73 & \text { Gestor Financeiro } & \text { Software } \\ 74 & \text { Presidente } & \text { Agroindústria } \\ 75 & \text { Presidente } & \text { Bens de Consumo } \\ 76 & \text { SUPERVISOR CONTABILIDAE } & \text { Eletro-Eletrônica } \\ 77 & \text { Supervisora de Contabilidade } & \text { Farmacêutica }\end{array}$

(a) identificação, (b) análise das dificuldade, (c) definição das alternativas (d) exame das consequências (e) escolha das alternativas (f) implantação do benefício

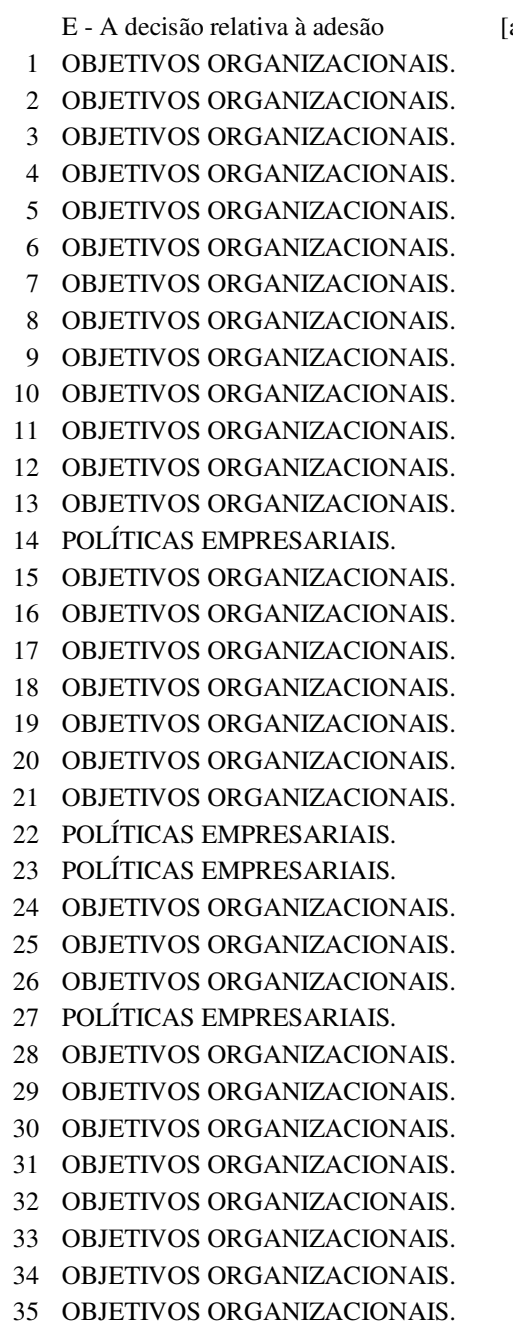

E - A decisão relativa à adesão

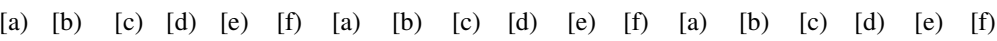
$\begin{array}{llllllllllllllllll}4 & 2 & 2 & 3 & 3 & 3 & 4 & 2 & 3 & 3 & 3 & 3 & 4 & 2 & 3 & 3 & 3 & 3\end{array}$ $\begin{array}{llllllllllllllllll}3 & 3 & 4 & 4 & 4 & 3 & 2 & 3 & 4 & 4 & 4 & 3 & 2 & 2 & 1 & 3 & 1 & 1\end{array}$ $\begin{array}{llllllllllllllllll}4 & 3 & 4 & 4 & 3 & 4 & 4 & 3 & 3 & 4 & 3 & 4 & 4 & 3 & 3 & 4 & 4 & 3\end{array}$ $\begin{array}{llllllllllllllllll}3 & 3 & 3 & 3 & 3 & 4 & 3 & 3 & 3 & 3 & 3 & 4 & 3 & 3 & 3 & 3 & 3 & 4\end{array}$ $\begin{array}{llllllllllllllllll}4 & 4 & 3 & 3 & 4 & 4 & 4 & 3 & 3 & 4 & 4 & 4 & 4 & 4 & 4 & 4 & 4 & 4\end{array}$ $\begin{array}{llllllllllllllllll}4 & 4 & 4 & 4 & 4 & 2 & 4 & 4 & 4 & 4 & 4 & 4 & 4 & 4 & 4 & 4 & 4 & 4\end{array}$ $\begin{array}{llllllllllllllllll}2 & 1 & 1 & 3 & 3 & 3 & 2 & 3 & 3 & 2 & 2 & 3 & 3 & 3 & 2 & 3 & 3 & 2\end{array}$ $\begin{array}{llllllllllllllllll}4 & 3 & 3 & 3 & 4 & 4 & 4 & 4 & 4 & 4 & 3 & 4 & 4 & 4 & 4 & 4 & 4 & 4\end{array}$ $\begin{array}{llllllllllllllllll}4 & 4 & 1 & 1 & 3 & 2 & 4 & 4 & 2 & 3 & 3 & 3 & 4 & 4 & 3 & 3 & 3 & 3\end{array}$ $\begin{array}{llllllllllllllllll}2 & 2 & 3 & 4 & 4 & 4 & 2 & 2 & 3 & 4 & 4 & 4 & 2 & 2 & 3 & 4 & 4 & 4\end{array}$ $\begin{array}{llllllllllllllllll}4 & 4 & 4 & 4 & 4 & 4 & 4 & 4 & 4 & 4 & 4 & 4 & 4 & 4 & 4 & 4 & 4 & 4\end{array}$ $\begin{array}{llllllllllllllllll}4 & 1 & 1 & 1 & 3 & 3 & 3 & 1 & 1 & 1 & 1 & 1 & 4 & 4 & 4 & 4 & 4 & 4\end{array}$ $\begin{array}{llllllllllllllllll}4 & 4 & 3 & 4 & 3 & 4 & 4 & 3 & 3 & 4 & 3 & 4 & 4 & 4 & 4 & 4 & 4 & 4\end{array}$ $\begin{array}{llllllllllllllllll}3 & 3 & 3 & 2 & 2 & 3 & 3 & 3 & 3 & 3 & 3 & 3 & 3 & 3 & 2 & 2 & 2 & 2\end{array}$ $\begin{array}{llllllllllllllllll}4 & 3 & 3 & 3 & 4 & 4 & 4 & 3 & 4 & 4 & 3 & 4 & 3 & 4 & 4 & 4 & 3 & 4\end{array}$ $\begin{array}{llllllllllllllllll}3 & 3 & 3 & 3 & 4 & 4 & 3 & 3 & 4 & 4 & 4 & 4 & 4 & 3 & 3 & 3 & 4 & 4\end{array}$ $\begin{array}{llllllllllllllllll}3 & 2 & 3 & 4 & 4 & 3 & 3 & 3 & 2 & 3 & 3 & 4 & 4 & 3 & 4 & 3 & 2 & 3\end{array}$ $\begin{array}{llllllllllllllllll}4 & 4 & 4 & 4 & 4 & 4 & 4 & 4 & 4 & 4 & 4 & 4 & 4 & 4 & 4 & 4 & 4 & 4\end{array}$ $\begin{array}{llllllllllllllllll}3 & 3 & 3 & 2 & 2 & 1 & 2 & 2 & 2 & 1 & 1 & 1 & 1 & 1 & 1 & 2 & 1 & 1\end{array}$ $\begin{array}{llllllllllllllllll}4 & 3 & 4 & 4 & 3 & 3 & 3 & 2 & 2 & 3 & 2 & 3 & 3 & 2 & 3 & 3 & 3 & 4\end{array}$

$\begin{array}{llllllllllllllllll}4 & 3 & 3 & 4 & 3 & 3 & 4 & 3 & 3 & 4 & 3 & 4 & 4 & 3 & 3 & 4 & 3 & 3 \\ 4 & 3 & 3 & 4 & 4 & 4 & 4 & 3 & 3 & 4 & 4 & 4 & 4 & 4 & 4 & 4 & 4 & 4 \\ 4 & 2 & 3 & 2 & 1 & 0 & 4 & 2 & 3 & 2 & 1 & 0 & 4 & 3 & 3 & 3 & 2 & 2 \\ 3 & 3 & 3 & 2 & 3 & 3 & 3 & 3 & 3 & 3 & 3 & 3 & 4 & 4 & 4 & 4 & 4 & 4 \\ 2 & 4 & 2 & 2 & 2 & 2 & 3 & 3 & 3 & 3 & 3 & 3 & 3 & 3 & 3 & 3 & 3 & 3 \\ 3 & 3 & 2 & 3 & 2 & 2 & 2 & 2 & 2 & 3 & 2 & 2 & 4 & 3 & 3 & 3 & 2 & 2 \\ 4 & 3 & 2 & 2 & 3 & 4 & 4 & 3 & 2 & 2 & 3 & 4 & 4 & 2 & 2 & 3 & 3 & 4 \\ 3 & 2 & 3 & 3 & 3 & 3 & 3 & 3 & 2 & 3 & 3 & 3 & 3 & 3 & 3 & 3 & 3 & 3 \\ 4 & 2 & 2 & 2 & 2 & 4 & 4 & 0 & 0 & 0 & 4 & 4 & 4 & 1 & 1 & 1 & 1 & 4 \\ 3 & 4 & 3 & 3 & 2 & 2 & 4 & 2 & 2 & 2 & 1 & 1 & 4 & 3 & 1 & 4 & 1 & 3 \\ 2 & 2 & 3 & 3 & 4 & 4 & 3 & 3 & 4 & 4 & 4 & 4 & 3 & 2 & 3 & 4 & 4 & 4\end{array}$


36 POLÍTICAS EMPRESARIAIS.

$\begin{array}{lllllllllllllllllllll}37 & \text { OBJETIVOS ORGANIZACIONAIS. } & 4 & 1 & 4 & 4 & 4 & 4 & 4 & 1 & 4 & 4 & 4 & 4 & 4 & 1 & 4 & 4 & 4 & 4\end{array}$ 38 OBJETIVOS ORGANIZACIONAIS. $\quad \begin{array}{lllllllllllllllllll}3 & 2 & 3 & 3 & 3 & 3 & 2 & 2 & 3 & 3 & 3 & 3 & 3 & 3 & 3 & 3 & 3 & 3\end{array}$ 39 OBJETIVOS ORGANIZACIONAIS. $\quad \begin{array}{llllllllllllllllllll}3 & 2 & 2 & 2 & 2 & 2 & 4 & 3 & 3 & 2 & 2 & 2 & 2 & 2 & 2 & 2 & 2 & 2 & 2\end{array}$ 40 OBJETIVOS ORGANIZACIONAIS. $\quad \begin{array}{rllllllllllllllllll}4 & 4 & 4 & 4 & 4 & 4 & 4 & 4 & 4 & 4 & 4 & 4 & 4 & 4 & 4 & 4 & 4 & 4\end{array}$ 41 OBJETIVOS ORGANIZACIONAIS. $\quad \begin{array}{lllllllllllllllllll}3 & 3 & 3 & 3 & 3 & 3 & 4 & 3 & 3 & 3 & 3 & 3 & 4 & 3 & 3 & 3 & 3 & 3\end{array}$ 42 OBJETIVOS ORGANIZACIONAIS. $\quad \begin{array}{rlllllllllllllllllll}4 & 2 & 4 & 3 & 4 & 4 & 2 & 2 & 2 & 2 & 2 & 2 & 4 & 4 & 4 & 4 & 4 & 4\end{array}$ 43 OBJETIVOS ORGANIZACIONAIS. $\quad \begin{array}{rllllllllllllllllll}4 & 3 & 3 & 4 & 3 & 4 & 4 & 4 & 4 & 4 & 4 & 4 & 3 & 3 & 4 & 4 & 4 & 4\end{array}$ 44 OBJETIVOS ORGANIZACIONAIS. $\quad \begin{array}{lllllllllllllllllll}2 & 3 & 3 & 4 & 4 & 4 & 2 & 3 & 4 & 4 & 4 & 4 & 4 & 4 & 4 & 4 & 4 & 4\end{array}$ 45 OBJETIVOS ORGANIZACIONAIS. $\quad \begin{array}{lllllllllllllllllll}4 & 3 & 3 & 3 & 3 & 4 & 4 & 3 & 3 & 3 & 3 & 4 & 4 & 3 & 3 & 3 & 3 & 4\end{array}$ 46 OBJETIVOS ORGANIZACIONAIS. $\quad \begin{array}{rllllllllllllllllll}4 & 3 & 4 & 4 & 3 & 4 & 3 & 3 & 3 & 3 & 3 & 3 & 3 & 3 & 4 & 4 & 4 & 4\end{array}$ 47 OBJETIVOS ORGANIZACIONAIS. $\quad \begin{array}{lllllllllllllllllll}4 & 3 & 2 & 2 & 3 & 3 & 4 & 3 & 2 & 2 & 3 & 3 & 4 & 2 & 2 & 3 & 3 & 3\end{array}$ 48 OBJETIVOS ORGANIZACIONAIS. $\quad \begin{array}{rllllllllllllllllll}4 & 4 & 4 & 4 & 4 & 4 & 4 & 4 & 4 & 4 & 4 & 4 & 4 & 4 & 4 & 4 & 4 & 4\end{array}$ 49 POLÍTICAS EMPRESARIAIS.

50 POLÍTICAS EMPRESARIAIS.

$\begin{array}{llllllllllllllllllll}51 & \text { OBJETIVOS ORGANIZACIONAIS. } & 1 & 2 & 2 & 2 & 2 & 2 & 3 & 3 & 3 & 3 & 3 & 3 & 3 & 3 & 3 & 3 & 3 & 3\end{array}$ 52 POLÍTICAS EMPRESARIAIS.

53 OBJETIVOS ORGANIZACIONAIS. $\quad \begin{array}{rllllllllllllllllll}4 & 4 & 4 & 4 & 4 & 4 & 4 & 4 & 4 & 4 & 4 & 4 & 4 & 4 & 4 & 4 & 4 & 4\end{array}$ 54 OBJETIVOS ORGANIZACIONAIS. $\quad \begin{array}{lllllllllllllllllll}0 & 2 & 4 & 4 & 4 & 4 & 0 & 2 & 4 & 4 & 4 & 4 & 0 & 2 & 4 & 4 & 4 & 4\end{array}$ 55 OBJETIVOS ORGANIZACIONAIS. $\quad \begin{array}{lllllllllllllllllll} & 4 & 1 & 1 & 1 & 2 & 3 & 2 & 0 & 0 & 1 & 1 & 1 & 4 & 3 & 3 & 3 & 3 & 4\end{array}$ 56 OBJETIVOS ORGANIZACIONAIS. $\quad \begin{array}{rllllllllllllllllll}4 & 3 & 3 & 3 & 4 & 4 & 3 & 3 & 3 & 3 & 3 & 3 & 4 & 4 & 4 & 4 & 4 & 4\end{array}$ $\begin{array}{llllllllllllllllllll}57 & \text { OBJETIVOS ORGANIZACIONAIS. } & 4 & 3 & 3 & 4 & 4 & 4 & 2 & 1 & 2 & 2 & 2 & 2 & 4 & 4 & 4 & 4 & 4 & 4\end{array}$ 58 OBJETIVOS ORGANIZACIONAIS. $\quad \begin{array}{rllllllllllllllllll}4 & 4 & 4 & 4 & 4 & 3 & 3 & 4 & 3 & 4 & 3 & 3 & 4 & 4 & 4 & 3 & 3 & 3\end{array}$ 59 OBJETIVOS ORGANIZACIONAIS. $\quad \begin{array}{lllllllllllllllllll} & 2 & 2 & 2 & 3 & 3 & 1 & 3 & 2 & 2 & 2 & 2 & 3 & 3 & 2 & 2 & 3 & 2 & 2\end{array}$ 60 OBJETIVOS ORGANIZACIONAIS. $\quad \begin{array}{llllllllllllllllllll}3 & 3 & 3 & 3 & 3 & 2 & 3 & 3 & 3 & 2 & 2 & 2 & 2 & 2 & 2 & 2 & 2 & 2\end{array}$ 61 OBJETIVOS ORGANIZACIONAIS. $\quad \begin{array}{lllllllllllllllllll} & 1 & 3 & 3 & 4 & 4 & 3 & 1 & 3 & 4 & 4 & 4 & 3 & 1 & 3 & 4 & 4 & 4 & 3\end{array}$ 62 OBJETIVOS ORGANIZACIONAIS. $\quad \begin{array}{rllllllllllllllllll}4 & 3 & 3 & 2 & 3 & 4 & 4 & 4 & 4 & 4 & 4 & 4 & 4 & 4 & 4 & 4 & 4 & 4\end{array}$ 63 OBJETIVOS ORGANIZACIONAIS. $\quad \begin{array}{rllllllllllllllllll}4 & 3 & 4 & 3 & 4 & 4 & 4 & 4 & 4 & 4 & 4 & 4 & 4 & 4 & 4 & 4 & 4 & 4\end{array}$ 64 OBJETIVOS ORGANIZACIONAIS. $\quad \begin{array}{lllllllllllllllllll}4 & 4 & 4 & 0 & 4 & 4 & 4 & 4 & 4 & 0 & 4 & 4 & 4 & 1 & 4 & 0 & 4 & 4\end{array}$ 6 OBJETIVOS ORGANIZACIONAIS. $\quad \begin{array}{lllllllllllllllllll}4 & 4 & 4 & 4 & 4 & 4 & 4 & 4 & 4 & 4 & 4 & 4 & 4 & 4 & 4 & 4 & 4 & 4 & 4\end{array}$ 66 OBJETIVOS ORGANIZACIONAIS. $\quad \begin{array}{lllllllllllllllllll}2 & 2 & 4 & 4 & 3 & 3 & 2 & 2 & 3 & 3 & 4 & 2 & 3 & 2 & 3 & 2 & 4 & 2\end{array}$ 67 OBJETIVOS ORGANIZACIONAIS. $\quad \begin{array}{rllllllllllllllllll}4 & 3 & 3 & 3 & 4 & 4 & 3 & 4 & 4 & 4 & 4 & 4 & 4 & 3 & 3 & 3 & 4 & 4\end{array}$ 68 OBJETIVOS ORGANIZACIONAIS. $\quad \begin{array}{lllllllllllllllllll}4 & 4 & 4 & 4 & 4 & 4 & 4 & 4 & 4 & 4 & 4 & 4 & 4 & 4 & 4 & 4 & 4 & 4\end{array}$ 69 OBJETIVOS ORGANIZACIONAIS. $\quad \begin{array}{lllllllllllllllllll} & 3 & 1 & 1 & 3 & 2 & 2 & 3 & 1 & 1 & 3 & 2 & 2 & 4 & 1 & 1 & 3 & 2 & 2\end{array}$ 70 OBJETIVOS ORGANIZACIONAIS. $\quad \begin{array}{rllllllllllllllllll}4 & 0 & 4 & 4 & 4 & 4 & 4 & 0 & 4 & 4 & 4 & 4 & 4 & 0 & 4 & 4 & 4 & 4\end{array}$ 71 OBJETIVOS ORGANIZACIONAIS. $\quad \begin{array}{lllllllllllllllllll}4 & 4 & 4 & 3 & 3 & 3 & 3 & 3 & 3 & 3 & 3 & 3 & 4 & 4 & 3 & 3 & 2 & 2\end{array}$ 72 POLÍTICAS EMPRESARIAIS.

73 OBJETIVOS ORGANIZACIONAIS. $\quad \begin{array}{lllllllllllllllllll}4 & 2 & 4 & 4 & 4 & 4 & 4 & 2 & 4 & 4 & 4 & 4 & 4 & 2 & 4 & 4 & 4 & 4\end{array}$ 74 OBJETIVOS ORGANIZACIONAIS. $\quad \begin{array}{llllllllllllllllllll} & 0 & 1 & 2 & 3 & 4 & 3 & 0 & 1 & 2 & 2 & 3 & 1 & 4 & 3 & 2 & 1 & 0 & 0\end{array}$ 75 OBJETIVOS ORGANIZACIONAIS. $\quad \begin{array}{llllllllllllllllllll}4 & 4 & 3 & 3 & 3 & 4 & 2 & 2 & 2 & 3 & 2 & 4 & 4 & 4 & 4 & 4 & 4 & 4\end{array}$ $\begin{array}{lllllllllllllllllllll}76 & \text { OBJETIVOS ORGANIZACIONAIS. } & 3 & 3 & 2 & 3 & 3 & 2 & 3 & 2 & 2 & 3 & 3 & 3 & 4 & 3 & 3 & 3 & 3 & 3\end{array}$ 77 OBJETIVOS ORGANIZACIONAIS. $\quad \begin{array}{rlllllllllllllllllll}4 & 3 & 3 & 3 & 3 & 4 & 4 & 3 & 3 & 3 & 3 & 4 & 4 & 3 & 3 & 3 & 3 & 4\end{array}$ 
I - INTESIDADE II - FREQUÊNCIA IMPORTÂNCIA

(a) identificação, (b) análise das dificuldade, (c) inicio de uma ação experimental (d) exame da ação experimental (e) processo definitivo

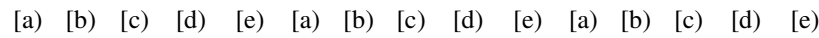

E - A decisão relativa à adesão

1 OBJETIVOS ORGANIZACIONAIS.

2 OBJETIVOS ORGANIZACIONAIS.

3 OBJETIVOS ORGANIZACIONAIS.

4 OBJETIVOS ORGANIZACIONAIS.

5 OBJETIVOS ORGANIZACIONAIS.

6 OBJETIVOS ORGANIZACIONAIS.

7 OBJETIVOS ORGANIZACIONAIS.

8 OBJETIVOS ORGANIZACIONAIS.

9 OBJETIVOS ORGANIZACIONAIS.

0 OBJETIVOS ORGANIZACIONAIS.

1 OBJETIVOS ORGANIZACIONAIS.

12 OBJETIVOS ORGANIZACIONAIS.

3 OBJETIVOS ORGANIZACIONAIS.

POLÍTICAS EMPRESARIAIS.

5 OBJETIVOS ORGANIZACIONAIS.

6 OBJETIVOS ORGANIZACIONAIS.

7 OBJETIVOS ORGANIZACIONAIS.

8 OBJETIVOS ORGANIZACIONAIS.

9 OBJETIVOS ORGANIZACIONAIS.

0 OBJETIVOS ORGANIZACIONAIS.

1 OBJETIVOS ORGANIZACIONAIS.

2 POLÍTICAS EMPRESARIAIS.

POLÍTICAS EMPRESARIAIS.

OBJETIVOS ORGANIZACIONAIS.

OBJETIVOS ORGANIZACIONAIS.

OBJETIVOS ORGANIZACIONAIS.

POLÍTICAS EMPRESARIAIS.

28 OBJETIVOS ORGANIZACIONAIS.

OBJETIVOS ORGANIZACIONAIS.

OBJETIVOS ORGANIZACIONAIS.

1 OBJETIVOS ORGANIZACIONAIS.

32 OBJETIVOS ORGANIZACIONAIS.

OBJETIVOS ORGANIZACIONAIS.

OBJETIVOS ORGANIZACIONAIS.

5 OBJETIVOS ORGANIZACIONAIS.

POLÍTICAS EMPRESARIAIS.

OBJETIVOS ORGANIZACIONAIS.

8 OBJETIVOS ORGANIZACIONAIS.

OBJETIVOS ORGANIZACIONAIS.

40 OBJETIVOS ORGANIZACIONAIS.

1 OBJETIVOS ORGANIZACIONAIS.

2 OBJETIVOS ORGANIZACIONAIS.

43 OBJETIVOS ORGANIZACIONAIS.

4 OBJETIVOS ORGANIZACIONAIS.

5 OBJETIVOS ORGANIZACIONAIS.

OBJETIVOS ORGANIZACIONAIS.

OBJETIVOS ORGANIZACIONAIS.

8 OBJETIVOS ORGANIZACIONAIS.

POLÍTICAS EMPRESARIAIS.

POLÍTICAS EMPRESARIAIS.

1 OBJETIVOS ORGANIZACIONAIS.

POLÍTICAS EMPRESARIAIS.

OBJETIVOS ORGANIZACIONAIS.

4 OBJETIVOS ORGANIZACIONAIS. $\begin{array}{lllllllllllllll}3 & 3 & 4 & 2 & 3 & 3 & 2 & 3 & 2 & 3 & 3 & 4 & 3 & 4 & 3\end{array}$

$\begin{array}{lllllllllllllll}4 & 3 & 3 & 3 & 4 & 4 & 3 & 3 & 3 & 4 & 4 & 3 & 3 & 3 & 4\end{array}$

$\begin{array}{lllllllllllllll}2 & 2 & 3 & 1 & 2 & 2 & 2 & 1 & 1 & 2 & 2 & 2 & 1 & 1 & 2\end{array}$

$\begin{array}{lllllllllllllll}2 & 3 & 2 & 3 & 4 & 3 & 3 & 2 & 3 & 3 & 3 & 2 & 2 & 4 & 3\end{array}$

$\begin{array}{lllllllllllllll}1 & 1 & 2 & 2 & 4 & 1 & 1 & 2 & 2 & 4 & 1 & 1 & 2 & 2 & 4\end{array}$ 


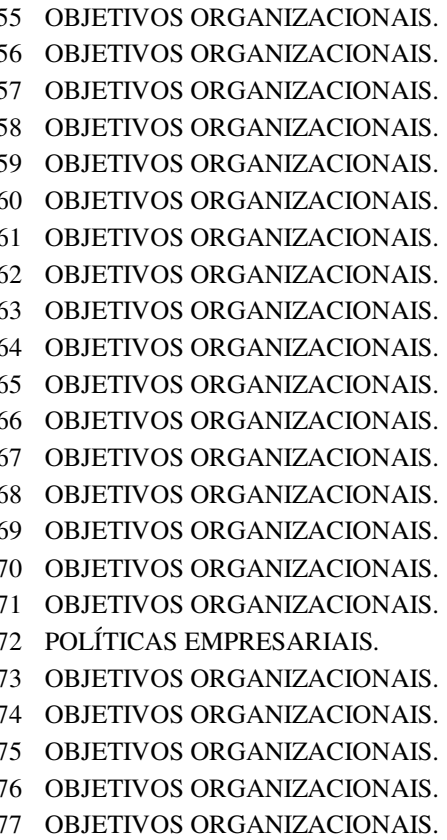

DINAMISMO

(a) Tecnologia necessária para a produção [b) Atitudes da concorrência [c) Demanda do mercado [d) Características dos produtos lançados no mercado [e) Disponibilidades de insumos [f) Preço dos insumos [g) Regulamentação política do setor

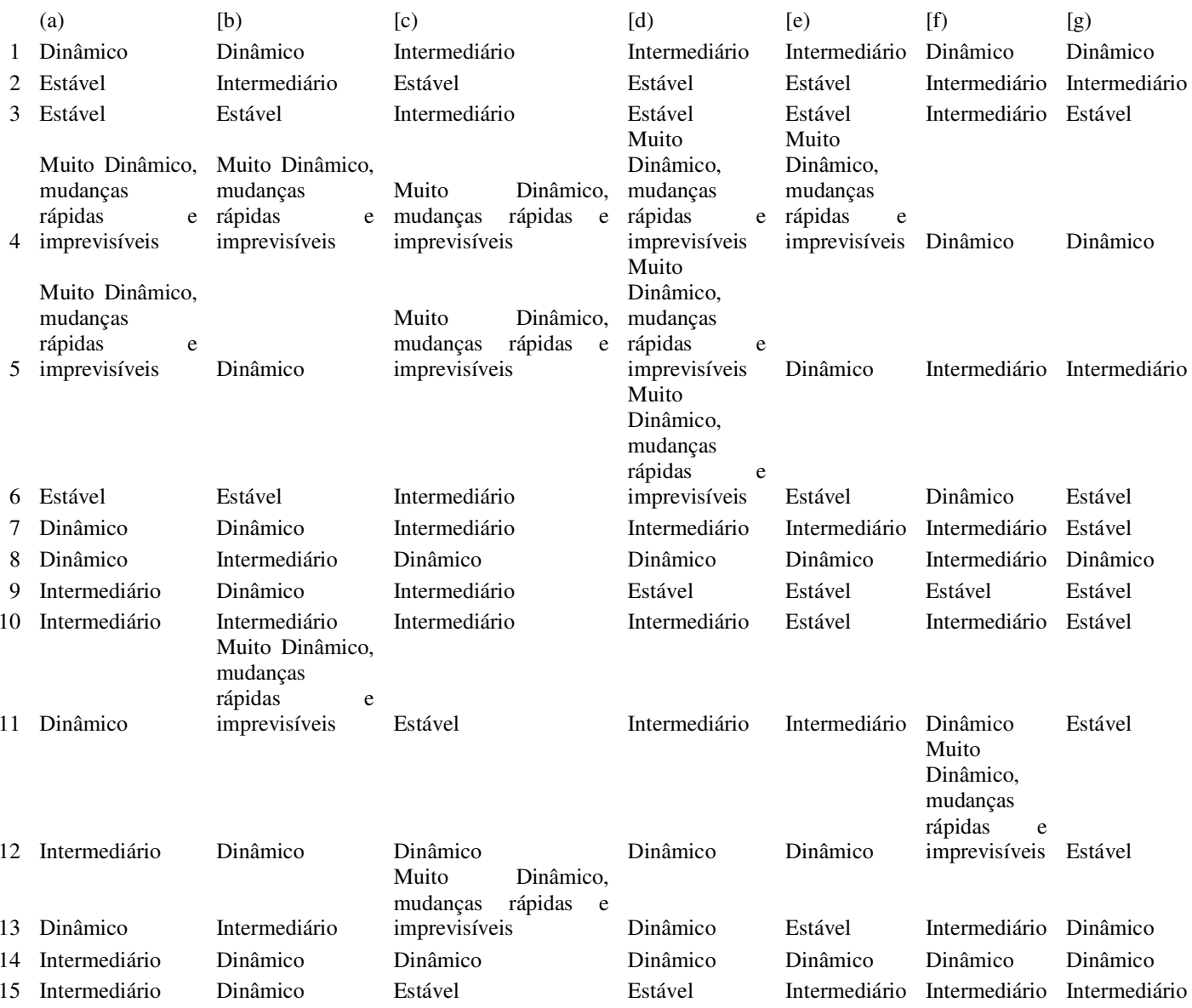




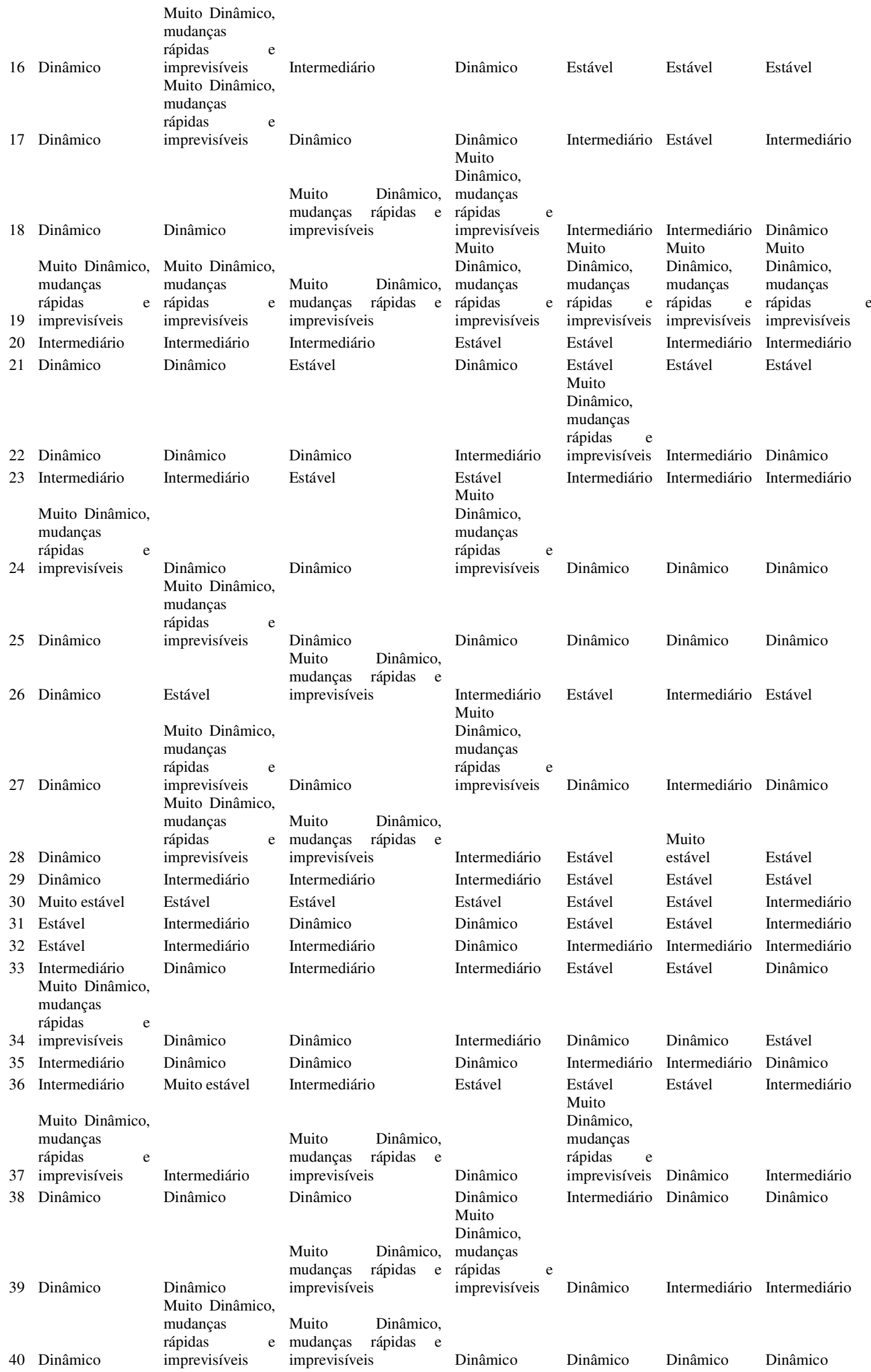




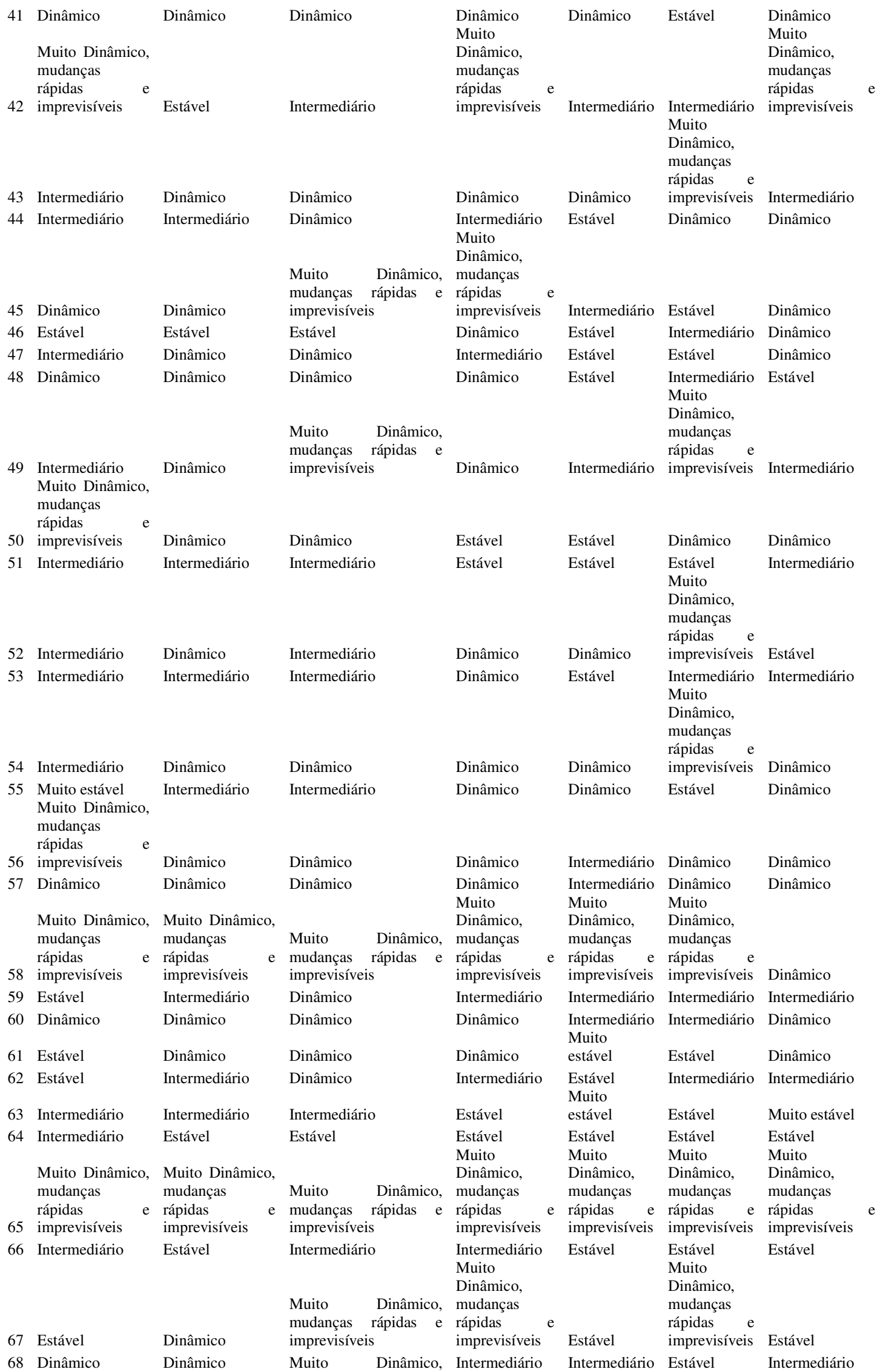




\begin{tabular}{|c|c|c|c|c|c|c|c|}
\hline & & & $\begin{array}{l}\text { mudanças rápidas } \\
\text { imprevisíveis }\end{array}$ & & & & \\
\hline 69 & Dinâmico & Intermediário & $\begin{array}{l}\text { Muito Dinâmico, } \\
\text { mudanças rápidas e } \\
\text { imprevisíveis }\end{array}$ & Dinâmico & Estável & Estável & Estável \\
\hline 70 & Dinâmico & Estável & Dinâmico & Dinâmico & Estável & Estável & Intermediário \\
\hline 71 & Dinâmico & Estável & Intermediário & Estável & Estável & Estável & Estável \\
\hline 72 & Intermediário & Intermediário & Estável & Muito estável & Dinâmico & Dinâmico & Estável \\
\hline 73 & Muito estável & Estável & Estável & Estável & Estável & $\begin{array}{l}\text { Estável } \\
\text { Muito }\end{array}$ & Estável \\
\hline & $\begin{array}{l}\text { Muito Dinâmico, } \\
\text { mudanças }\end{array}$ & & & & & $\begin{array}{l}\text { Dinâmico, } \\
\text { mudanças }\end{array}$ & \\
\hline 74 & $\begin{array}{l}\text { rápidas } \\
\text { imprevisíveis }\end{array}$ & Dinâmico & Intermediário & Intermediário & Dinâmico & $\begin{array}{l}\text { rápidas e } \\
\text { imprevisíveis }\end{array}$ & Dinâmico \\
\hline & $\begin{array}{l}\text { Muito Dinâmico, } \\
\text { mudanças } \\
\text { rápidas } \quad \mathrm{e}\end{array}$ & & & & & & \\
\hline 75 & imprevisíveis & Intermediário & Dinâmico & Intermediário & Dinâmico & Intermediário & Intermediário \\
\hline 76 & Intermediário & Intermediário & Dinâmico & Dinâmico & Intermediário & Dinâmico & Dinâmico \\
\hline 77 & Intermediário & Dinâmico & Dinâmico & Dinâmico & Dinâmico & Dinâmico & Dinâmico \\
\hline
\end{tabular}

\section{HETEROGENEIDADE}

[a) Características dos produtos encontrados no mercado] [b) Tecnologia de produção/ comercialização/ serviço adotada] (c) Características dos fornecedores], [d) Características dos Concorrentes] [Características dos Clientes]

\begin{tabular}{|c|c|c|c|c|c|}
\hline & [a) & [b) & [c) & [d) & [e) \\
\hline & $\begin{array}{l}\text { Heterogêneos/ } \\
\text { diferenciados }\end{array}$ & $\begin{array}{l}\text { Totalmente heterogêneos/ } \\
\text { diferenciados }\end{array}$ & $\begin{array}{l}\text { Heterogêneos/ } \\
\text { diferenciados }\end{array}$ & $\begin{array}{l}\text { Heterogêneos/ } \\
\text { diferenciados }\end{array}$ & Intermediário \\
\hline & Intermediário & Heterogêneos/ diferenciados & $\begin{array}{l}\text { Heterogêneos/ } \\
\text { diferenciados }\end{array}$ & $\begin{array}{l}\text { Heterogêneos/ } \\
\text { diferenciados }\end{array}$ & Intermediário \\
\hline 3 & $\begin{array}{l}\text { Heterogêneos/ } \\
\text { diferenciados }\end{array}$ & Intermediário & Intermediário & $\begin{array}{l}\text { Totalmente heterogêneos/ } \\
\text { diferenciados }\end{array}$ & $\begin{array}{l}\text { Homogêneos/ } \\
\text { semelhantes }\end{array}$ \\
\hline 4 & Intermediário & Intermediário & Intermediário & Intermediário & Intermediário \\
\hline 5 & $\begin{array}{l}\text { Heterogêneos/ } \\
\text { diferenciados }\end{array}$ & Heterogêneos/ diferenciados & Intermediário & $\begin{array}{l}\text { Heterogêneos/ } \\
\text { diferenciados }\end{array}$ & $\begin{array}{l}\text { Heterogêneos/ } \\
\text { diferenciados }\end{array}$ \\
\hline 6 & Intermediário & Intermediário & Intermediário & Intermediário & $\begin{array}{l}\text { Intermediário } \\
\text { Heterogêneos/ }\end{array}$ \\
\hline & $\begin{array}{l}\text { Intermediário } \\
\text { Heterogêneos/ }\end{array}$ & Heterogêneos/ diferenciados & Intermediário & Intermediário & diferenciados \\
\hline 8 & diferenciados & Heterogêneos/ diferenciados & Intermediário & Intermediário & $\begin{array}{l}\text { Intermediário } \\
\text { Totalmente }\end{array}$ \\
\hline & Interm & Intermediário & $\begin{array}{l}\text { Heterogêneos/ } \\
\text { diferenciados }\end{array}$ & $\begin{array}{l}\text { Heterogêneos/ } \\
\text { diferenciados }\end{array}$ & $\begin{array}{l}\text { heterogêneos/ } \\
\text { diferenciados }\end{array}$ \\
\hline & $\begin{array}{l}\text { Homogêneos/ } \\
\text { semelhantes }\end{array}$ & Homogêneos/ semelhantes & $\begin{array}{l}\text { Homogêneos/ } \\
\text { semelhantes }\end{array}$ & Intermediário & Homogêneos/ \\
\hline & Intermediário & Heterogêneos/ diferenciados & $\begin{array}{l}\text { Homogêneos/ } \\
\text { semelhantes }\end{array}$ & Intermediário & $\begin{array}{l}\text { Totalmente } \\
\text { homogêneos/ } \\
\text { semelhantes }\end{array}$ \\
\hline & $\begin{array}{l}\text { Homogêneos/ } \\
\text { semelhantes }\end{array}$ & Homogêneos/ semelhantes & $\begin{array}{l}\text { Homogêneos/ } \\
\text { semelhantes }\end{array}$ & $\begin{array}{l}\text { Homogêneos/ } \\
\text { semelhantes }\end{array}$ & $\begin{array}{l}\text { Homogêneos/ } \\
\text { semelhantes }\end{array}$ \\
\hline & $\begin{array}{l}\text { Homogêneos/ } \\
\text { semelhantes }\end{array}$ & Homogêneos/ semelhantes & $\begin{array}{l}\text { Homogêneos/ } \\
\text { semelhantes }\end{array}$ & Intermediário & $\begin{array}{l}\text { Homogêneos/ } \\
\text { semelhantes }\end{array}$ \\
\hline & $\begin{array}{l}\text { Heterogêneos/ } \\
\text { diferenciados }\end{array}$ & Intermediário & $\begin{array}{l}\text { Heterogêneos/ } \\
\text { diferenciados }\end{array}$ & Intermediário & $\begin{array}{l}\text { Heterogêneos/ } \\
\text { diferenciados }\end{array}$ \\
\hline & $\begin{array}{l}\text { Homogêneos/ } \\
\text { semelhantes }\end{array}$ & Homogêneos/ semelhantes & $\begin{array}{l}\text { Heterogêneos/ } \\
\text { diferenciados }\end{array}$ & $\begin{array}{l}\text { Heterogêneos/ } \\
\text { diferenciados }\end{array}$ & $\begin{array}{l}\text { Heterogêneos/ } \\
\text { diferenciados }\end{array}$ \\
\hline & Intermediário & Heterogêneos/ diferenciados & $\begin{array}{l}\text { Heterogêneos/ } \\
\text { diferenciados }\end{array}$ & Intermediário & $\begin{array}{l}\text { Homogêneos/ } \\
\text { semelhantes }\end{array}$ \\
\hline & $\begin{array}{l}\text { Homogêneos/ } \\
\text { semelhantes }\end{array}$ & Homogêneos/ semelhantes & $\begin{array}{l}\text { Homogêneos/ } \\
\text { semelhantes }\end{array}$ & Intermediário & $\begin{array}{l}\text { Homogêneos/ } \\
\text { semelhantes }\end{array}$ \\
\hline & $\begin{array}{l}\text { Heterogêneos/ } \\
\text { diferenciados }\end{array}$ & Heterogêneos/ diferenciados & Intermediário & $\begin{array}{l}\text { Heterogêneos/ } \\
\text { diferenciados }\end{array}$ & $\begin{array}{l}\text { Heterogêneos/ } \\
\text { diferenciados }\end{array}$ \\
\hline & $\begin{array}{l}\text { Homogêneos/ } \\
\text { semelhantes }\end{array}$ & Homogêneos/ semelhantes & $\begin{array}{l}\text { Homogêneos/ } \\
\text { semelhantes }\end{array}$ & Intermediário & $\begin{array}{l}\text { Homogêneos/ } \\
\text { semelhantes }\end{array}$ \\
\hline & $\begin{array}{l}\text { Homogêneos/ } \\
\text { semelhantes }\end{array}$ & Homogêneos/ semelhantes & $\begin{array}{l}\text { Homogêneos/ } \\
\text { semelhantes }\end{array}$ & $\begin{array}{l}\text { Homogêneos/ } \\
\text { semelhantes }\end{array}$ & $\begin{array}{l}\text { Homogêneos/ } \\
\text { semelhantes }\end{array}$ \\
\hline & Intermediário & Intermediário & Intermediário & Intermediário & Intermediário \\
\hline
\end{tabular}


22 Intermediário

23 Intermediário

24 Intermediário

25 Intermediário Heterogêneos/

26 diferenciados Heterogêneos/

27 diferenciados Totalmente

homogêneos/

28 semelhantes

29 Intermediário Homogêneos/

30 semelhantes Heterogêneos/

31 diferenciados Homogêneos/

32 semelhantes

33 Intermediário Heterogêneos/

34 diferenciados Homogêneos/

35 semelhantes Heterogêneos/

36 diferenciados

37 Intermediário

Heterogêneos/

38 diferenciados

Homogêneos/

39 semelhantes

Heterogêneos/

40 diferenciados

Homogêneos/

41 semelhantes

42 Intermediário

43 Intermediário Homogêneos/

44 semelhantes Heterogêneos/

45 diferenciados

Homogêneos/

46 semelhantes

47 Intermediário

Homogêneos/

48 semelhantes

Totalmente

homogêneos/

49 semelhantes

Heterogêneos/

50 diferenciados

Homogêneos/

51 semelhantes

Heterogêneos/

52 diferenciados

Heterogêneos/

53 diferenciados

Heterogêneos/

54 diferenciados

Heterogêneos/

55 diferenciados

56 Intermediário

57 Intermediário
Totalmente heterogêneos/ Totalmente heterogêneos/

$\begin{array}{ll}\text { diferenciados } & \begin{array}{l}\text { diferenciados } \\ \text { Homogêneos/ } \\ \text { Homogemelhantes }\end{array}\end{array}$

Intermediário Intermediário

Intermediário Intermediário

Heterogêneos/ diferenciados Intermediário

Totalmente heterogêneos/ Heterogêneos/

diferenciados diferenciados

Homogêneos/

semelhantes

Homogêneos/

Intermediário semelhantes

Homogêneos/

Homogêneos/ semelhantes semelhantes

Heterogêneos/

Heterogêneos/ diferenciados diferenciados

Homogêneos/ semelhantes Intermediário

Intermediário

Intermediário

Heterogêneos/ diferenciados Intermediário Homogêneos/

Homogêneos/ semelhantes semelhantes

Heterogêneos/ diferenciados Intermediário

Heterogêneos/ diferenciados Intermediário

Heterogêneos/

Heterogêneos/ diferenciados diferenciados

Homogêneos/

Heterogêneos/ diferenciados semelhantes

Totalmente heterogêneos/ Heterogêneos/

diferenciados diferenciados

Homogêneos/

Homogêneos/ semelhantes semelhantes

Intermediário

Intermediário

Homogêneos/ semelhantes

Homogêneos/

Homogêneos/ semelhantes Intermediário

Heterogêneos/ diferenciados Intermediário

$\begin{array}{ll}\text { Intermediário } & \begin{array}{l}\text { Heterogêneos/ } \\ \text { diferenciados }\end{array}\end{array}$

Homogêneos/ semelhantes Intermediário

Totalmente homogêneos/ Homogêneos/

Homogêneos/semelhantes semelhantes semelhantes

Homogêneos/

Homogêneos/ semelhantes semelhantes

Homogêneos/

Homogêneos/ semelhantes semelhantes

Homogêneos/

Homogêneos/ semelhantes semelhantes

Heterogêneos/

Heterogêneos/ diferenciados diferenciados

Homogêneos/

Heterogêneos/ diferenciados semelhantes

Heterogêneos/

Heterogêneos/ diferenciados diferenciados

Homogêneos/

Homogêneos/ semelhantes semelhantes

Heterogêneos/

Heterogêneos/ diferenciados diferenciados

Intermediário
Heterogêneos/

Intermediário

Homogêneos/

semelhantes

Intermediário

Intermediário

Totalmente heterogêneos/

diferenciados

Intermediário

Intermediário

Homogêneos/

semelhantes

Intermediário

Intermediário

Heterogêneos/

diferenciados

Intermediário

Homogêneos/

semelhantes

Heterogêneos/

diferenciados

Intermediário

erogêneos/ heterogêneos/

diferenciados diferenciados

Homogêneos/

semelhantes

Heterogêneos/

diferenciados

Homogêneos/

semelhantes

Intermediário

Homogêneos/

semelhantes

Homogêneos/

semelhantes

Heterogêneos/

diferenciados

Heterogêneos/

diferenciados

Heterogêneos/

diferenciados

Homogêneos/

semelhantes

Homogêneos/

semelhantes

Intermediário

Intermediário

Homogêneos/

semelhantes

Heterogêneos/

diferenciados

Intermediário

Homogêneos/

semelhantes

Intermediário
Totalmente

heterogêneos/

diferenciados

Intermediário

Homogêneos/

semelhantes

Intermediário

Heterogêneos/

diferenciados

mogêneos/

Homogêneos/

semelhantes

Intermediário

Homogêneos/

semelhantes

Intermediário

Intermediário

Homogêneos/

semelhantes

Homogêneos/

semelhantes

Intermediário

Heterogêneos/

diferenciados

Heterogêneos/

diferenciados

Homogêneos/

semelhantes

Heterogêneos/

diferenciados

Homogêneos/

semelhantes

Intermediário

Homogêneos/

semelhantes

Homogêneos/

semelhantes

Intermediário

Heterogêneos/

diferenciados

Heterogêneos/

diferenciados

Totalmente

homogêneos/

semelhantes

Homogêneos/

semelhantes

Homogêneos/

semelhantes

Homogêneos/

semelhantes

Totalmente

heterogêneos/

diferenciados

Intermediário

Intermediário

Homogêneos/

semelhantes

Homogêneos/

semelhantes

Intermediário 


\begin{tabular}{|c|c|c|c|c|c|}
\hline 58 & $\begin{array}{l}\text { Heterogêneos/ } \\
\text { diferenciados }\end{array}$ & Heterogêneos/ diferenciados & $\begin{array}{l}\text { Heterogêneos/ } \\
\text { diferenciados }\end{array}$ & $\begin{array}{l}\text { Heterogêneos/ } \\
\text { diferenciados }\end{array}$ & Intermediário \\
\hline 59 & $\begin{array}{l}\text { Heterogêneos/ } \\
\text { diferenciados }\end{array}$ & Intermediário & $\begin{array}{l}\text { Homogêneos/ } \\
\text { semelhantes }\end{array}$ & Intermediário & $\begin{array}{l}\text { Heterogêneos/ } \\
\text { diferenciados }\end{array}$ \\
\hline 60 & $\begin{array}{l}\text { Heterogêneos/ } \\
\text { diferenciados } \\
\text { Totalmente }\end{array}$ & Intermediário & Intermediário & $\begin{array}{l}\text { Totalmente heterogêneos/ } \\
\text { diferenciados }\end{array}$ & $\begin{array}{l}\text { Heterogêneos/ } \\
\text { diferenciados }\end{array}$ \\
\hline 61 & $\begin{array}{l}\text { heterogêneos/ } \\
\text { diferenciados } \\
\text { Homogêneos/ }\end{array}$ & Heterogêneos/ diferenciados & Intermediário & $\begin{array}{l}\text { Heterogêneos/ } \\
\text { diferenciados } \\
\text { Homogêneos/ }\end{array}$ & Intermediário \\
\hline 62 & semelhantes & Homogêneos/ semelhantes & Intermediário & semelhantes & Intermediário \\
\hline 63 & $\begin{array}{l}\text { Intermediário } \\
\text { Totalmente }\end{array}$ & Intermediário & $\begin{array}{l}\text { Heterogêneos/ } \\
\text { diferenciados }\end{array}$ & $\begin{array}{l}\text { Heterogêneos/ } \\
\text { diferenciados }\end{array}$ & $\begin{array}{l}\text { Heterogêneos/ } \\
\text { diferenciados } \\
\text { Totalmente }\end{array}$ \\
\hline 64 & $\begin{array}{l}\text { homogêneos/ } \\
\text { semelhantes } \\
\text { Totalmente }\end{array}$ & Homogêneos/ semelhantes & $\begin{array}{l}\text { Homogêneos/ } \\
\text { semelhantes }\end{array}$ & $\begin{array}{l}\text { Totalmente homogêneos/ } \\
\text { semelhantes }\end{array}$ & $\begin{array}{l}\text { homogêneos/ } \\
\text { semelhantes } \\
\text { Totalmente }\end{array}$ \\
\hline 65 & $\begin{array}{l}\text { homogêneos/ } \\
\text { semelhantes }\end{array}$ & $\begin{array}{l}\text { Totalmente homogêneos/ } \\
\text { semelhantes }\end{array}$ & $\begin{array}{l}\text { Totalmente homogêneos/ } \\
\text { semelhantes }\end{array}$ & $\begin{array}{l}\text { Totalmente homogêneos/ } \\
\text { semelhantes }\end{array}$ & $\begin{array}{l}\text { homogêneos/ } \\
\text { semelhantes }\end{array}$ \\
\hline 66 & $\begin{array}{l}\text { Homogêneos/ } \\
\text { semelhantes }\end{array}$ & Homogêneos/ semelhantes & $\begin{array}{l}\text { Heterogêneos/ } \\
\text { diferenciados }\end{array}$ & $\begin{array}{l}\text { Heterogêneos/ } \\
\text { diferenciados }\end{array}$ & $\begin{array}{l}\text { Homogêneos/ } \\
\text { semelhantes }\end{array}$ \\
\hline 67 & $\begin{array}{l}\text { Homogêneos/ } \\
\text { semelhantes }\end{array}$ & Intermediário & Intermediário & $\begin{array}{l}\text { Homogêneos/ } \\
\text { semelhantes }\end{array}$ & Intermediário \\
\hline 68 & $\begin{array}{l}\text { Homogêneos/ } \\
\text { semelhantes }\end{array}$ & Heterogêneos/ diferenciados & $\begin{array}{l}\text { Heterogêneos/ } \\
\text { diferenciados }\end{array}$ & $\begin{array}{l}\text { Homogêneos/ } \\
\text { semelhantes }\end{array}$ & Intermediário \\
\hline 69 & $\begin{array}{l}\text { Heterogêneos/ } \\
\text { diferenciados }\end{array}$ & Homogêneos/ semelhantes & $\begin{array}{l}\text { Homogêneos/ } \\
\text { semelhantes }\end{array}$ & $\begin{array}{l}\text { Homogêneos/ } \\
\text { semelhantes }\end{array}$ & $\begin{array}{l}\text { Heterogêneos/ } \\
\text { diferenciados }\end{array}$ \\
\hline 70 & $\begin{array}{l}\text { Homogêneos/ } \\
\text { semelhantes }\end{array}$ & Homogêneos/ semelhantes & $\begin{array}{l}\text { Homogêneos/ } \\
\text { semelhantes }\end{array}$ & $\begin{array}{l}\text { Homogêneos/ } \\
\text { semelhantes }\end{array}$ & $\begin{array}{l}\text { Homogêneos/ } \\
\text { semelhantes } \\
\text { Totalmente }\end{array}$ \\
\hline 71 & Intermediário & Intermediário & $\begin{array}{l}\text { Homogêneos/ } \\
\text { semelhantes }\end{array}$ & $\begin{array}{l}\text { Homogêneos/ } \\
\text { semelhantes }\end{array}$ & $\begin{array}{l}\text { homogêneos/ } \\
\text { semelhantes }\end{array}$ \\
\hline 72 & $\begin{array}{l}\text { Homogêneos/ } \\
\text { semelhantes }\end{array}$ & Homogêneos/ semelhantes & $\begin{array}{l}\text { Homogêneos/ } \\
\text { semelhantes }\end{array}$ & $\begin{array}{l}\text { Homogêneos/ } \\
\text { semelhantes }\end{array}$ & $\begin{array}{l}\text { Homogêneos/ } \\
\text { semelhantes }\end{array}$ \\
\hline 73 & $\begin{array}{l}\text { Heterogêneos/ } \\
\text { diferenciados }\end{array}$ & Heterogêneos/ diferenciados & $\begin{array}{l}\text { Heterogêneos/ } \\
\text { diferenciados }\end{array}$ & $\begin{array}{l}\text { Heterogêneos/ } \\
\text { diferenciados }\end{array}$ & $\begin{array}{l}\text { Heterogêneos/ } \\
\text { diferenciados }\end{array}$ \\
\hline 74 & $\begin{array}{l}\text { Heterogêneos/ } \\
\text { diferenciados }\end{array}$ & Heterogêneos/ diferenciados & $\begin{array}{l}\text { Heterogêneos/ } \\
\text { diferenciados }\end{array}$ & $\begin{array}{l}\text { Heterogêneos/ } \\
\text { diferenciados }\end{array}$ & $\begin{array}{l}\text { Intermediário } \\
\text { Totalmente }\end{array}$ \\
\hline 75 & $\begin{array}{l}\text { Heterogêneos/ } \\
\text { diferenciados }\end{array}$ & Intermediário & Intermediário & Intermediário & $\begin{array}{l}\text { heterogêneos/ } \\
\text { diferenciados }\end{array}$ \\
\hline 76 & $\begin{array}{l}\text { Intermediário } \\
\text { Homogêneos/ }\end{array}$ & Homogêneos/ semelhantes & Intermediário & $\begin{array}{l}\text { Totalmente homogêneos/ } \\
\text { semelhantes }\end{array}$ & Intermediário \\
\hline 77 & semelhantes & Intermediário & Intermediário & Intermediário & Intermediário \\
\hline
\end{tabular}

Hostilidade

6 - Você acredita que o setor no qual sua empresa compete está [a) Saturado (quantidade de empresas muito grande para o tamanho do setor] [b) Dominado (poucas empresas dominam e ditam regras)] [c) Restritivo (regulamentações, tecnologias exigidas e outras implicações dificultam a entrada

$\begin{array}{lll}\text { [a) Saturado } & {[\mathrm{b}) \text { Dominado }} & \text { [c) Restritivo } \\ \text { Está razoavelmente } & \text { Está razoavelmente } & \text { Está razoavelmente } \\ \text { Não está } & \text { Não está } & \text { Não está } \\ \text { Está pouco } & \text { Está razoavelmente } & \text { Não está } \\ \text { Está razoavelmente } & \text { Está razoavelmente } & \text { Está muito } \\ \text { Está razoavelmente } & \text { Está pouco } & \text { Está pouco } \\ \text { Não está } & \text { Está razoavelmente } & \text { Está razoavelmente } \\ \text { Não está } & \text { Não está } & \text { Está razoavelmente } \\ \text { Está razoavelmente } & \text { Está muito } & \text { Está muito } \\ \text { Não está } & \text { Não está } & \text { Está pouco } \\ \text { Está razoavelmente } & \text { Está razoavelmente } & \text { Não está } \\ \text { Está razoavelmente } & \text { Está muito } & \text { Está extremamente } \\ \text { Está razoavelmente } & \text { Está razoavelmente } & \text { Está pouco } \\ \text { Não está } & \text { Está pouco } & \text { Está razoavelmente } \\ \text { Não está } & \text { Não está } & \text { Não está } \\ \text { Está razoavelmente } & \text { Está muito } & \text { Está pouco } \\ \text { Está razoavelmente } & \text { Está pouco } & \text { Não está } \\ \text { Está muito } & \text { Está razoavelmente } & \text { Não está } \\ \text { Não está } & \text { Está razoavelmente } & \text { Não está }\end{array}$




\begin{tabular}{|c|}
\hline Está muito \\
\hline Está pouco \\
\hline Está pouco \\
\hline Não está \\
\hline Está razoavelmente \\
\hline Não está \\
\hline Está razoavelmente \\
\hline Não está \\
\hline Está razoavelmente \\
\hline Está razoavelmente \\
\hline Está pouco \\
\hline Não está \\
\hline Está pouco \\
\hline Está razoavelmente \\
\hline Não está \\
\hline Não está \\
\hline Não está \\
\hline Não está \\
\hline Está muito \\
\hline Está razoavelmente \\
\hline Não está \\
\hline Está razoavelmente \\
\hline Está razoavelmente \\
\hline Não está \\
\hline Não está \\
\hline Está razoavelmente \\
\hline Está razoavelmente \\
\hline Não está \\
\hline Está razoavelmente \\
\hline Está razoavelmente \\
\hline Não está \\
\hline Está razoavelmente \\
\hline Está razoavelmente \\
\hline Está razoavelmente \\
\hline Não está \\
\hline Está pouco \\
\hline Está pouco \\
\hline Não está \\
\hline Está razoavelmente \\
\hline Não está \\
\hline Está razoavelmente \\
\hline Está razoavelmente \\
\hline Está razoavelmente \\
\hline Está razoavelmente \\
\hline Não está \\
\hline Está muito \\
\hline Não está \\
\hline Não está \\
\hline Está pouco \\
\hline Não está \\
\hline Não está \\
\hline Não está \\
\hline Está muito \\
\hline Está razoavelmente \\
\hline Está pouco \\
\hline Está extremamente \\
\hline Está pouco \\
\hline Está pouco \\
\hline Está pouco \\
\hline
\end{tabular}

\begin{tabular}{|c|c|}
\hline Está muito & Está muito \\
\hline Está muito & Não está \\
\hline Está pouco & Não está \\
\hline Está extremamente & Está extremamente \\
\hline Está pouco & Está razoavelmente \\
\hline Está razoavelmente & Está muito \\
\hline Está muito & Não está \\
\hline Está razoavelmente & Está muito \\
\hline Está muito & Está razoavelmente \\
\hline Está razoavelmente & Está pouco \\
\hline Não está & Não está \\
\hline Está pouco & Não está \\
\hline Está pouco & Está razoavelmente \\
\hline Está razoavelmente & Está pouco \\
\hline Está muito & Não está \\
\hline Está razoavelmente & Está razoavelmente \\
\hline Está pouco & Não está \\
\hline Está razoavelmente & Não está \\
\hline Não está & Não está \\
\hline Está muito & Está muito \\
\hline Está pouco & Está pouco \\
\hline Não está & Não está \\
\hline Está razoavelmente & Está razoavelmente \\
\hline Está razoavelmente & Está muito \\
\hline Não está & Está pouco \\
\hline Está pouco & Não está \\
\hline Não está & Está razoavelmente \\
\hline Está razoavelmente & Não está \\
\hline Está pouco & Está razoavelmente \\
\hline Está razoavelmente & Está razoavelmente \\
\hline Está extremamente & Está muito \\
\hline Está pouco & Está razoavelmente \\
\hline Está pouco & Está razoavelmente \\
\hline Está razoavelmente & Está pouco \\
\hline Está razoavelmente & Não está \\
\hline Está razoavelmente & Está muito \\
\hline Está razoavelmente & Está muito \\
\hline Está pouco & Não está \\
\hline Está razoavelmente & Está muito \\
\hline Está extremamente & Está extremamente \\
\hline Está razoavelmente & Está razoavelmente \\
\hline Está muito & Está muito \\
\hline Está muito & Está extremamente \\
\hline Está razoavelmente & Está pouco \\
\hline Está razoavelmente & Está muito \\
\hline Está muito & Está pouco \\
\hline Está pouco & Está pouco \\
\hline Está razoavelmente & Não está \\
\hline Está muito & Está razoavelmente \\
\hline Não está & Não está \\
\hline Está razoavelmente & Está extremamente \\
\hline Não está & Está muito \\
\hline Está muito & Está muito \\
\hline Está razoavelmente & Está muito \\
\hline Está pouco & Não está \\
\hline Está muito & Está razoavelmente \\
\hline Está razoavelmente & Está razoavelmente \\
\hline Está muito & Está muito \\
\hline Está extremamente & Está pouco \\
\hline
\end{tabular}


12 - Sua empresa é auditada por:

9 - A empresa optou pela utilização do RTT (regime tributário de transição)?

$\begin{array}{ll}1 & \text { Sim } \\ 2 & \text { Sim } \\ 3 & \text { Sim } \\ 4 & \text { Sim }\end{array}$

5 Não sei

6 Sim

7 Não sei

8 Sim

9 Não

10 Sim

11 Sim

$12 \mathrm{Sim}$

13 Não

14 Sim

15 Sim

16 Não

17 Sim

18 Sim

19 Sim

20 Sim

$21 \mathrm{Sim}$

22 Sim

23 Sim

24 Não

$25 \mathrm{Sim}$

$26 \mathrm{Sim}$

27 Não sei

$28 \mathrm{Sim}$

29 Sim

30 Sim

31 Sim

32 Não

33 Sim

$34 \mathrm{Sim}$

$35 \mathrm{Sim}$

$36 \mathrm{Sim}$

37 Sim

38 Sim

39 Sim

40 Não

41 Sim

42 Não

43 Sim

$44 \mathrm{Sim}$

45 Sim

46 Sim

$$
\begin{gathered}
11 \text { - Comparando com o setor } \\
\text { onde sua empresa atua, ela é } \\
\text { considerada de: }
\end{gathered}
$$

Médio porte

Médio porte

Médio porte

Médio porte

Grande porte

Grande porte

Pequeno porte

Médio porte

Médio porte

Grande porte

Médio porte

Grande porte

Pequeno porte

Grande porte

Médio porte

Médio porte

Grande porte

Grande porte

Médio porte

Grande porte

Médio porte

Médio porte

Médio porte

Grande porte

Grande porte

Grande porte

Médio porte

Médio porte

Médio porte

Grande porte

Médio porte

Médio porte

Médio porte

Grande porte

Grande porte

Grande porte

Médio porte

Médio porte

Grande porte

Médio porte

Grande porte

Pequeno porte

Médio porte

Grande porte

Grande porte

Médio porte outra empresa de auditoria de origem nacional

não é auditada

Ernest Young

Ernest Young

Price Waterhouse

Price Waterhouse

Ernest Young

Ernest Young

não é auditada

KPMG

outra empresa de auditoria de origem nacional

Deloitte

Price Waterhouse

Price Waterhouse

Price Waterhouse

KPMG

Ernest Young

Deloitte

KPMG

KPMG

não é auditada

Ernest Young

outra empresa de auditoria de origem nacional

Ernest Young

outra empresa de auditoria de

origem nacional

KPMG

outra empresa de auditoria de origem nacional

não é auditada

outra empresa de auditoria de

origem nacional

KPMG

Price Waterhouse

não é auditada

outra empresa de auditoria de origem nacional

KPMG

Price Waterhouse

Price Waterhouse

Deloitte

não é auditada

Price Waterhouse

não é auditada

outra empresa de auditoria de origem nacional

não é auditada

não é auditada

Price Waterhouse

Ernest Young

outra empresa de auditoria de origem nacional 


$\begin{array}{ll}47 & \text { Sim } \\ 48 & \text { Sim } \\ 49 & \text { Sim } \\ 50 & \text { Sim } \\ 51 & \text { Sim } \\ 52 & \text { Sim } \\ 53 & \text { Sim } \\ 54 & \text { Sim } \\ 55 & \text { Sim } \\ 56 & \text { Não } \\ 57 & \text { Não } \\ 58 & \text { Não } \\ 59 & \text { Sim } \\ 60 & \text { Sim } \\ 61 & \text { Sim } \\ 62 & \text { Sim } \\ 63 & \text { Sim } \\ 64 & \text { Sim } \\ 65 & \text { Não } \\ 66 & \text { Não } \\ 67 & \text { Não sei } \\ 68 & \text { Sim } \\ 69 & \text { Sim } \\ 70 & \text { Sim } \\ 71 & \text { Sim } \\ 72 & \text { Não } \\ 73 & \text { Não } \\ 74 & \text { Sim } \\ 75 & \text { Não } \\ 76 & \text { Sim } \\ 77 & \text { Sim }\end{array}$

$\begin{array}{ll}\begin{array}{l}\text { Privado - brasileiro } \\ \text { Privado - brasileiro } \\ \text { Privado - europeu } \\ \text { Privado - europeu } \\ \text { Privado - brasileiro }\end{array} & \begin{array}{l}\text { Grande porte } \\ \text { Grande porte } \\ \text { Grande porte } \\ \text { Grande porte } \\ \text { Grande porte }\end{array} \\ \text { Privado - brasileiro } & \text { Grande porte } \\ \text { Privado - brasileiro } & \text { Grande porte } \\ \text { Privado - outros } & \text { Médio porte } \\ \text { Privado - europeu } & \text { Grande porte } \\ \text { Privado - europeu } & \text { Pequeno porte } \\ \text { Privado - brasileiro } & \text { Médio porte } \\ \text { Privado - outros } & \text { Grande porte } \\ \text { Privado - brasileiro } & \text { Grande porte } \\ \text { Privado - brasileiro } & \text { Médio porte } \\ \text { Privado - outros } & \text { Pequeno porte } \\ \text { Privado - brasileiro } & \text { Grande porte } \\ \text { Privado - brasileiro } & \text { Grande porte } \\ \text { Privado - brasileiro } & \text { Médio porte } \\ \text { Privado - brasileiro } & \text { Médio porte } \\ \text { Privado - brasileiro } & \text { Grande porte } \\ \text { Privado - norte-americano } & \text { Médio porte } \\ \text { Privado - brasileiro } & \text { Médio porte } \\ \text { Privado - brasileiro } & \text { Médio porte } \\ \text { Privado - brasileiro } & \text { Grande porte } \\ \text { Privado - europeu } & \text { Grande porte } \\ \text { Privado - brasileiro } & \text { Médio porte } \\ \text { Privado - brasileiro } & \text { Médio porte } \\ \text { Privado - brasileiro } & \text { Grande porte } \\ \text { Privado - brasileiro } & \text { Grande porte } \\ \text { Privado - brasileiro } & \text { Médio porte } \\ \text { Privado - brasileiro } & \text { Grande porte }\end{array}$

outra empresa de auditoria de origem nacional

Deloitte

Deloitte

Price Waterhouse

Deloitte

outra empresa de auditoria de origem nacional

não é auditada

Price Waterhouse

KPMG

não é auditada

Deloitte

KPMG

outra empresa de auditoria de origem nacional

outra empresa de auditoria de origem nacional

KPMG

Price Waterhouse

Price Waterhouse

Ernest Young

não é auditada

outra empresa de auditoria de origem nacional

Ernest Young

Ernest Young

Price Waterhouse

Ernest Young

KPMG

outra empresa de auditoria de origem nacional

outra empresa de auditoria de origem nacional

KPMG

não é auditada

Price Waterhouse

KPMG

\section{CARACTERÍSTICAS DE DESEMPENHO}

[a) As margens de lucro de seus principais produtos/ serviços como estão na média] [b) O crescimento do lucro como se comportou] [c) O crescimento da receita como se comportou]

$\begin{array}{llll} & \text { aa } & {[\mathrm{b} \text { ) }} & \text { [c) } \\ 1 & \text { Abaixo do esperado } & \text { Abaixo do esperado } & \text { Abaixo do esperado } \\ 2 & \text { Abaixo do esperado } & \text { Abaixo do esperado } & \text { Abaixo do esperado } \\ 3 & \text { Esperado } & \text { Acima do esperado } & \text { Esperado } \\ 4 & \text { Abaixo do esperado } & \text { Abaixo do esperado } & \text { Abaixo do esperado } \\ 5 & \text { Abaixo do esperado } & \text { Esperado } & \text { Acima do esperado } \\ 6 & \text { Abaixo do esperado } & \text { Abaixo do esperado } & \text { Abaixo do esperado } \\ 7 & \text { Abaixo do esperado } & \text { Abaixo do esperado } & \text { Abaixo do esperado } \\ 8 & \text { Abaixo do esperado } & \text { Abaixo do esperado } & \text { Abaixo do esperado } \\ 9 & \text { Esperado } & \text { Esperado } & \text { Esperado } \\ 0 & \text { Abaixo do esperado } & \text { Abaixo do esperado } & \text { Esperado } \\ 1 & \text { Esperado } & \text { Acima do esperado } & \text { Acima do esperado } \\ 2 & \text { Abaixo do esperado } & \text { Abaixo do esperado } & \text { Abaixo do esperado } \\ 3 & \text { Muito acima do esperado } & \text { Abaixo do esperado } & \text { Abaixo do esperado } \\ 4 & \text { Acima do esperado } & \text { Muito acima do esperado } & \text { Muito acima do esperado } \\ 5 & \text { Abaixo do esperado } & \text { Abaixo do esperado } & \text { Abaixo do esperado } \\ 6 & \text { Esperado } & \text { Esperado } & \text { Esperado } \\ 7 & \text { Esperado } & \text { Esperado } & \text { Esperado } \\ 8 & \text { Esperado } & \text { Esperado } & \text { Esperado } \\ 9 & \text { Esperado } & \text { Esperado } & \text { Esperado } \\ 0 & \text { Esperado } & \text { Esperado } & \text { Abaixo do esperado } \\ 1 & \text { Esperado } & \text { Abaixo do esperado } & \text { Esperado }\end{array}$




\begin{tabular}{|c|c|}
\hline 22 & Esperado \\
\hline 23 & Esperado \\
\hline 24 & Esperado \\
\hline 25 & Esperado \\
\hline 26 & Esperado \\
\hline 27 & Esperado \\
\hline 28 & Abaixo do esperado \\
\hline 29 & Acima do esperado \\
\hline 30 & Esperado \\
\hline 31 & Esperado \\
\hline 32 & Esperado \\
\hline 33 & Esperado \\
\hline 34 & Esperado \\
\hline 35 & Esperado \\
\hline 36 & Esperado \\
\hline 37 & Esperado \\
\hline 38 & Muito abaixo do esperado \\
\hline 39 & Esperado \\
\hline 40 & Esperado \\
\hline 41 & Esperado \\
\hline 42 & Esperado \\
\hline 43 & Abaixo do esperado \\
\hline 44 & Esperado \\
\hline 45 & Esperado \\
\hline 46 & Esperado \\
\hline 47 & Esperado \\
\hline 48 & Abaixo do esperado \\
\hline 49 & Esperado \\
\hline 50 & Esperado \\
\hline 51 & Acima do esperado \\
\hline 52 & Esperado \\
\hline 53 & Esperado \\
\hline 54 & Esperado \\
\hline 55 & Esperado \\
\hline 56 & Esperado \\
\hline 57 & Esperado \\
\hline 58 & Muito acima do esperado \\
\hline 59 & Esperado \\
\hline 60 & Esperado \\
\hline 61 & Acima do esperado \\
\hline 62 & Esperado \\
\hline 63 & Esperado \\
\hline 64 & Esperado \\
\hline 65 & Esperado \\
\hline 66 & Esperado \\
\hline 67 & Acima do esperado \\
\hline 68 & Esperado \\
\hline 69 & Esperado \\
\hline 70 & Esperado \\
\hline 71 & Abaixo do esperado \\
\hline 72 & Abaixo do esperado \\
\hline 73 & Esperado \\
\hline 74 & Acima do esperado \\
\hline 75 & Abaixo do esperado \\
\hline 76 & Esperado \\
\hline 77 & Esperado \\
\hline
\end{tabular}

\begin{tabular}{|c|c|}
\hline Acima do esperado & Muito acima do esperado \\
\hline Esperado & Acima do esperado \\
\hline Esperado & Esperado \\
\hline Abaixo do esperado & Abaixo do esperado \\
\hline Abaixo do esperado & Esperado \\
\hline Abaixo do esperado & Abaixo do esperado \\
\hline Abaixo do esperado & Abaixo do esperado \\
\hline Esperado & Acima do esperado \\
\hline Esperado & Esperado \\
\hline Esperado & Esperado \\
\hline Abaixo do esperado & Abaixo do esperado \\
\hline Abaixo do esperado & Acima do esperado \\
\hline Esperado & Esperado \\
\hline Esperado & Esperado \\
\hline Esperado & Abaixo do esperado \\
\hline Acima do esperado & Acima do esperado \\
\hline Muito abaixo do esperado & Muito abaixo do esperado \\
\hline Esperado & Esperado \\
\hline Esperado & Esperado \\
\hline Esperado & Acima do esperado \\
\hline Esperado & Acima do esperado \\
\hline Abaixo do esperado & Abaixo do esperado \\
\hline Esperado & Abaixo do esperado \\
\hline Esperado & Esperado \\
\hline Esperado & Esperado \\
\hline Esperado & Esperado \\
\hline Abaixo do esperado & Abaixo do esperado \\
\hline Esperado & Esperado \\
\hline Esperado & Esperado \\
\hline Acima do esperado & Acima do esperado \\
\hline Abaixo do esperado & Acima do esperado \\
\hline Esperado & Esperado \\
\hline Esperado & Esperado \\
\hline Abaixo do esperado & Abaixo do esperado \\
\hline Esperado & Esperado \\
\hline Esperado & Esperado \\
\hline Muito acima do esperado & Muito acima do esperado \\
\hline Abaixo do esperado & Esperado \\
\hline Abaixo do esperado & Abaixo do esperado \\
\hline Acima do esperado & Acima do esperado \\
\hline Esperado & Esperado \\
\hline Esperado & Esperado \\
\hline Abaixo do esperado & Abaixo do esperado \\
\hline Esperado & Esperado \\
\hline Esperado & Esperado \\
\hline Acima do esperado & Acima do esperado \\
\hline Abaixo do esperado & Muito abaixo do esperado \\
\hline Esperado & Esperado \\
\hline Esperado & Esperado \\
\hline Abaixo do esperado & Abaixo do esperado \\
\hline Abaixo do esperado & Abaixo do esperado \\
\hline Esperado & Esperado \\
\hline Esperado & Abaixo do esperado \\
\hline Abaixo do esperado & Esperado \\
\hline Esperado & Abaixo do esperado \\
\hline Esperado & Esperado \\
\hline
\end{tabular}


instrumentos gerenciais

5 - Em que nível sua empresa utiliza os seguintes instrumentos ou práticas gerenciais? [j) ABC/ ABM] [1) EVA] [m) Uso sistemático de Benchmarking] [n) Balanço Scorecard] [o) Análise de cenários de planejamento estratégico] [p) Indicadores não financeiros

[j)

$$
\text { Concluiu }
$$

plenamente

1 Não utiliza

implantação

2 Não utiliza

Não utiliza

Está em fase inicial Está em fase inicial

3 de implantação

de implantação

4 Não utiliza

5 Não utiliza

Está estudando

Não utiliza

Está em fase inicial Concluiu plenamente de implantação

[m)

[n)

[o)

[p)

sua Está em fase final de implantação

de implantação

Está em fase

Não utiliza

Não utiliza

Concluiu plenamente sua implantação sua implantação implantação

Está em fase final

Concluiu plenamente e implantação

sua implantação

Concluiu plenamente

sua implantação

Não utiliza

Concluiu plenamente

sua implantação sua implantação

sua implantação Não utiliza

Está fom fase de sua implantação ando a Está estudando a Está estudando a Está estudando a $\quad$ Está estudando a

7 Não utiliza adoção

Concluiu plenamente

Não utiliza

Está em fase final de Está em fase final Está em fase final de

Concluiu plenamente

Concluiu plenament

8 implantação de implantação

implantação

Não utiliza

Não utiliza

Está em fase final de adoção

implantação

adoção

9 Não utiliza

Não utiliza

Concluiu plenamente

10 Não utiliza

Não utiliza

Não utiliza

Não utiliza

Está em fase inicial Está em fase final de Concluiu plenamente de implantação

implantação

sua implantação

Não utiliza

Não utiliza

Não utiliza

Concluiu plenamente Concluiu plenamente sua implantação sua implantação Está estudando a

Concluiu plenamente Está em fase inicial Concluiu plenamente de implantação

sua implantação

Não utiliza

Está em fase inicial de viabilidade de sua implantação adoção

Concluiu plenamente

12 sua implantação Não utiliza

Concluiu plenamente plenamente sua implantação implantação

13 Não utiliza

Não utiliza

Concluiu plenamente

sua implantação

Não utiliza

Concluiu

Está em fase inicial Está em fase inicial Está em fase final de plenamente

14 de implantação de implantação implantação

Concluiu

Concluiu plenamente plenamente

15 sua implantação

implantação

sua Está em fase final de implantação

Concluiu

Não utiliza

Não utiliza implantação

plenamente

implantação

Concluiu

plenamente

Não utiliza

implantação

Concluiu

plenamente

17 Não utiliza

implantação

Está em fase final

18 Não utiliza de implantação

sua Concluiu plenamente Está estudando a

sua Está em fase final de Concluiu plenamente implantação sua implantação

Concluiu plenamente Concluiu plenamente sua implantação

sua implantação

sua Está em fase final de Concluiu plenamente implantação

sua implantação

sua Concluiu plenamente Está em fase final de sua implantação implantação

ua Concluiu plenamente Concluiu plenamente sua implantação sua implantação sua implantação

adoção

Está em fase final de Está em fase inicial Está em fase final de Está em

19 implantação de implantação Concluiu

Concluiu plenamente plenamente 20 sua implantação implantação

sua Concluiu plenamente sua implantação

de implantação

Concluiu

21 Não utiliza

Não utiliza Concluiu

Está em fase final de plenamente

22 implantação

implantação

sua

Concluiu plenamente sua implantação

implantação

Está estudando

adoção

Não utiliza

Concluiu

plenamente

implantação

Concluiu

plenamente

25 Não utiliza

implantação

\section{Não utiliza}

Não utiliza

sua

Não utiliza

sua
Não utiliza

Não utiliza

Não utiliza a $\mathrm{C}$

Concluiu plenamente sua implantação Concluiu plenamente sua implantação

Concluiu plenamente sua implantação implantação

al Está em fase inicial de Está em fase final de implantação implantação

Concluiu plenamente sua implantação

Concluiu plenamente sua implantação Está estudando a viabilidade de sua adoção

Concluiu plenamente sua implantação Concluiu plenamente Concluiu plenamente sua implantação sua implantação

Concluiu plenamente sua implantação

Concluiu plenamente

Concluiu plenamente sua implantação 
Está em fase inicial 26 de implantação

27 Não utiliza

28 Não utiliza

29 Não utiliza

30 Não utiliza

31 Não utiliza

32 Não utiliza

viabilidade de sua viabilidade de sua

33 adoção

Não utiliza

Não utiliza

Não utiliza

Não utiliza

Não utiliza

adoção
Está estudando a

Está em fase inicial viabilidade de sua Está em fase inicial de implantação adoção

Não utiliza

Está estudando a

viabilidade de sua

34 Não utiliza adoção

Está estudando a Está estudando a

viabilidade de sua viabilidade de sua

35 adoção

adoção

Concluiu

plenamente sua

36 Não utiliza

Não utiliza

Concluiu plenamente sua implantação

Não utiliza

Está em fase final de implantação

la

Não utiliza

Está em fase inicial de plenamente implantação mplantação

Não utiliza

viabilidade de sua adoção

Não utiliza

Está em fase inicia
de implantação 38 de implantação

adoção Está estudando a Está estudand

Está estudando a

Não utiliza
Concluiu
plenamente sua
implantação
Está estudando
viabilidade de sua

Está em fase inicial Está em fase inicial de implantação Concluiu

Concluiu plenamente 39 sua implantação

Não utiliza

Concluiu plenamente plenamente sua implantação implantação

40 Não utiliza

Não utiliza Concluiu

Concluiu plenamente plenamente

Não utiliza

Não utiliza

implantação

sua

41 sua implantação

Não utiliza

42 Não utiliza

Na utiliza

43 Não utiliza

Não utiliza

Concluiu plenamente 44 sua implantação

\section{Não utiliza}

Está estudando a

viabilidade de sua Concluiu plenamente

45 Não utiliza

adoção

Concluiu

Concluiu plenamente

plenamente

implantação

sua Concluiu plenamente

sua implantação

Está estudando a Está estudando a

Está em fase inicial viabilidade de sua viabilidade de sua

47 de implantação

adoção

Concluiu

Concluiu plenamente plenamente

48 sua implantação

implantação

Concluiu

plenamente

adoção

sua Concluiu plenamente sua implantação

Concluiu

plenamente

implantação

Concluiu

49 Não utiliza

implantação

sua Concluiu plenamente sua implantação

plenamente implantação Concluiu

plenamente implantação

50 Não utiliza

Não utiliza

Não utiliza

Concluiu

51 Não utiliza

Não utiliza

Concluiu plenamente sua implantação

plenamente implantação

Está estudando a

Está em fase inicial Concluiu plenamente viabilidade de sua de implantação sua implantação adoção

52 Não utiliza

Não utiliza

Não utiliza Não utiliza

Não utiliza

Está em fase final de implantação

Não utiliza

Está em fase inicial de

$\begin{array}{ll}\text { Não utiliza } & \text { implantação } \\ \text { Concluiu plenamente Concluiu plenamente }\end{array}$ sua implantação sua implantação

Concluiu plenamente Concluiu plenamente sua implantação sua implantação

Está em fase inicial de Está em fase inicial de implantação implantação

Está em fase final de Concluiu plenamente implantação sua implantação

Está em fase inicial de Concluiu plenamente implantação sua implantação

Concluiu plenamente

Não utiliza sua implantação

Está estudando a

Concluiu plenamente viabilidade de sua sua implantação adoção

Concluiu plenamente Cor

Concluiu plenamente sua implantação sua implantação

Concluiu plenamente

sua implantação Não utiliza

a Concluiu plenamente Concluiu plenamente sua implantação sua implantação

Está em fase inicial de implantação implantação

sua Concluiu plenamente Concluiu plenamente sua implantação sua implantação

Concluiu plenamente Concluiu plenamente sua implantação sua implantação

Concluiu plenamente Concluiu plenamente sua implantação sua implantação

Está estudando a Está estudando a viabilidade de sua viabilidade de sua adoção adoção

\section{a}

Concluiu plenamente Concluiu plenamente sua implantação sua implantação

Concluiu plenamente

sua implantação Não utiliza

Está em fase final de

implantação Não utiliza

Concluiu plenamente Concluiu plenamente

sua implantação sua implantação

Está em fase inicial de Está em fase final de implantação implantação

sua Concluiu plenamente Está em fase final de sua implantação implantação

sua Concluiu plenamente

sua implantação Não utiliza

sua Concluiu plenamente Concluiu plenamente sua implantação sua implantação

sua Concluiu plenamente Concluiu plenamente sua implantação sua implantação

Están

Concluiu plenamente sua implantação

53 Não utiliza

Concluiu plenamente sua implantação
Está em fase final de implantação 
Concluiu plenamente 54 sua implantação

55 Não utiliza

Está em fase final de Está em fase final

56 implantação

Concluiu plenamente

57 sua implantação

Concluiu plenamente plenamente

58 sua implantação implantação

Está em fase inicial Está em fase inicial 59 de implantação de implantação

60 Não utiliza

61 Não utiliza

Concluiu plenamente plenamente

62 sua implantação

Concluiu plenamente

63 sua implantação

Concluiu

Concluiu plenamente plenamente

64 sua implantação implantação

65 Não utiliza Não utiliza

Concluiu plenamente

66 sua implantação Não utiliza

Concluiu plenamente

67 sua implantação Não utiliza

68 Não utiliza

Não utiliza

Está em fase inicial

69 de implantação

Concluiu plenamente

70 sua implantação

Concluiu plenamente

71 sua implantação

72 Não utiliza

73 Não utiliza

74 Não utiliza

75 Não utiliza

76 Não utiliza

Está estudando a

viabilidade de sua

77 adoção de implantação Concluiu

plenamente implantação Concluiu plenamente implantação
Concluiu

Concluiu plenamente plenamente sua implantação implantação Concluiu

Concluiu plenamente plenamente sua implantação implantação

Concluiu plenamente sua implantação

de implantação Concluiu

plenamente implantação

Não utiliza

Concluiu

sua Concluiu plenamente plenamente sua implantação implantação

Concluiu

plenamente implantação implantação

Está em fase inicial de implantação

Não utiliza

Não utiliza

Não utiliza

Concluiu

sua Concluiu plenamente plenamente sua implantação implantação Concluiu plenamente sua implantação Não utiliza Concluiu

sua Concluiu plenamente plenamente sua implantação implantação

Não utiliza Não utiliza

Concluiu plenamente sua implantação

Não utiliza

Concluiu plenamente sua implantação

Não utiliza

Não utiliza

Não utiliza

Está estudando

sua Concluiu plenamente Concluiu plenamente sua implantação sua implantação

sua Concluiu plenamente Concluiu plenamente sua implantação sua implantação

Concluiu plenamente Está em fase final de sua implantação implantação

sua Concluiu plenamente Concluiu plenamente sua implantação sua implantação

sua Concluiu plenamente Concluiu plenamente sua implantação sua implantação

sua Está em fase final de Está em fase inicial de implantação implantação Está em fase inicial de Concluiu plenamente implantação sua implantação Não utiliza Não utiliza

sua Concluiu plenamente Concluiu plenamente sua implantação sua implantação

Concluiu plenamente Concluiu plenamente sua implantação sua implantação

sua Concluiu plenamente Concluiu plenamente sua implantação sua implantação

Não utiliza Não utiliza

Concluiu plenamente Concluiu plenamente sua implantação sua implantação

Concluiu plenamente Concluiu plenamente sua implantação sua implantação

Concluiu plenamente Concluiu plenamente sua implantação sua implantação $\begin{array}{ll}\text { Está em fase inicial } & \text { Concluiu plenamente } \\ \text { de implantação } & \text { sua implantação }\end{array}$

viabilidade

Concluiu

sua Concluiu plenamente plenamente sua implantação

implantação

sua Concluiu plenamente sua implantação

Não utiliza Está em fase final de implantação

Não utiliza

Não utiliza

Não utiliza

Concluiu plenamente Concluiu plenamente sua implantação sua implantação

sua Concluiu plenamente Concluiu plenamente sua implantação sua implantação

Concluiu plenamente Concluiu plenamente sua implantação sua implantação

Concluiu plenamente Concluiu plenamente sua implantação sua implantação

Concluiu plenamente Está em fase final de sua implantação implantação

Não utiliza

Está em fase inicial de implantação

Está em fase final de implantação implantação

Não utiliza

Não utiliza

implantação

implantação

sua Está em fase final de implantação

Está em fase final de implantação Concluiu

Concluiu plenamente plenamente sua implantação
Concluiu plenamente sua implantação

sua implantaça

Concluiu plenamente sua implantação sua implantação 
Instrumento gerenciais

5 - Em que nível sua empresa utiliza os seguintes instrumentos ou práticas gerenciais? [d) Demonstrações de resultados mensais] [e) Custeio variável ou por absorção] [f) Orçamento não participativo (diretoria impões metas aos gerentes)] [g) Orçamento participativo (gerentes participam ativamente) [h) Custeio alvo - uso sistemático] [i) Relatórios de controle de qualidade]

[d) Concluiu plenamente Concluiu plenamente

1 sua implantação Concluiu plenamente

2 sua implantação

Está em fase inicial Concluiu plenamente

3 de implantação Concluiu plenamente

4 sua implantação

Concluiu plenamente Concluiu plenamente

5 sua implantação

Concluiu plenamente Está em fase final de

6 sua implantação Concluiu plenamente

7 sua implantação

8 sua implantação Concluiu plenamente

9 sua implantação Concluiu plenamente Concluiu plenamente

10 sua implantação Concluiu plenamente Concluiu plenamente

11 sua implantação Concluiu plenamente Concluiu plenamente

12 sua implantação Concluiu plenamente Está em fase final de

13 sua implantação

14 sua implantação Concluiu plenamente Concluiu plenamente

15 sua implantação Concluiu plenamente Concluiu plenamente

16 sua implantação Concluiu plenamente

17 sua implantação Concluiu plenamente

18 sua implantação Concluiu plenamente Está em fase final de

19 sua implantação Concluiu plenamente Concluiu plenamente

20 sua implantação Concluiu plenamente Concluiu plenamente

21 sua implantação Concluiu plenamente

22 sua implantação sua implantação

Não utiliza

Está estudando

Concluiu plenamente viabilidade de sua

23 sua implantação adoção

Concluiu plenamente

24 sua implantação Não utiliza Concluiu plenamente Concluiu plenamente

25 sua implantação sua implantação

[f) $[\mathrm{g})$

Concluiu plenamente sua implantação

[h)

Não utiliza

Não utiliza

Não utiliza

Não utiliza

Não utiliza

Está em fase final de sua implantação

Não utiliza

sua implantação implantação

Concluiu plenamente

sua implantação Não utiliza Está estudando a

Concluiu plenamente viabilidade de sua sua implantação adoção

Não utiliza

[i)

Concluiu plenamente sua implantação

Não utiliza

Concluiu plenamente sua implantação

Concluiu plenamente sua implantação

Concluiu plenamente sua implantação

Está em fase final de Está em fase final de Está em fase final de Está em fase final de implantação implantação Concluiu plenamente Está em fase final de sua implantação implantação

implantação

implantação

Não utiliza Não utiliza

Está em fase final de Concluiu plenamente Concluiu plenamente Está em fase final de implantação sua implantação sua implantação

implantação

Está estudando a viabilidade

Não utiliza

Não utiliza

Não utiliza

Concluiu plenamente

sua implantação

Não utiliza

Concluiu plenamente sua implantação

Não utiliza

Não utiliza

Concluiu plenamente

sua implantação

Concluiu plenamente

sua implantação sua implantação

de sua adoção

Concluiu plenamente sua implantação

Concluiu plenamente sua implantação

sua implantação

Não utiliza

Não utiliza

Concluiu plenamente sua implantação

Concluiu plenamente sua implantação

$\begin{array}{llll}\text { sua implantação } & \text { sua implantação } & \text { implantação } & \text { implantação }\end{array}$

Concluiu plenamente Concluiu plenamente Está em fase final de Concluiu plenamente sua sua implantação

sua implantação

implantação

implantação

Concluiu plenamente Concluiu plenamente Concluiu plenamente sua sua implantação

Não utiliza

Concluiu plenamente

sua implantação

sua implantação

implantação

Concluiu plenamente sua implantação

Concluiu plenamente Concluiu plenamente Concluiu plenamente sua sua implantação

Não utiliza sua implantação implantação

Está em fase final de Está em fase final de Está em fase final de Está em fase final de implantação implantação

implantação

implantação

sua implantação $\quad$ implantação $\quad$ de implantação inicial Concluiu

Concluiu plenamente Concluiu plenamente Concluiu plenamente Concluiu plenamente sua sua implantação sua implantação

Concluiu plenamente Concluiu plenamente

sua implantação

sua implantação sua implantação

implantação

Está em fase inicial de implantação

Concluiu plenamente sua implantação

sua implantação

Não utiliza

Não utiliza

Concluiu plenamente Concluiu plenamente Concluiu plenamente sua sua implantação sua implantação

implantação

Concluiu plenamente

sua implantação

Não utiliza

Concluiu

Não utiliza

implantação

Concluiu plenamente Concluiu plenamente Concluiu plenamente

sua implantação implantação

implantação

Está estudando a

Está em fase inicial Está em fase final de viabilidade de sua Está em fase inicial

27 de implantação implantação

Concluiu plenamente Concluiu plenamente

28 sua implantação sua implantação Não utiliza

Concluiu plenamente Concluiu plenamente Concluiu plenamente

29 sua implantação sua implantação sua implantação

de implantação

Está em fase inicial de implantação

Não utiliza

Está em fase inicial de implantação

Concluiu plenamente sua implantação

Não utiliza

$\begin{array}{lll}\text { Concluiu plenamente } & \text { Concluiu plenamente } & \text { Concluiu p } \\ \text { sua implantação } & \text { sua implantação } & \text { implantação }\end{array}$

Concluiu plenamente Concluiu plenamente Concluiu plenamente sua

30 Concluiu plenamente Concluiu plenamente Não utiliza 
sua implantação Concluiu plenamente

31 sua implantação

Concluiu plenamente

32 sua implantação Concluiu plenamente

33 sua implantação

Concluiu plenamente

34 sua implantação

Concluiu plenamente Concluiu plenamente

35 sua implantação

Concluiu plenamente Concluiu plenamente

36 sua implantação

Concluiu plenamente Concluiu plenamente

37 sua implantação

38 implantação Concluiu plenament

39 sua implantação Concluiu plenamente

40 sua implantação Concluiu plenamente

41 sua implantação sua implantação

Não utiliza

de implantação implantação

Concluiu plenamente sua implantação

Não utiliza

Está em fase final de Está em fase final de implantação implantação

Concluiu plenamente sua implantação sua implantação

Está estudando a

Está em fase inicial viabilidade de sua

42 de implantação adoção

Concluiu plenamente Concluiu plenamente

43 sua implantação sua implantação Concluiu plenamente Concluiu plenamente

44 sua implantação sua implantação Concluiu plenamente Concluiu plenamente

45 sua implantação Concluiu plenamente Concluiu plenamente 46 sua implantação Está em fase final de Está em fase inicial 47 implantação Concluiu plenamente Concluiu plenamente

48 sua implantação Concluiu plenamente Concluiu plenamente

49 sua implantação Concluiu plenamente Concluiu plenamente

50 sua implantação Concluiu plenamente

51 sua implantação

Concluiu plenamente Concluiu plenamente

52 sua implantação Concluiu plenamente Concluiu plenamente

53 sua implantação Concluiu plenamente

54 sua implantação Concluiu plenamente sua implantação

viabilidade de sua adoção

Não utiliza

Não utiliza

Concluiu plenamente sua implantação

Não utiliza

Concluiu plenamente sua implantação

Concluiu plenamente sua implantação

\section{Não utiliza} sua implantação sua implantação Concluiu plenamente sua implantação sua implantação Concluiu plenamente

55 sua implantação Concluiu plenamente Está em fase final de

56 sua implantação

Concluiu plenamente Está em fase final de

57 sua implantação Concluiu plenamente Concluiu plenamente

58 sua implantação Concluiu plenamente Concluiu plenamente

59 sua implantação Concluiu plenament

60 sua implantação Concluiu plenamente

61 sua implantação Concluiu plenamente Concluiu plenamente

62 sua implantação Concluiu plenamente Concluiu plenamente

63 sua implantação Concluiu plenamente

64 sua implantação Concluiu plenamente

65 sua implantação implantação implantação

Concluiu plenamente sua implantação sua implantação Não utiliza Concluiu plenamente Está em fase final de

sua implantação implantação

Não utiliza

Concluiu plenamente sua implantação

Não utiliza sua implantação sua implantação sua implantação

Não utiliza sua implantação sua implantação

Não utiliza

sua implantação

Não utiliza

Não utiliza

Concluiu plenamente

sua implantação

Não utiliza

Está estudando a

Concluiu plenamente viabilidade de sua Concluiu plenamente sua sua implantação

Concluiu plenamente sua implantação adoção

Está em fase inicial

de implantação

Concluiu plenamente sua implantação

Não utiliza

Não utiliza

Está em fase final de Está em fase inicial

implantação

de implantação

Concluiu plenamente sua implantação

sua implantação

Concluiu plenamente Está em fase final de sua implantação implantação

Concluiu plenamente Concluiu plenamente sua implantação sua implantação sua implantação
Está estudando

Está estudando a Está estudando a adoção adoção

Concluiu plenamente sua implantação

Não utiliza

Concluiu plenamente Concluiu plenamente sua implantação sua implantação

Concluiu plenamente sua implantação

Concluiu plenamente Concluiu plenamente sua implantação

plenamente Concluiu plenamente sua sua implantação

Está em fase final de implantação de implantação implantação

Concluiu plenamente Concluiu plenamente Concluiu plenamente sua sua implantação Concluiu plenamente sua implantação

sua implantação

implantação

Concluiu plenamente sua implantação

Não utiliza

Concluiu plenamente Concluiu plenamente sua implantação sua implantação

Concluiu plenamente sua implantação

Concluiu plenamente sua

Não utiliza implantação

Está estudando

Concluiu plenamente viabilidade de sua Concluiu plenamente sua sua implantação adoção

Concluiu plenamente sua implantação

Nach

Não utiliza

implantação

Concluiu plenamente sua implantação

Não utiliza sua implantação implantação

Concluiu plenamente Concluiu plenamente Concluiu plenamente sua sua implantação

Concluiu plenamente sua implantação

Está em fase final de implantação

sua implantação

implantação

Está em fase final de Está em fase final de implantação implantação

Concluiu plenamente sua implantação

Concluiu plenamente Concluiu plenamente sua implantação implantação

Está em fase final de Está em fase final de Concluiu plenamente sua implantação

implantação

Não utiliza

Não utiliza

Concluiu plenamente

sua implantação

Não utiliza

implantação

Concluiu plenamente sua implantação

Concluiu plenamente sua implantação

Concluiu plenamente Concluiu plenamente sua sua implantação sua implantação implantação

Concluiu plenamente Concluiu plenamente Concluiu plenamente sua sua implantação sua implantação implantação

Concluiu plenamente Concluiu plenamente Concluiu plenamente sua sua implantação sua implantação implantação

Concluiu plenamente Concluiu plenamente Concluiu plenamente sua sua implantação sua implantação implantação 
Concluiu plenamente Concluiu plenamente Concluiu plenamente Concluiu plenamente

66 sua implantação

Concluiu plenamente Concluiu plenamente Concluiu plenamente Concluiu plenamente

68 sua implantação

Concluiu plenamente Concluiu plenamente

69 sua implantação

Concluiu plenamente Concluiu plenamente

70 sua impla

Concluiu plenamente Concluiu plenamente

71 sua implantaç

Concluiu plenamente Concluiu plenamente

72 sua implantação

Concluiu plenamente

73 sua implantação

Está estudando a

viabilidade de sua Está em fase inicial

74 adoção

Concluiu plenamente

75 sua implantação

$\begin{array}{ll}\text { sua implantação } & \text { sua implantação } \\ \text { Concluiu plenamente } & \text { Concluiu plenamente }\end{array}$

77 sua implantação sua implantação sua implantação (1)

Não utiliza sua implantação

Não utiliza

Concluiu plenamente

sua implantação

sua implantação

sua implantação

Concluiu plenamente

sua implantação

Não utiliza

$\begin{array}{ll}\text { implantação } & \begin{array}{l}\text { implantação } \\ \text { Está estudando a }\end{array} \\ \text { Está em fase inicial viabilidade de sua }\end{array}$

$\begin{array}{ll}\text { implantação } & \begin{array}{l}\text { implantação } \\ \text { Está estudando a } \\ \text { Está em fase inicial viabilidade de sua }\end{array}\end{array}$

Está em fase inicial de implantação

adoção

Concluiu plenamente

sua implantação

Não utiliza

Concluiu plenamente sua implantação
Não utiliza

Concluiu plenamente sua implantação

sua implantação implantação sua implantação implantação

Concluiu plenamente Concluiu plenamente Concluiu plenamente Concluiu plenamente sua sua implantação sua implantação sua implantação

Concluiu plenamente

Concluiu plenamente Concluiu plenamente

Está em fase final de

ESCOPO implantação

Concluiu plenamente sua implantação

Concluiu plenamente sua implantação implantação implantação

Não utiliza

Está estudando a viabilidade de sua adoção

Está em fase inicial de implantação

Concluiu plenamente sua implantação

Concluiu plenamente sua implantação
Concluiu plenamente sua

a) temporal b) quantificação c) foco d) tempestividade

1 Principalmente ao futuro

2 Principalmente ao passado

3 Principalmente ao futuro

4 Principalmente ao futuro Igualmente ao passado e ao

5 futuro

Igualmente ao passado e ao

6 futuro Igualmente ao passado e ao

7 futuro

8 Principalmente ao futuro Igualmente ao passado e ao

9 futuro Igualmente ao passado e ao

10 futuro

11 Principalmente ao futuro Igualmente ao passado e ao

12 futuro

13 Principalmente ao passado Igualmente ao passado e ao

14 futuro

15 Principalmente ao passado

16 Principalmente ao passado Igualmente ao passado e ao

17 futuro

18 Principalmente ao futuro Igualmente ao passado e ao

19 futuro

20 Principalmente ao futuro Igualmente ao passado e ao

21 futuro

22 Principalmente ao futuro

23 Principalmente ao passado

24 Principalmente ao passado b)

Igualmente financeiras e não financeiras Igualmente financeiras e não financeiras

Igualmente financeiras e não financeiras

Principalmente financeiras

Igualmente financeiras e não financeiras

Igualmente financeiras e não financeiras

Principalmente financeiras

Principalmente financeiras

Principalmente financeiras

Igualmente financeiras e não financeiras

Igualmente financeiras e não financeiras

Igualmente financeiras e não financeiras

Igualmente financeiras e não financeiras

Exclusivamente não financeiras

Igualmente financeiras e não financeiras

Igualmente financeiras e não financeiras

Igualmente financeiras e não financeiras

Principalmente financeiras

Principalmente financeiras

Igualmente financeiras e não financeiras

Igualmente financeiras e não financeiras

Igualmente financeiras e não financeiras

Igualmente financeiras e não financeiras

Principalmente financeiras c)

Igualmente interno e

externo

Exclusivamente interno
Igualmente interno e

externo

Principalmente externo Médio

Igualmente interno

externo

Igualmente interno

Principalmente interno
Igualmente interno
externo

Principalmente interno

Principalmente interno

Igualmente interno

externo

Igualmente interno

externo

Principalmente interno

Igualmente interno externo

Principalmente interno

Exclusivamente interno Igualmente interno

externo

Igualmente interno

externo

Principalmente interno Igualmente interno

externo

Igualmente interno

externo

Igualmente interno

externo

interno

Igualmente interno 


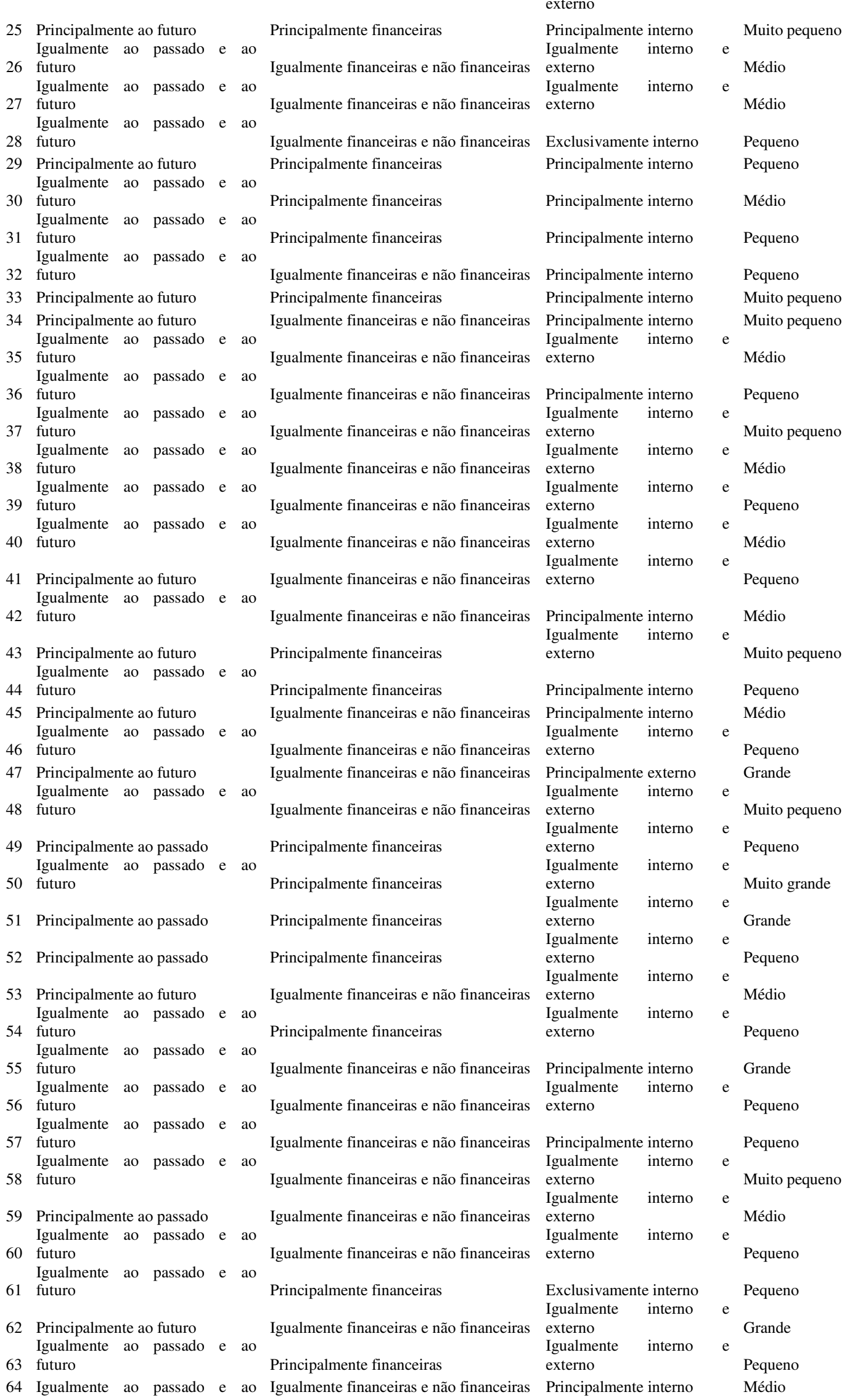




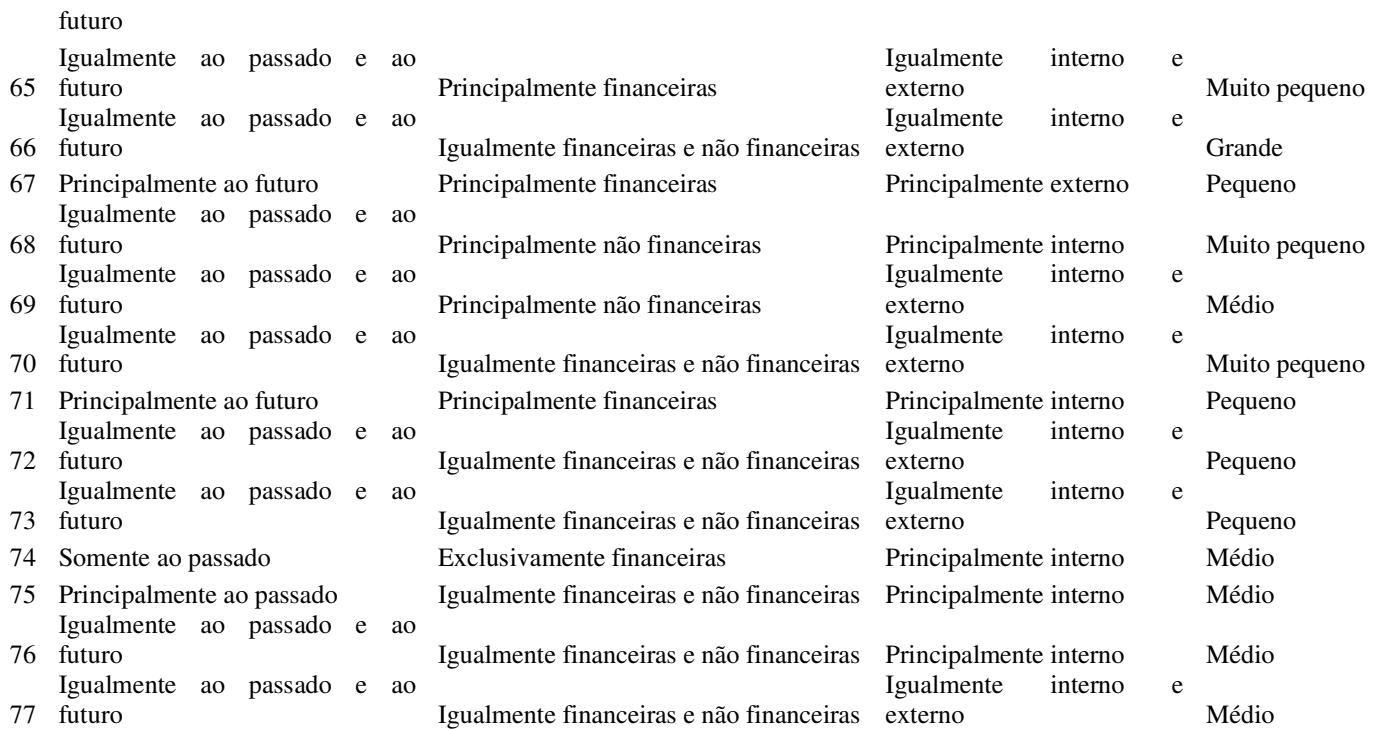

Agregação

5 - Em que nível sua empresa utiliza os seguintes instrumentos ou práticas gerenciais? [a) Relatórios por divisão e/ ou filial] [b) Análise sistemática (rotineira e automática) de custo-volume-lucro] [c) Preço de transferência interno entre divisões de negócios]

[a)

[b)

1 Concluiu plenamente sua implantação

2 Não utiliza

3 Está em fase final de implantação

4 Não utiliza

5 Concluiu plenamente sua implantação

6 Está em fase final de implantação

7 Está em fase inicial de implantação

8 Concluiu plenamente sua implantação Está estudando a viabilidade de sua

9 adoção

10 Concluiu plenamente sua implantação

11 Concluiu plenamente sua implantação

12 Concluiu plenamente sua implantação

13 Concluiu plenamente sua implantação

14 Concluiu plenamente sua implantação

15 Concluiu plenamente sua implantação

16 Concluiu plenamente sua implantação

17 Concluiu plenamente sua implantação

18 Não utiliza

19 Está em fase final de implantação

20 Concluiu plenamente sua implantação

21 Concluiu plenamente sua implantação

22 Concluiu plenamente sua implantação

23 Não utiliza

24 Concluiu plenamente sua implantação

25 Concluiu plenamente sua implantação

26 Concluiu plenamente sua implantação Está estudando a viabilidade de sua

27 adoção

28 Não utiliza

29 Concluiu plenamente sua implantação

30 Não utiliza

31 Não utiliza Não utiliza

Não utiliza

Não utiliza

adoção
Concluiu plenamente sua implantação

Está em fase final de implantação

Concluiu plenamente sua implantação

Está em fase final de implantação

Está em fase final de implantação

Está em fase final de implantação

Concluiu plenamente sua implantação

Concluiu plenamente sua implantação

Concluiu plenamente sua implantação

Está em fase final de implantação

Está em fase final de implantação

Concluiu plenamente sua implantação

Concluiu plenamente sua implantação

Concluiu plenamente sua implantação

Concluiu plenamente sua implantação

Está em fase final de implantação

Concluiu plenamente sua implantação

Concluiu plenamente sua implantação

Concluiu plenamente sua implantação

Concluiu plenamente sua implantação

Concluiu plenamente sua implantação

Concluiu plenamente sua implantação

Concluiu plenamente sua implantação

Está em fase inicial de implantação

Está estudando a viabilidade de sua

Concluiu plenamente sua implantação

Está em fase inicial de implantação

Está estudando a viabilidade de sua Está estudando a viabilidade de sua

adoção adoção
Concluiu plenamente sua implantação

Não utiliza

Está em fase inicial de implantação

Concluiu plenamente sua implantação

Concluiu plenamente sua implantação

Está em fase final de implantação

Não utiliza

Está em fase final de implantação

Não utiliza

Concluiu plenamente sua implantação

Não utiliza

Concluiu plenamente sua implantação

Concluiu plenamente sua implantação

Concluiu plenamente sua implantação

Concluiu plenamente sua implantação

Não utiliza

Não utiliza

Está em fase final de implantação

Está em fase final de implantação

Não utiliza

Concluiu plenamente sua implantação

Não utiliza

Não utiliza

Não utiliza

Não utiliza

Não utiliza

Não utiliza

Concluiu plenamente sua implantação

Não utiliza
Concluiu plenamente sua implantação 
32 Não utiliza

33 Concluiu plenamente sua implantação

34 Concluiu plenamente sua implantação

35 Está em fase final de implantação

36 Não utiliza

37 Não utiliza

38 Está em fase final de implantação

39 Concluiu plenamente sua implantação

40 Está em fase final de implantação

41 Concluiu plenamente sua implantação Está estudando a viabilidade de 42 adoção

43 Concluiu plenamente sua implantação

44 Concluiu plenamente sua implantação

45 Concluiu plenamente sua implantação

46 Concluiu plenamente sua implantação Está estudando a viabilidade de sua 47 adoção

48 Concluiu plenamente sua implantação

49 Concluiu plenamente sua implantação

50 Concluiu plenamente sua implantação

51 Concluiu plenamente sua implantação

52 Não utiliza

53 Concluiu plenamente sua implantação

54 Concluiu plenamente sua implantação

55 Concluiu plenamente sua implantação

56 Concluiu plenamente sua implantação

57 Concluiu plenamente sua implantação

58 Concluiu plenamente sua implantação

59 Está em fase final de implantação

60 Concluiu plenamente sua implantação

61 Não utiliza

62 Concluiu plenamente sua implantação

63 Concluiu plenamente sua implantação

64 Concluiu plenamente sua implantação

65 Concluiu plenamente sua implantação

66 Concluiu plenamente sua implantação

67 Concluiu plenamente sua implantação

68 Concluiu plenamente sua implantação Está estudando a viabilidade de sua

69 adoção

70 Concluiu plenamente sua implantação

71 Concluiu plenamente sua implantação

72 Não utiliza

73 Está em fase final de implantação

74 Está em fase inicial de implantação

75 Está em fase inicial de implantação

76 Concluiu plenamente sua implantação Está estudando a viabilidade de sua 77 adoção
Não utiliza

Concluiu plenamente sua implantação

Concluiu plenamente sua implantação

Está em fase final de implantação

Concluiu plenamente sua implantação

Concluiu plenamente sua implantação

Está em fase final de implantação

Concluiu plenamente sua implantação

Está em fase final de implantação

Concluiu plenamente sua implantação

sua Está estudando a viabilidade de adoção

Concluiu plenamente sua implantação

Concluiu plenamente sua implantação

Concluiu plenamente sua implantação

Concluiu plenamente sua implantação

Está em fase inicial de implantação

Concluiu plenamente sua implantação

Concluiu plenamente sua implantação

Concluiu plenamente sua implantação

Concluiu plenamente sua implantação

Concluiu plenamente sua implantação

Concluiu plenamente sua implantação

Não utiliza

Concluiu plenamente sua implantação

Concluiu plenamente sua implantação

Está em fase final de implantação

Concluiu plenamente sua implantação

Concluiu plenamente sua implantação

Concluiu plenamente sua implantação

Não utiliza

Concluiu plenamente sua implantação

Concluiu plenamente sua implantação

Concluiu plenamente sua implantação

Concluiu plenamente sua implantação

Concluiu plenamente sua implantação

Concluiu plenamente sua implantação

Concluiu plenamente sua implantação

Não utiliza

Concluiu plenamente sua implantação

Concluiu plenamente sua implantação

Concluiu plenamente sua implantação

Concluiu plenamente sua implantação

Concluiu plenamente sua implantação

Está em fase inicial de implantação

Concluiu plenamente sua implantação

Está em fase inicial de implantação
Não utiliza

Está em fase final de implantação

Não utiliza

Está estudando a viabilidade de sua adoção

Concluiu plenamente sua implantação

Não utiliza

Está em fase final de implantação

Concluiu plenamente sua implantação

Está em fase final de implantação

Não utiliza

Está estudando a viabilidade de sua adoção

Concluiu plenamente sua implantação

Concluiu plenamente sua implantação

Não utiliza

Concluiu plenamente sua implantação

Está estudando a viabilidade de sua adoção

Concluiu plenamente sua implantação

Concluiu plenamente sua implantação

Concluiu plenamente sua implantação

Não utiliza

Não utiliza

Não utiliza

Concluiu plenamente sua implantação

Concluiu plenamente sua implantação

Concluiu plenamente sua implantação

Não utiliza

Concluiu plenamente sua implantação

Concluiu plenamente sua implantação

Não utiliza

Não utiliza

Concluiu plenamente sua implantação

Não utiliza

Não utiliza

Não utiliza

Está estudando a viabilidade de sua adoção

Concluiu plenamente sua implantação

Concluiu plenamente sua implantação

Não utiliza

Concluiu plenamente sua implantação

Concluiu plenamente sua implantação

Não utiliza

Não utiliza

Está em fase inicial de implantação

Não utiliza

Concluiu plenamente sua implantação

Não utiliza

comparabilidade

relevância

confiabilidade

a) fidedignidade b) imparciabilidade

$\begin{array}{ll}\text { a) capacidade de avaliação, b) capacidade } & \text { a) fidedignic } \\ \text { de feed back, c) disponibilidade } & \text { c) veracidade }\end{array}$

a)

b)

c)

a)

5
4
5
5
5

a)

b)

5
2
5
5
4

a) equidade b) consistência

a)

5

b)

c) 


\begin{tabular}{|c|c|c|c|c|c|c|c|c|}
\hline 6 & 4 & 4 & 4 & 4 & 3 & 4 & 3 & 4 \\
\hline 7 & 2 & 3 & 2 & 3 & 2 & 2 & 1 & 3 \\
\hline 8 & 5 & 5 & 5 & 5 & 4 & 3 & 4 & 3 \\
\hline 9 & 5 & 4 & 1 & 3 & 4 & 4 & 4 & 5 \\
\hline 10 & 5 & 5 & 5 & 5 & 5 & 5 & 5 & 5 \\
\hline 11 & 5 & 5 & 5 & 5 & 5 & 5 & 5 & 5 \\
\hline 12 & 5 & 5 & 5 & 5 & 5 & 5 & 5 & 5 \\
\hline 13 & 4 & 4 & 3 & 3 & 3 & 3 & 4 & 4 \\
\hline 14 & 4 & 4 & 4 & 4 & 3 & 3 & 3 & 3 \\
\hline 15 & 4 & 4 & 4 & 4 & 3 & 4 & 3 & 2 \\
\hline 16 & 5 & 5 & 5 & 5 & 5 & 5 & 5 & 5 \\
\hline 17 & 5 & 5 & 5 & 5 & 4 & 5 & 5 & 5 \\
\hline 18 & 5 & 5 & 5 & 5 & 4 & 3 & 4 & 4 \\
\hline 19 & 4 & 4 & 4 & 4 & 4 & 4 & 4 & 4 \\
\hline 20 & 4 & 4 & 5 & 5 & 5 & 5 & 5 & 5 \\
\hline 21 & 5 & 5 & 5 & 5 & 5 & 5 & 5 & 5 \\
\hline 22 & 4 & 4 & 4 & 5 & 4 & 5 & 5 & 5 \\
\hline 23 & 5 & 5 & 4 & 4 & 4 & 1 & 5 & 5 \\
\hline 24 & 5 & 5 & 5 & 5 & 5 & 5 & 5 & 4 \\
\hline 25 & 4 & 4 & 4 & 5 & 3 & 5 & 5 & 5 \\
\hline 26 & 5 & 4 & 5 & 5 & 4 & 5 & 4 & 4 \\
\hline 27 & 4 & 4 & 3 & 4 & 3 & 5 & 4 & 3 \\
\hline 28 & 5 & 5 & 5 & 4 & 4 & 5 & 5 & 5 \\
\hline 29 & 5 & 5 & 5 & 5 & 4 & 4 & 4 & 2 \\
\hline 30 & 3 & 5 & 4 & 5 & 4 & 5 & 5 & 5 \\
\hline 31 & 5 & 5 & 5 & 5 & 5 & 5 & 5 & 5 \\
\hline 32 & 1 & 2 & 2 & 1 & 2 & 3 & 3 & 3 \\
\hline 33 & 4 & 5 & 5 & 4 & 3 & 1 & 4 & 4 \\
\hline 34 & 5 & 3 & 5 & 5 & 5 & 5 & 4 & 5 \\
\hline 35 & 4 & 4 & 4 & 4 & 4 & 4 & 4 & 5 \\
\hline 36 & 5 & 4 & 3 & 5 & 4 & 5 & 5 & 5 \\
\hline 37 & 4 & 5 & 5 & 5 & 4 & 5 & 4 & 5 \\
\hline 38 & 3 & 3 & 3 & 3 & 3 & 4 & 4 & 4 \\
\hline 39 & 4 & 5 & 4 & 5 & 5 & 5 & 5 & 5 \\
\hline 40 & 4 & 4 & 4 & 4 & 4 & 4 & 4 & 4 \\
\hline 41 & 5 & 5 & 4 & 5 & 5 & 5 & 5 & 5 \\
\hline 42 & 5 & 5 & 5 & 5 & 5 & 1 & 5 & 1 \\
\hline 43 & 5 & 4 & 4 & 5 & 5 & 5 & 5 & 3 \\
\hline 44 & 5 & 5 & 4 & 5 & 5 & 1 & 5 & 3 \\
\hline 45 & 5 & 5 & 4 & 5 & 4 & 4 & 4 & 4 \\
\hline 46 & 5 & 4 & 5 & 5 & 5 & 4 & 5 & 3 \\
\hline 47 & 2 & 3 & 1 & 1 & 1 & 5 & 3 & 5 \\
\hline 48 & 5 & 5 & 5 & 5 & 5 & 5 & 5 & 5 \\
\hline 49 & 5 & 5 & 4 & 4 & 4 & 5 & 4 & 4 \\
\hline 50 & 5 & 5 & 5 & 5 & 4 & 5 & 5 & 5 \\
\hline 51 & 3 & 4 & 3 & 3 & 3 & 4 & 4 & 4 \\
\hline 52 & 5 & 5 & 5 & 5 & 4 & 4 & 3 & 3 \\
\hline 53 & 5 & 5 & 5 & 5 & 5 & 5 & 5 & 5 \\
\hline 54 & 5 & 5 & 5 & 5 & 5 & 5 & 5 & 5 \\
\hline 55 & 4 & 5 & 4 & 5 & 5 & 5 & 5 & 5 \\
\hline 56 & 4 & 5 & 5 & 5 & 3 & 3 & 5 & 5 \\
\hline 57 & 5 & 5 & 5 & 5 & 5 & 5 & 5 & 4 \\
\hline 58 & 5 & 5 & 5 & 5 & 5 & 5 & 5 & 5 \\
\hline 59 & 5 & 5 & 5 & 5 & 3 & 5 & 3 & 5 \\
\hline 60 & 5 & 5 & 5 & 5 & 4 & 4 & 4 & 4 \\
\hline 61 & 5 & 5 & 5 & 4 & 3 & 1 & 3 & 5 \\
\hline 62 & 5 & 5 & 5 & 5 & 5 & 5 & 5 & 5 \\
\hline 63 & 5 & 4 & 4 & 3 & 3 & 3 & 4 & 5 \\
\hline 64 & 5 & 5 & 4 & 5 & 4 & 4 & 4 & 4 \\
\hline 65 & 5 & 5 & 5 & 5 & 4 & 3 & 5 & 5 \\
\hline 66 & 4 & 4 & 4 & 5 & 4 & 3 & 5 & 5 \\
\hline 67 & 5 & 4 & 4 & 5 & 4 & 3 & 4 & 5 \\
\hline
\end{tabular}




$\begin{array}{lllllllll}68 & 5 & 5 & 5 & 5 & 5 & 5 & 5 & 5 \\ 69 & 4 & 4 & 3 & 5 & 5 & 5 & 5 & 5 \\ 70 & 5 & 5 & 5 & 5 & 5 & 5 & 5 & 5 \\ 71 & 5 & 5 & 5 & 5 & 5 & 5 & 5 & 5 \\ 72 & 5 & 5 & 5 & 5 & 5 & 1 & 1 & 5 \\ 73 & 4 & 5 & 3 & 4 & 4 & 3 & 4 & 4 \\ 74 & 3 & 3 & 3 & 2 & 1 & 2 & 3 & 4 \\ 75 & 3 & 3 & 2 & 2 & 2 & 3 & 2 & 3 \\ 76 & 5 & 5 & 5 & 5 & 5 & 5 & 5 & 5 \\ 77 & 3 & 4 & 5 & 4 & 4 & 4 & 4 & 4\end{array}$

